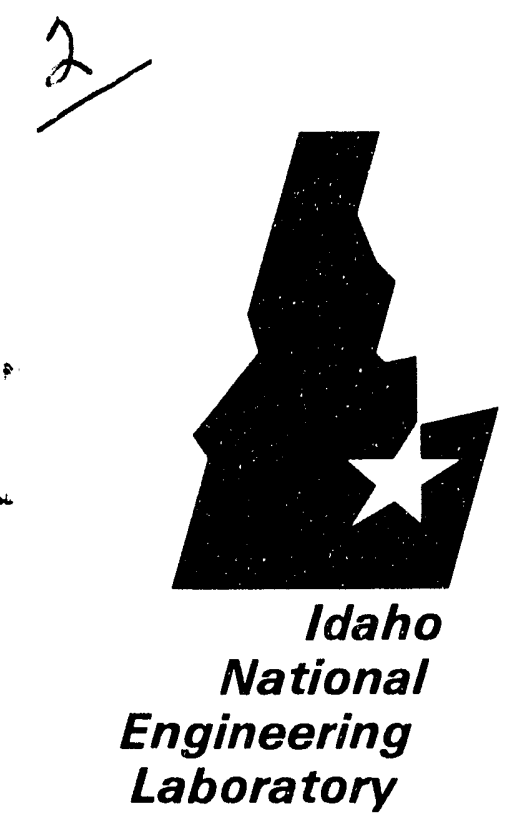
EGG-MS-10646
May 1993

Bench-Scale Arc Melter for R\&D in Thermal Treatment of Mixed Wastes

Managed

by the U.S.

Department

of Energy

P. C. Kong
J. D. Grandy
A. D. Watkins
T. L. Eddy
G. L. Anderson

$\stackrel{n}{E} E G_{2} G_{\text {idaho }}$

Work performed under

DOE Contract

No. DE-ACO7-761D01570 
This document contains new concepts or the author(s) interpretation of new calculations and/or measurements; accordingly. EG\&G Idaho, Inc. is required by the United States Government to include the following disclaimer:

\section{DISCLAIMER}

This report was prepared as an account of work sponsored by an agency of the United States Government. Neither the United States Government nor any agency thereof, nor any of their employees, makes any warranty, express or implied, or assumes any legal liability or responsibility for the accuracy. completeness, or usefulness of any information. apparatus, product or process disclosed, or represents that its use would not infringe privately owned rights. References herein to any specific commercial product. process, or service by trade name, trademark. manufacturer, or otherwise, does not necessarily constitute or imply its endorsement, recommendation, or favoring by the United States Goveri, ment or any agency thereof. The views and opinions of authors expressed herein do not necessarily state or reflect those of the United States Government or any agency thereof. 
EGG-MS-10646

\title{
Bench-Scale Arc Melter for R\&D in Thermal Treatment of Mixed Wastes
}

\author{
P. C. Kong \\ J. D. Grandy \\ A. D. Watkins \\ T. L. Eddy \\ G. L. Anderson
}

Published May 1993
Idaho National Engineering Laboratory
EG\&G Idaho, Inc. Idaho Falls, Idaho 83415

\author{
Prepared for the \\ U.S. Department of Energy \\ Office of Environmental Restoration and Waste Management \\ Under DOE Idaho Field Office \\ Contract DE-AC07-76ID01570
}

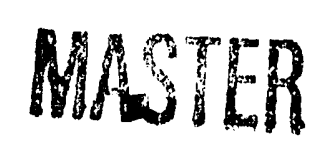




\begin{abstract}
A small de arc melter was designed and constructed to run bench-scale investigations on various aspects of development for high-temperature $\left(1,500-1,800^{\circ} \mathrm{C}\right)$ processing of simulated transuranic-contaminated waste and soil located at the Radioactive Waste Management Complex (RWMC). Several recent system design and treatment studies have shown that high-temperature melting is the preferred treatment. The small are melter is needed to establish techniques and procedures (with surrogates) prior to using a similar melter with the transuranic-contaminated wastes in appropriate facilities at the site. This report documents the design and construction, starting and heating procedures, and tests evaluating the melter's ability to process several waste types stored at the RWMC. It is found that a thin graphite strip provides reliable starting with initial high current capability for partially melting the soil/waste mixture. The heating procedure includes (1) the initial high current-low voltage mode, (2) a low current-high voltage mode that commences after some slag has formed and arcing dominates over the receding graphite conduction path, and (3) a predominantly Joule heating mode during which the current can be increased within the limits to maintain relatively quiescent operation. Several experiments involving the melting of simulated wastes are discussed. Energy balance, slag temperature, and electrode wear measurements are presented. Recommendations for further refinements to enhance its processing capabilities are identified. Future studies anticipated with the arc melter include waste form processing development; dissolution, retention, volatilization, and collection for transuranic and low-level radionuclides, as well as high vapor pressure metals; electrode material development to minimize corrosion and erosion; refractory corrosion and/or skull formation effects; crucible or melter geometry; metal oxidation; and desirable melt reduction/oxidation (redox) conditions.
\end{abstract}




\section{ACKNOWLEDGMENTS}

This $1 \quad$ was prepared for the Office of Waste Technology Development of EG\&G Idaho, Inc., u. der contract to the U.S. Department of Energy Idaho Field Office. Funding was provided by the Idaho Waste Processing Facility (IWPF).

This is one of a series of reports for technology development under the IWPF funding. Contributions to the report far exceed the list of authors indicated. We appreciate the assistance and efforts of all those who contributed to the development of this technology. 


\section{CONTENTS}

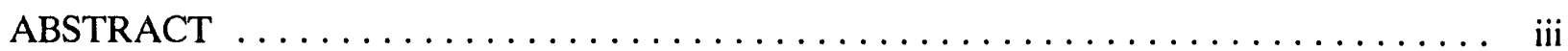

ACKNOWLEDGMENTS $\ldots \ldots \ldots \ldots \ldots \ldots \ldots \ldots \ldots \ldots \ldots \ldots \ldots \ldots$

ACRONYMS AND NOMENCLATURE $\ldots \ldots \ldots \ldots \ldots \ldots \ldots \ldots \ldots \ldots \ldots \ldots$

1. INTRODUCTION $\ldots \ldots \ldots \ldots \ldots \ldots \ldots \ldots \ldots \ldots \ldots \ldots \ldots \ldots \ldots \ldots$

1.1 Research and Development Applications $\ldots \ldots \ldots \ldots \ldots \ldots \ldots \ldots \ldots \ldots$

1.1.1 Waste Form Processing $\ldots \ldots \ldots \ldots \ldots \ldots \ldots \ldots \ldots \ldots$

1.1.2 Dissolution, Retention, Volatilization, and Trapping Studies for

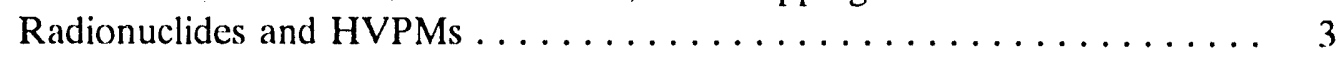

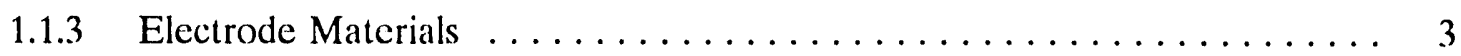

1.1.4 Effects of the Arc Power, Jet, and Roots $\ldots \ldots \ldots \ldots \ldots \ldots \ldots \ldots$

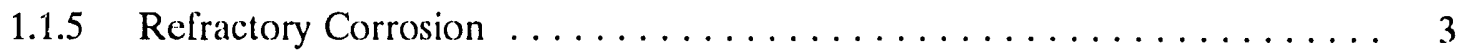

1.1.6 Skull Formation $\ldots \ldots \ldots \ldots \ldots \ldots \ldots \ldots \ldots \ldots \ldots \ldots \ldots \ldots$

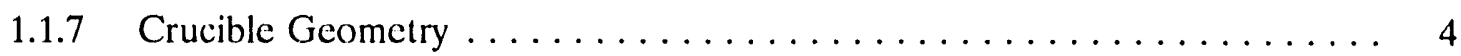

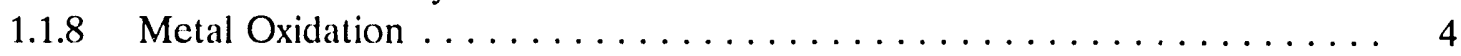

1.1.9 Melt Oxidation and Reduction State $\ldots \ldots \ldots \ldots \ldots \ldots \ldots \ldots \ldots$

1.1.10 Crystallization/Devitrification of Melt $\ldots \ldots \ldots \ldots \ldots \ldots \ldots \ldots \ldots$

1.2 Input Waste Stream and Final Waste Form Series $\ldots \ldots \ldots \ldots \ldots \ldots \ldots$

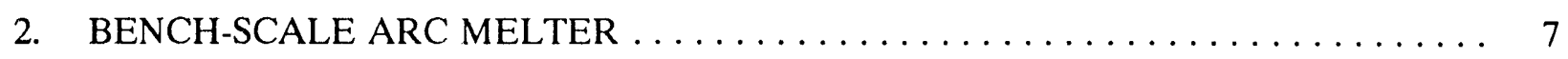

2.1 System Design and Construction $\ldots \ldots \ldots \ldots \ldots \ldots \ldots \ldots \ldots \ldots \ldots$

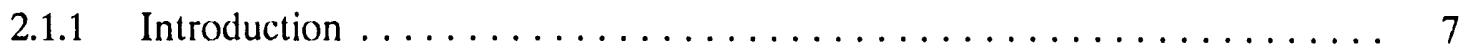

2.1.2 Experimental Apparatus . . . . . . . . . . . . . . . . . . . 7

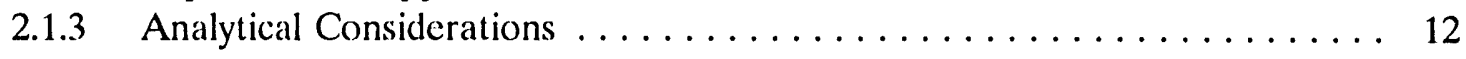

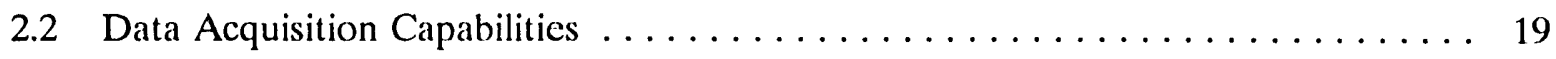

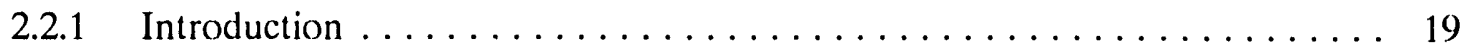

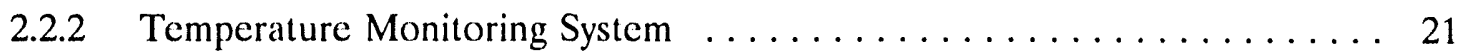

2.2.3 Current and Voltage Measurements .................. 21

2.2.4 Optical Monitoring Capabilities ................... 21

3. OPERATIONAL CHARACTERISTICS $\ldots \ldots \ldots \ldots \ldots \ldots \ldots \ldots \ldots \ldots \ldots$

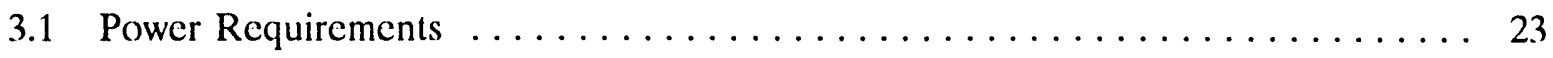

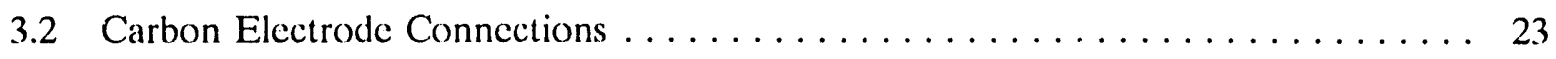




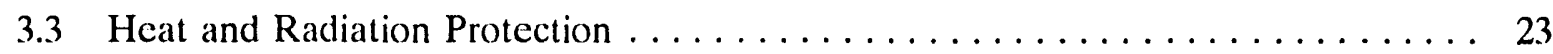

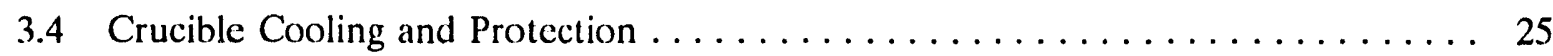

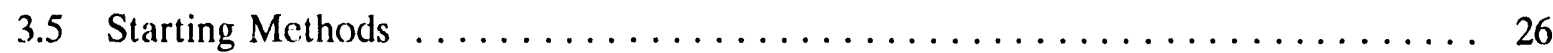

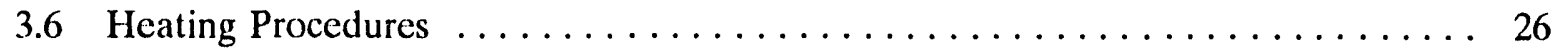

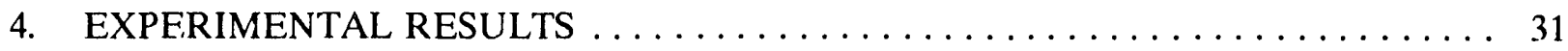

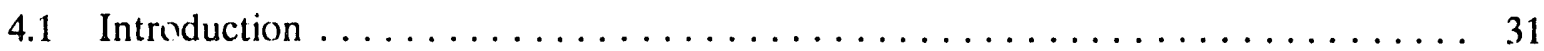

4.2 Description and Purpose of Experiments $\ldots \ldots \ldots \ldots \ldots \ldots \ldots \ldots \ldots \ldots \ldots$

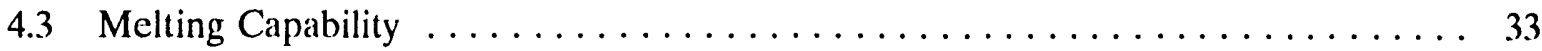

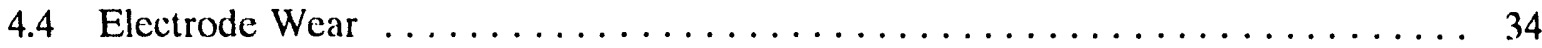

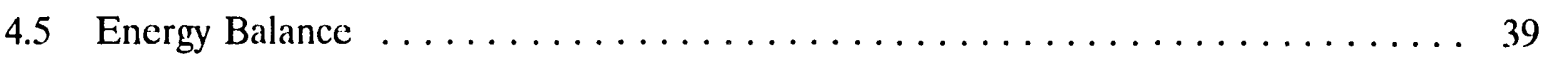

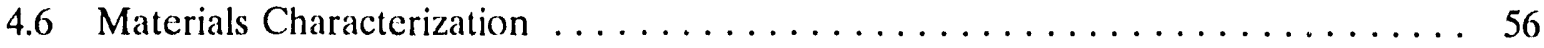

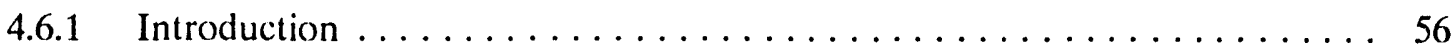

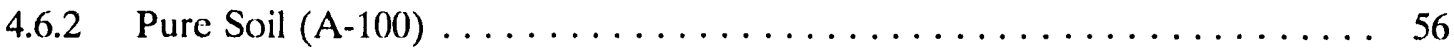

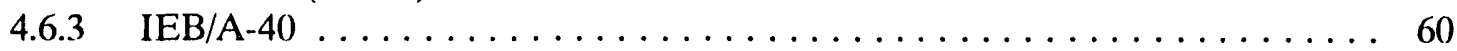

4.6.4 Hydrated Metal Oxide, Metal Dissolution and Oxidation, and Cemented Organic Experiments ...................... 60

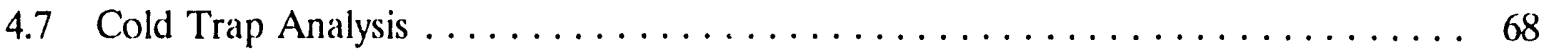

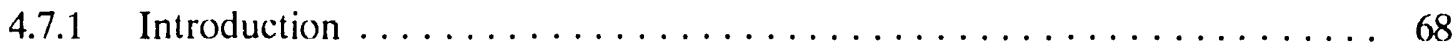

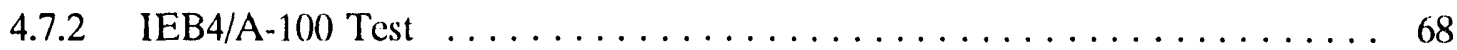

4.7.3 Hydrated Metal Oxide Test $\ldots \ldots \ldots \ldots \ldots \ldots \ldots \ldots \ldots \ldots \ldots . \ldots \ldots$

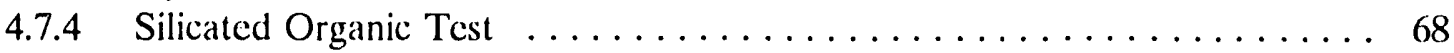

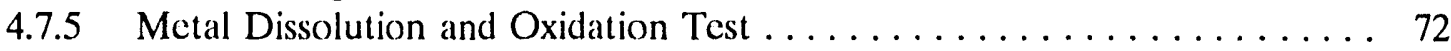

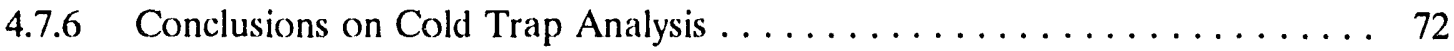

5. CONCLUSIONS AND RECOMMENDATIONS $\ldots \ldots \ldots \ldots \ldots \ldots \ldots \ldots \ldots$

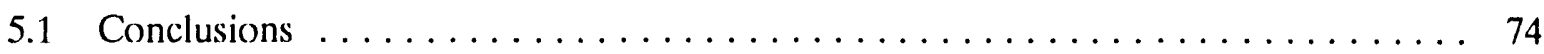

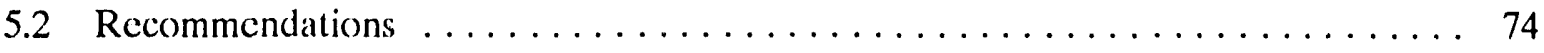

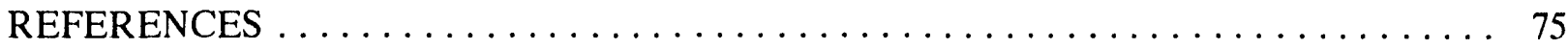

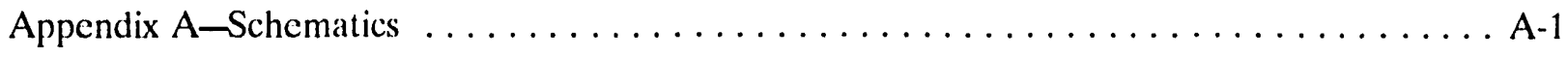


Appendix B-Test Summaries . . . . . . . . . . . . . . . .

Appendix C--Computer Code Listings $\ldots \ldots \ldots \ldots \ldots \ldots \ldots \ldots \ldots \ldots \ldots \ldots \ldots \ldots \ldots \ldots \ldots \ldots$

\section{FIGURES}

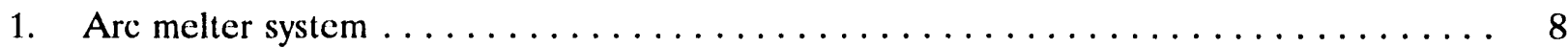

2. Left is a front view and right is a side view of the modified plasma reactor chamber showing the ports and electrode drive assembly $\ldots \ldots \ldots \ldots \ldots \ldots \ldots \ldots \ldots \ldots$

3. Crucible assembly sitting in the chamber bottom $\ldots \ldots \ldots \ldots \ldots \ldots \ldots \ldots \ldots$

4. Stepping motor controller $\ldots \ldots \ldots \ldots \ldots \ldots \ldots \ldots \ldots \ldots \ldots \ldots \ldots \ldots \ldots$

5. Electrode geometry as viewed through the front port of the reactor chamber $\ldots \ldots \ldots 11$

6. V-I characteristics of a single TAFA $30-\mathrm{HF}$ power supply $\ldots \ldots \ldots \ldots \ldots \ldots \ldots$

7. Data acquisition system for monitoring and storing temperature, flow, and electric

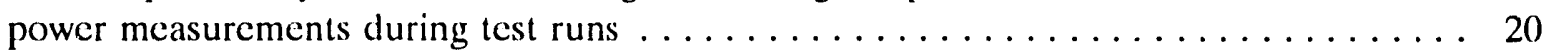

8. Rear view of the data acquisition system showing the back panel for easy connection

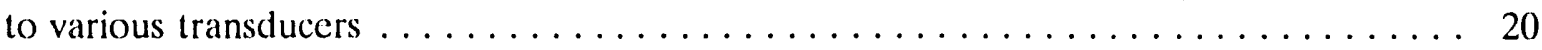

9. Approximate dimensions of the carbon starting bar or strip $\ldots \ldots \ldots \ldots \ldots \ldots \ldots$

10. Current and voltage profile with time for Test $6 \ldots \ldots \ldots \ldots \ldots \ldots \ldots \ldots$

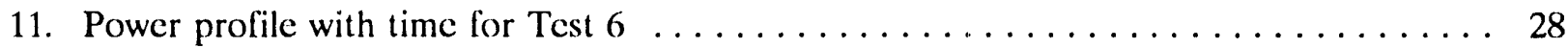

12. Current and voltage profile with time for Test $7 \ldots \ldots \ldots \ldots \ldots \ldots \ldots$

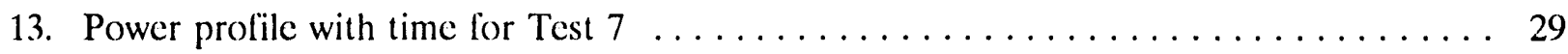

14. Convective flow pattern in an $8 \mathrm{~kg}$ soil melt $\ldots \ldots \ldots \ldots \ldots \ldots \ldots \ldots \ldots$

15. Soil thermocouple temperature as a function of time for Test $6 \ldots \ldots \ldots \ldots$

16. Soil thermocouple temperature as a function of time for Test $7 \ldots \ldots \ldots \ldots$

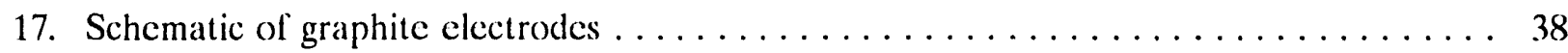

18. Plot of uncoated anode erosion rate $\ldots \ldots \ldots \ldots \ldots \ldots \ldots \ldots \ldots \ldots \ldots \ldots \ldots$

19. Plot of uncoated cathode erosion rate $\ldots \ldots \ldots \ldots \ldots \ldots \ldots \ldots \ldots \ldots \ldots \ldots \ldots$ 
20. Plot of anode erosion rate for $\mathrm{Al}_{2} \mathrm{O}_{3}$ coated electrodes $\ldots \ldots \ldots \ldots \ldots \ldots \ldots \ldots$

21. Plot of cathode crosion rate for $\mathrm{Al}_{2} \mathrm{O}_{3}$ coated electrodes $\ldots \ldots \ldots \ldots \ldots \ldots \ldots \ldots$

22. Plot of anode erosion rate for $\mathrm{ZrO}_{2}$ coatings $\ldots \ldots \ldots \ldots \ldots \ldots \ldots \ldots \ldots \ldots \ldots \ldots$

23. Plot of cathode erosion rate for $\mathrm{ZrO}_{2}$ coatings $\ldots \ldots \ldots \ldots \ldots \ldots \ldots \ldots \ldots \ldots$

24. Current-voltage response of the arc melter for Test 8 on IEB/A-100 soil $\ldots \ldots \ldots 45$

25. Current-voltage response of the are melter for Test 9 on IEB4/A-100 soil with $\mathrm{ZrO}_{2}$

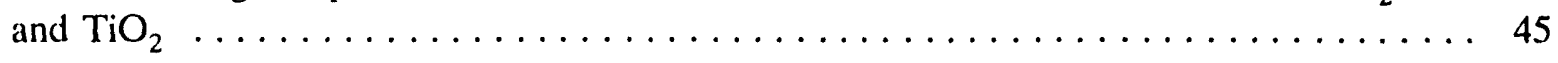

26. Current-voltage response of the are melter for Test 10a on IEB4/H-series $\ldots \ldots \ldots 46$

27. Current-voltage response of the are melter for Test $10 \mathrm{~b}$ on IEB $4 / \mathrm{H}$-series $\ldots \ldots \ldots 46$

28. Current-voltage response of the are melter for Test 11 on metal dissolution with

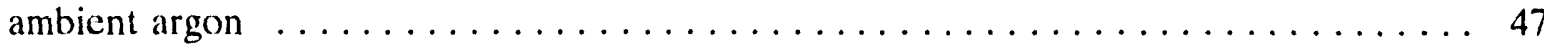

29. Current-voltage response of the are melter for Test 12 on metal dissolution with

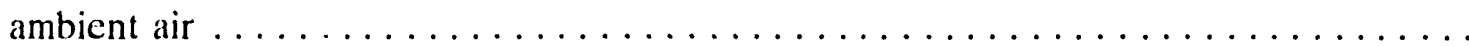

30. Current-voltage response of the arc melter for Test 13 on metal dissolution with

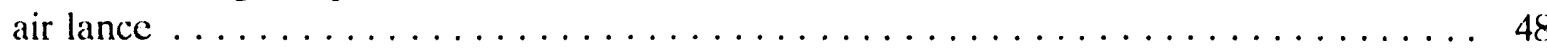

31. Current-voltage response of the are melter for Test 14 on silicated organics $\ldots \ldots \ldots 48$

32. Power input and losses to cooling for Test 8 on IEB/A-100 soil $\ldots \ldots \ldots \ldots \ldots \ldots$

33. Power input and losses to cooling for Test 9 on IEB4/A-100 soil with $\mathrm{ZrO}_{2}$ and $\mathrm{TiO}_{2} \ldots 49$

34. Power input and losses to cooling for Test 10a on IEB4/H-series $\ldots \ldots \ldots \ldots \ldots \ldots$

35. Power input and losses to cooling for Test $10 \mathrm{~b}$ on IEB4/H-series $\ldots \ldots \ldots \ldots \ldots$

36. Power input and losses to cooling for Test 11 on metal dissolution with ambient

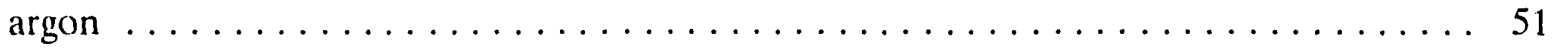

37. Power input and losses to cooling for Test 12 on metal dissolution with ambient air . . . 51

38. Power input and losses to cooling for Test 13 on metal dissolution with air lance $\ldots . .52$

39. Power input and losses to cooling for Test 14 on silicated organics $\ldots \ldots \ldots \ldots \ldots$

40. Soil thermocouple temperature as a function of time for Test 8

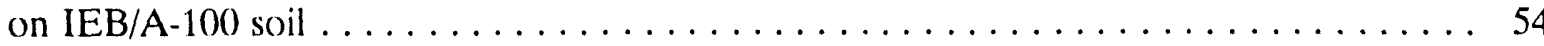


41. Soil thermocouple temperature as a function of time for Test 12 on metal dissolution with ambient air

42. Soil thermocouple temperature as a function of time for Test 13 on metal dissolution

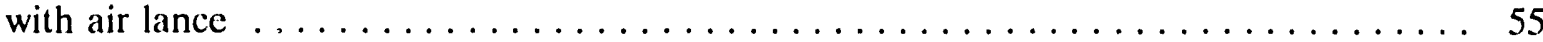

43. Soil thermocouple temperature as a function of time for Test 14 on silicated organics . . 55

44. SEM micrograph of the pure soil IEB/A-100 waste form produced in Test $3 \ldots \ldots \ldots 7$

45. SEM secondary electron image of a metal-like sphere in the graphite (Test 3) $\ldots \ldots 57$

46. Metal-like spheres in the glassy region with relatively high carbon diffusion (Test 3) $\ldots 58$

47. Composition of the metal-like spheres in the glassy region with relatively high carbon

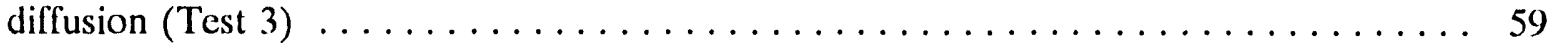

48. IEB/A-40 waste form chunks produced in the arc melter (Test 6$) \ldots \ldots \ldots \ldots$

49. X-ray diffraction trace for the more crystalline region on the IEB/A-40 waste form produced in the arc melter and its possible mineral phases (Test 6$) \ldots \ldots \ldots \ldots \ldots 6$

50. SEM micrographs of the crystalline region of IEB/A-40 produced in Test $6 \ldots \ldots 3$

51. SEM micrograph of the IEB4/H-90 waste form produced by the hydrated metal oxide

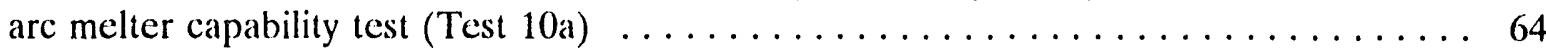

52. SEM micrographs of the IEB4/M-90 (Test 12) and IEB4/S-90 (Test 14) waste forms produced by the metal dissolution and oxidation and cemented organic are melter

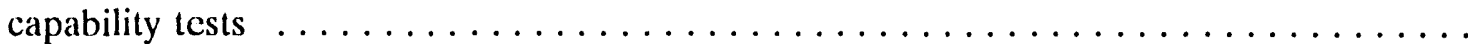

53. Speculated zirconia crystallites crystallized from the melt during the metal dissolution and oxidation (argon atmosphere) are melter capability test (Test 11) . . . . . . .

54. X-ray diffraction traces of Test 9 cold trap residue. Test 9 melted only pure IEB4/A-100 soil; there were no waste additions

55. IEB4/A-100 plus hydrated metal oxides X-ray diffraction traces. These compounds were present in the cold trap residue

56. IEB4/A-100 plus hydrated metal oxides X-ray diffraction trace (top), plus the traces of the added metal hydroxides. The added metal hydroxides were not found in the cold

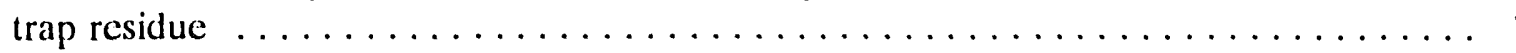

57. X-ray diffraction traces from the silicated organic experiments: cold trap and monocalcium silicate trace 


\section{TABLES}

1. I.put waste stream chemical compositions $\ldots \ldots \ldots \ldots \ldots \ldots \ldots \ldots \ldots \ldots \ldots \ldots \ldots$

2. Estimated waste form composition from waste streams after

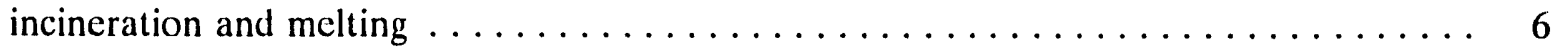

3. Mean mass $T(t)$ for $10 \mathrm{~kg}$ of IEB/A-100 soil heated at a rate of $10 \mathrm{~kW} \ldots \ldots \ldots 13$

4. Estimation of heat transfer rate between melt at $1,500^{\circ} \mathrm{C}$ and cooling water surrounding crucible with the slag skull providing the most thermal

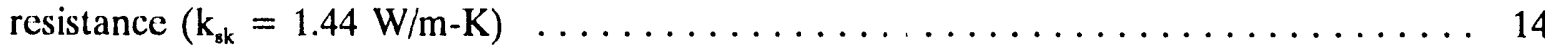

5. Typical convective heat transfer coefficient ranges $\ldots \ldots \ldots \ldots \ldots \ldots \ldots \ldots$

6. Table of calculated values for heat removal from crucible by cooling water $\ldots \ldots \ldots 16$

7. Slag properties of IEB/A-100 and A-40 at different temperatures $\ldots \ldots \ldots \ldots \ldots$

8. Arc melter current and voltage as a function of geometry and temperature . . . . . 19

9. Description and measurements obtained for arc melter starting and heating

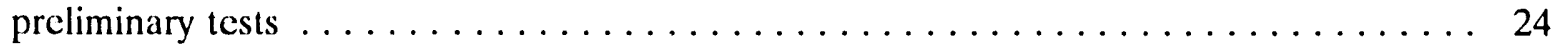

10. Descriptions and measurements obtained for simulated-waste arc-melting tests $\ldots \ldots .32$

11. Optical pyrometer measurements of the melt from various tests $\ldots \ldots \ldots \ldots \ldots$

12. Summary of mass balance results for Tests $10-14 \ldots \ldots \ldots \ldots \ldots \ldots \ldots \ldots \ldots$

13. Electrode crosion data (mass in grams) $\ldots \ldots \ldots \ldots \ldots \ldots \ldots \ldots \ldots \ldots \ldots \ldots \ldots \ldots$

14. Average crosion rates for electrodes during are melter experiments $\ldots \ldots \ldots \ldots . \ldots 44$

15. EDS chemistries of metal dissolution and oxidation, (Ar atmosphere) experimental melt. Ar2-1 represents the general glass, Ar2-2 represents the glass located at Spot 2 in Figure 53, and Ar2-3 represents the zirconia particle chemistry located at Spot 3

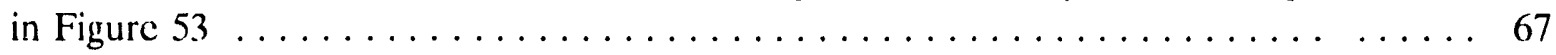

16. Hydrated metal oxide sludge cheriical composition $\ldots \ldots \ldots \ldots \ldots \ldots \ldots \ldots$

17. Chemical composition of Micro-cel $E$ and Floor DRI $\ldots \ldots \ldots \ldots \ldots \ldots \ldots$ 


\section{ACRONYMS AND NOMENCLATURE}

A

$A_{\text {s }}$

$\mathrm{c}_{\mathrm{p}}$

$\mathrm{c}_{\mathrm{v}}$

D

E

h

$\mathrm{h}_{\text {ave }}$

I

IEB

IEB4

$\mathrm{k}$

$\mathrm{L}$

$\mathrm{m}$

$\mathrm{Nu}$

$\operatorname{Pr}$

q

Q

s

$\mathrm{rf}$

$\mathrm{R}$

$\mathrm{Re}$

RTD area

cross sectional area $\left(\mathrm{m}^{2}\right)$

specific heat at constant pressure

specific heat at constant volume

diameter

internal energy (J)

film heat transfer coefficient $\left(\mathrm{W} / \mathrm{m}^{2}-\mathrm{K}\right)$

average $h$ over length of channel

electric current (A)

iron-enriched basalt

IEB with $\mathrm{ZrO}_{2}$ and $\mathrm{TiO}_{2}$

thermal conductivity $(\mathrm{W} / \mathrm{m}-\mathrm{K})$

length

mass $(\mathrm{kg})$

Nusselt No., $\mathrm{Nu}=\mathrm{hD} / \mathrm{k}$

Prandtl No.

heat flux $\left(\mathrm{W} / \mathrm{m}^{2}\right)$

heat transfer rate (W)

height of channel

radio-frequency

electrical resistance (Ohms)

Reynolds No.

resistance thermometer device 


\begin{tabular}{|c|c|}
\hline RWMC & Radioactive Waste Management Complex \\
\hline SS & stainless steel \\
\hline $\mathbf{t}$ & time \\
\hline $\mathrm{T}$ & temperature \\
\hline $\mathrm{U}$ & velocity $(\mathrm{m} / \mathrm{s})$ \\
\hline V & voltage (V) \\
\hline VOC & Volts - open circuit \\
\hline $\mathbf{w}$ & width of channel \\
\hline$W$ & work rate $(\mathrm{W})$ \\
\hline $\mathbf{x}$ & distance \\
\hline \multicolumn{2}{|l|}{ Greek } \\
\hline$\sigma$ & electrical conductivity (Ohm-m) ${ }^{-1}$ \\
\hline \multicolumn{2}{|l|}{ Subscripts } \\
\hline B & bulk or mixed condition \\
\hline $\mathrm{c}$ & channel \\
\hline e & electrical \\
\hline $\mathrm{h}$ & hydraulic \\
\hline melt & meited slag \\
\hline sk & skull \\
\hline SS & stainless steel \\
\hline$w$ & water \\
\hline
\end{tabular}




\section{Bench-Scale Arc Melter for R\&D in Thermal Treatment of Mixed Wastes}

\section{INTRODUCTION}

The objeciive of this report is to describe the design, construction, and development of procedures for operating a bench-scale arc melter. The are melter will be used to develop techniques and procedures with simulated waste materials, including radionuclide surrogates, which can be duplicated with transuranic (TRU) and low-level (LL) radionuclides and similar equipment in hot cells at the site. Examples include the dissolution, retention, volatilization, and collection of TRU and LL nuclides and high vapor pressure metals (HVPMs); metal decontamination via surface oxidation; and the waste form phase composition and process development. The arc melter will also be used to test various melter design concepts such as electrode material development to minimize corrosion and crosion, refractory corrosion and/or skull formation effects, and crucible or melter geometry. In addition, the bench-scale melter can provide information on general waste composition processing requirements for nonradioactive, radioactive and hazardous waste streams. Processes of interest include metal melting and oxidation rates, desirable melt oxidation/reduction (redox) conditions, and crystallization/devitrification of the slag. An immediate need is to initiate in-house testing of IEB4, an iron-enriched basalt (IEB) modified with Group IVB oxide additives $\left(\mathrm{ZrO}_{2}\right.$ and $\left.\mathrm{TiO}_{2}\right)$, for ex situ vitrification of the buried and stored TRU-contaminated wastes at the Idaho National Enginecring Laboratory (INEL).

A robust thermal treatment process has evolved from preliminary buried waste system design studies (BWSDS) ${ }^{1}$ and stored waste system design studies (SWSDS) ${ }^{2}$ for treating TRU-contaminated waste (TRUW) using an iron-enriched basalt medium. Most of the previous research performed on IEB and has shown that for disposal the waste form is long-lived., $3,4,5$ At the end of the IEB research program, it was found that the incorporation of zirconia further adds waste form longevity and lowers leach rates. ${ }^{6,7,8}$ These rates were first identified when Three-Mile Island core debris was being investigated for fuel disposal or recovery. ${ }^{9,10,11,12}$ Present waste form research at the INEL is focused on the improvements attainable with zirconia and titania additives. It is well known that zirconium and titanium oxides are the basic components in SYNROC ceramic waste forms ${ }^{13,14,15}$ and these oxides enhance the IEB4 waste form. ${ }^{8,16,17}$ The thermal treatment process is robust in that the composition of the radionuclides ( $\mathrm{U}, \mathrm{Pu}, \mathrm{etc}$.) has a large tolerance (20-30\% as oxides) and in that high-temperature thermal conditions can be obtained to maintain fluidity, even with zirconia and titania additions that may elevate the melting temperature. Ewing and Lutze (Ref. 14) indicate that the higher thermal stability of ceramic waste forms permits higher waste loadings and thus a reduction in the material to be handled and storage in rock units at greater depth or in canister arrays with closer spacings.

The are melter is a lab/bench prepilot unit ( $<50 \mathrm{lb}$ capacity) using water-cooled metal crucibles to produce a protective skull. The electrodes must be able to operate above the melt in both oxidizing and reducing atmospheres. In the design and construction of the are melter, several initial constraints were proposed. 
- Construction of the plasma arc melter will only require modification to the existing equipment.

- These modifications will consist of construction of a new electrode mounting and translation device and the addition of a temperature and video monitoring system.

- The use of this arc melter will be limited to nonradioactive isotopes and small amounts of hazardous metals as allowed by the independent safety review committee.

- A water-cooled crucible will be constructed and used for waste analog tests to eliminate potential contamination that could result from use of a ceramic crucible.

- Materials volatilized from the melt are to be collected in a liquid nitrogen cold trap and the scrubbing system.

- The input power to the arc melter will not exceed $240 \mathrm{~kW}$, the maximum available power from the power supplies.

An existing water-cooled plasma reactor chamber was converted into the arc reactor chamber. The motor track for electrode translation, the electrode mount and connectors, thermocouple support, and additional windows were added to the chamber. A water-cooled metal crucible jacket with removable stainless steel (SS) crucible inserts was constructed to perform the melt operation. A heat reflector and ceramic fiber insulation were added to the inside top of the reactor chamber to prevent overheating. An existing off-gas scrubber system can be connected to the arc chamber to remove particles and noxious gases from the off-gas stream. A liquid nitrogen trap was added for cooling and to ensure the harmless integrity of the exhaust gas. A video camera is used to provide instant feedback of the melter in operation. Access was provided for waste additions during operation.

The plasma arc melter is completely instrumented to monitor and store data on (a) temperatures at several locations within the melt, (b) heat losses to cooling water, (c) chemical analysis of off-gas, (d) electrical power input, and (c) arc power. Provisions have been made for periodic sampling and testing of the melt composition during melting of simulated wastes.

\subsection{Research and Development Applications}

Knowledge accumulated from the research and development phase of the bench-scale arc melter is important. This knowledge will lead to effective cost saving in proper design, construction, and operation of the demonstration unit. The bench-scale prototype melter also provides research and development capabilities to identify extrinsic and intrinsic waste processing parameters that will significantly influence waste form performance characteristics. These processing parameters are an integral part of the functional unit that will provide information to the public that the waste forms are safe and the properties are copmarable to their natural analogs. 


\subsubsection{Waste Form Processing}

This arc melter prototype provides the capability for waste form processing. Different waste stream compositions can be tested in the melter to obtain different waste form compositions and associated process characteristics. The performance of these waste forms can then be compared as a function of their chemical compositions and processing characteristics in the melter. This provides the opportunity to define the most desirable procedure to produce a durable waste form.

\subsubsection{Dissolution, Retention, Volatilization, and Trapping Studies for Radionuclides and HVPMs}

This arc melter prototype provides the capabilities for dissolution. retention, volatilization, and trapping studies for the radionuclides (TRUs, activated and fission products) and high vapor pressure metals (HVPMs). The melt chemistry, temperature, and interaction of the arc roots and the melt have tremendous influences on the dissolution, retention, and volatilization of the radionuclides and HVPMs. It is very desirable to define an operating procedure that allows high dissolution and maximum retention of these elements in the slag. The melter also provides an opportunity for determining the condition under which the HVPMs will volatilize from the melt and the means to trap and dispose of these elements.

\subsubsection{Electrode Materials}

Electrode materials influence directly the melter operations, the melt chemistry, and indirectly the waste form performance characteristics. The abilities of the electrodes to maintain stable are operations in oxidizing and reducing atmospheres are important. These abilities will define the material lifetime as well as the duration of the are melter operation due to electrode wear. The electrode materials can influence the melt chemistry significantly during operation, particularly in the case of a dip electrode, which may change the oxidation state of the melt and indirectly influence the waste form performance characteristics. The bench-scale are melter offers the capability for defining and testing proper electrode materials and electrode wear conditions for optimum waste processing.

\subsubsection{Effects of the Arc Power, Jet, and Roots}

The are power directly influences the melt temperature, foaming, and chemistry by excessive vaporization of the volatile components. The electrode wear phenomena are directly due to the actions of the are roots and jets and are indirectly due to the are power. The melter offers the opportunity to investigate these interlocking interactions and their relationship to a proper waste processing.

\subsubsection{Refractory Corrosion}

If a refractory lining is required inside the crucible, the refractory corrosion by the melt at different melt temperatures is important. This is because refractory materials can significantly alter the melt composition and thus the waste form properties. The are melter has the capability to perform studies to provide the optimum recommendation. 


\subsubsection{Skull Formation}

If a water-cooled metal crucible is used, a skull will form on the crucible wall. The thickness of the skull will determine the rate of heat loss to the cooling water, which in turn affects the melt temperature and the melt circulation to homogenize the melt composition. The melter tests will give an indication of skull thickness and uniformity.

\subsubsection{Crucible Geometry}

The crucible geometry, dimension, and aspect ratios are important to the thermal equilibration, homogenization, foaming height, and tapping of the melt. The melter design is flexible enough for testing of different crucible geometry.

\subsubsection{Metal Oxidation}

The Radioactive Waste Management Complex (RWMC) waste streams contain a large quantity of contaminated metals. Dissolution, oxidation, and retention of the metals in the melt is important to melter capability. Arc melter prototype studies will provide the critically needed information for design and operation of the demonstration facility.

\subsubsection{Melt Oxidation and Reduction State}

The redox state of the melt is critical to the long-term performance of the waste form and can change the waste form composition, thus influencing positively or negatively waste form performance characteristies. The redox state of the melt relates intimately to a number of the above parameters. In situ sampling of the melt periodically will reveal the redox state of the melt during operation. This melter provides casy access for these studies.

\subsubsection{Crystallization/Devitrification of Melt}

The present design of the prototype allows a short turnover time for waste melting operation. The crucible insert containing the melt can be easily taken out and put in a temperature-controlled environment for crystallization and growth of desirable mineral phases. A new crucible insert can be replaced immediately, and the melting operation can be resumed.

\subsection{Input Waste Stream and Final Waste Form Series}

The are melter is to be used to generate waste forms from a variety of input waste streams. The chemical composition of the various waste streams from the Rocky Flats Plant is given in Table 1. IEB is being considered as the stabilizing medium for radioactive and hazardous wastes at the INEL Radioactive Waste Management Complex (RWMC) because the average composition of the waste, after combustion of organics, is that of an iron-enriched basalt. The addition of soil facilitates the processing, improves the stability, and shifts the composition toward a natural basalt. The major focus on IEB considered to date has been the A-series final waste form (FWF), where "A" indicates an "Average" transuranic-contaminated waste (TRUW) composition defined elsewhere ${ }^{3}$ and given in Table 2. The notation "A-40" means 60 wt\% "average" TRUW plus $40 \mathrm{wt} \%$ soil. The waste form compositions resulting from the various input 
Table 1. Input waste stream chemical compositions.

\begin{tabular}{|c|c|c|c|c|}
\hline $\begin{array}{l}\text { Content code/ } \\
\text { name }\end{array}$ & $\begin{array}{l}\text { Rocky } \\
\text { Flats } \\
\text { Plant }\end{array}$ & $\begin{array}{c}\text { Original waste } \\
\text { chemical composition } \\
(\mathrm{wt} \%)\end{array}$ & $\begin{array}{c}\text { Primary packaging } \\
\text { additions }\end{array}$ & Designator \\
\hline $\begin{array}{l}\text { 1/first stage } \\
\text { sludge }\end{array}$ & 741 & $\begin{array}{l}\mathrm{H}_{2} \mathrm{O}(60 \%), \mathrm{SiO}_{2}(14 \%), \\
\mathrm{Al}_{2} \mathrm{O}(3 \%), \\
\mathrm{FeO}(0 \%), \mathrm{Fe}_{2} \mathrm{O}_{3}(3 \%), \\
\mathrm{MgO}(2 \%), \\
\mathrm{CaO}(2 \%), \mathrm{Na}_{2} \mathrm{O}(11 \%), \\
\mathrm{K}_{2} \mathrm{O}(2 \%), \text { other }(3 \%)\end{array}$ & Portland cement & (H1) \\
\hline $\begin{array}{l}2 / \text { second stage } \\
\text { sludge }\end{array}$ & 742 & $\begin{array}{l}\mathrm{H}_{2} \mathrm{O}(60 \%), \mathrm{SiO}_{2}(19 \%) \\
\mathrm{Al}_{2} \mathrm{O}_{3}(2 \%), \\
\mathrm{FeO}(0 \%), \mathrm{Fe}_{2} \mathrm{O}_{3}(2 \%) \\
\mathrm{MgO}(4 \%), \\
\mathrm{CaO}(10 \%), \mathrm{Na}_{2} \mathrm{O}(2 \%) \\
\mathrm{K}_{2} \mathrm{O}(1 \%), \text { other }(0 \%)\end{array}$ & Portland cement & $(\mathrm{H} 2)$ \\
\hline 3/organic setups & 743 & $\begin{array}{l}\text { Texaco regal oil }(28 \%) \text {, } \\
\mathrm{CCl}_{4}(19 \%), \\
\mathrm{Cl}_{2} \mathrm{CHCH} \mathrm{Cl}_{2} \mathrm{Cl}(10 \%) \text {, } \\
\text { misc. oils (hydraulic, } \\
\text { gearbox, freon, etc.) } \\
(43 \%)\end{array}$ & Calcium silicates & $(\mathrm{S})$ \\
\hline 4/special setups & 744 & $\begin{array}{l}\text { Alcohols, organic acids } \\
\text { and } \\
\text { chelating agents }(100 \%) \\
\text { (specific makeup } \\
\text { unknown) }\end{array}$ & $\begin{array}{l}\text { Portland cement, } \\
\text { magnesia cement }\end{array}$ & $(\mathrm{P})$ \\
\hline 5/cvaporator salts & 745 & $\begin{array}{l}\mathrm{NaNO}_{3}(60 \%) \\
\mathrm{KNO}_{3}(30 \%) \\
\text { misc. }(10 \%)\end{array}$ & None & $(\mathrm{N})$ \\
\hline $\begin{array}{l}\text { 480/unleached } \\
\text { light non-SS } \\
\text { source metal }\end{array}$ & UNK & $\begin{array}{l}\mathrm{Fe}(62 \%) \\
\text { other(Cu,Al, Cr,ctc.) } \\
(26 \%) \\
\mathrm{SiO}_{2}(3 \%), \mathrm{Al}_{2} \mathrm{O}_{3}(2 \%) \\
\mathrm{CaO}(2 \%) \\
\text { other(combustible) }(5 \%)\end{array}$ & None & $(\mathrm{M})$ \\
\hline
\end{tabular}


Table 2. Estimated waste form composition from waste streams after incineration and melting.

\begin{tabular}{|c|c|c|c|c|c|c|c|c|c|}
\hline & $\mathrm{SiO}_{2}$ & $\mathrm{Al}_{2} \mathrm{O}_{3}$ & $\begin{array}{l}\mathrm{FeO}+ \\
\mathrm{Fe}_{2} \mathrm{O}_{3}\end{array}$ & $\mathrm{CaO}$ & $\mathrm{MgO}$ & $\mathrm{Na}_{2} \mathrm{O}$ & $\mathrm{K}_{2} \mathrm{O}$ & $\mathrm{TiO}_{2}$ & Misc \\
\hline A- 0 & 38.0 & 7.4 & 34.5 & 8.3 & 4.6 & 4.8 & 2.4 & 0.0 & 0.0 \\
\hline H1-0 & 25.1 & 7.0 & 30.2 & 12.5 & 3.0 & 16.0 & 2.5 & 0.0 & 3.7 \\
\hline $\mathrm{H} 2-0$ & 31.0 & 4.7 & 22.7 & 22.7 & 6.0 & 3.2 & 2.2 & 0.2 & 0.3 \\
\hline S-0 & 33.4 & 2.9 & 37.5 & 25.6 & 0.0 & 0.0 & 0.0 & 0.0 & 0.0 \\
\hline P-0 & 17.4 & 8.4 & 24.4 & 41.8 & 8.0 & 0.0 & 0.0 & 0.0 & 0.0 \\
\hline $\mathrm{N}-0$ & 0.5 & 0.2 & 25.3 & 0.0 & 0.0 & 45.0 & 29.0 & 0.0 & 0.0 \\
\hline M-0 & 2.5 & 5.1 & 75.1 & 1.0 & 0.0 & 0.0 & 0.0 & 0.0 & 16.3 \\
\hline SOIL & 65.4 & 13.0 & 4.5 & 10.0 & 2.4 & 1.7 & 2.9 & 0.6 & 0.0 \\
\hline
\end{tabular}

waste streams shown in Table 1 and the INEL soil being considered are given in Table 2, where A-0, H-(), etc., are the "pure" waste compositions and A-100, H-100, etc., would be pure soil.

It has also been found that the addition of small amounts of $\mathrm{TiO}_{2}$ and $\mathrm{ZrO}_{2}$ to the soil (giving IEB4) results in the formulation of crystals in the waste form which incorporate the actinide (transuranic) elements. These crystals are more leach resistant than other glasses and ceramics, including borosilicate glass (BSG) and IEB, and are a component of the composition of the SYNROC ceramic waste forms. The generation of both IEB and IEB4 waste forms are discussed in this report. A shorthand format, IEB4/A-40, has been selected to indicate that the soil is mixed with some $\mathrm{TiO}_{2}$ and $\mathrm{ZrO}_{2}$ before combining with $60 \mathrm{wt} \%$ of the simulated average TRUW composition. The compositions used are often those assumed after incineration to simulate probable melting conditions, but not always. 


\section{BENCH-SCALE ARC MELTER}

\subsection{System Design and Construction}

\subsubsection{Introduction}

A relatively simple design using transferred ares was desired to examine the various $R \& D$ topics. ${ }^{16,17,18}$ A melter using consumable graphite electrodes was selected. The are melter is designed to provide minimum contact between the graphite electrodes and the melt. Graphite electrodes in contact with the melt can change the oxidation state of the melt causing reduction of some metal oxides-in particular the iron oxide to metallic iron. This change in the oxidation state may have significant negative influence on the durability of the waste form. The reduction of the iron or other transition metal oxides will cause excessive foaming of the melt and make the melt operation difficult to control.

The present design features both the anode and the cathode sustaining the ares above the melt. A sketch of the are melter system is shown in Figure 1. This arrangement prevents the electrode from contacting the melt and decreasing the opportunity of melt reduction by the electrodes. The cathodic are attaches to the melt where the current passes through and provides joule heating of the melt. The anodic are leaves the surface and reattaches to the anode above the melt. This mode of heating combines both are and joule heating of the melt and provides a much higher heat transfer and heating rates of the materials than the conventional joule-heated melter. The are gap above the melt can be constantly adjusted by a step motor to maintain a stable are operation. Another important feature of the are melter is a water-cooled crucible-pot assembly, with a removable SS crucible insert. This design is for fast turnaround batch operations, without the need to tap the melt. A small entry port provides thermocouple aceess to the melt for temperature measurement. Thermocouples are installed to measure the heat loss to the crucible cooling water, the electrode, and the off-gas. Electrode feed openings are insulated and protected by boron nitride. A liquid nitrogen cold trap is used to condense volatile particles from the off-gas. The whole system is completed with a wet scrubber to clean the off-gas.

\subsubsection{Experimental Apparatus}

2.1.2.1 Melter Chamber. An existing large plasma reactor has been modilied to become the melter chamber (see Figure 2). Of the upper chamber's live ports, three are for aceess, one is for exhaust gas, and one is unused. The top of the chamber has been modified for mounting the electrode feedthrough and translation system. Additional ports have been installed for observation and for thermocouple entry into the melter crucible. A cooling system and heat shield have been installed inside near the top of the upper chamber to prevent overheating during melting. The lower chamber has two ports, one of which is used as the cooling water inlet and the other as an outlet for melter crucible.

2.1.2.2 Water-Cooled Metal Crucible. The schematics for the crucible design are given in Appendix A (Figures A-1 and A-2). Figure 3 shows the crucible assembly sitting in the bottom of the chamber. The crucible is constructed with 0.125 in. thick SS. The water-cooled crucible-pot assembly consists of a right cylindrical outer jacket, or pot, 11 in. in diameter and 16 in. in height 


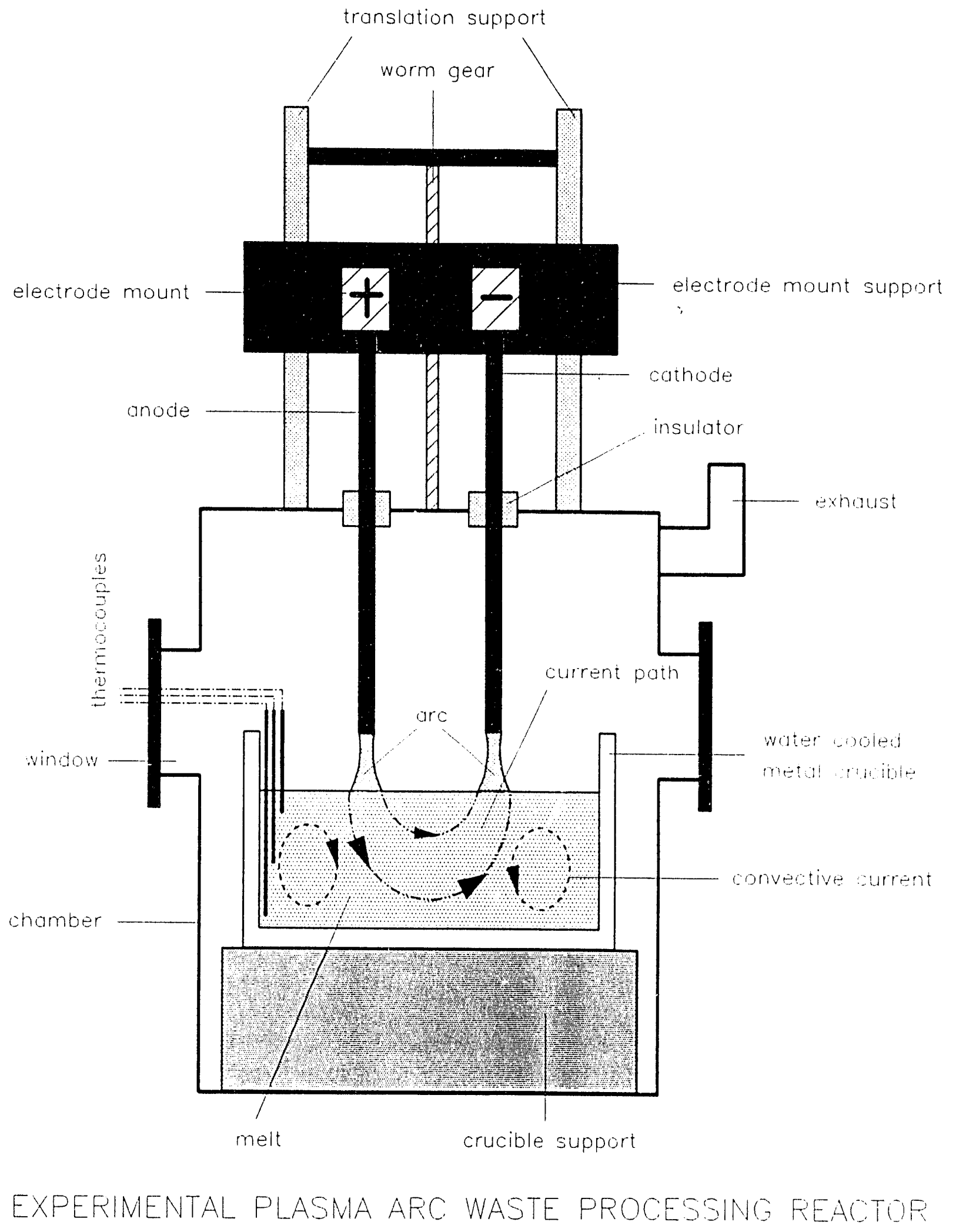

Figure 1. Arc melter system. 


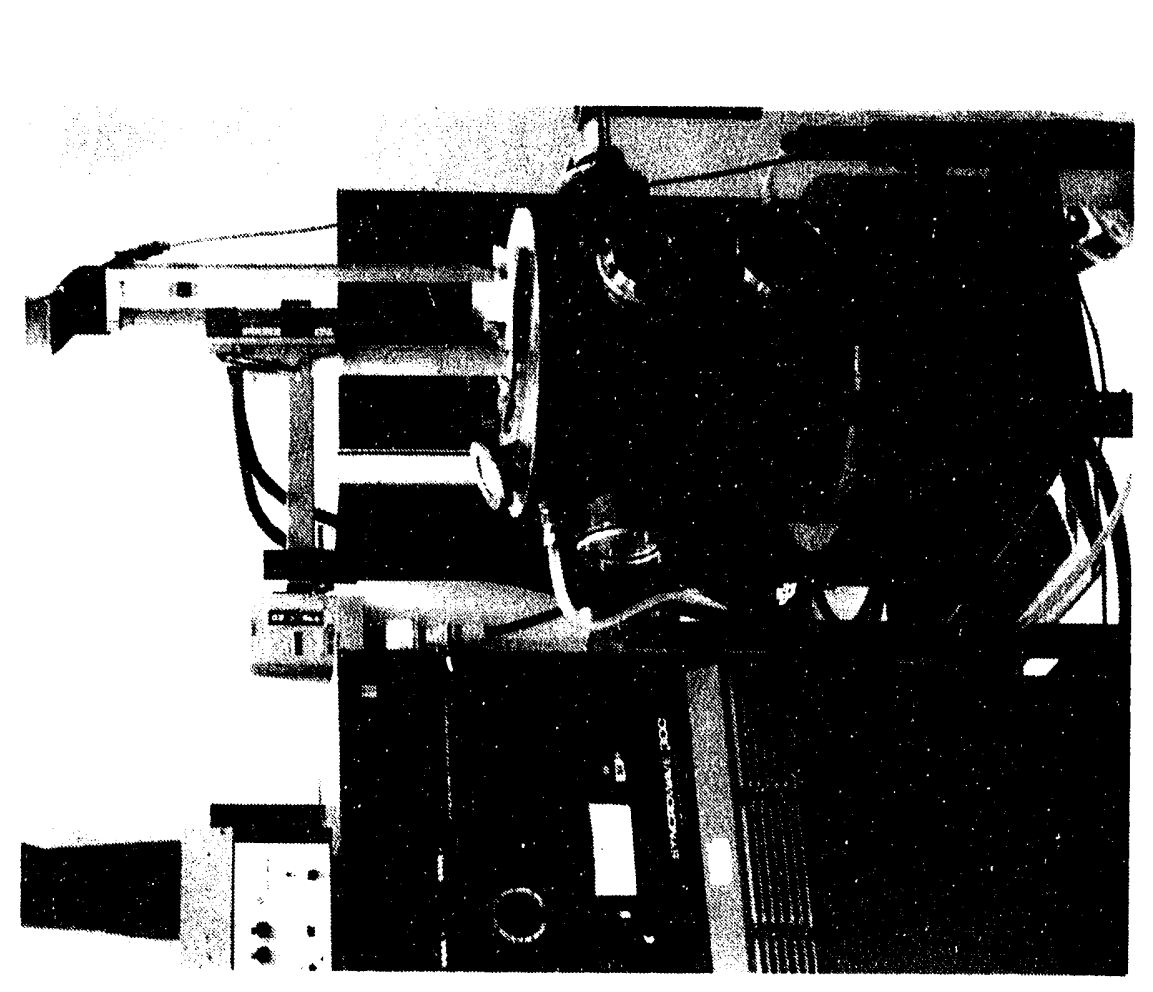

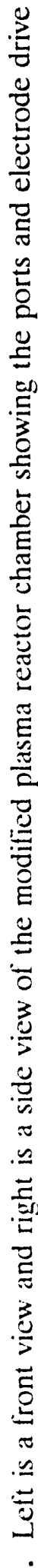

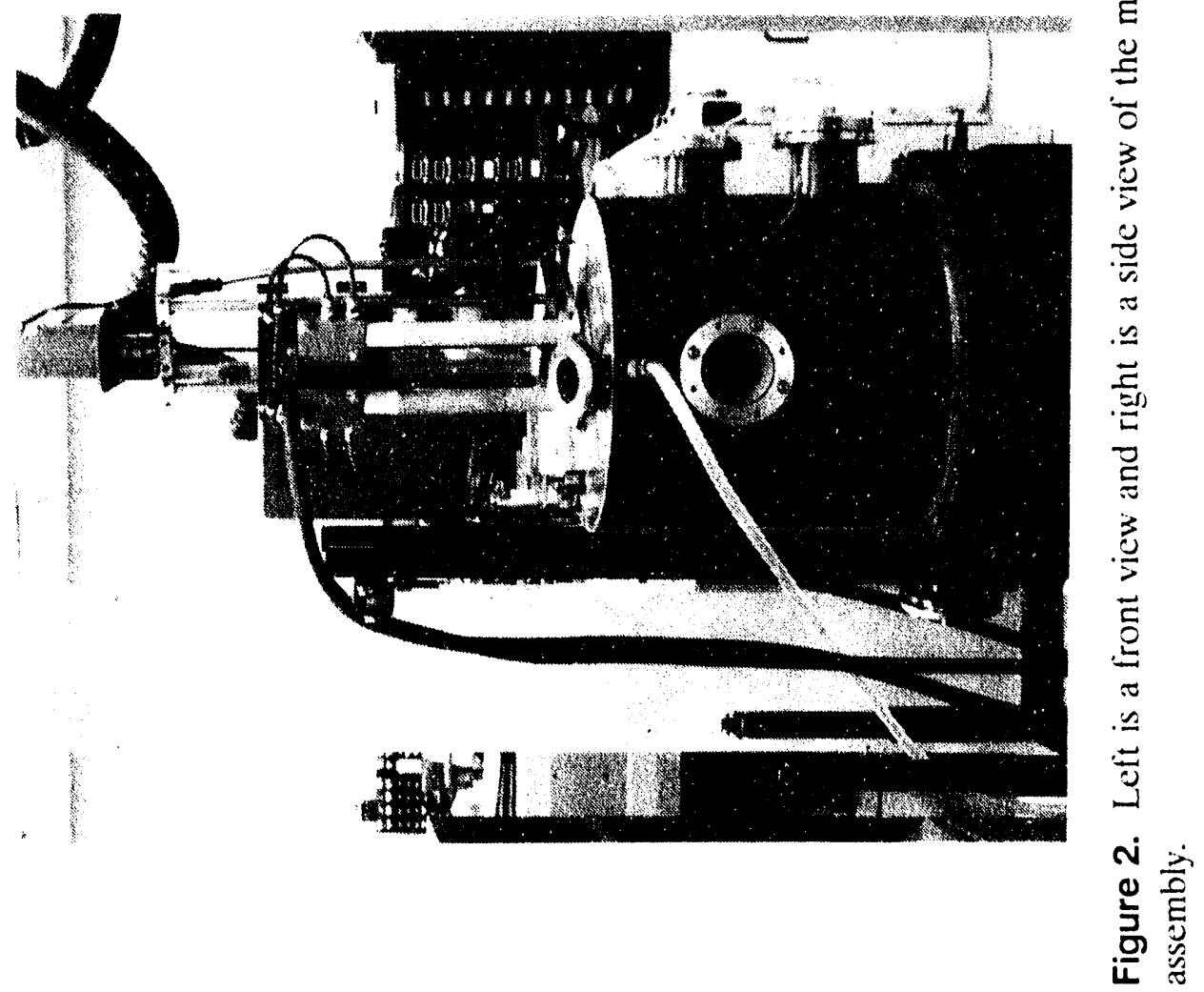




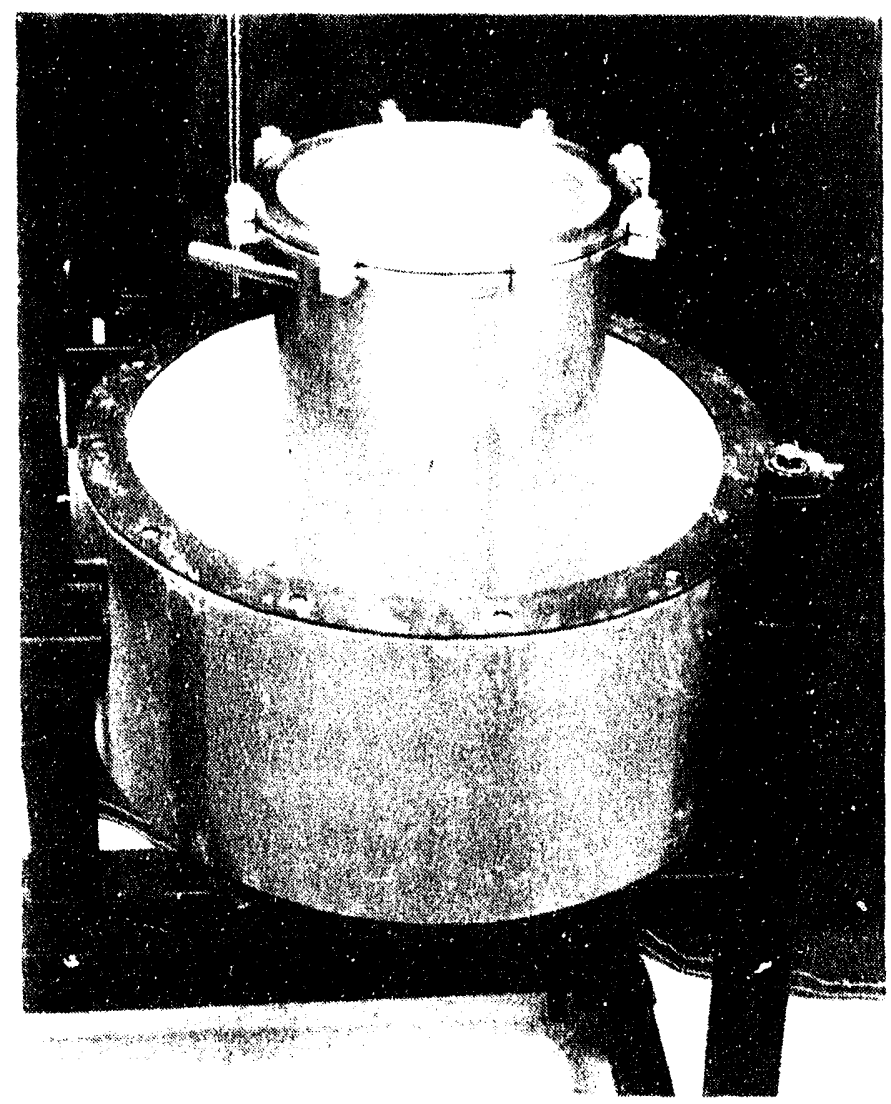

Figure 3. (rucible assembly silling in the chamber bothom.

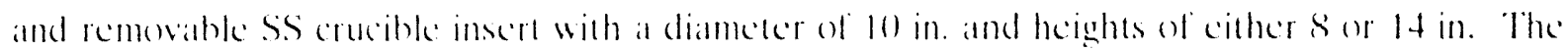
llexible crucible insert sie allows for dillerent batch siess. The corling galp between the jacked and the crucible insert is $(1.5 \mathrm{in}$. A ring hange and bolt clamps ane used with an () ring seal to

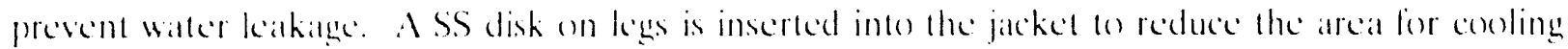
water thew and therehy increase the conling capability allong the bollom of the crucible.

2.1.2.3 DC Arc Electrode System. The schematies for the ane dectrode system ance given

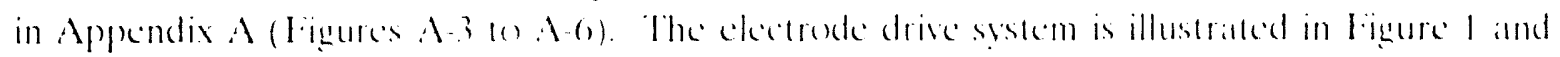

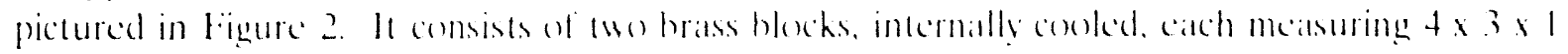
in. for clectrical connedion. Tiwo concentric neass lubes (diameders 1 in. and 10.5 in., respectively)

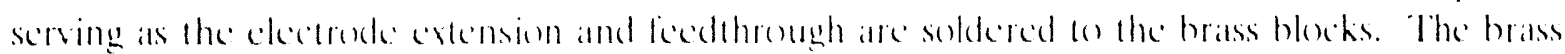

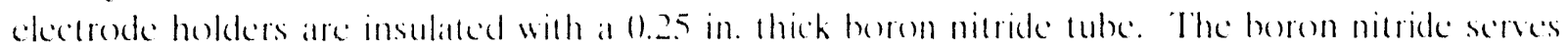
as both electrical and high-kemperature insulation. A boron nitride insedt further isolates the

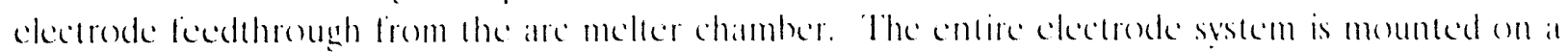
werm gear support, and the moxement of the chectrokes is controlled by a stepping moter esce

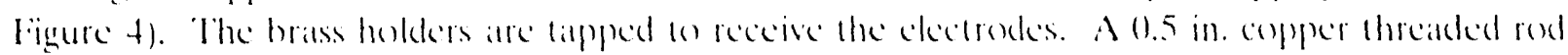
is used to connect the graphete electrodes 10 the holder. Two $2 \times 0.25$ in. dists of horon nitride

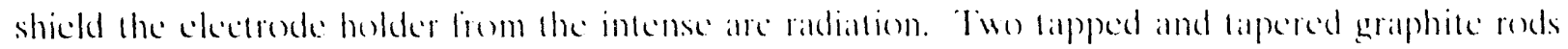
(1).5 $\times 6$ in.) are used as the clectrodes. A view of the ckectodes through the front port is pictured in ligure 5. 


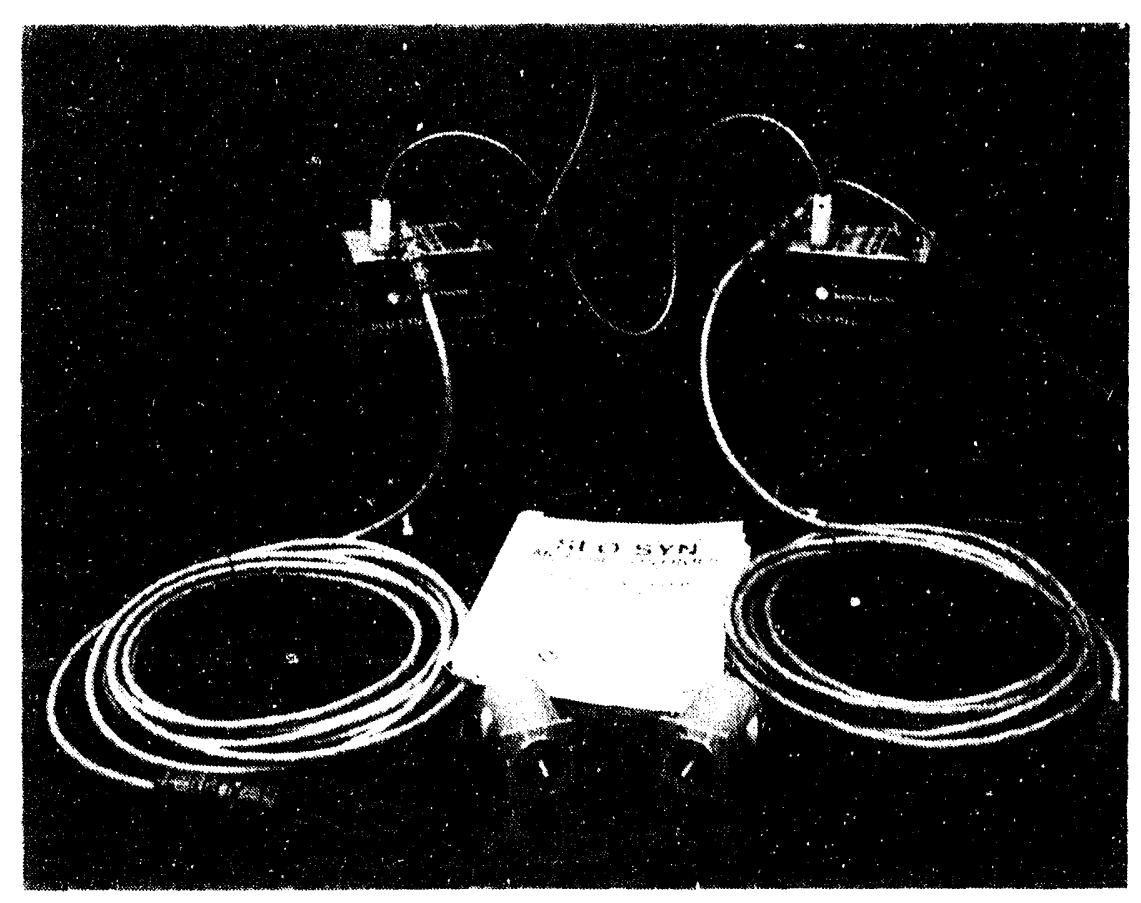

Figure 4. Stepping motor controller.

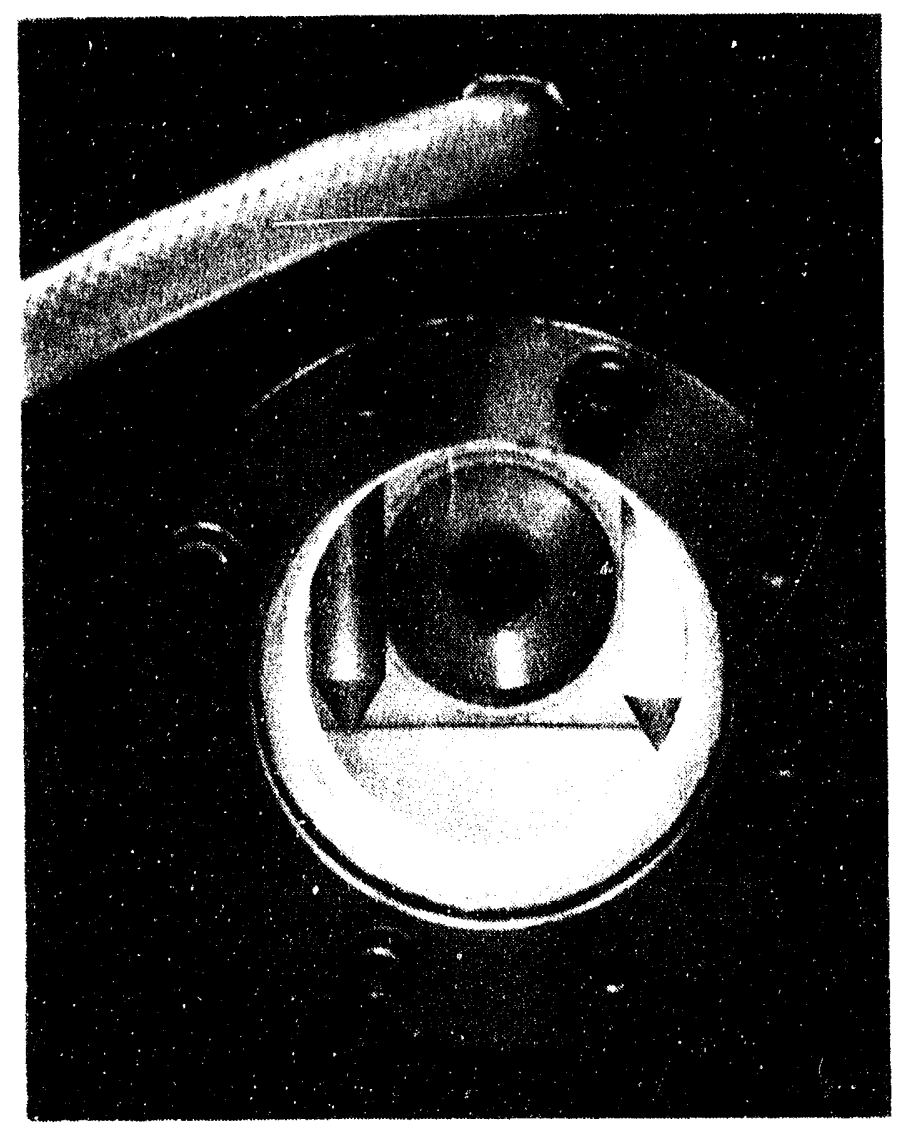

Figure 5. Liectrode geometry as viewed through the front port of the reactor chamber. 
2.1.2.4 Cold Trap. Exhaust gas temperatures exiting the melter can reach $350^{\circ} \mathrm{C}$ and may contain volatilized compounds. A SS liquid nitrogen cold trap is used both to cool the exhaust gas and to condense and trap volatile materials.

2.1.2.5 Off-Gas Treatment System. An existing wet scrubber is in place to use with the are melter system when necessary. The wet scrubber has not been used in the preliminary tests, since noxious gases or hazardous particles are not generated. The scrubber system can be utilized in the future when necessary; for instance, when HVPMs like lead, zinc, etc., are present in the melt. The wet scrubber is placed after the cold trap to retain any escaped particles. Scrubber water can be neutralized prior to disposal.

\subsubsection{Analytical Considerations}

In general, the geometry for the design considerations is as shown in Figure 1 and in Figures A-1 and A-2 using an 8 in. high $\times 10$ in. diameter SS crucible in a 16 in. high $\times 11$ in. diameter jacketing pot. The crucible is filled with soil or simulated waste to a height of approximately 4 in. (approximatcly $6.5 \mathrm{~kg}$ or $14 \mathrm{lbm}$ ).

2.1.3.1 Energy Balance Considerations. From simple first law calculations, the energy required to melt A-100 soil to slag can be approximated. Detailed calculations including geometry and more exact property determinations are beyond the seope of this work.

The first law of thermodynamics for a control volume integrated over time can be expressed as

$$
\int \dot{Q} d t+\int \dot{W}_{e} d t=\int \frac{d E}{d t} d t
$$

where the changes between input and output llow enthalpy, kinetic energy and potential energy changes are assumed negligible, and $\mathrm{E}\left(=\mathrm{mc}_{\mathrm{v}} \mathrm{T}\right)$ is the total internal energy of the soil plus melted slag. Assuming also that the unmelted soil provides a good insulator until the melted slag reaches the walls (as indicated by the slow rise in thermocouple measurements during a run - see Figures 15 and 16), the process can be assumed adiabatic to a lirst approximation. The resulting First Law equation is

$$
\int \dot{W}_{e} d t=\int m c_{v} d \bar{T}
$$

The average temperature of a $10 \mathrm{~kg}$ mass of soil with a $\mathrm{c}_{\mathrm{v}}$ of $1,700 \mathrm{~J} / \mathrm{kg}-\mathrm{K}$ initially at $15^{\circ} \mathrm{C}$ and a constant power input of $100 \mathrm{~A}$ at $100 \mathrm{~V}=10 \mathrm{~kW}$ is given in Table 3 as a function of heating time. The total time to melt into slag is unexpectedly (because of the simplified assumptions) close to the times obtained in the last two tests (Test 6 and 7).

2.1.3.2 Wall Heat Transfer Considerations. The heat transler rate from the melted slag to the cooling water is estimated. Detailed heat transfer calculations considering geometrical effects and well determined (by measurement) property values are beyond the seope of this work. The heat transfer rate from the melted slag to the cooling water is approximated by assuming a plane wall geometry to determine local effects and reference book property values for similar 
Table 3. Mean mass $T(t)$ for $10 \mathrm{~kg}$ of $I E B / A-100$ soil heated at a rate of $10 \mathrm{~kW}$.

\begin{tabular}{ccc}
\hline \multirow{2}{*}{$\begin{array}{c}\text { Time l } \\
\text { (minutes) }\end{array}$} & \multicolumn{2}{c}{ Temperature T } \\
\cline { 2 - 3 } & Seconds & ${ }^{\circ} \mathrm{C}$ \\
\hline 0 & 0 & 15 \\
10 & 600 & 368 \\
20 & 1,200 & 721 \\
30 & 1,800 & 1,073 \\
40 & 2,400 & 1,426 \\
50 & $3,(300$ & 1,780 \\
60 & 3,600 & 2,132 \\
\hline
\end{tabular}

materials. Heat from a $1,500^{\circ} \mathrm{C}$ slag/skull interlace transfers through the skull, the SS crucible wall into the water in steady state. Assuming that the thermal resistance of the SS is negligible and that the water film coefficient will adjust (via boiling if necessary), then the predominant thermal resistance is the skull. Using the linear Fourier heat conduction equation for the heat flux, $\mathrm{q}$

$$
q_{s k}=-k_{s k} \frac{d T_{s k}}{d x_{s k}}
$$

and recognizing that the heat through each layer is the same in steady state and equal to the total heat transfer,

$$
q_{\text {total }}=q_{\text {melt }}=q_{\text {sk }}=q_{s s}=q_{w}
$$

then the heat flux and water heat transfer coeflicient can be calculated for different assumed skull thicknesses as shown in Table 4. The properties used are $\mathrm{T}_{\text {melt }}=1,50()^{\circ} \mathrm{C}, \mathrm{T}_{\mathrm{SS}}=15()^{\circ} \mathrm{C}$ (assuming $50^{\circ} \mathrm{C}$ superheat above the 1 -atm boiling temperature on the wall if boiling) $\mathrm{k}_{\mathrm{sk}}=2 \mathrm{to}$ $10 \mathrm{BTU}-\mathrm{in} / \mathrm{h}-\mathrm{ft}^{2}-\mathrm{F}$ or 0.288 to $1.440 \mathrm{~W} / \mathrm{m}-\mathrm{K}$ (based on a glassy/granite skull) ${ }^{19}$ where the maximum value is used in Table 4 to determine the maximum heat transfer rate. $Q_{w, \max }$ in Table 4 is the product of $Q_{s k}$ and the effective area of the melt (taken to be the bottom 4 in. of the crucible). The heat transter coefficients in Table 4 can be compared with the typical range of values for diflerent types of heat transfer given in Table $5 .^{20}$

Comparison of the $h$ values for different skull thicknesses in Table 4 with the typical values in Table 5 indicates that boiling heat transfer will probably occur at the crucible-water interface. The velocity of the water flow needs to be sufficient to permit a subcooled nucleate boiling regime in which the vapor bubbles condense rapidly either on the surface or near the generation point. If the velocity is too small, film boiling and burnout (pinholes, etc.) can occur. 
Table 4. Estimation of heat transfer rate between melt at $1,500^{\circ} \mathrm{C}$ and cooling water surrounding crucible with the slag skull providing the most thermal resistance $\left(\mathrm{k}_{\mathrm{sk}}=1.44 \mathrm{~W} / \mathrm{m}-\mathrm{K}\right)$.

\begin{tabular}{|c|c|c|c|c|c|c|}
\hline \multicolumn{2}{|c|}{$\Delta r_{\text {sk }}$} & \multirow{2}{*}{$\begin{array}{c}\mathrm{q}_{\mathrm{sk}} \\
\left(\mathrm{W} / \mathrm{m}^{2}\right)\end{array}$} & \multirow{2}{*}{\multicolumn{2}{|c|}{$\begin{array}{c}\mathrm{h}_{\mathrm{w}} \\
\left(\mathrm{BTU} / \mathrm{hr}-\mathrm{ft}^{2}-\mathrm{F}\right)\end{array}$}} & \multicolumn{2}{|c|}{$\mathrm{Q}_{\mathrm{w}, \max }$} \\
\hline in. & $\mathrm{mm}$ & & & & $\mathrm{W} / \mathrm{m}^{2}-\mathrm{K}$ & $\mathrm{kW}$ \\
\hline 0.125 & 3.18 & 3.18 & 611,320 & 2,153 & 12,226 & 80.5 \\
\hline 0.250 & 6.35 & 6.35 & 306,142 & 1,078 & 6,123 & 40.3 \\
\hline 0.500 & 12.70 & 12.70 & 153,071 & 539 & 3,061 & 20.2 \\
\hline 0.750 & 19.05 & 19.05 & 102,047 & 359 & 2,041 & 13.4 \\
\hline 1.000 & 25.40 & 25.40 & 77,760 & 274 & 1,555 & 10.2 \\
\hline
\end{tabular}

Table 5. Typica! convective heat transfer coefficient ranges.

\begin{tabular}{lcc}
\hline \multicolumn{1}{c}{ Condition } & $\begin{array}{c}\mathrm{h} \\
\left(\mathrm{BTU} / \mathrm{hr}-\mathrm{ft}^{2}-\mathrm{F}\right)\end{array}$ & $\begin{array}{c}\mathrm{h} \\
\left(\mathrm{W} / \mathrm{m}^{2}-\mathrm{K}\right)\end{array}$ \\
\hline Air, free convection & $1-3$ & $5-15$ \\
Air, forced convection & $3-56$ & $15-300$ \\
Water, forced convection & $50-2,000$ & $300-12,000$ \\
Water boiling & $500-10,000$ & $3,000-55,000$ \\
Steam conciensing & $1,000-20,000$ & $5,500-100,000$ \\
Subcooled nucleate boiling & $10^{4}-10^{7}$ & $5 \times 10^{4}-5 \times 10^{7}$ \\
\hline
\end{tabular}

It appears that vertical wall heat trensfer rates are marginal because of the modest velocities. Velocities on the crucible bottom are too low because of inverted natural convection for conditions when the soil is all melted. The crucible-pot system was therefore modified using a coil of copper tubing to create two spiral channels from the bottom of the crucible to the top. A disk with a 1 -in. center hole was positioned immediately below the crucible bottom, with a decreasing gap at larger radii to lessen the velocity decrease with increasing cross-sectional area. The modified system worked well with a total melt.

2.1.3.3 Cooling Water Flow Considerations. A more complicated, but standard, analysis of the cooling water flow rate to carry away the heat transferred through the crucible was made. The analysis is based on the overall heat transfer relations,

$$
\dot{Q}=h_{a v e} A_{s}\left(T_{\text {wall }}-T_{B}\right)=\dot{m}_{w} c_{p, w}\left(T_{w 2}-T_{w 1}\right)
$$

where $h_{a v e}$ is the average heat transfer coefficient, $A_{s}$ is the channel cross-sectional area, $T_{B}=$ $\left(T_{w 1}+T_{w 2}\right)$ is the water bulk temperature, and $m$-dot is the water mass flow rate. The value for $h_{a v e}$ is obtained from the Nusselt Number correlation for laminar or turbulent tlow determined by 
the Reynolds Number. The hydraulic diameter for a rectangular cross section $s$ by $w$ is used as the characteristic length,

$$
D_{h}=\frac{4 A_{s}}{\text { wetted perimeter }}=\frac{4 s w}{2 s+2 w}
$$

Above the critical Re of 3,000 , the turbulent flow equation of Colburn ${ }^{21}$ neglecting entrance region effects, is used:

$$
N u_{D}=0.023 \operatorname{Re}_{D}^{4 / 5} \operatorname{Pr}^{1 / 3}
$$

For laminar flow, the equation of Hausen 22,23 is used which incluiles the entrance region effect via the channel length $L_{c}$ :

$$
N u_{\text {ave }}=3.65+\frac{0.0668\left(D_{h} / L_{c}\right)}{1+0.04\left[\left(D_{h} / L_{c}\right)\right.} \frac{\operatorname{Re}{ }_{D} \operatorname{Pr}}{\operatorname{Re} \operatorname{Pr}^{2 / 3}}
$$

Table 6 indicates the result of calculations based on a measured maximum water flow rate through the crucible-pot assembly of $8 \mathrm{gpm}\left(0.506 \mathrm{~kg} / \mathrm{s}\right.$ or $\left.505 \times 10^{6} \mathrm{~m}^{3} / \mathrm{s}\right)$. Different channel sizes are considered. Case 1 is for no additional channels. To remove the heat transferred to the water from the crucible as shown in Table 4 for different skull thicknesses, it appears that channels similar to Case 2 would be required.

2.1.3.4 Voltage-Current-Time Considerations. The initial difficulty in operating and restarting the arc melter was in part due to unresolved starting procedures and in part due to inadequate power supply V-I characteristics with the initial power supplies used. Each are/Joule heated system operation is different depending on the electrode geometry (gap length L), the material/melt/slag resistance, the are/Joule voltage-current characteristics, and the power supply characteristics. The following discussion considers these factors for the bench-scale are melter used here.

The slag propertics are obtained from prior IEB research. ${ }^{3,5}$ Electrical conductivitics as a function of temperature for soil (A-100) and average waste plus $40 \%$ soil (A-40) are given in Table 7 (from Ref. 3).

The voltage and current in the circuit are related by Ohm's Law,

$$
V=I R
$$

and the resistance is approximated by

$$
R=\frac{L}{A \sigma}
$$

where $A$ is the cross-sectional area of the slag, $L$ the length between electrodes, and o the electrical conductivity. 


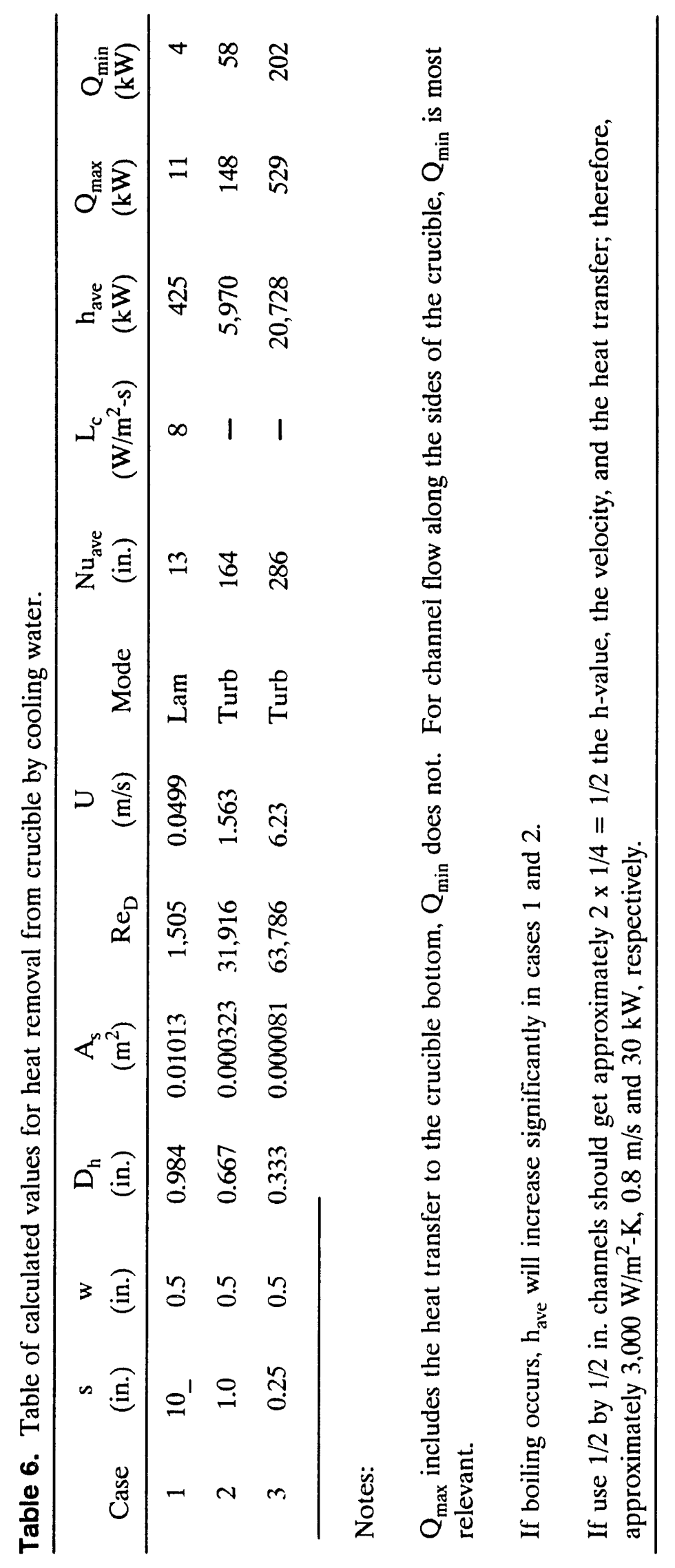


Table 7. Slag properties of IEB/A-100 and A-40 at different temperatures.

\begin{tabular}{ccc} 
& \multicolumn{2}{c}{$\begin{array}{c}\text { Electrical conductivity } \\
(\text { Ohm-m })^{-1}\end{array}$} \\
\cline { 2 - 3 }$\left({ }^{\circ} \mathrm{C}\right)$ & $\mathrm{A}-100$ & $\mathrm{~A}-40$ \\
\hline 1,400 & 0.8 & 5.0 \\
1,500 & 1.5 & 8.0 \\
1,600 & 3.0 & 15.0 \\
1,700 & 6.0 & 25.0 \\
1,800 & 12.0 & 40.0 \\
\hline
\end{tabular}

The V-I characteristics of a single TAFA 30-HF power supply is shown in Figure 6. Each curve represents the $\mathrm{V}$-I characteristic for maximum power (unsaturated reactor) and exceeds the $100 \%$ duty cycle ratings. The $100 \%$ duty cycle rating is given as $75 / 150 / 300 \mathrm{~A}$ at $50 / 100 / 200 \mathrm{~V}$ with open circuit voltages of $100 / 200 / 400 \mathrm{~V}$, depending on the buss setup. Attempting to restart the current flow with 80 or with 200 VOC had been unsuccessful; therefore, two power supplies were set up for $400 \mathrm{VOC}$ and used in parallel.

Currents calculated with operating voltage at $200 \mathrm{~V}$ and $300 \mathrm{~V}$ (assuming $400 \mathrm{VOC}$ ) based on different electrode gap lengths, L, different melted slag cross-sectional areas, A, and slag temperatures $\mathrm{T}$ for both A-100 and A-40 compositions are given in Table 8 . The calculations neglect are resistance and voltage drop which should be approximately $20 \mathrm{~V}$ with small $(1-3 \mathrm{~mm})$ arc gaps and are therefore based on the slag resistance only.

Calculations for A-100 slag (melted soil) for the current electrode separation (5 in.) and typical initial cross-sectional areas available $\left(<2 \times 2 \mathrm{in}^{2}\right)$ indicate that very high temperatures $\left(>1,800^{\circ} \mathrm{C}\right)$ would be required to pass more than $50-75 \mathrm{~A}$ at $200-300 \mathrm{~V}$. With $\mathrm{A}-40$ slag (40\% soil, $60 \%$ average TRU-contaminated waste) the resistance decreases by a factor of 5 to 6 , relaxing the constraints imposed by the present power supply.

The reduction of the electrode separation to 3 in. would increase the current capability about a factor of 2 , if needed. The smaller gap may significantly lengthen the time to heat the material near the walls. Optimum geometrical considerations still need to be made.

With either composition, the best starting procedure uses a high initial current (200-300 A) through the conducting strip for initial heating of the soil. When the combined graphite/slag resistance increases to cause the voltage to get up to 50-75\% of the maximum loaded voltage, start reducing the current to maintain the voltage, heating and continued melting. This procedure was tested and validated on both A-40 IEB and IEB4 compositions, as well on the subsequent melts discussed in this report. 


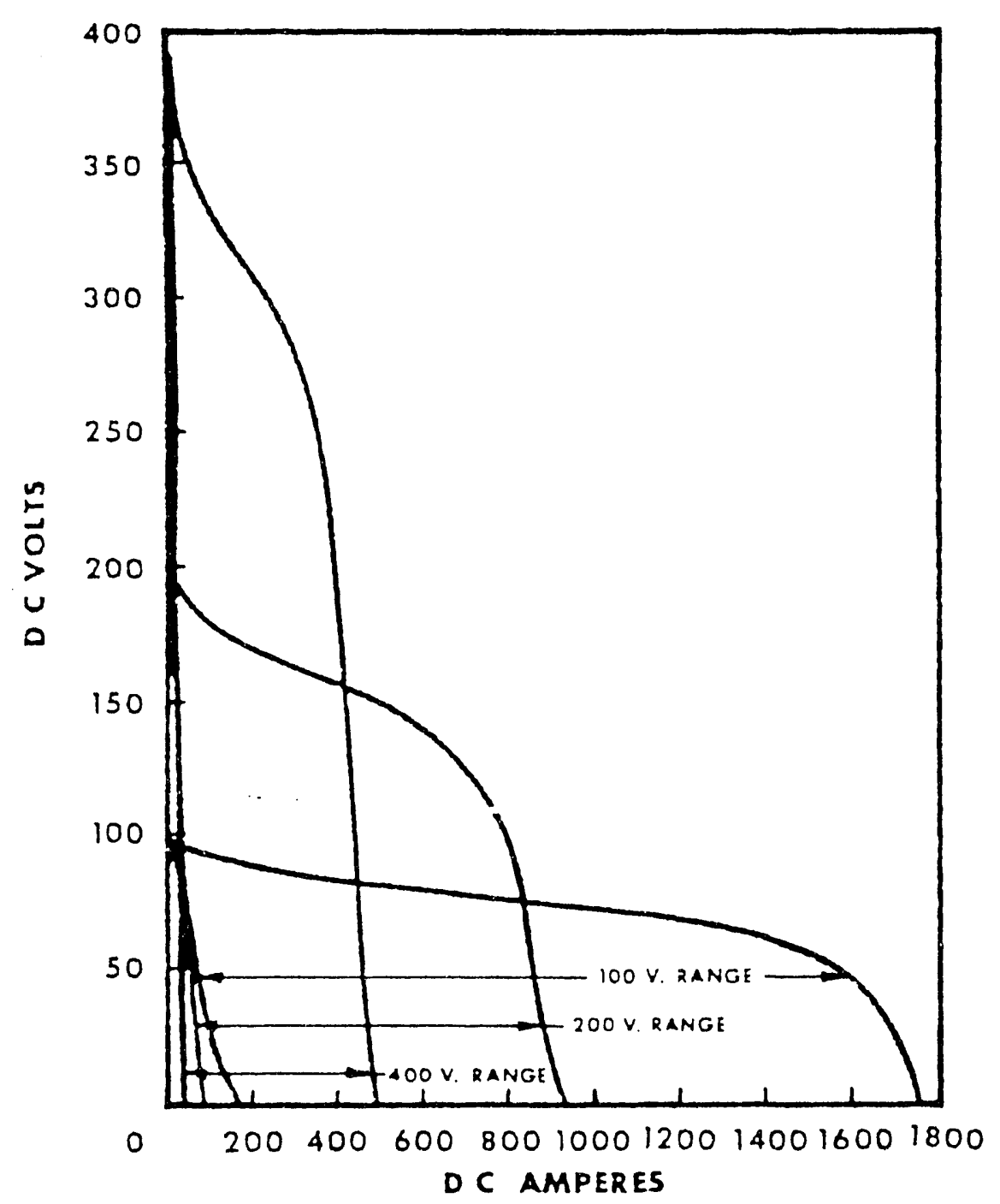

Figure 6. V-I characteristics of a single TAFA $30-\mathrm{HF}$ power supply. 
Table 8. Arc melter current and voltage as a function of geometry and temperature.

\begin{tabular}{|c|c|c|c|c|c|c|c|}
\hline \multirow{2}{*}{\multicolumn{2}{|c|}{$\begin{array}{c}\mathrm{L} \\
(\mathrm{m})\end{array}$}} & \multicolumn{4}{|c|}{$\mathrm{I}(\mathrm{A})$} & \multirow[b]{2}{*}{$200 \mathrm{~V}$} & \multirow[b]{2}{*}{$300 \mathrm{~V}$} \\
\hline & & $\begin{array}{c}A \\
\left(\mathrm{~m}^{2}\right)\end{array}$ & Slag & $\begin{array}{c}\mathrm{T} \\
\left({ }^{\circ} \mathrm{C}\right)\end{array}$ & $\begin{array}{c}\mathrm{R} \\
(\mathrm{Ohm})\end{array}$ & & \\
\hline \multicolumn{8}{|c|}{ 5-in. Electrode Gap } \\
\hline 0.125 & & 0.0025 & $A-100$ & 1,400 & 62.5 & 3.2 & 4.8 \\
\hline \multirow[t]{2}{*}{ (5 in.) } & $(2 \times 2$ in. $)$ & 1,600 & 16.7 & 12 & 18 & & \\
\hline & & 1,800 & 4.2 & 48 & 72 & & \\
\hline \multirow[t]{3}{*}{0.125} & & 0.0025 & A-40 & 1,400 & 10.0 & 20 & 30 \\
\hline & & 1,600 & 3.33 & 60 & 90 & & \\
\hline & & 1,800 & 1.25 & 160 & 240 & & \\
\hline \multicolumn{8}{|c|}{ 3-in. Electrode Gap } \\
\hline 0.075 & & 0.0025 & A-100 & 1,400 & 37.5 & 5.3 & 8 \\
\hline \multirow[t]{2}{*}{ (3 in.) } & $(2 \times 2$ in. $)$ & 1,600 & 10.0 & 20 & 30 & & \\
\hline & & 1,800 & 2.5 & 80 & 120 & & \\
\hline \multirow[t]{3}{*}{0.075} & & 0.0025 & A-40 & 1,400 & 6.0 & 33 & 50 \\
\hline & & 1,600 & 2.0 & 100 & 150 & & \\
\hline & & 1,800 & 0.75 & 267 & 400 & & \\
\hline
\end{tabular}

\subsection{Data Acquisition Capabilities}

\subsubsection{Introduction}

The overall purpose of the data acquisition system for these tests is to provide centralized means of simultaneously taking many different readings from thermocouples, voltage sources, etc.; displaying them in real time for monitoring the process; and simultaneously storing them for later analysis. The system was developed around a Fluke model 2285B data logger with an overall capability to handle up to 120 separate data channels (see Figure 7). A back panel was manufactured to easily interface between the data logger and standard connectors for thermocouple and voltage measurements (see Figure 8). The data logger is controlled remotely by an IBM personal computer, with software provided by Fluke. The channels on the data logger are programmed to transmit data through the RS-232 communications port to the computer, where it is displayed and stored. 


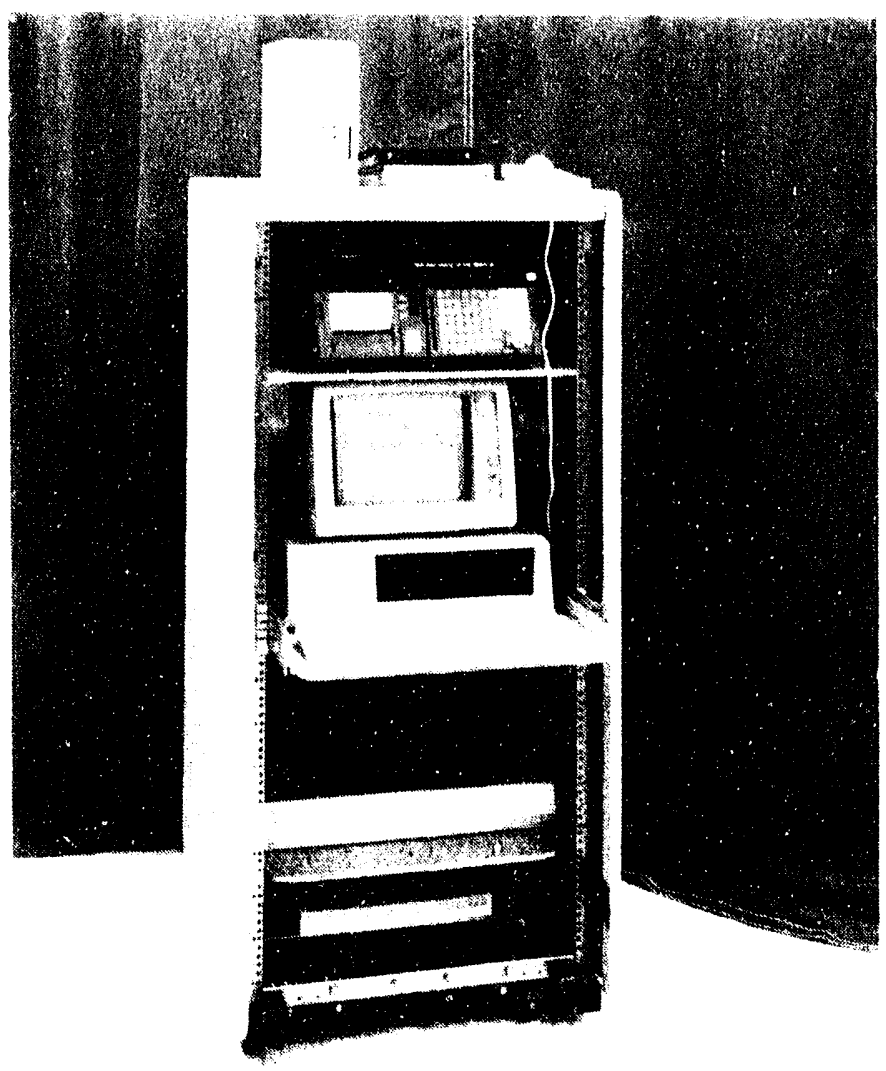

Figure 7. Dalla atcquisition system for monitoring and storing kemperature, llow, and clectric power measurements during lest runs.

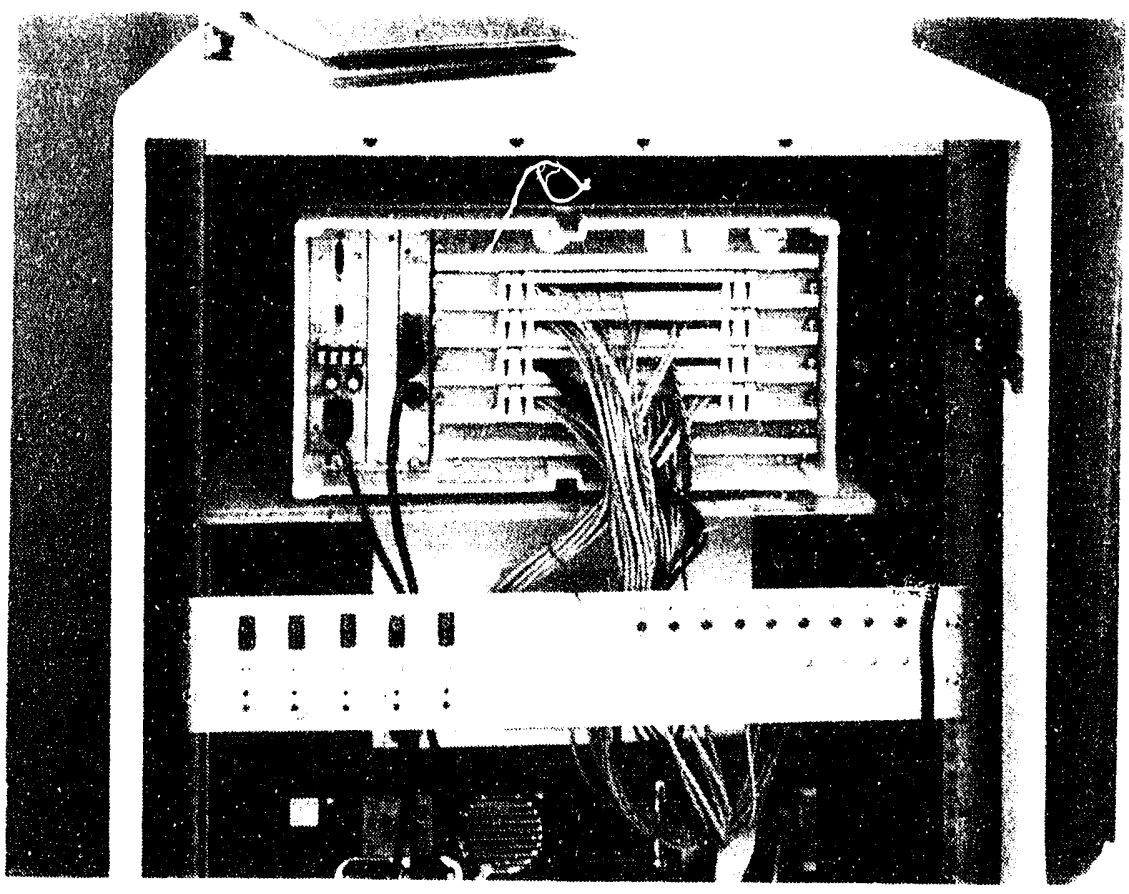

Figure 8. Rear view of the data acyuisition system showing the back pandel lor casy connection (1) various transducers. 


\subsubsection{Temperature Monitoring System}

The back panel (see Figure 8) has connectors for 5 type-K and 5 type-C thermocouples. In addition, there are 9 channels with connections for 3-wire RTD measurements. The type-K thermocouples $\left(-200\right.$ to $\left.1,250^{\circ} \mathrm{C}\right)$ are used to monitor various cooling-water temperatures and the type-C $\left(0\right.$ to $\left.2,320^{\circ} \mathrm{C}\right)$ are used for higher temperature applications such as soil/melt temperature and exhaust temperature. The exhaust and soil temperatures are monitored to assess the progress of the melt. Cooling-water temperatures are monitored both for salety and calorimetry. Starting with Test 5, water flow meters were connected to the various cooling lines. This additional information would be enough to do energy balance calculations; however, the temperature measurements appeared to drift randomly a few degrees while the melter was operating, making any energy balance calculations questionable. For Test 7 , the thermocouples were replaced by RTDs in an attempt to improve the measurements. The RTDs appeared to be less susceptible to interference caused by operation of the arc.

Also starting with Test 7, an optical pyrometer was used to make limited measurements of the surface temperature of the melt. The pyrometer is a simple disappearing filament type and could be subject to errors caused by a dust film collecting on the viewing port. This problem was eliminated by improvements to the optical port, making it a simple hinged port that can be casily opened and cleaned while the are melter is operating.

\subsubsection{Current and Voltage Measurements}

The back panel is set up with 4 standard BNC connectors for voltage measurements. Because the data logger is limited in measuring only up to 64 VDC and the power supply has a $400 \mathrm{~V}$ capability, direct measurements are not possible. For the first 6 tests, voltage and amperage have been read and recorded directly from meters on the power supplies. Test 7 included the first current/voltage measurements by monitoring directly across the current shunt $(2,000 \mathrm{~A}, 50 \mathrm{mV})$ located in the power console. The voltage measurements directly across the power leads at the are melter were done by using a 100:1 voltage divider and power surge protector on the input to the data logger that conditions the signal to acceptable levels. The input channel on the data logger is then programmed to automatically compensate for the 100:1 reduction in signal strength and gives a correct voltage reading.

\subsubsection{Optical Monitoring Capabilities}

Progress of the melt can be seen visually through one of three window ports in the jacket of the are melter. One port on the top provides the best overall view, and two ports on the side allow additional viewing. During initial tests, the windows tended to fog up with dust and condensed particulate from the melt. To prevent this, the ports have been fitted with outlets for argon gas to llow continuously over the glass. This helped considerably, but in recent low dust tests there seems to be an entrainment of particles by the gas flow that collect on the windows. Future tests will determine the effect of gas flow rate on deposits forming on the windows.

A video system, used for the first time in Test 7, monitors the progress of the melt. This system uses a PULNIX TM-540 $(512 \times 480$ CCD array) to produce video signals that can be recorded with a Sony tape recorder. The CCD array can be coupled to any variety of eamera 
lenses to get the correct focal length, image magnification, etc. This lens must be fitted with a narrow bandpass filter to reduce the intense light emanating from the are regions. In this case, a narrow bandpass filter at $6.32 .8 \mathrm{~nm}$ was used. Videos have been made of selected portions of all are melter experiments since Test 7. 


\section{OPERATIONAL CHARACTERISTICS}

Initial tests provided experience and data necessary for improvement of the are melter toward operational status. Each test provided valuable information for improvement of various parts of the system. Subsequent tests at higher power and greater temperatures revealed more problems, which when solved, resulted in a more reliable and capable system. Overall, the program exhibited normal process development. Table 9 summarizes the description, purpose, location of related figures, energy input, average power, and mass balance for each of the preliminary tests (Tests 1-7). This chapter discusses observations made during the development of the starting and heating procedures.

\subsection{Power Requirements}

While the first test could not be considered suceessful as far as melting soil, it was very useful in defining the power requirements necessary for this particular melter design. It was suspected the Miller welding power supply would be inadequate to run the are melter, but its portability and ease of use prompted a trial run with it. The uscful operating voltage of 60) $\mathrm{V}$ and 80) VOC was not nearly enough to operate the are melter with the 5 -in. spacing between electrodes. The single TAFA power supply with a $100 \mathrm{~V}$ operating range did much better, but the voltage was inadequate to restart. Its initial suecess was probably due to the good conduction path provided by the steel shot embedded in the soil. Onee the steel shot melted and sunk to the bottom of the melt, the single power supply could no longer operate. The rest of the tests were done with two TAFA power supplies hooked in parallel and set for an operational voltage of approximately $200 \mathrm{~V}(400 \mathrm{VOC})$. This power supply configuration was sufficient to operate the are melter over the range of operational conditions during a melt. A third power supply is available to provide more current if hooked in parallel with the others, but it is probably not necessary based on the melter tests so lar. Another alternative is to connect the two power supplies in series and operate at $400 \mathrm{~V}$ and 800 VOC. The cables presently in use are only rated for $600 \mathrm{~V}$, so this arrangement is not possible until new cables are purchased. However, the higher voltage does not appear to be necessary.

\subsection{Carbon Electrode Connections}

After the first two tests, it hecame apparent there was a problem on how the carbon electrodes were being attached to the brass, water-eoled holders. The 6 in. long carbon rods were tapered on one end and threaded on the other to be screwed into the holders. Three electrodes broke at exactly the same place at the base of threads on the carbon rod. Belore Test 3, a threaded copper insert with a threaded extension was made to attach to the brass holder. The earbon rods were threaded on the inside, then screwed onto the eopper insert. For the remaining tests, the carbon electrodes did not break ofl even though they were used for longer periods and at much higher temperatures.

\subsection{Heat and Radiation Protection}

Test 3 was the first suceessful test in that a signilicant quantity of the soil was melted. The resultant heat and radiation from the melt began to expose weaknesses in the eooling design of 


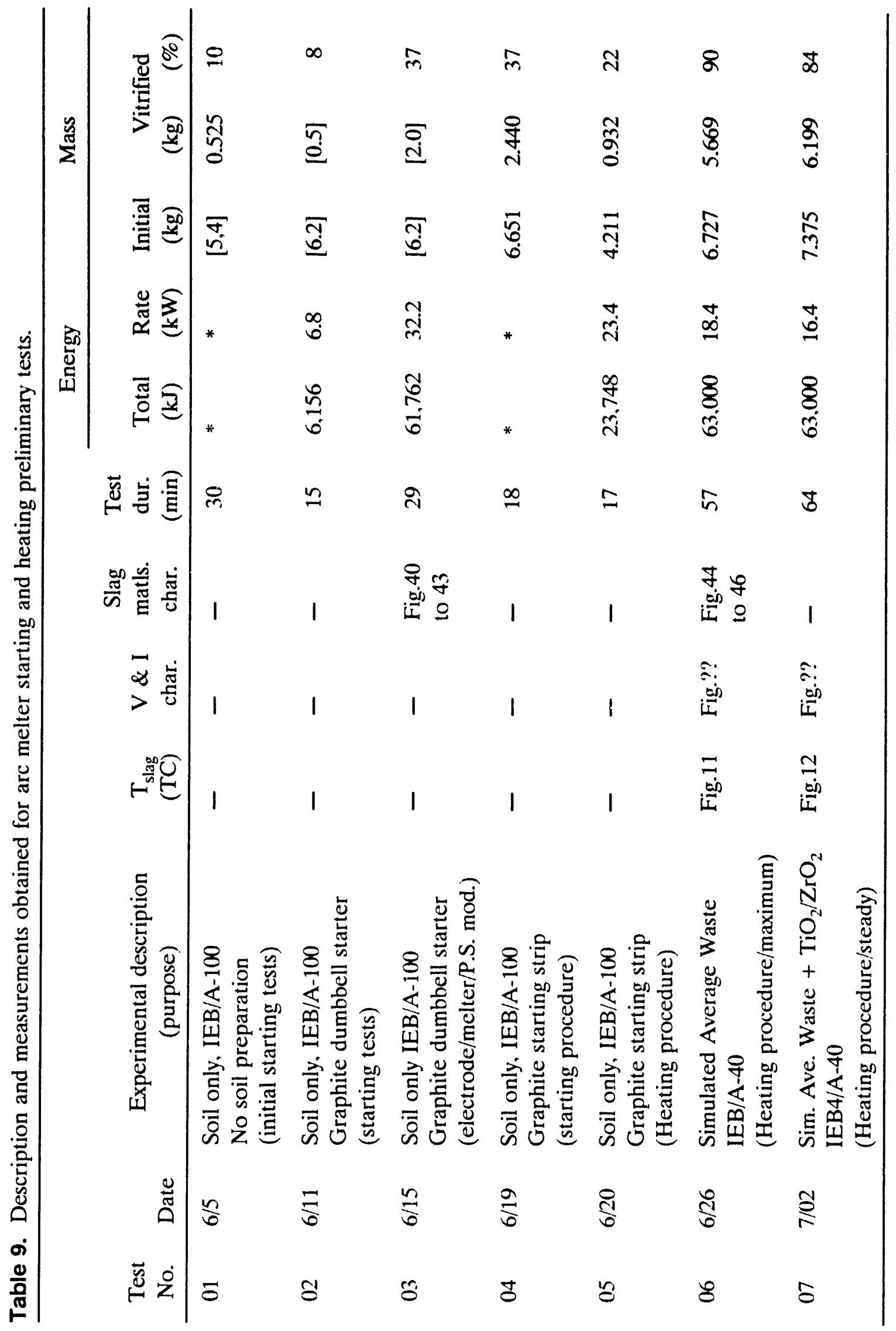


the melter. The melter was built with no cooling capability on the top, a design flaw from its beginning as a plasma reacior. This llaw was remedied previously hy soldering copper cooling coils on the top. For the present use, the cooling coils needed to be removed to make room for the electrodes and ports on top of the melter. During Test 3, the top became very hot (almost glowing red) and necessitated a premature shutdown of the are melter. Because of the limited space on top of melter, the solution chosen was to put a liberboard insulator and water-cooled radiation reflector on the inside. The radiation reflector was constructed of $1 / 16$ in. SS plate with copper cooling coils silver soldered to the backside. Holes were cut where necessary to accommodate the electrodes and viewing ports, etc. Subsequent tests have shown this solution to be very effective, with the top of the melter becoming only slightly warm during operation.

\subsection{Crucible Cooling and Protection}

Alter Test 3, the eflectiveness of the water cooling for the crucible came into question, since a small crater was formed on the inside of the crucible near the top, resulting in a pinhole leak at the bottom of the erater. There was also evidence of melting in several other places around the top part of the crucible. In addition the O-ring in the top on the crucible holder was burned and broken. The drain for the cooling water is about $1 \mathrm{in}$. below the top of the crucible holder. This results in an air space at the top of the ecoling channel and less than adequate cooling. To alleviate this problem, a solid baflle was welded around the outlet to just below the top of the crucible holder. This forees the water up to the top of crucible holder betore it can drain out over the baftle. Subsequent runs have resulted in no damage to the O-ring and no visible melting spots around the top part of the crucibles.

The crucible cooling water enters in the crucible container at an angle to induce a swirl around the outside walls. Unfortunately, this results in a stagnant flow of water at the bottom center of the crucible. This was a known problem, but due to time constraints, a fix consisting of channels and balfles to direct water flow to this area was never accomplished prior to Test 5. During Test 5, which was running very smoothly, a hole was melted in the bottom of the crucible causing llooding of the are melter. The hole was off enter about $1 \mathrm{in}$. and oceurred where the slag was closest to the bottom. A factor in melting the hole in the bottom of the crucible was that there was less dirt and therefore melting oceurred eloser to the bottom. However, a completely suceessful melt should result in nearly all the material being melted, including the material near the bottom. The eenter of the erucible on the bottom (water-cosled side) showed extreme discoloration to about $1 / 2$ the radius, indicating that it was at a very high temperature.

In Tests 6 and 7, this eooling problem was solved by using a plate with a $3 / 4 \mathrm{in}$. hole in the eenter to fore the water flow to the eenter of the crucible bottom then outward to the sides. To improve heat transfer from the sides of the crucible, copper coils were placed along the side of the crucible to both direct llow and increase the water velocity. Test 6 ended slightly prematurely when a pinhole leak developed in the side wall of the crucible, above the melt, but below the original lill line. The damage was identical to that in Test 3; but in this case, there were three small round craters in a row with the pinholes in the bottom of each one. Prior to Test 7, the spaces between the eoils were filled in with plummer's putty, reducing volume in the eooling cavity and forcing the water to llow laster. This has the effect of increasing heat transfer to the crucible walls and making subnucleate boiling of the cooling water kess likely. Protection for the crucibles was increased by lining them with a thin (approx. 1/16 in.) layer of paint-on ceramic on 
the inside. In these last two tests, the melt extended to the very bottom of the crucible; and the ceramic liner had been incorporated into the melt. Removal the slag after cooling revealed only a paper thin skull between the slag and the SS of the crucible in some areas, particularly on the bottom.

\subsection{Starting Methods}

The most reliable starting method obtained is a thin solid graphite strip placed between the electrodes (see Figure 9). The strip provides a good eurrent path and effectively heats up the surrounding soil. Once the soil has melted and becomes a conducting path itself, the graphite strip slowly burns away. Early tests (1-3) experimented with a variety materials and methods that were less than sucessful at least for this system. The graphfoil worked similarly to the carbon strip exeept that the ability to heat the soil was not as good and it tended to de-laminate and become ineffective. Carbon powder worked well at the start, but it tended to be blown away in the are attachment regions. Carbon powder also oxidizes very fast in the middle before good heating of the soil can take place. Metal shavings did not provide a good solid conduction path for starting. Steel shot was better, but there is still the problem of melt contamination with the metal.

Beginning with Test 4 using the thin graphite strips between the electrode contacts, starting procedures were developed that produced consistent results. The current can be quickly raised to about $300 \mathrm{~A}$ (at about $50-100 \mathrm{~V}$ ) with a $5-10 \mathrm{~mm}$ are gap to heat the soil into slag near and under the electrodes. Under these conditions, the TAFA power supplies set at 400 VOC and hooked in parallel seem adequate to start the melts. As the melt progresses, the voltage increases in time as the high conductance graphite burns/sublimes away. If the nower supply cannot provide the voltage at the set current (e.g. $>200 \mathrm{~V}$ at $300 \mathrm{~A}$ ) the circuit breaks. For this reason, once the graphite strip has been consumed, the current must be reduced $(50-150 \mathrm{~A})$ to maintain stable operation.

\subsection{Heating Procedures}

In the adopted heating procedure initially tried in Test 5 and verified in Tests 6 and 7, the melts are started with a low voltage - high current mode (50)-150 $\mathrm{V}$ and $150-300 \mathrm{~A})$ and then slowly moved into a high voltage - low current (250)-300 $\mathrm{V}$ and 50-150 A) operating mode. The voltage-current and power input plots of this behavior are shown in Figure 10 and Figure 11 for Test 6 and in Figure 12 and Figure 1.3 for Test 7. As the graphite conducting path becomes depleted, current must pass through the melted soil having a higher resistance. This causes the current to decrease and the voltage to rise. Test 6 and each test thereafter shows this behavior.

In Test 6, after stable operation was obtained for 40 minutes, the current was increased to determine the maximum heating limitations of the melter (see Figure 10 and Figure 11). As the current increased, the voltage decreased. At approximately $150 \mathrm{~A}$ and $200 \mathrm{~V}(30 \mathrm{~kW}), 90 \%$ of the soil was melted (Table 9) and the cooling system failed, resulting in a pinhole leak in the side wall resulting in the breaking of the circuit. Alter Test 6 , the melter coling channels were modified to increase the water velocity. Subsequent tests exceeded $40 \mathrm{~kW}$ on occasion, operated 


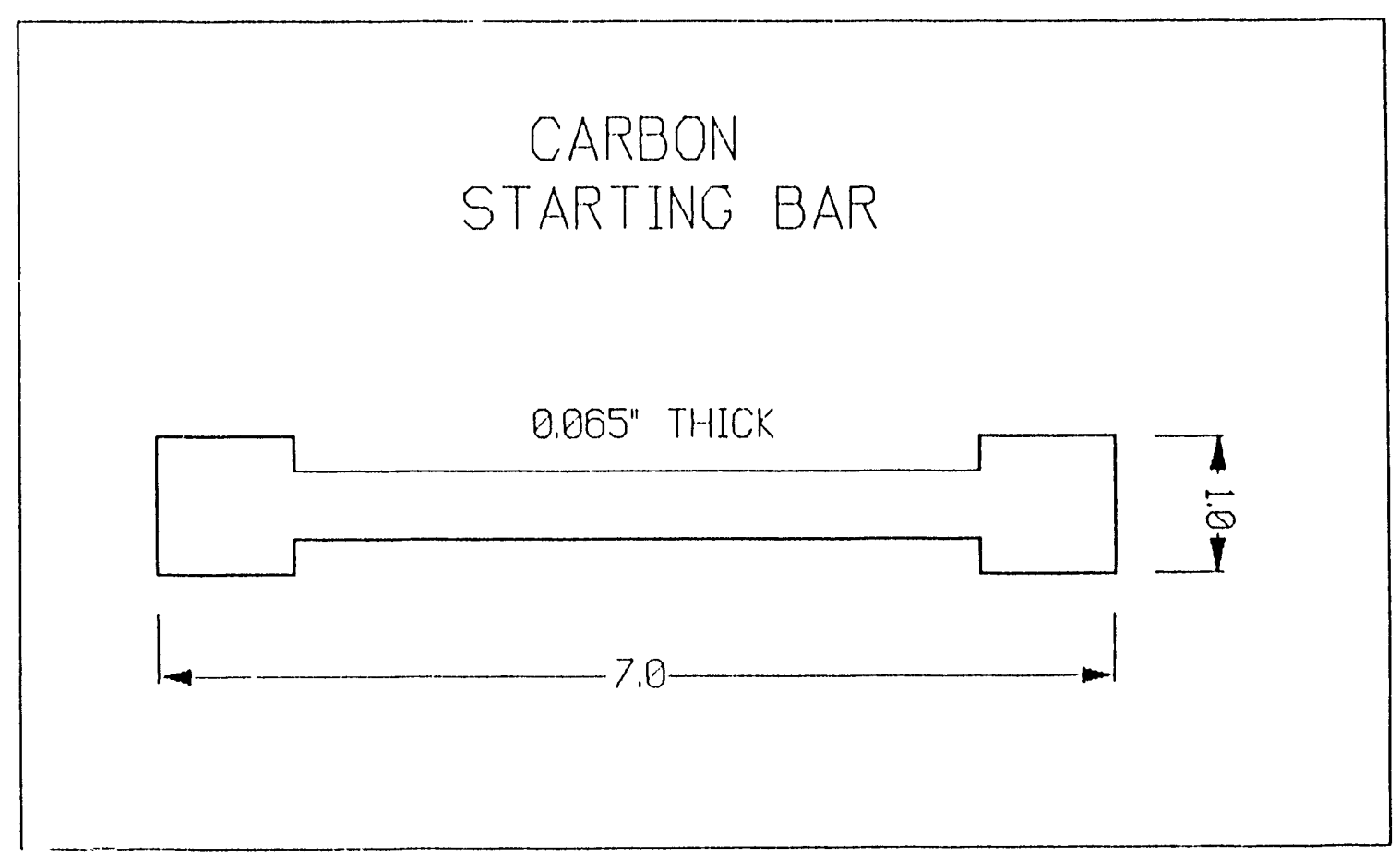

Figure 9. Approximate dimensions of the carbon starting bar or strip.

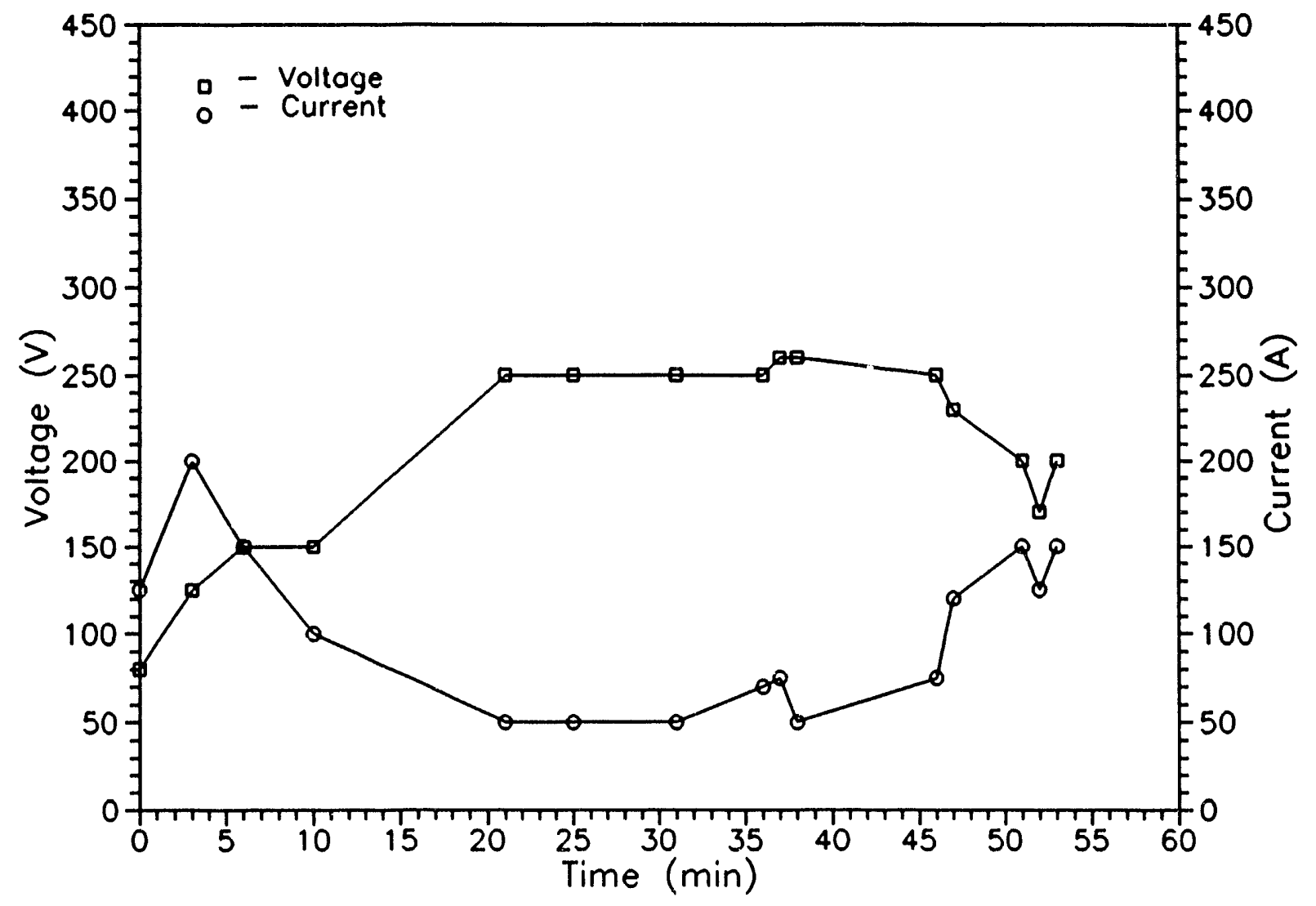

Figure 10. Current and voltage profile with time for Test 6. 


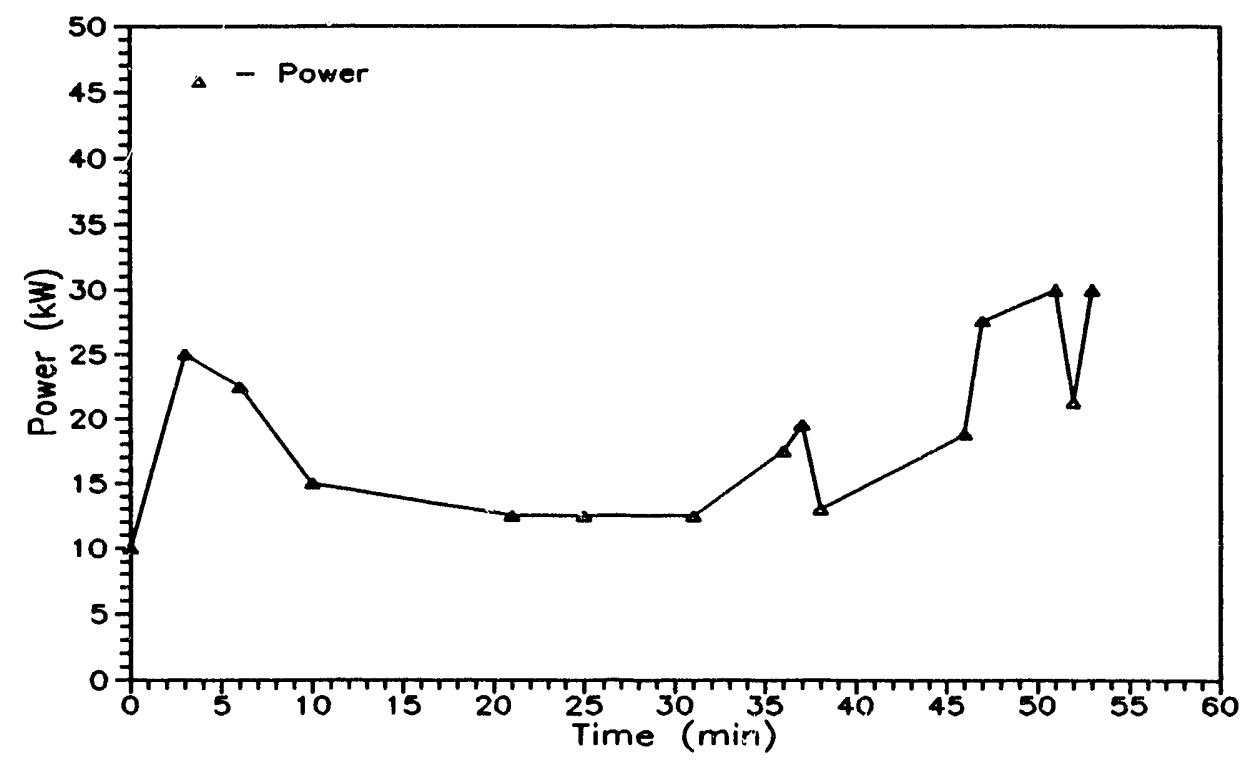

Figure 11. Power profile with time for Test 6.

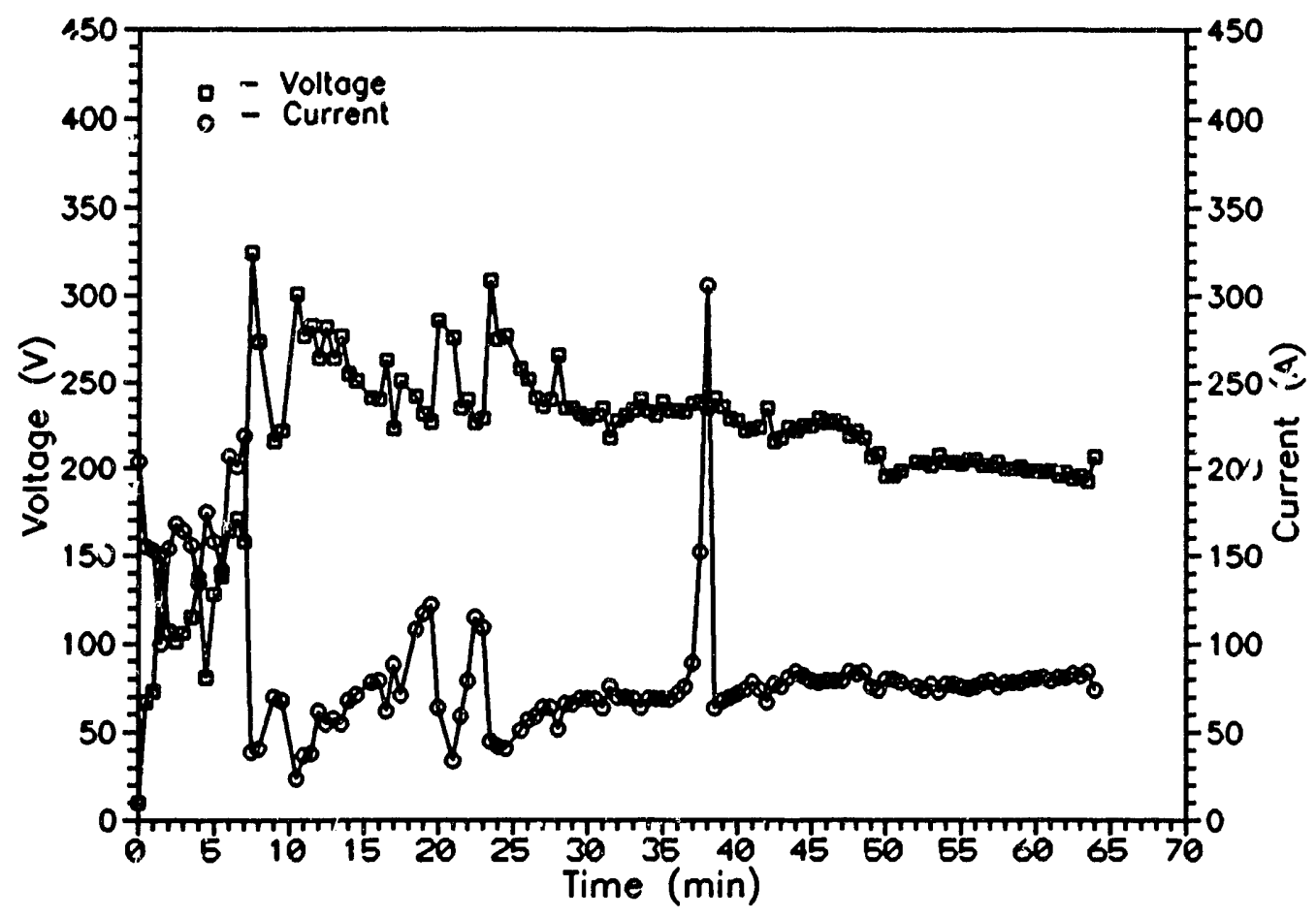

Figure 12. Cirrent and voltage profile with time for Test 7. 


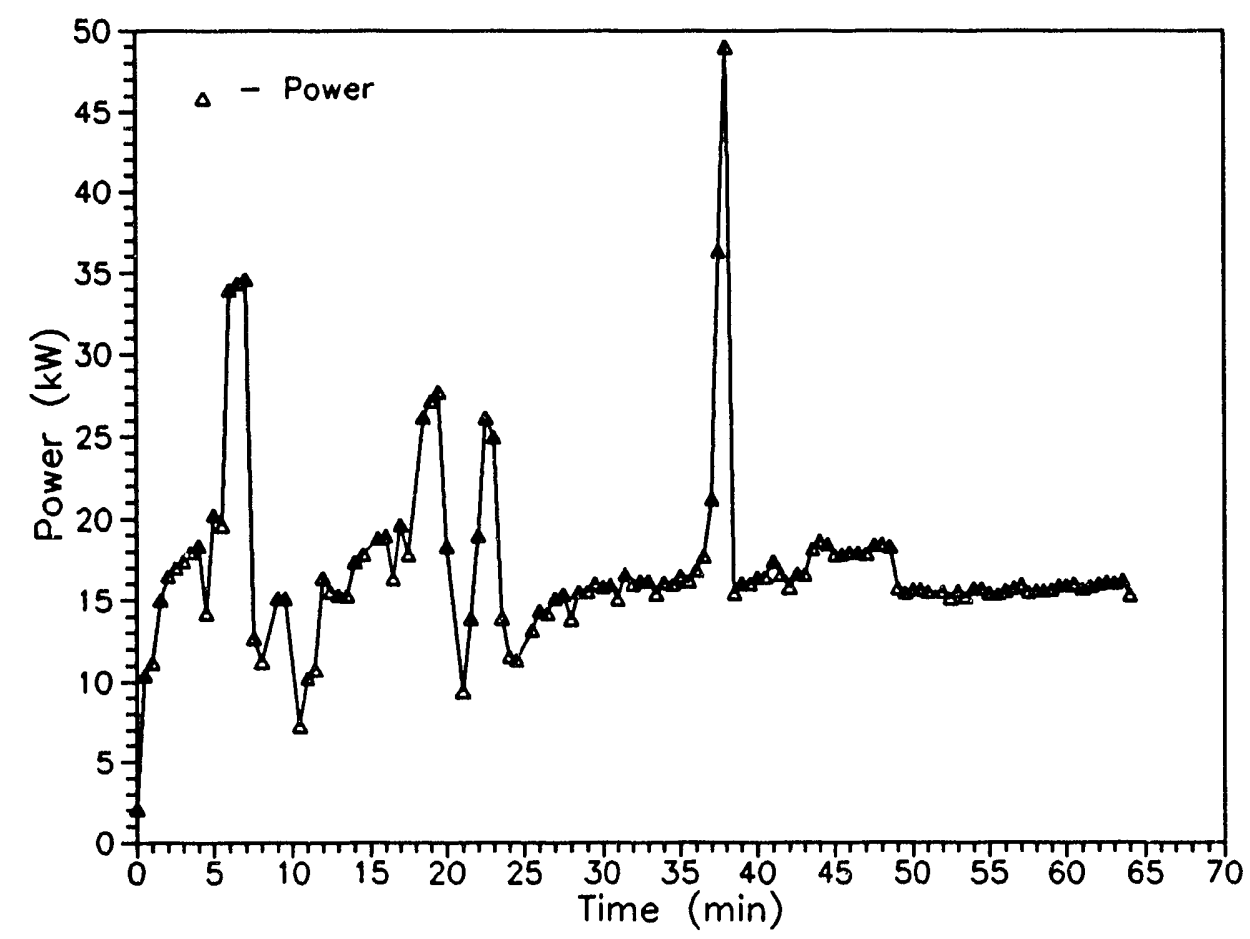

Figure 13 Power profile with time for Test 7.

above $35 \mathrm{k}$.' for extended periods, lasted up to 4 hours (usually limited by electrode life), and occurred under conditions with almost complete melting within the crucible.

Test 7 was operated conservatively (see Figure 12) at a low current $(\sim 70 \mathrm{~A})$ and higher voltage $(200-250 \mathrm{~V})$ with a power level of approximately $17 \mathrm{~kW}$ (see Figure 13). The heating process was uneventful. It was terminated when it appeared to be fully melted after 64 minutes. All tests after Test 6 were manually terminated by the operator and were not caused by failure of equipment.

The input energy, average power, and mass balance for the preliminary tests are summarized in Table 9. Tests 6 and 7 represent the culmination of the Phase I development of starting and heating procedures. The energy requirement for melting is $2-3 \mathrm{~kW}-\mathrm{h} / \mathrm{kg}$, which exceeds the usual large scrap stecl melter value of approximately $1 \mathrm{~kW}-\mathrm{h} / \mathrm{kg}$. The present low efficiency is partially due to scale, but mostly due to the lack of insulating refractory in the SS crucible that results in a high energy loss to the cooling water when the soil becomes melted. The rate of melting is similar to scrap melting, which takes about 1 hour to melt one pot or chamber of material, irrespective of size.

In the earlier tests, after the conducting path was consumed or "lowered" into the melt and if th: current was not reduced, a "dust storm" in the are melter chamber was usually observed for a $r$ stain period. The nature of the melting was much different than the adopted mode. The are sength was longer because the arc was attempting to carry the current without significant help from the high-resistance slag. The are(s) would strike in various locations, including the crucible wall, often forming a violent turbulence in the melt that included the formation of bubbles. The 
bubbling, arc jet effects and strong entrainment probably caused the release or flow of the rather fine unmelted soil (dust) in bursts and clouds within the chamber. Lowering the current and the electrode gap to the melt reduces the effect to obtain controllable regimes between a quiescent, a rolling boil, and a firecracker mode, all well below the dust storm turbulence previously obtained. Also, once the melt pool under the electrodes becomes big enough, the current can be increased without promoting the release of soil dust.

As shown in Test 6, heating can be operated in several modes depending on arc gap, current, and stage of melting: (1) a quiescent mode with small arc gap and modest current where most of the surface was dark, yellow circles occurred around the arc attachment immediately below each electrode; (2) strong convective currents resembling a rolling boil mode in which either the slag under the electrodes (early on) or at a location between the electrodes (later), and/or at alternate sides of the crucible in regions where melting had not been obvious before, and finally the whole top of the melt appeared as a slowly or moderately rolling boil; (3) a firecracker mode that appeared to be when the electrodes were just in contact with the surface and at the highest currents allowing continued operation with the V-I characteristics available here. The firecracker mode resembled the random trajectory of bright yellow (as viewed through the protective glass) rockets emitted from the slag at the base of the electrodes and landing elsewhere in the melt or on the walls. At other times, the electrodes were immersed into the slag and operated totally in the Joule-heater type of mode. There was no slag stuck to the electrodes upon emerging from the slag melt and there was little difference in operating conditions (voltage or current).

Foaming does not appear in be a problem with arc melting. Foaming was a major problem when making the IEB/IEB4 materials for the IEB cold tests using induction heating in crucibles and oven heating in crucibles. In the arc melter, the materials were not preprocessed by heating to reduce the amount of gases given off. In Test 7 , some obvious foaming caused the arc to occasionally extinguish when foam bubbled up and touched the electrodes. The arc could immediately be restarted by lowering the electrodes to make contact with the melt. It seems that the $400 \mathrm{~V}$ open circuit voltage is sufficient (at low current of about $50 \mathrm{~A}$ ) to restart by contact for this geometry. 


\section{EXPERIMENTAL RESULTS}

\subsection{Introduction}

This section documents the results of arc melter capability demonstration tests (Tests 8-14) for various simulated waste type compositions stored at the RWMC. The capability tests also evaluated the effects of material addition during arc melter operating conditions. Specific experiments included melting of clean RWMC soil, soil with titania and zirconia additives, soil with simulated cemented organic waste stream, soil with simulated hydrated metal oxide sludges, effects of high aluminum addition on melter operation, and the dissolution and oxidation of high metal waste stream. The dissolution and oxidation of high metal waste stream in the melter wer: performed under an ambient argon and air atmospheres, and with air lanced into the melt. Electrode corrosion and erosion under different waste stream and melter operating conditions were studied. Mass balance studies for each melt was performed to identify material loss during operation. Energy balance was performed for material addition during are melter operation to investigate energy sinks in the system. Material characterizations were performed for in situ sampled slags, cold trap materials, and crucible slags. Recommendations for further refinements to enhance the arc melter's capabilities are identified. Table 10 summarizes the test description and the location of figures and tables related to each test.

\subsection{Description and Purpose of Experiments}

In Phase I, shakedown tests of the arc melter showed that simulated average waste composition of A-0 and RWMC soil could be casily processed into IEB/A-40 and IEB4/A-40 glass-ceramic final waste forms. Steady starting and operating procedures were also established for the are melter. In Phase II, the scope of work was to perform capability tests for the are melter under different waste stream scenarios. Capability tests, such as melting of pure soil, soil with $5 \%$ percent each of titania $\left(\mathrm{TiO}_{2}\right)$ and zirconia $\left(\mathrm{ZrO}_{2}\right)$, processing of cemented organic, hydrated metal oxides, and metal dissolution and oxidation (Ar, Air, Air lance environments) with soil were conducted.

These tests were not meant for detailed scientific investigations but to demonstrate melter versatility. Detailed scientific studies of the are melter process parameters for different waste streams scenarios were not in the scope of this work.

Starting and operating techniques for the are melter were developed in the first 5 tests. Test 1 used low and high open circuit voltage power supplies to investigate different are melter starting techniques. Test 2 used two high open circuit power supplies to test a graphite dumbbell as a starting mechanism. Test 3 implemented are melter enhancements to prevent the melter electrodes from breaking during operation. Tests 4 and 5 established a starting procedure using a $1 / 4$ in. graphite strip and the initial heating current-time procedure required. The heating procedure included, initially a high current and low voltage followed by a low current and high voltage mode.

Tests 6 and 7 were run to test the capability of the are melter to produce IEB/A-40) and IEB4/A-40 slags for extended times. Test 6 indicated the need for increased cooling at the 


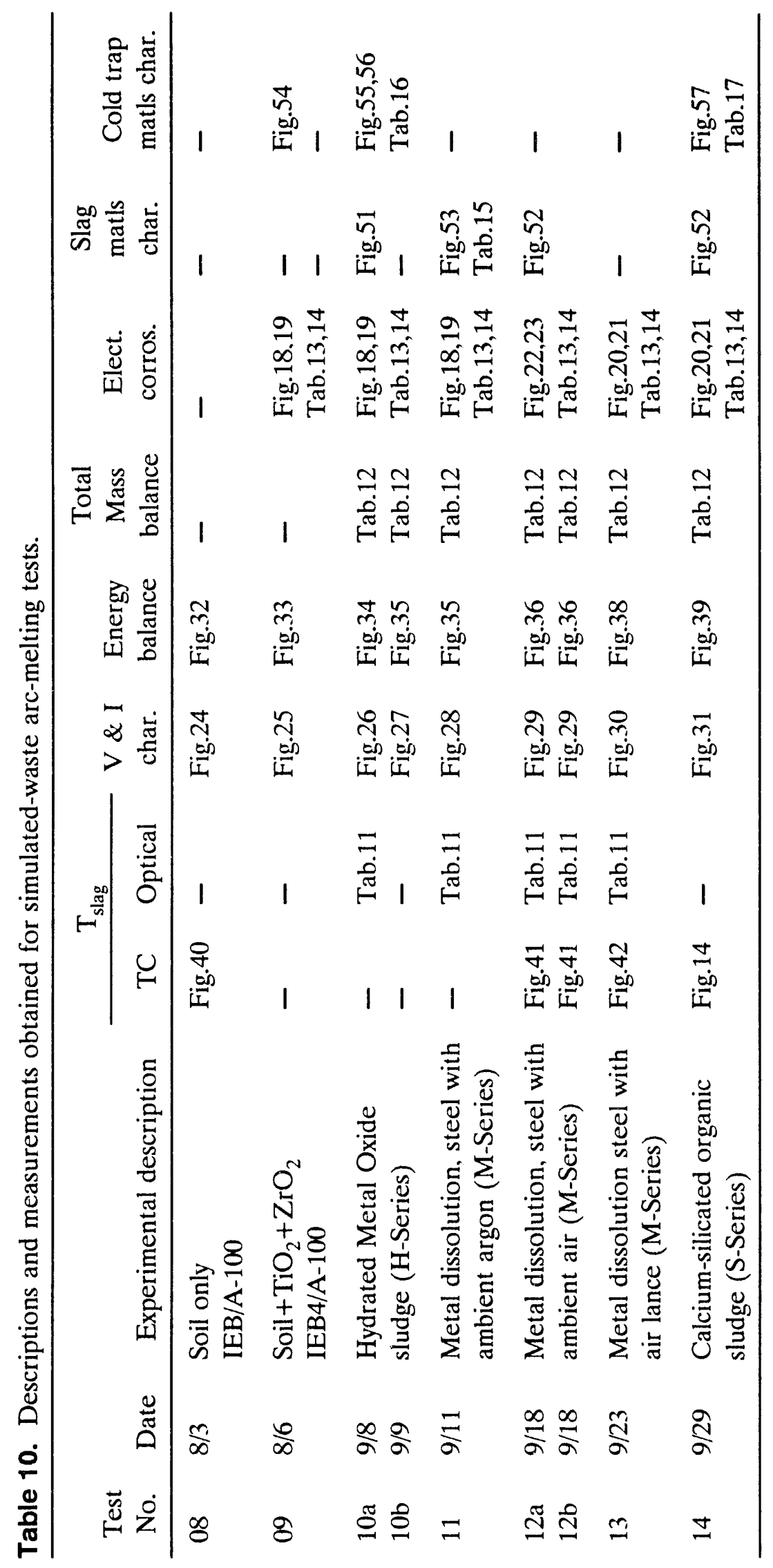


crucible walls. Additional monitoring equipment was installed for Test 7 to monitor the progress of the melt.

Tests 1-7 provided the experience and data necessary for shakedown of the arc melter for operation of the capability tests. Each test provides valuable information for improving the arc melter. Subsequent tests at higher power and temperatures revealed more problems, which when solved, resulted in an even more reliable and capable system. Additional details for Tests 1-7 are contained in Appendix B.

Tests 8-14 were performed to determine the capability of the arc melter under different process scenarios. Tests 8 and 9 demonstrated the arc melter's capability to melt high-temperature melting RWMC soil, and soil plus $5 \mathrm{wt} \%$ each titania $\left(\mathrm{TiO}_{2}\right)$ and zirconia $\left(\mathrm{ZrO}_{2}\right)$. The soil plus additive test (Test 9) determined that the addition of the $5 \mathrm{wt} \%$ each of $\mathrm{TiO}_{2}$ and $\mathrm{ZrO}_{2}$ slightly lowered the melting temperature of the soil. The waste form from Test 9 appeared to be a much denser and better glass than the one obtained from Test 8 . Test 10 was conducted to demonstrate the are melter capability for processing the hydrated metal oxide (H-series high $\mathrm{Na}$ waste stream) and to evaluate the effects of oxide dehydration on the melting process. The effect of chemical corrosion from the decomposition of the metal hydroxides on the carbon electrodes was also evaluated. Results indicate that the metal hydroxides decomposed upon entering the melt, and the rate of electrode corrosion from the decomposition of the metal hydroxides is much higher than the rate of electrode corrosion in other tests. Tests 11-13 demonstrated metal dissolution and oxidation of a high metal component $(\mathrm{Fe})$ waste stream under ambient argon, ambient air, and bubbling air environments. Metal melted upon entry into the melt and subsequently solidified at the bottom of the crucible. The objectives of Test 14 were to determine the response of the are melter when cemented organics were added to the melt. Large amounts of carbon were released when the cemented organic was added to the melt. Even though air was injected above the melt during the addition of the cemented organic, increased amounts would be needed to provide a stoichiometric mixture for complete combustion of the organic contained in the simulated sludge. Additional details for these tests are contained in Appendix B.

\subsection{Melting Capability}

In Phase 1 and 2 testing of the arc melter system, 14 tests have been completed. The testing and development of the are melter has resulted in system hardware and procedures that can be used for experiments on final waste forms. An adequate power supply configuration along with starting methods and a heating schedule for melting have been developed. In Phase I, problems discovered and eventually solved include secure attachment of carbon electrodes, cooling protection for the top of the melter, and an adequate design for cooling the SS crucible. Phase II demonstrated the capability of the arc melter to process different waste stream scenarios, such as cemented organics, hydrated metal oxide sludges, and metal dissolution and oxidation in argon, air, and bubbling air environments.

Tests 6 and 7 confirmed the ability of the are melter (and present power supply characteristics) to melt A-40 simulated relerence waste in a reasonable period, without extensive pretreatment (e.g., preheating to minimize loaming, remove carbonate related materials, ete.) in a relatively quieseent mode. During these tests, the melts became hot enough to come to a full 
rolling boil. This tendency increased the convective heating of the outer parts of the melt and mixing of the materials. The overall effect enhanced the homogeneity of the final waste form. Test 13 (soil was added to the melt in $2 \mathrm{~kg}$ increments) showed that $8 \mathrm{~kg}$ was the optimum amount for complete melting and mixing of materials in the present crucible. A sample of the convective cells in the melt is shown in Figure 14.

Slag temperatures attained during melting were $1,600-1,800^{\circ} \mathrm{C}$ in the vicinity of the electrodes and were as high as 1,300$)^{\circ} \mathrm{C}$ on the surface of the "unmelted" region near the hot slag. The slag temperature at the electrodes registered a much higher temperature. These temperatures are in excess of $2,000^{\circ} \mathrm{C}$. These optical pyrometer measurements were in concurrence with the readings of the thermocouple immersed in the soil, which, after a rise to a plateau of approximately $1,250^{\circ} \mathrm{C}$, peaked at approximately $1,770^{\circ} \mathrm{C}$ as shown in Figure 15 and Figure 16. However, Table 11, shows that inconsistencies exist in the optical pyrometry data from test to test. In the melt, a two-dimensional temperature gradient exists on the surface of the melt. If the temperature is not measured at the same position on the surface of the melt, different surface temperatures are obtained. The optical pyrometer was manually aimed at the surface of the melt during the experiments, introducing the possibility for error in the measurements. Fixturing of the optical pyrometry measurements would reduce temperature differences due to positional error.

A mass balance was determined for Tests 10-14, results of which are summarized in Table 12. In general, the result indicated that approximately $15-16 \%$ of the original soil weight was not accounted for. Reasons for these differences are speculated to be from the loss of water of hydration, decomposition calcium cabonates, and volatilization organics into gases. These losses can be up to $11 \%$ of the initial soil weight. ${ }^{24}$ Other loses are thought to be from the entrainment of fine soil particles in the off-gas during melting. These fine particles are not captured in the are melter cold trap, but pass into the laboratory exhaust system.

\subsection{Electrode Wear}

Electrode lifetime is an important design consideration in any type of are furnace. Although the are melter experiments were not conducted to specifically study the problem of electrode wear, some useful data and information could still be collected while performing the experiments. Sine electrode wear may depend somewhat on a particular are furnace design, obtaining at least some crosion rate data for the are melter is important.

The electrodes are 1 in. in diameter and 6 in. long and are screwed onto a water-cooled copper attachment. Figure 17 shows a schematic of the graphite electrodes. The graphite is Grade G10, with a density of $1.66 \mathrm{~g} / \mathrm{cm}$. The use of carbon electrodes could affect two important aspects of operating the melter for waste remediation. First of all, since the electrodes are of fixed length and erosion will occur at a steady rate, the amount of time the are melter can operate will depend on the length of the electrodes. Secondly, if carbon from the electrodes is introduced into the melt, it would tend to reduce iron oxides to iron, which is undesirable for creating an IEB waste form. To prevent carbon contamination, the are melter is normally operated with the 


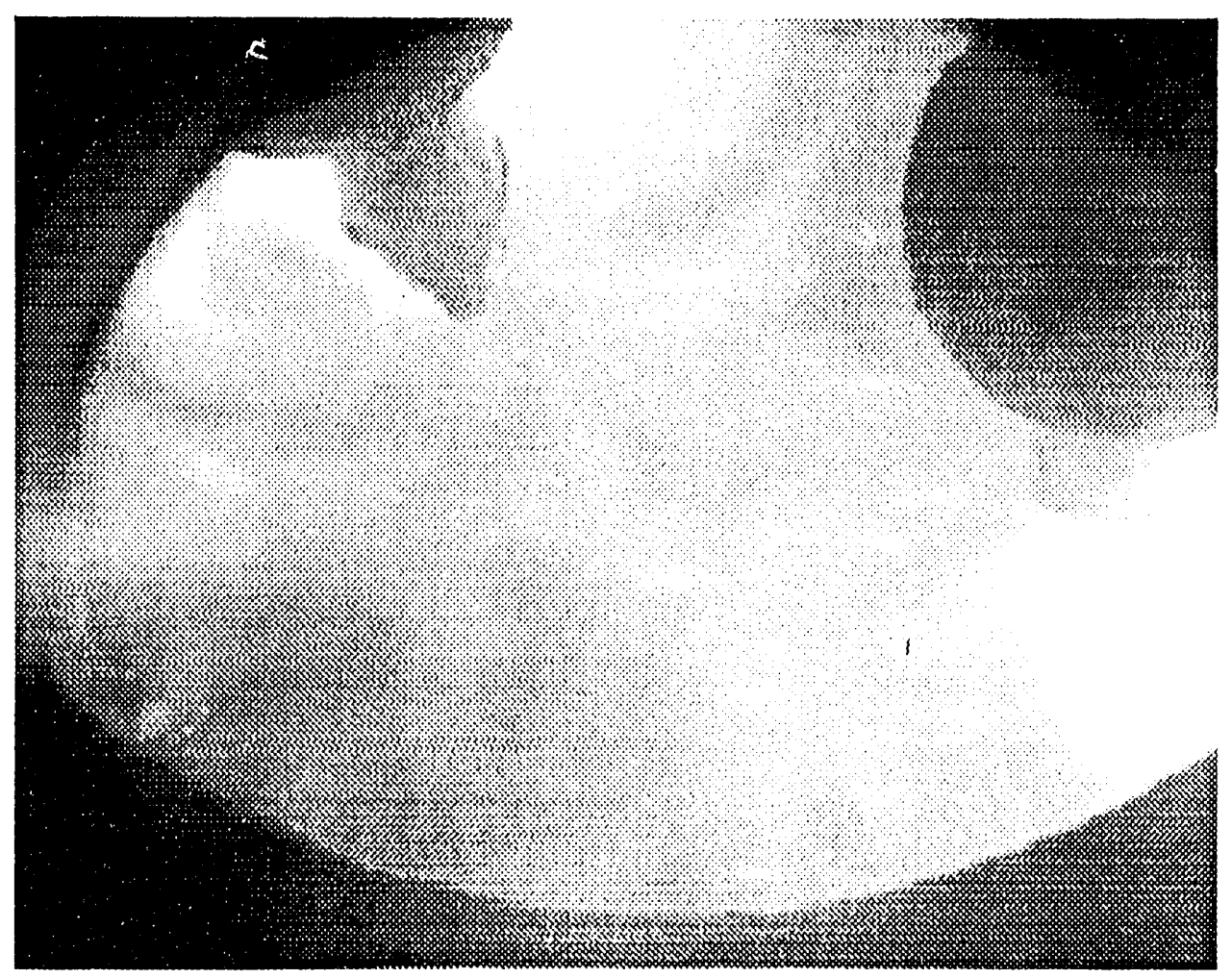

Figure 14. Convective llow pattern in an $8 \mathrm{~kg}$ soil melt.

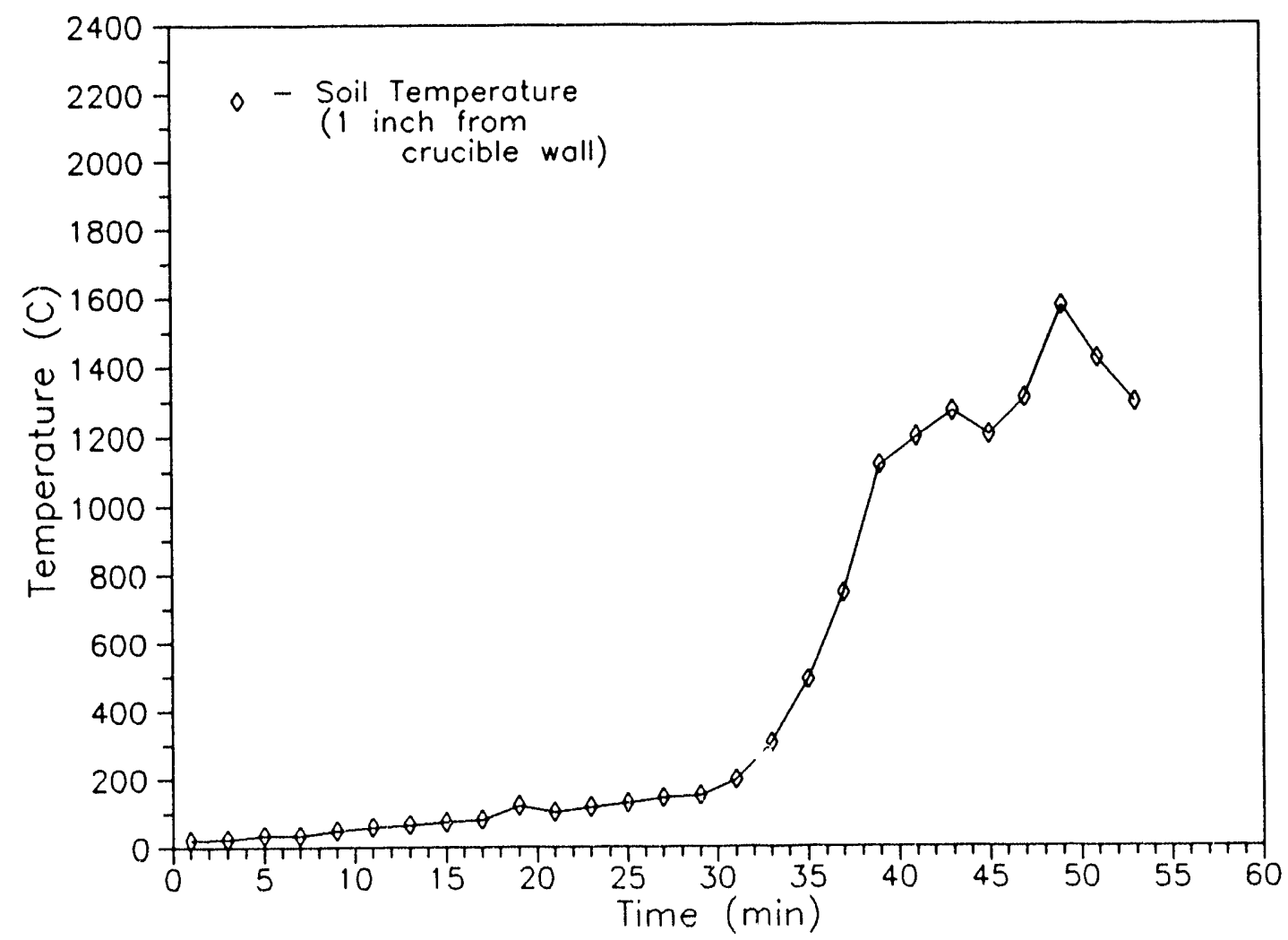

Figure 15. Soil thermocouple temperature as a function of time lor Test 6. 


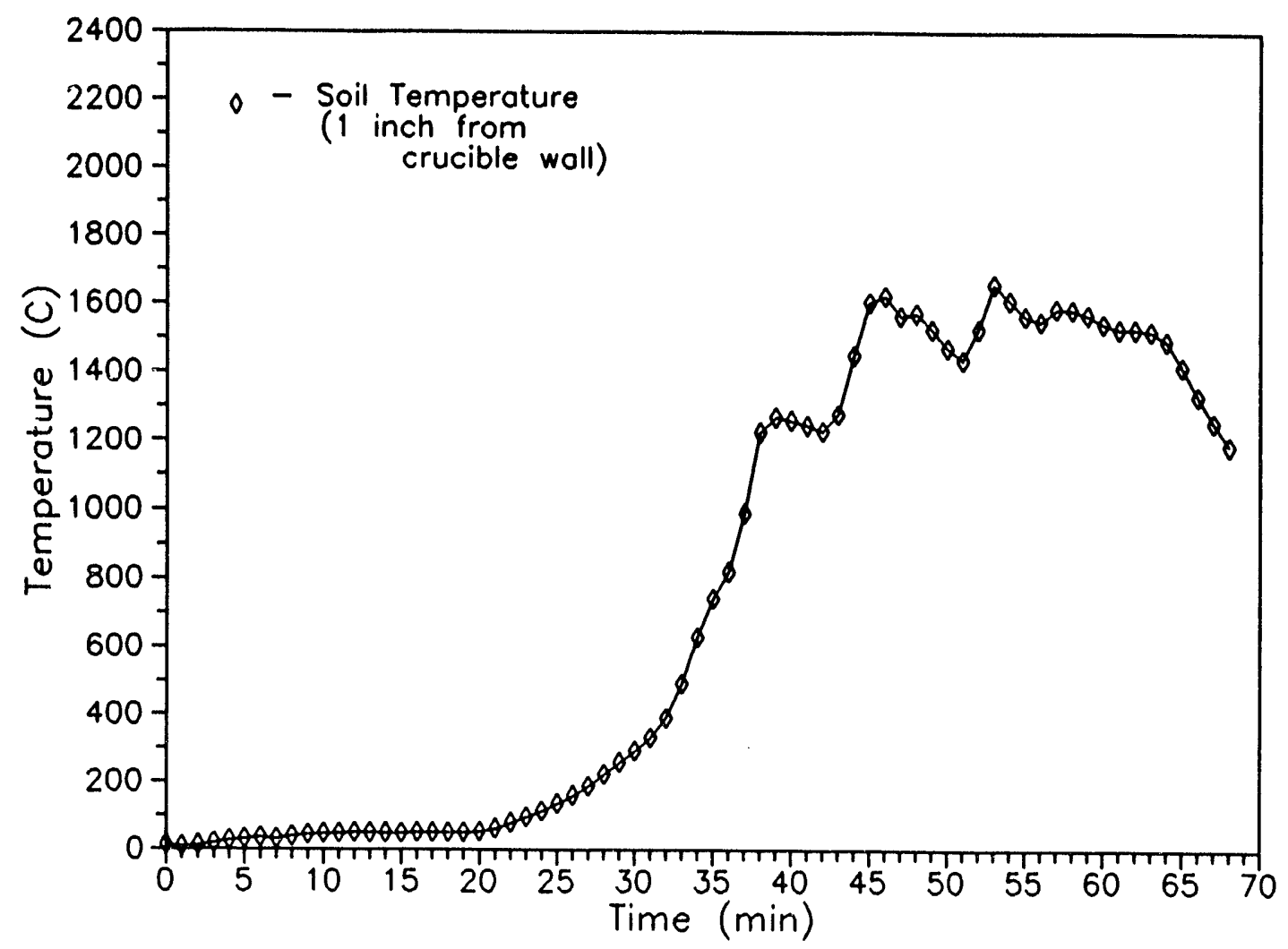

Figure 16. Soil thermocouple temperature as a function of time for Test 7.

Table 11. Optical pyrometer measurements of the melt from various tests.

\begin{tabular}{|c|c|c|c|c|}
\hline \multirow{2}{*}{$\begin{array}{c}\text { Test } \\
\text { number }\end{array}$} & \multicolumn{3}{|c|}{$\begin{array}{l}\text { Temperature } \\
\left({ }^{\circ} \mathrm{C}\right) \\
\end{array}$} & \multirow[b]{2}{*}{ Comments } \\
\hline & Anode & Cathode & Melt & \\
\hline 10 & 1,864 & 1,571 & 1,433 & IEB4/H-80 \\
\hline 11 & 2,738 & 2,079 & 1,566 & $\begin{array}{l}6 \mathrm{~kg}-\text { IEB4/A-100, during heatup prior } \\
\text { to stabilization of melt }\end{array}$ \\
\hline \multirow[t]{4}{*}{12} & 2,068 & 1,809 & 1,618 & $6 \mathrm{~kg}-\mathrm{IEB} 4 / \mathrm{A}-100$ \\
\hline & 2,454 & 1,974 & 1,405 & $6 \mathrm{~kg}-\mathrm{IEB} 4 / \mathrm{A}-100$ \\
\hline & 2,452 & 2,015 & 1,553 & $6 \mathrm{~kg}-\mathrm{IEB} 4 / \mathrm{M}-75$ \\
\hline & 2,247 & 2,615 & 1,669 & $6 \mathrm{~kg}-\mathrm{IEB} 4 / \mathrm{M}-75$ \\
\hline \multirow[t]{2}{*}{13} & 2,604 & 1,699 & 1,399 & $6 \mathrm{~kg}-\mathrm{IEB} 4 / \mathrm{A}-100$ \\
\hline & 2,503 & 2,184 & 1,662 & $8 \mathrm{~kg}-\mathrm{IEB} 4 / \mathrm{A}-100$, flow lines \\
\hline 14 & - & - & - & No data \\
\hline
\end{tabular}


Table 12. Summary of mass balance results for Tests 10-14.

Weight lraction of soil

$(\%)$

Soil fraction

Test 10

Test $11^{\mathrm{a}} \quad$ Test $12 \quad$ Test 13

Test 14

Fraction of soil vitrified

73.3

54.7

69.1

81.0

73.3

Fraction of soil not vitrified

2.6

3.5

12.6

0

2.6

Fraction of soil condensed or

8.9

$-$

1.6

3.6

7.7

precipitated in cold trap or chamber

Fraction of soil in vapor, fumes, or

15.2

41.8

16.7

15.4

16.4 gases (by difference)

a. Test was terminated early because of expected crucible leak. 
_ Surface coated with $0.006^{\prime \prime} \mathrm{ZrO2}$

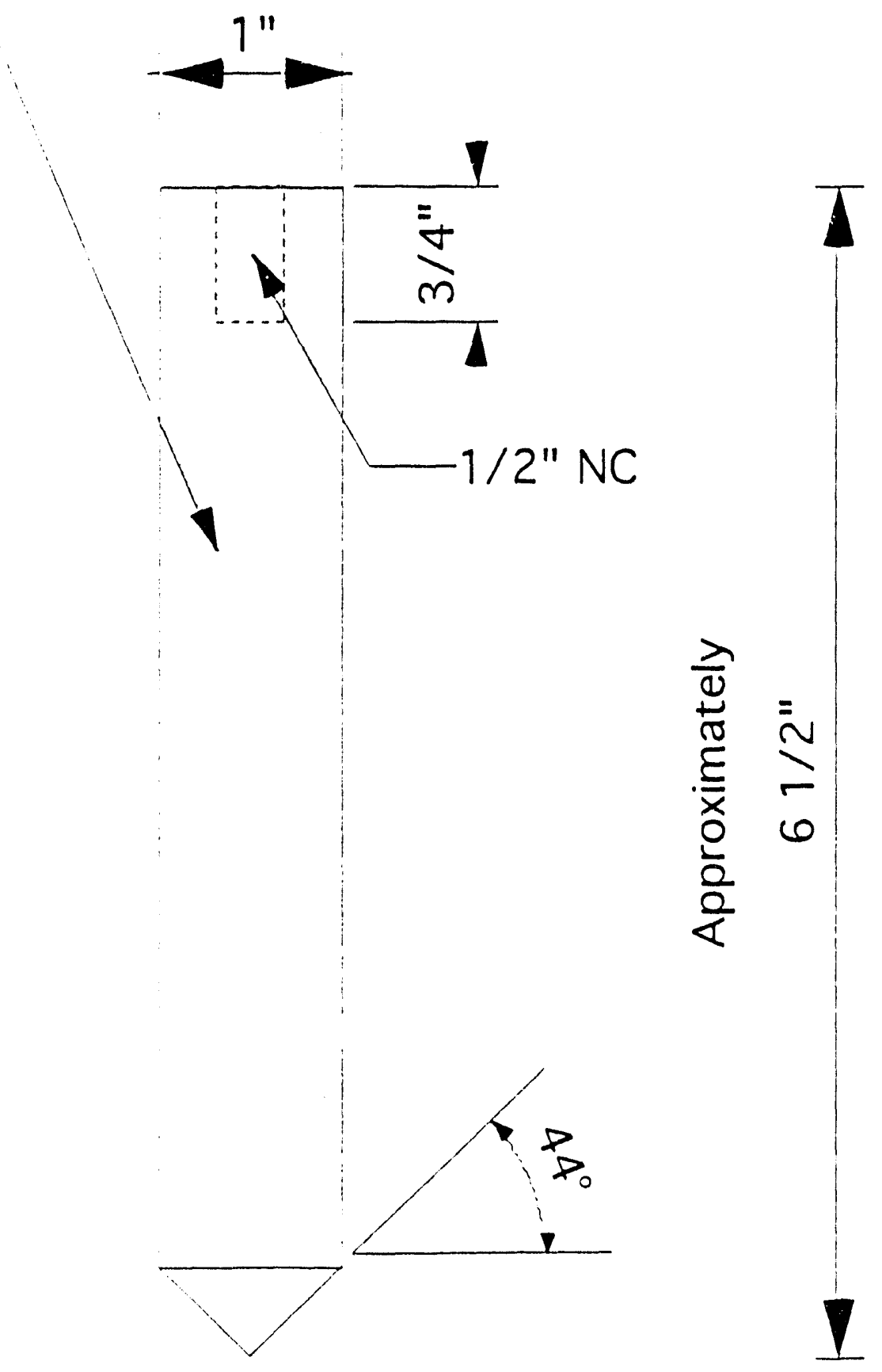

Material: Graphite, type G10 (see attached)

Metal Dissolution and Oxide Experiment, Air Environ.

Figure 17. Schematic of graphite electrodes. 
electrodes slightly above the melt, with an are drawn between the electrodes and the melt. Most of the erosion takes place due to direct $\mathrm{CO}_{2}$ formation from oxygen in the air.

Measurements of carbon electrode erosion began with Test 9 and lasted until Test 14. Starting with Test 12 , coatings were plasma sprayed onto the graphite electrodes in an attempt to reduce erosion. The coatings comprised $\mathrm{Al}_{2} \mathrm{O}_{3}$ or $\mathrm{ZrO}_{2}$, with thicknesses of 0.006 and 0.012 in. The coatings proved effective in reducing the rate of erosion. Table 13 shows the measurements and results for all of the operational tests. Included in the table is the amount of current that flowed through the electrodes during each melting test. The Ampere-hours were computed from data taken with the data acquistion system and constitute an average over the length of the experiment.

Figure 18 and Figure 19 show plots of the data in Table 13 for the uncoated anodes and cathodes. A linefit to the data in each case gives the average erosion rate, which is $0.429 \mathrm{~g} / \mathrm{A} \cdot \mathrm{h}$ for the anode and $0.372 \mathrm{~g} / \mathrm{A} \cdot \mathrm{h}$ for the cathode. Figure 20 and Figure 21 show anode and cathode data for the $\mathrm{Al}_{2} \mathrm{O}_{3}$ coated electrodes and Figure 22 and Figure 23 show similar data but for $\mathrm{ZrO}_{2}$ coatings. While the coatings generally decrease the amount of erosion, ironically the thicker coatings proved less effective in each case, except for the $\mathrm{Al}_{2} \mathrm{O}_{3}$ coatings on the anode for which the erosion rate was about the same for thick and thin coats. Table 14 shows the results of the linefits. Overall, the coatings were quite effective in reducing cathode erosion but only somewhat effective for anode crosion. The thin $\mathrm{ZrO}_{2}$ coating appears most effective; however, with only one data point apiece, specific conclusions suetr as this should await more investigation.

\subsection{Energy Balance}

An energy balance analysis is important to determine the overall system efliciency and to account for energy losses during operation of the are melter. Energy losses for individual system components can be determined that could point out which components may need improvement. Since the analysis requires measurement of water temperatures and flow rates for individual water cooling circuits, the are melter was fitted with thermocouples and flow meters. In addition, electrical probes were used to measure current and voltage. With the exception of the flow meters, measurements were taken automatically during the course of each experiment with the data logger system. Flow meter readings were taken periodically during the experiments by hand.

Energy balance calculations were accomplished with the aid of several computer programs written in FORTRAN (see Appendix C). Although the data acquisition system automatically saved data in a user delined lile, the data file format was not amenable to data processing. The program LOTODAT converts the original data file into a condensed form and writes it to another user defined file. The average water flow rates are specifically written into the LOTODAT program, since these data were not recorded by the data logger. In addition, the program creates a file for input into the are melter energy balance program, EBALAM, plus a separate plotting file for voltage and current. The program also calculates the total Ampere-hours, the average power and total energy consumed during the experiment. EBALAM can then read the input file created for it and do the energy balance calculations based on the thermocouple readings, cooling water flow rates and current and voltage readings. Because the original data logger files vary somewhat from experiment to experiment, a different version of the FORTRAN programs must 


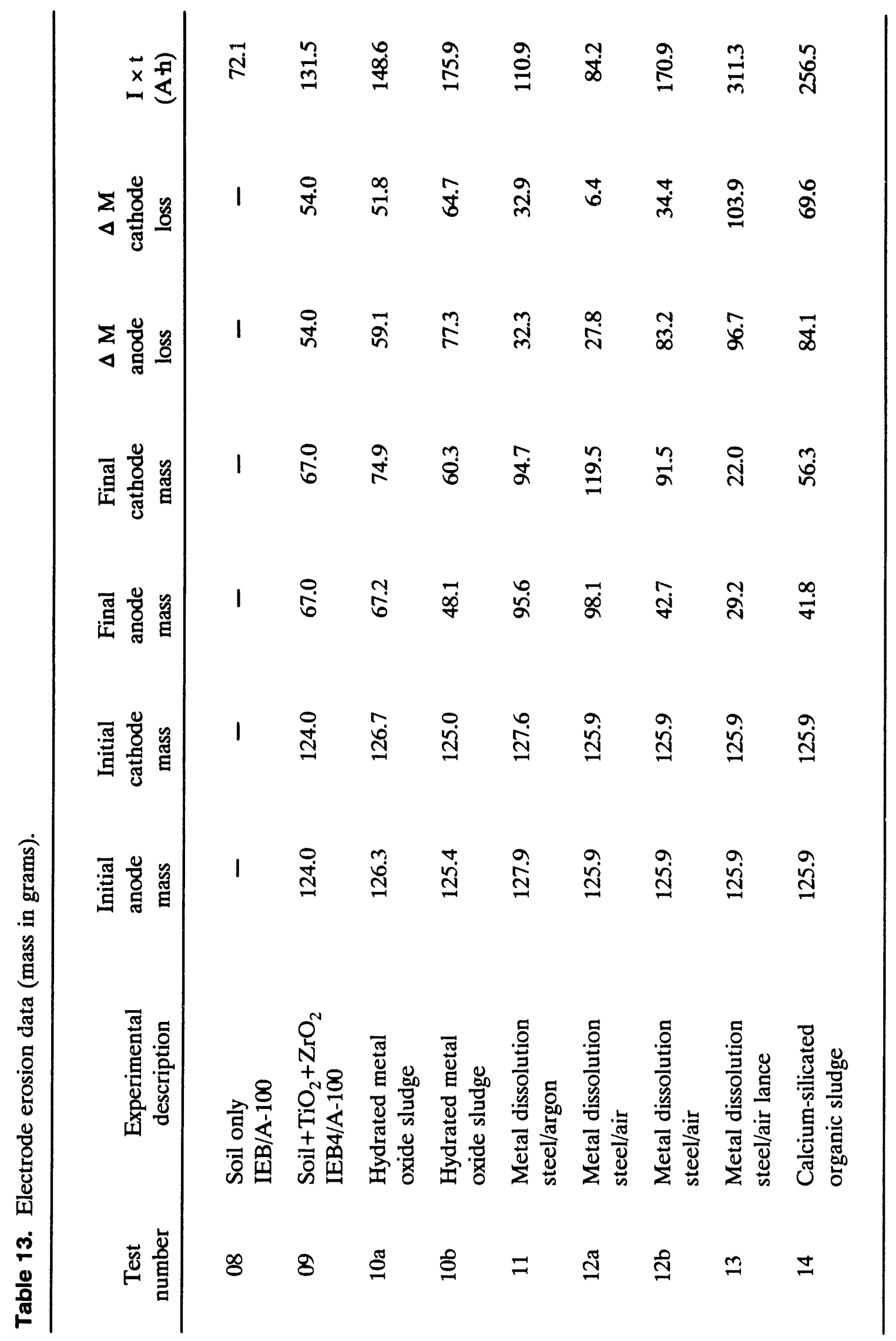




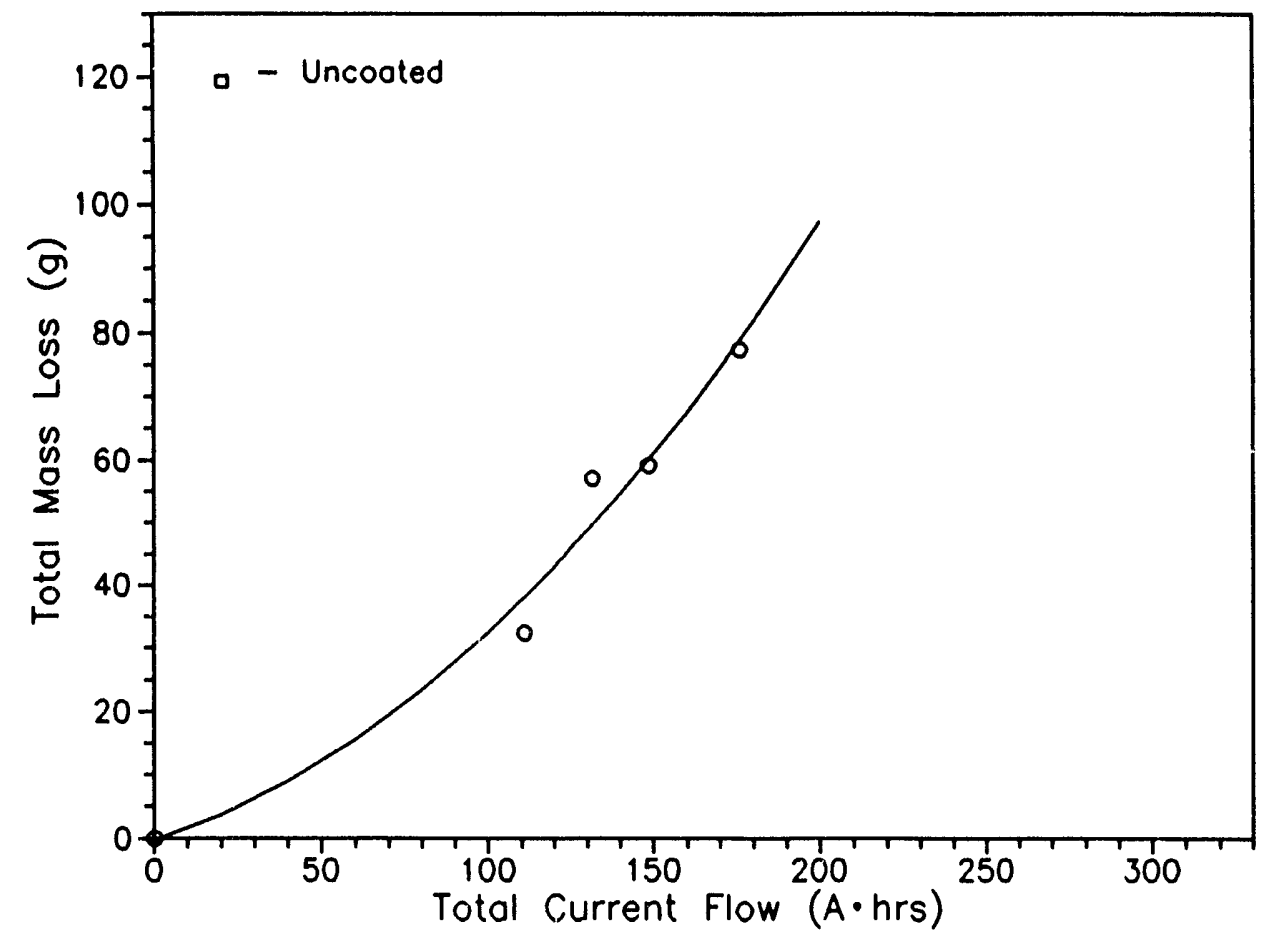

Figure 18. Plot of uncoated anode erosion rate.

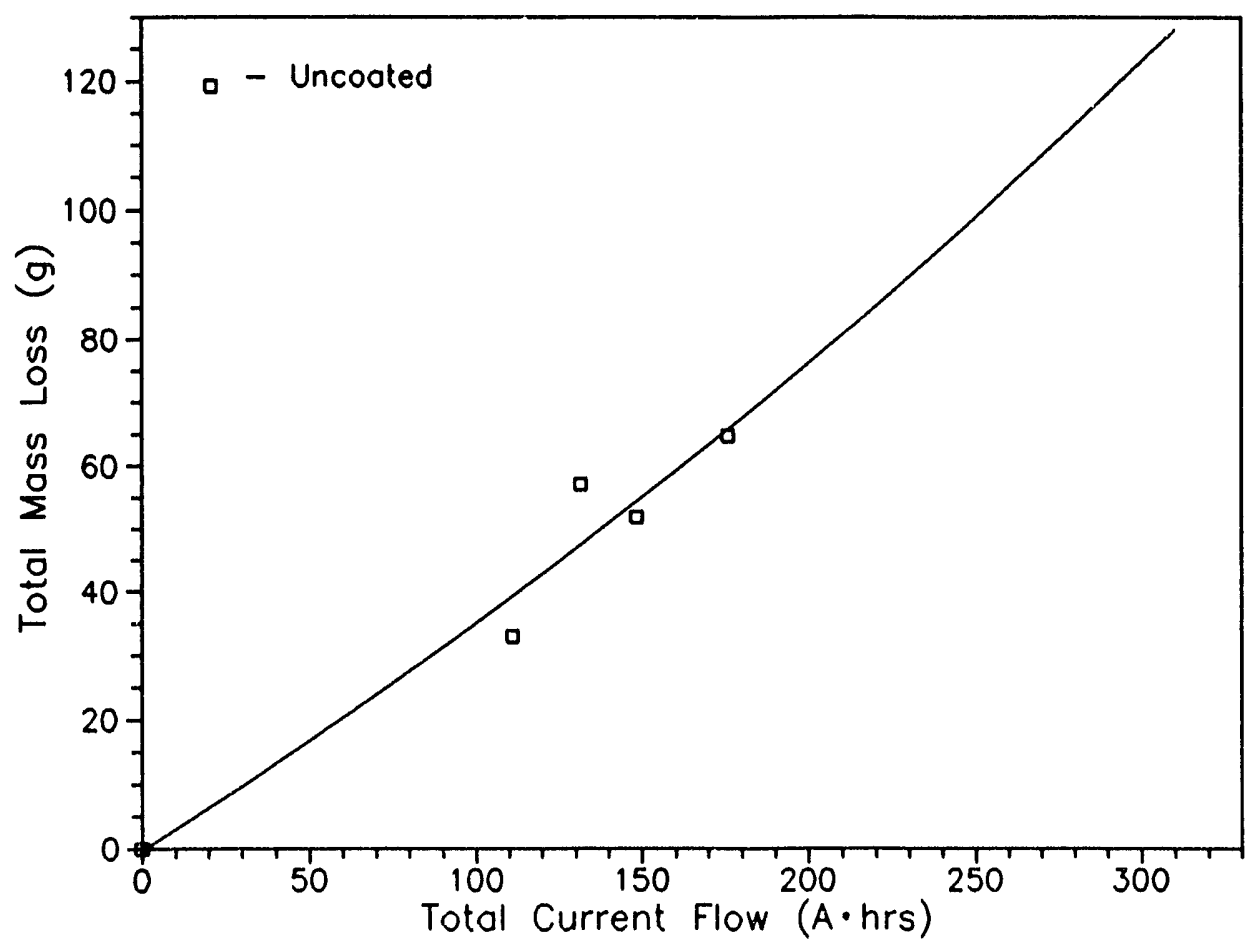

Figure 19. Plot of uncoated cathode crosion rate. 


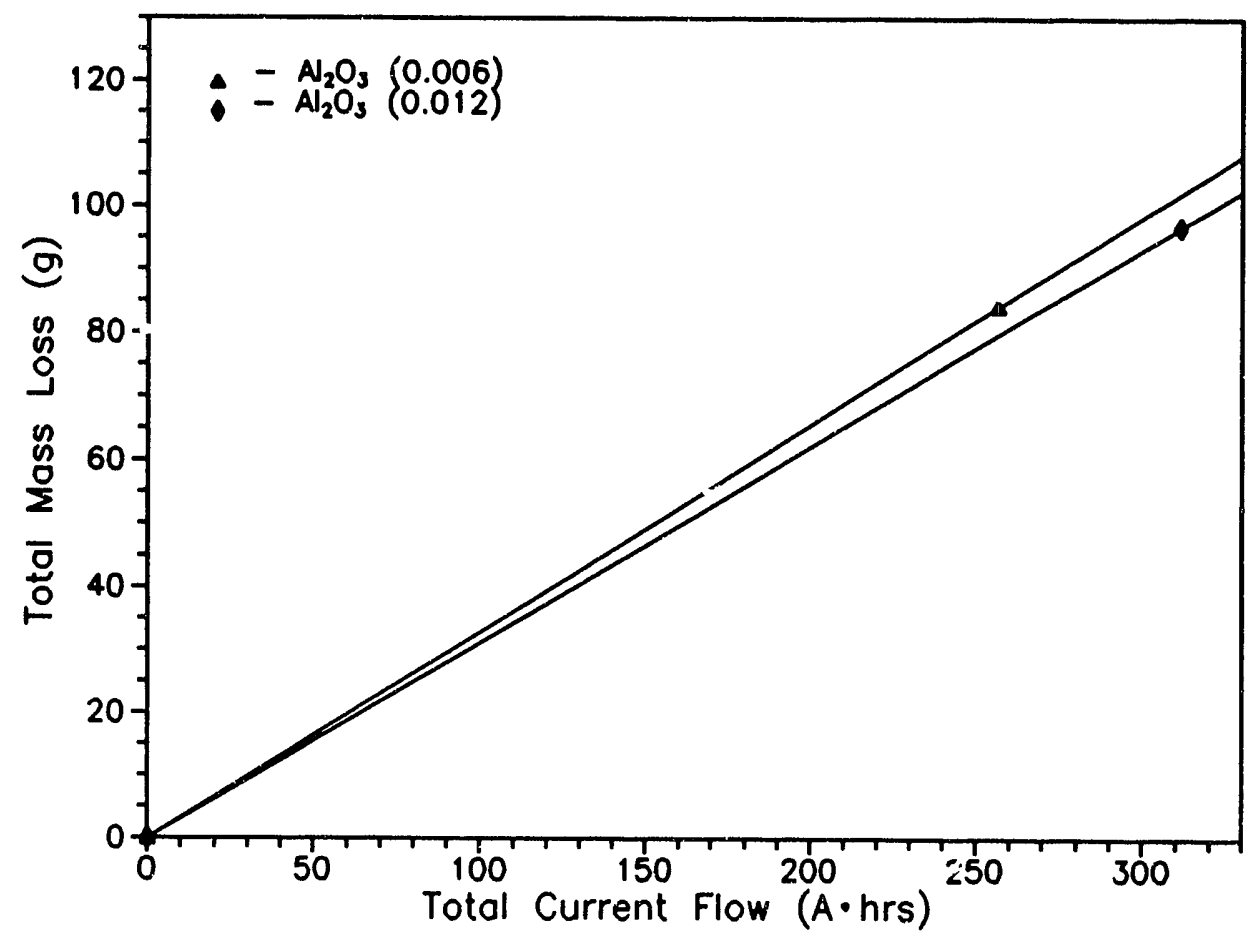

Figure 20. Plot of anode e osion rate for $\mathrm{Al}_{2} \mathrm{O}_{3}$ coated electrodes.

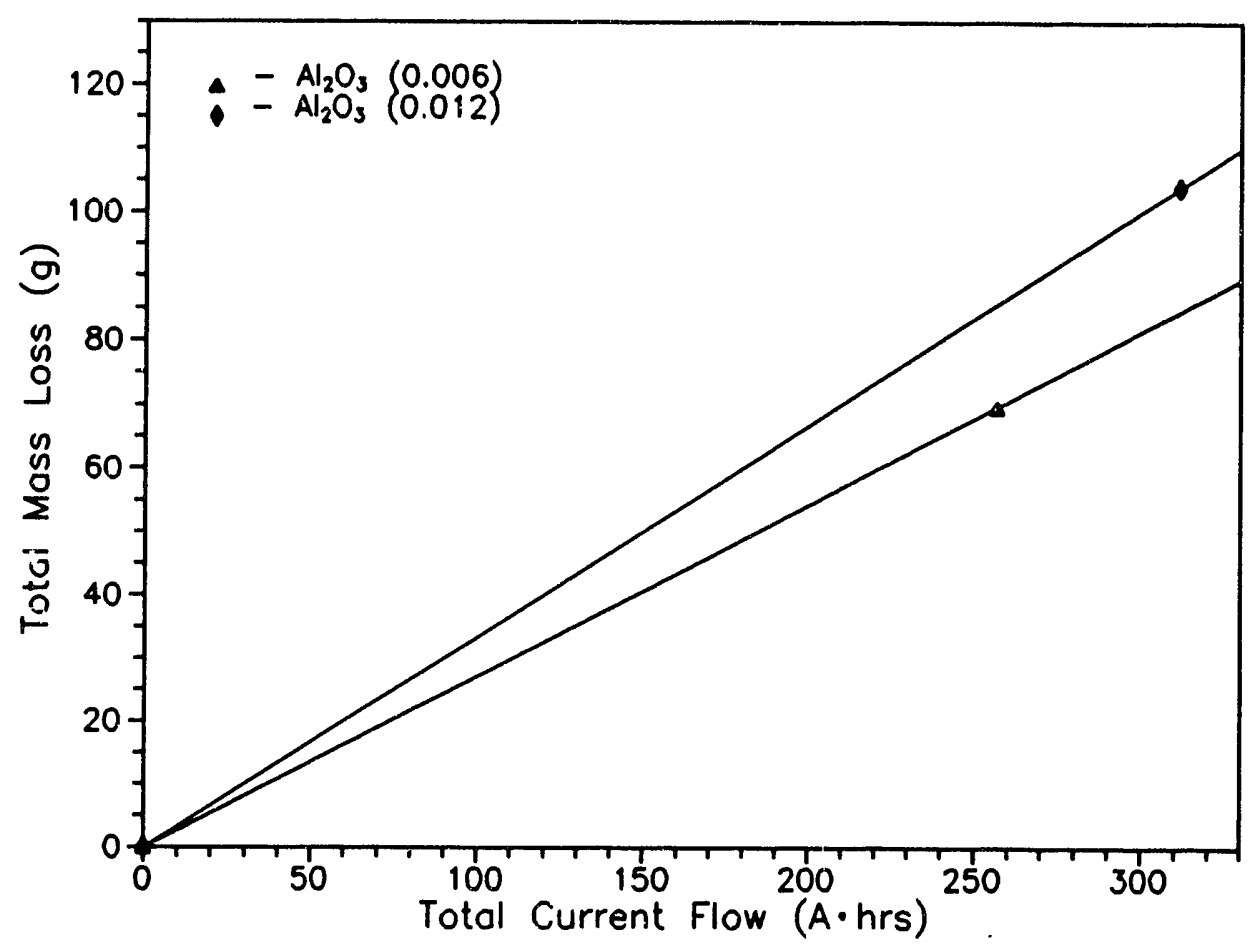

Figure 21. Plot of cathode erosion rate for $\mathrm{Al}_{2} \mathrm{O}_{3}$ coated electrodes. 


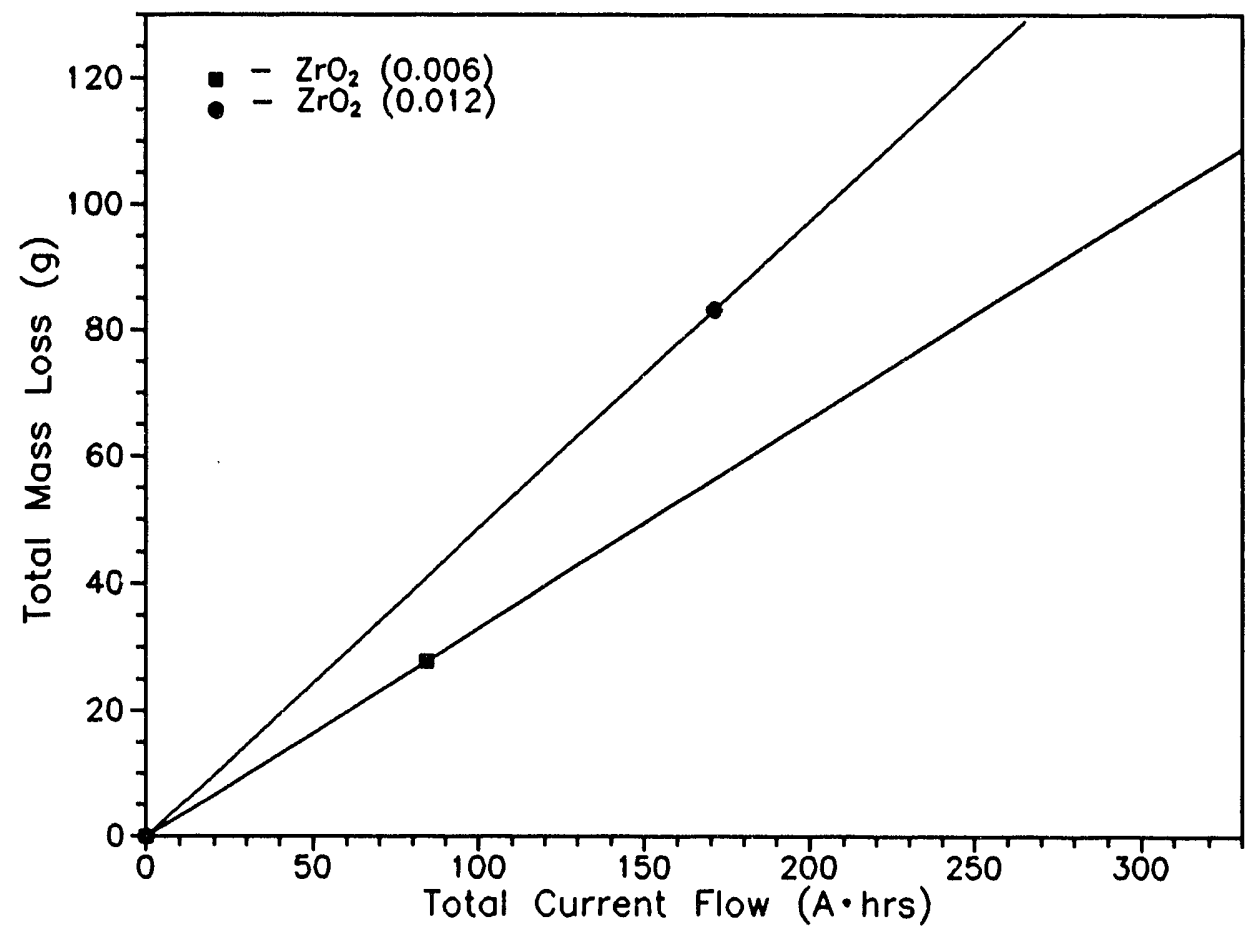

Figure 22. Plot of anode erosion rate for $\mathrm{ZrO}_{2}$ coatings.

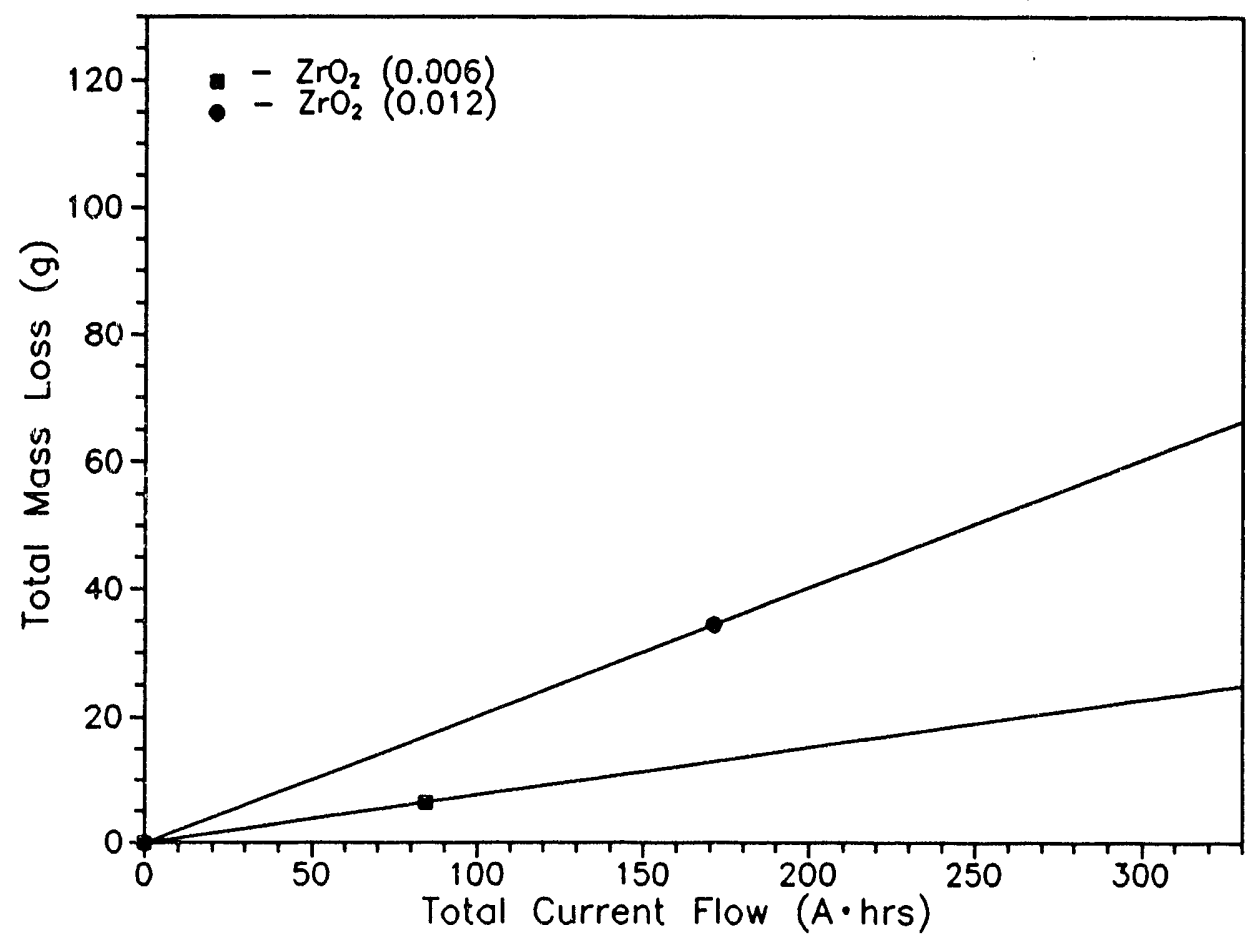

Figure 23. Plot of cathode crosion rate for $\mathrm{ZrO}_{2}$ coatings. 
Table 14. Average erosion rates for electrodes during arc melter experiments.

\begin{tabular}{llcc}
\hline $\begin{array}{c}\text { Test } \\
\text { number }\end{array}$ & Electrode coating & $\begin{array}{c}\text { Anode erosion } \\
(\mathrm{g} / \mathrm{A} \cdot \mathrm{h})\end{array}$ & $\begin{array}{c}\text { Cathode erosion } \\
(\mathrm{g} / \mathrm{A} \cdot \mathrm{h})\end{array}$ \\
\hline & & 0.429 & 0.372 \\
$13,10,11$ & Uncoated & 0.311 & 0.334 \\
14 & $\mathrm{Al}_{2} \mathrm{O}_{3}, 0.012$ in. & 0.328 & 0.271 \\
$12 \mathrm{~b}$ & $\mathrm{Al}_{2} \mathrm{O}_{3}, 0.006$ in. & 0.487 & 0.201 \\
$12 \mathrm{a}$ & $\mathrm{ZrO}_{2}, 0.012$ in. & 0.330 & 0.076 \\
\hline
\end{tabular}

be used with data from each experiment. The data and programs for each experiment are stored together on a floppy disk.

Figures 24-31 show the current-voltage response of the arc melter during each experiment. The arcmelter starts in a low-voltage, high current operating mode. As melt pools begin to form under the electrodes and the carbon starting strip is burned away, the arc melter transitions early on into a high voltage mode of operation. The current can be controlled at the power supplies. Early experiments ( $8 \& 9$ for example) were done with low currents of about 50 Amperes. Later experiments were done using higher current levels. The graphs show the current and voltage fluctuating during operation, sometimes significantly. This behavior points out the dynamic changes in melter operation as electrodes are shortened by erosion, electrode to melt spacing changes, more of soil/simulated waste becomes melted, additions to the inelt are made, etc. The large spike variations seen on some of the graphs (Volts $=433$, Amps $=0$ ) occur when the arc is unexpectedly extinguished. In most cases, the arc is easily restarted by lowering the electrodes toward the melt.

Figures 32-39 show the power input and losses to cooling over the duration of the experiment. The bottom dotted line represents the power lost to cooling of the electrode holders. The losses are relatively small and tend to increase only slightly during the experiments. The next dotted line is the sum of electrode and chamber power losses. The distance between the two lines is then lost due the chamber water cooling only. Similarly the distance between the top dotted line and the next lower one will be the power lost to cooling water in the crucible. The solid line is the total power going into the system. The distance between this line and the dotted line below (total water cooling losses) must then be the power being absorbed into melting the soil/simulated waste. The amount of power going into melting the soil varies from approximately $5-10 \mathrm{~kW}$. While increasing the total power into the arc melter tends to raise the amount going into melting the soil, the majority of the extra power is lost to the cooling systems (compare experiments 8 \& 9 with $13 \& 14$ ). Test 13 is especially interesting, since, except for the first 15 minutes, the total power remains constant once the current is set. The current is increased at 40 minutes and again near the end of the experiment. The cooling water losses, however, show 


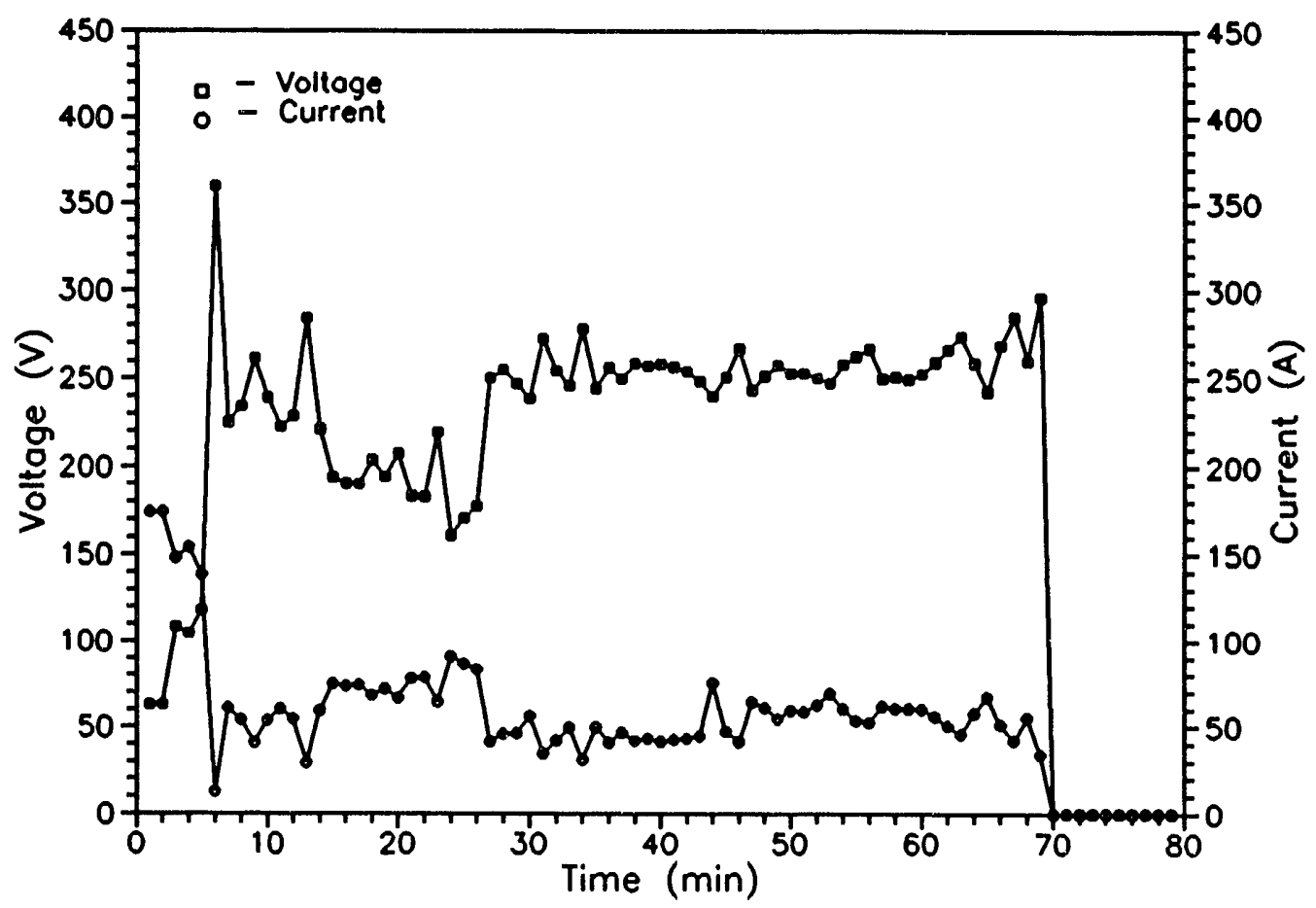

Figure 24. Current-voltage response of the arc melter for Test 8 on IEB/A-100 soil.

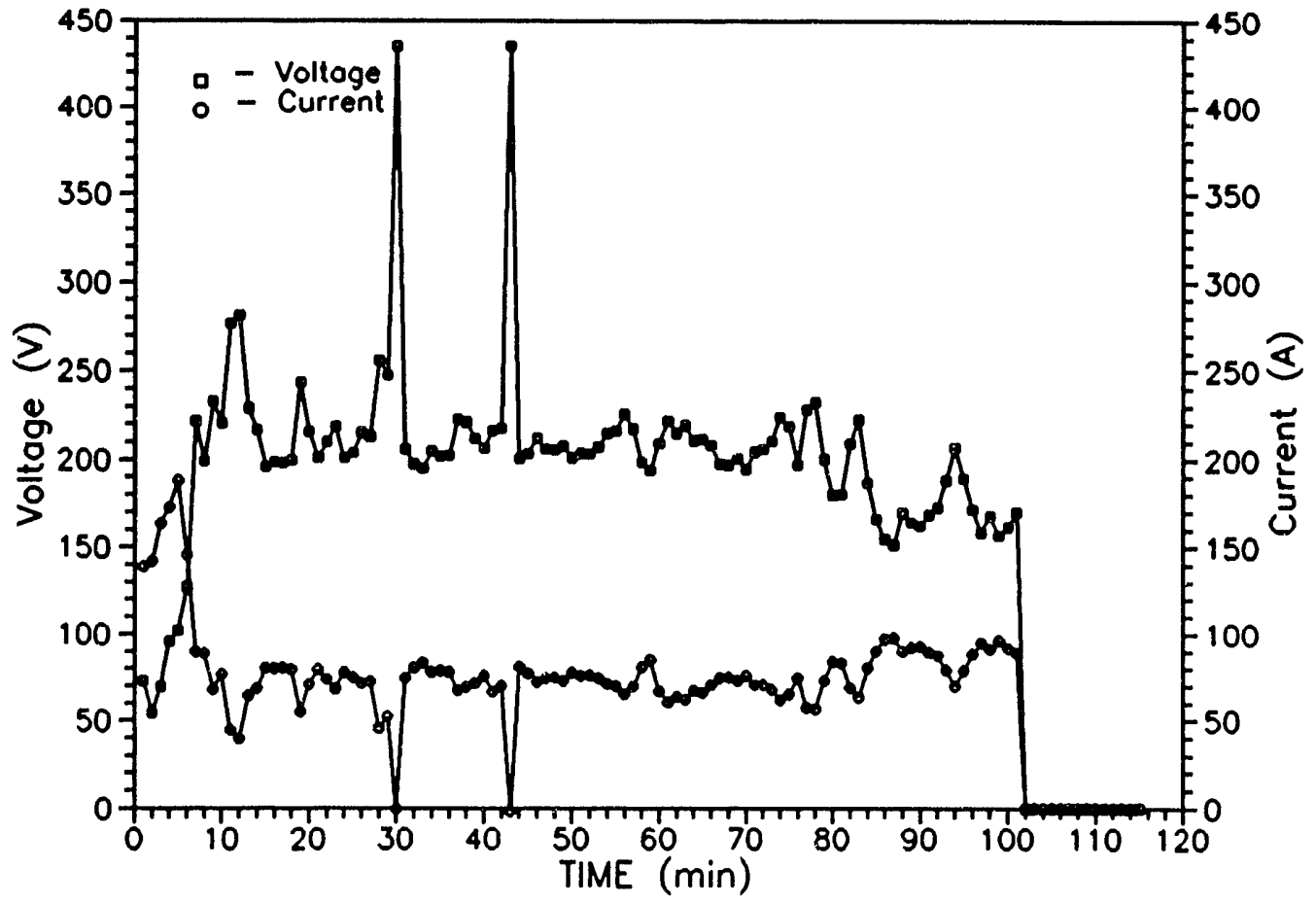

Figure 25. Current-voltage response of the are melter for Test 9 on IEB4/A-100 soil with $\mathrm{ZrO}_{2}$ and $\mathrm{TiO}_{2}$. 


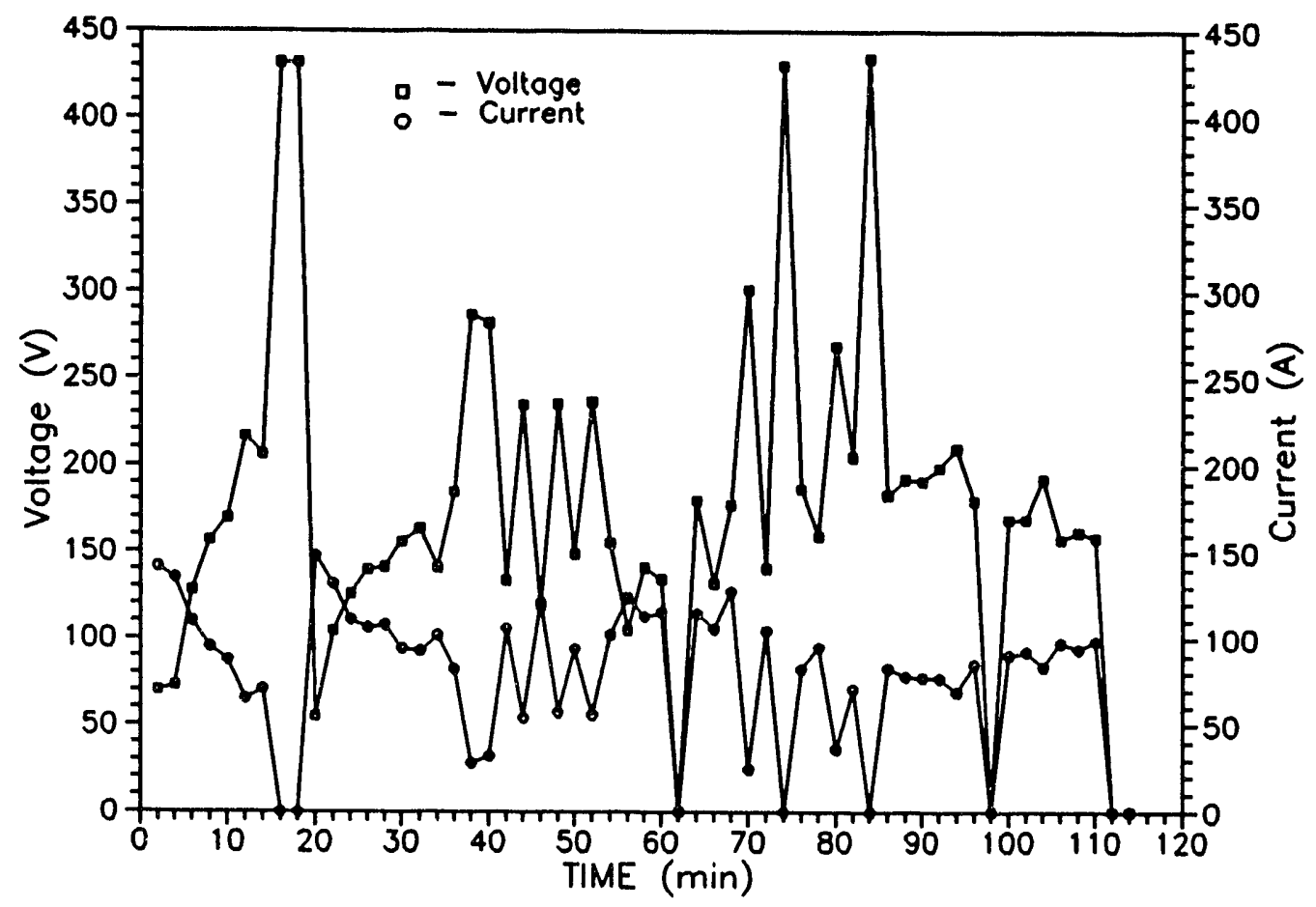

Figure 26. Current-voltage response of the arc melter for Test 10a on IEB4/H-series.

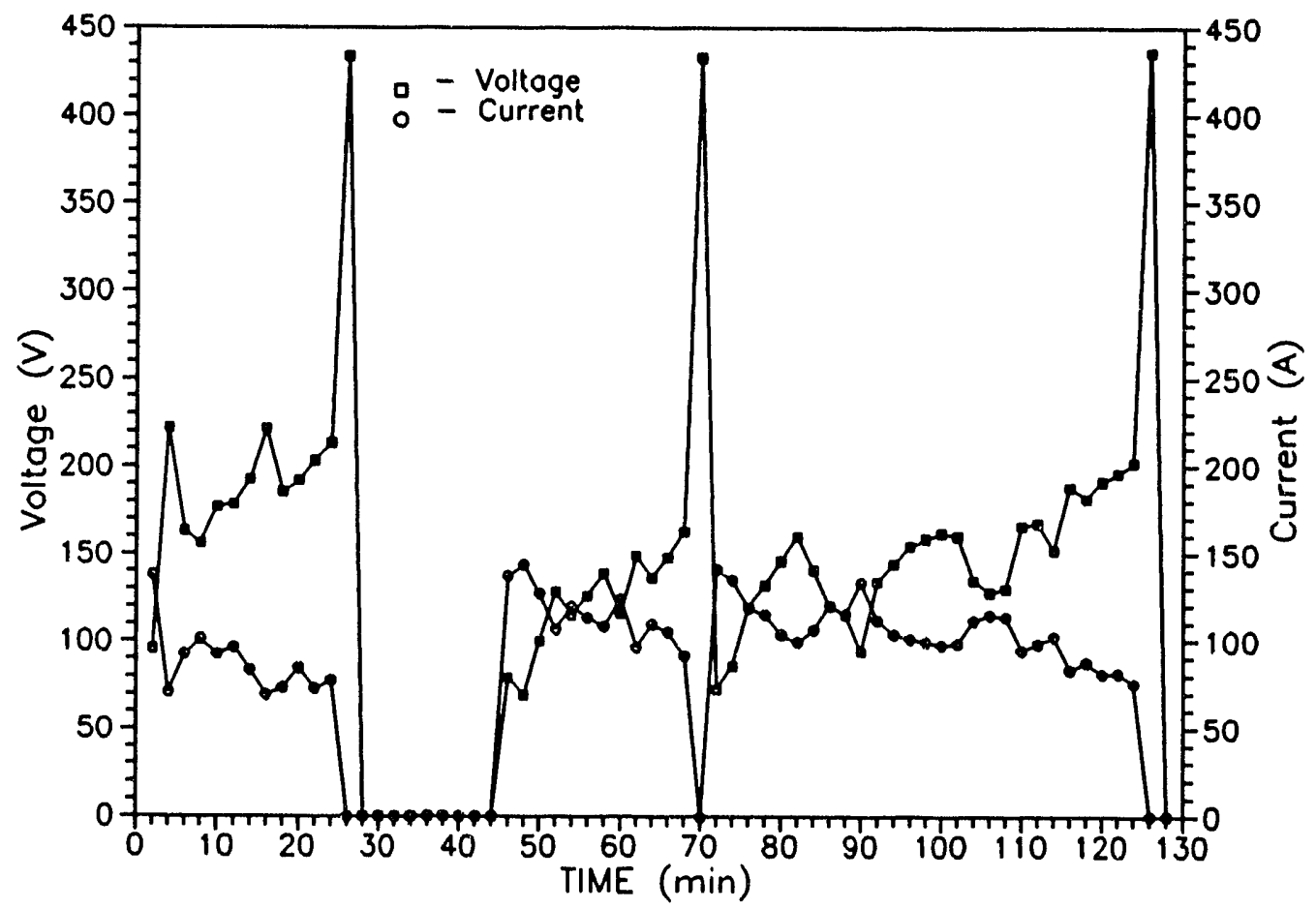

Figure 27. Current-voltage response of the arc melter for Test $10 \mathrm{~b}$ on IEB4/H-series. 


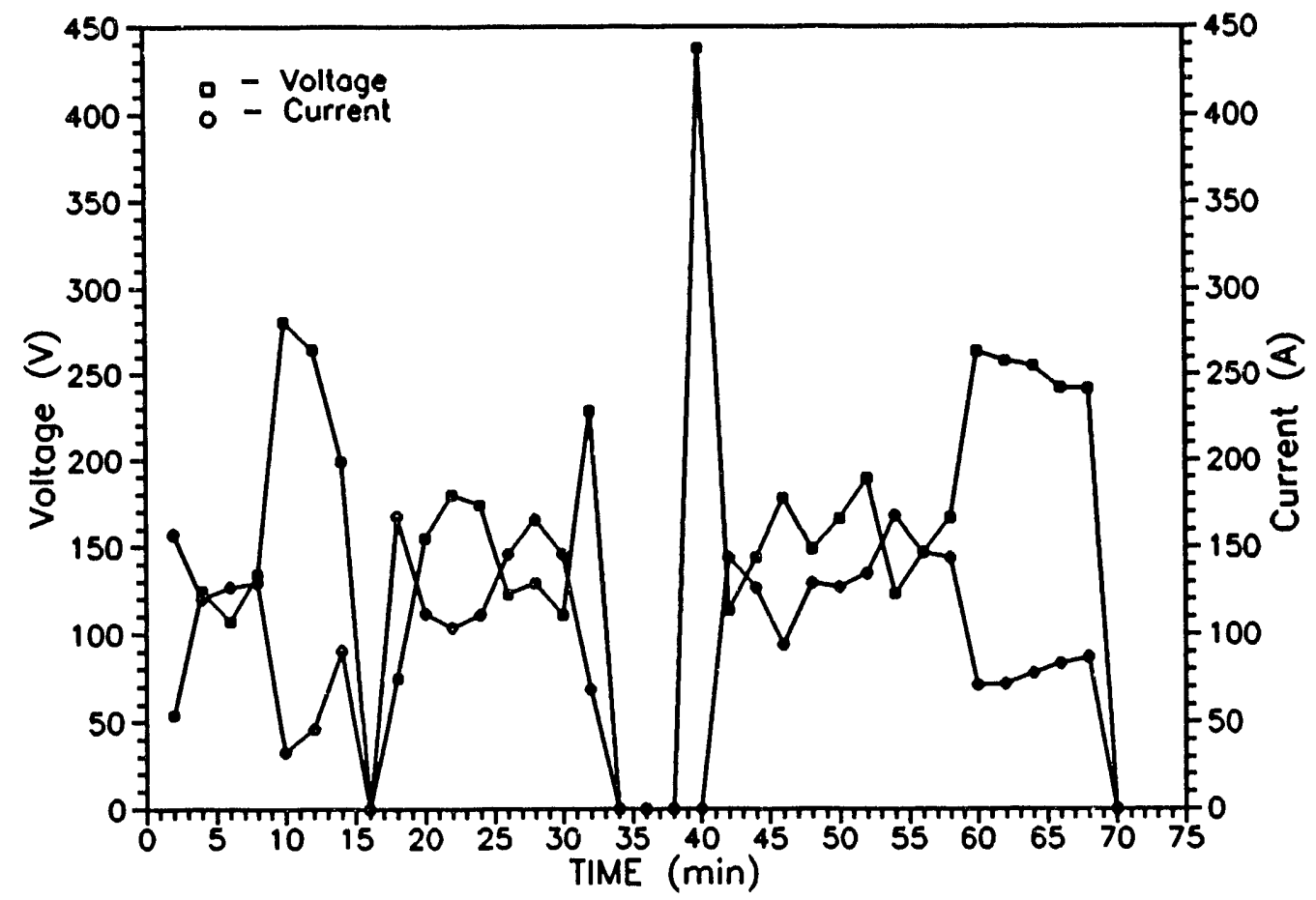

Figure 28. Current-voltage response of the arc melter for Test 11 on metal dissolution with ambient argon.

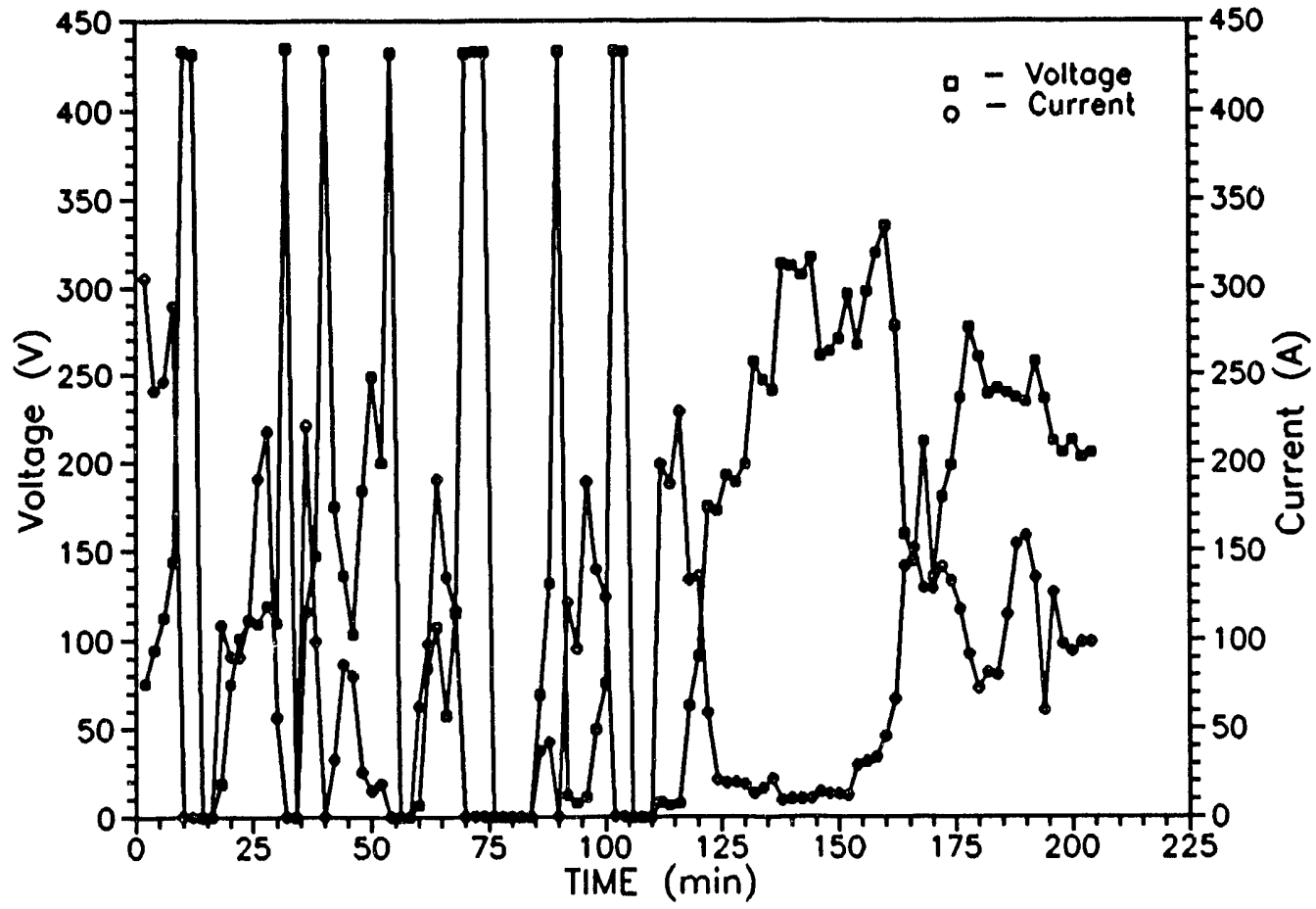

Figure 29. Current-voltage response of the are melter for Test 12 on metal dissolution with ambient air. 


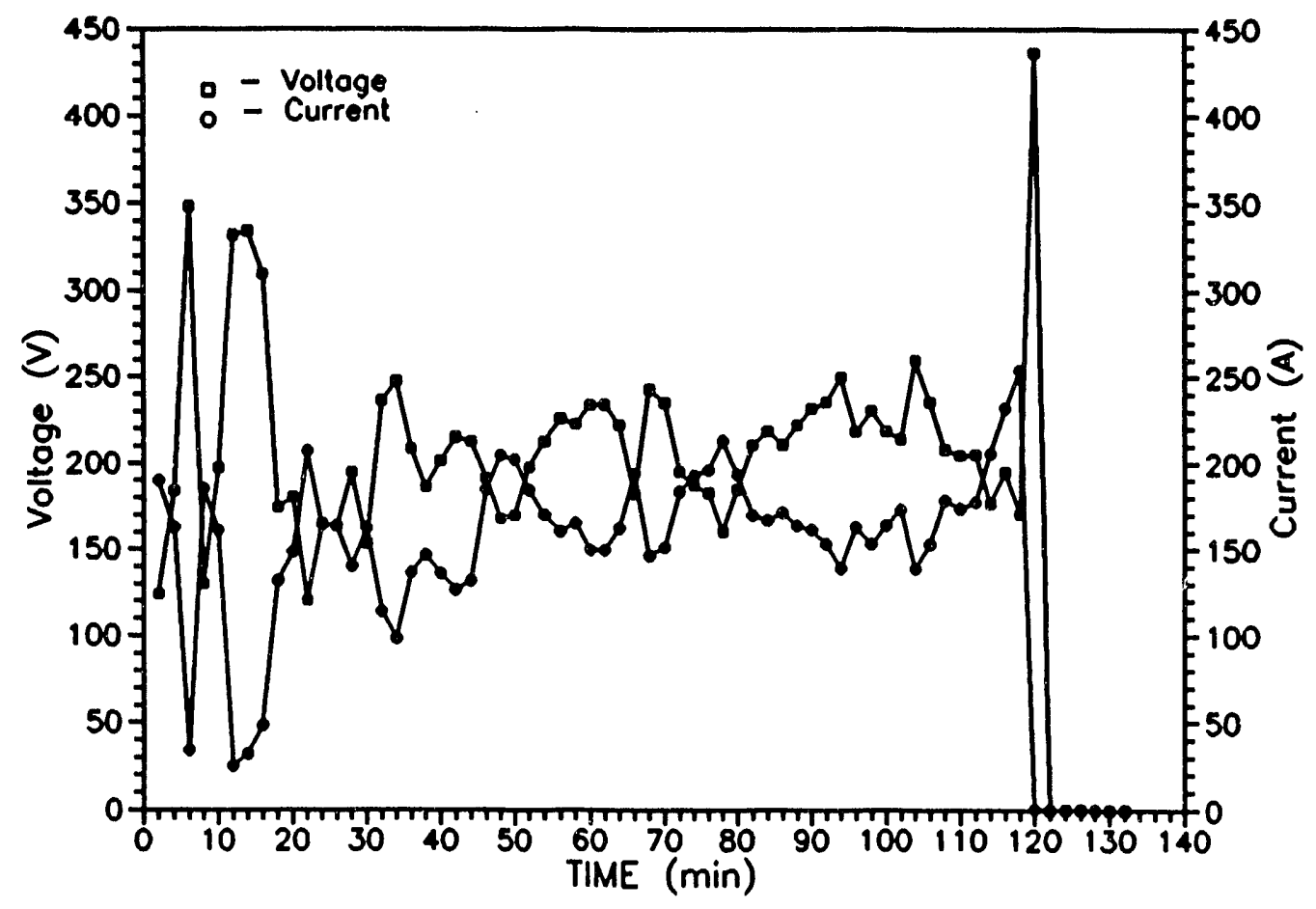

Figure 30. Current-voltage response of the arc melter for Test 13 on metal dissolution with air lance.

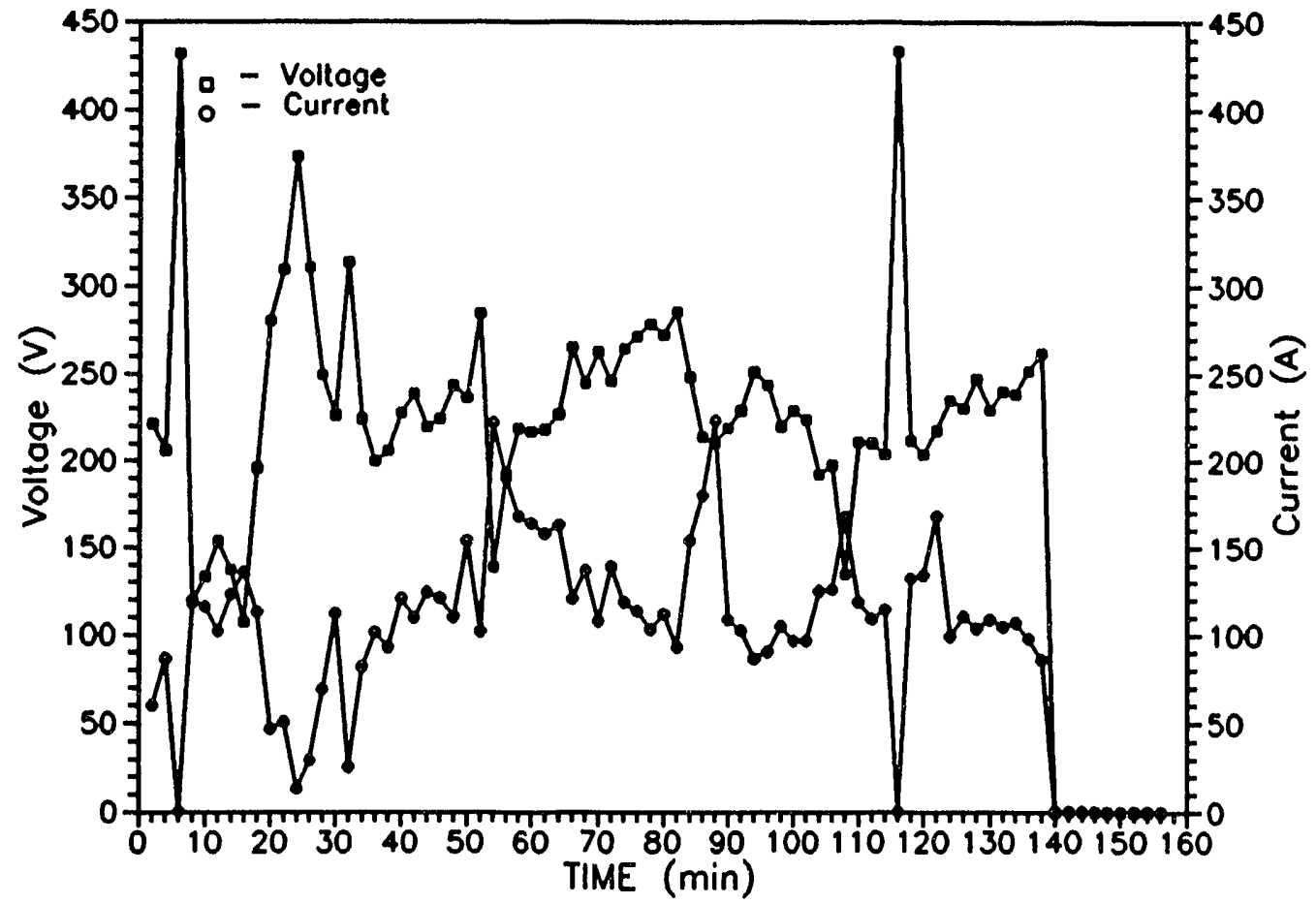

Figure 31. Current-voltage response of the arc melter for Test 14 on silicated organics. 


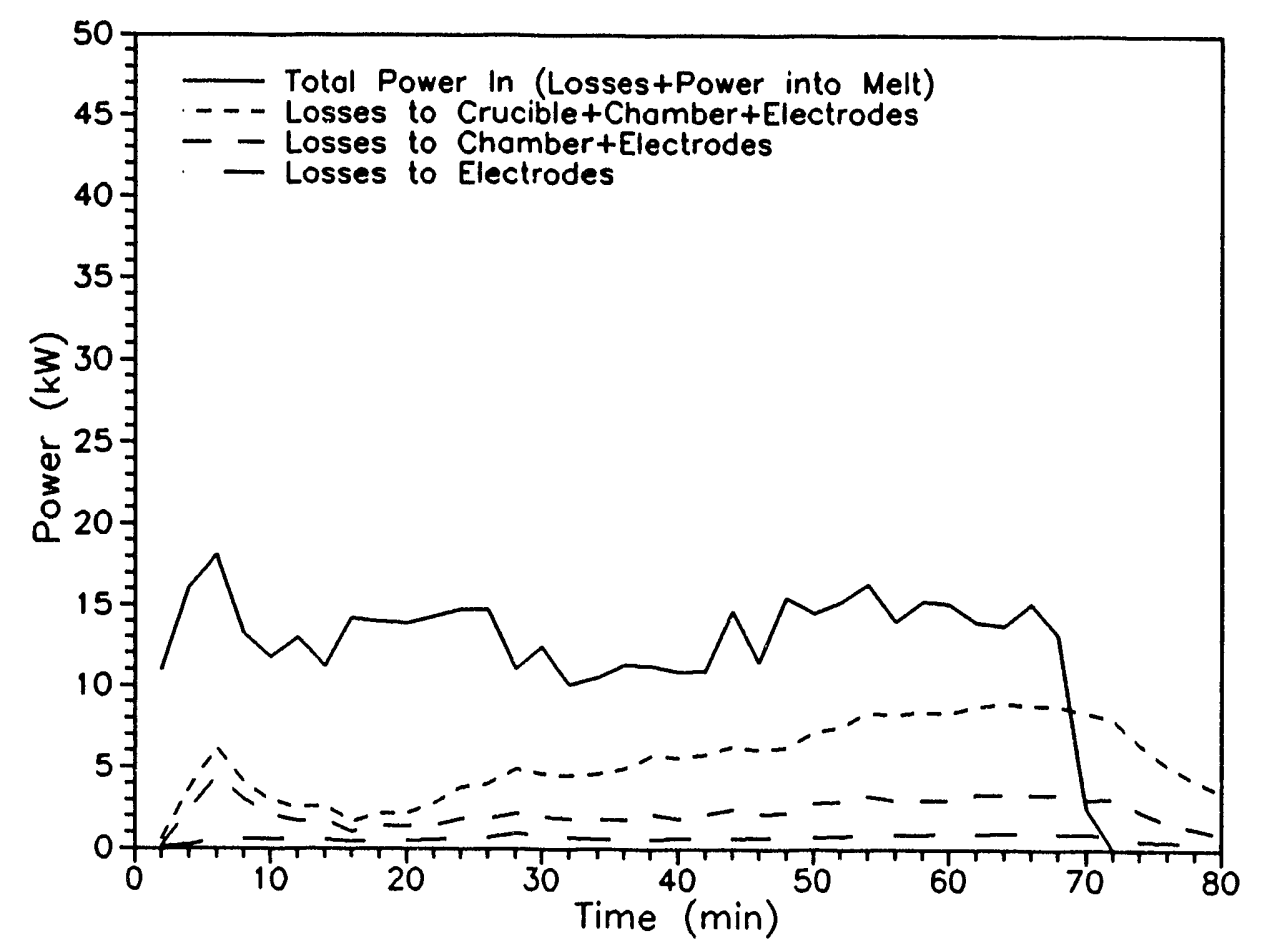

Figure 32. Power input and losses to cooling for Test 8 on IEB/A-100 soil.

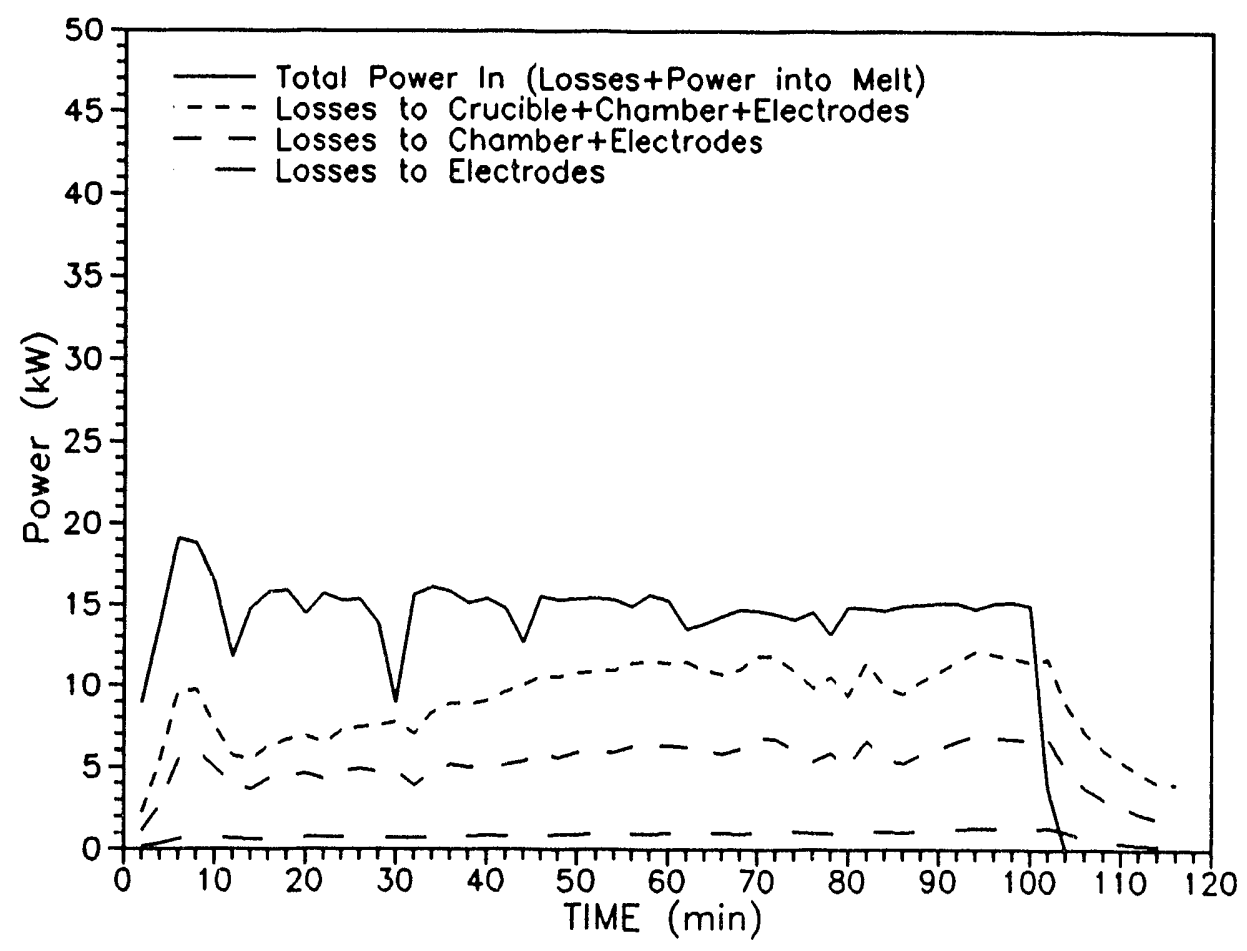

Figure 33. Power input and losses to cooling for Test 9 on IEB4/A-100 soil with $\mathrm{ZrO}_{2}$ and $\mathrm{TiO}_{2}$. 


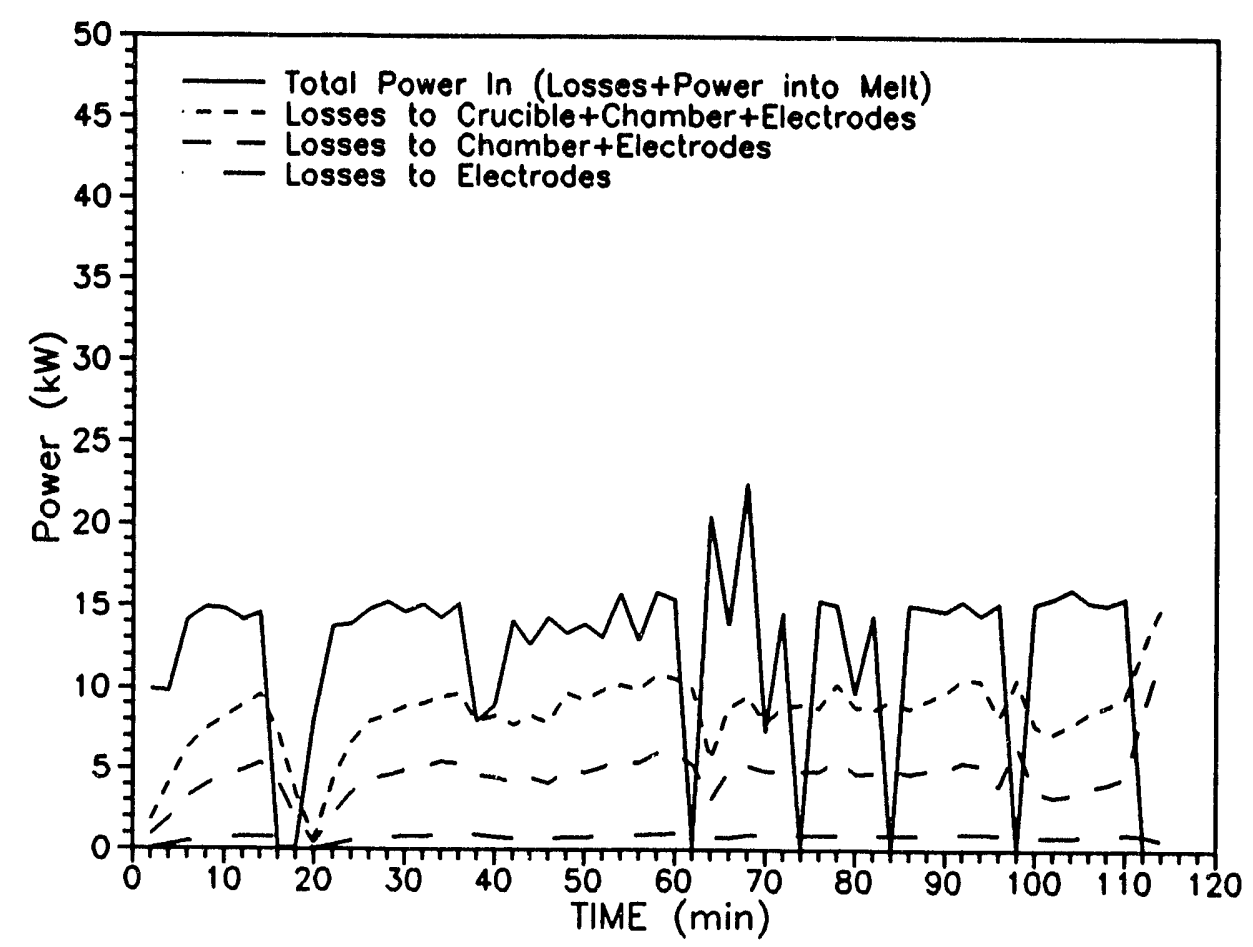

Figure 34. Power input and losses to cooling for Test 10a on IEB4/H-series.

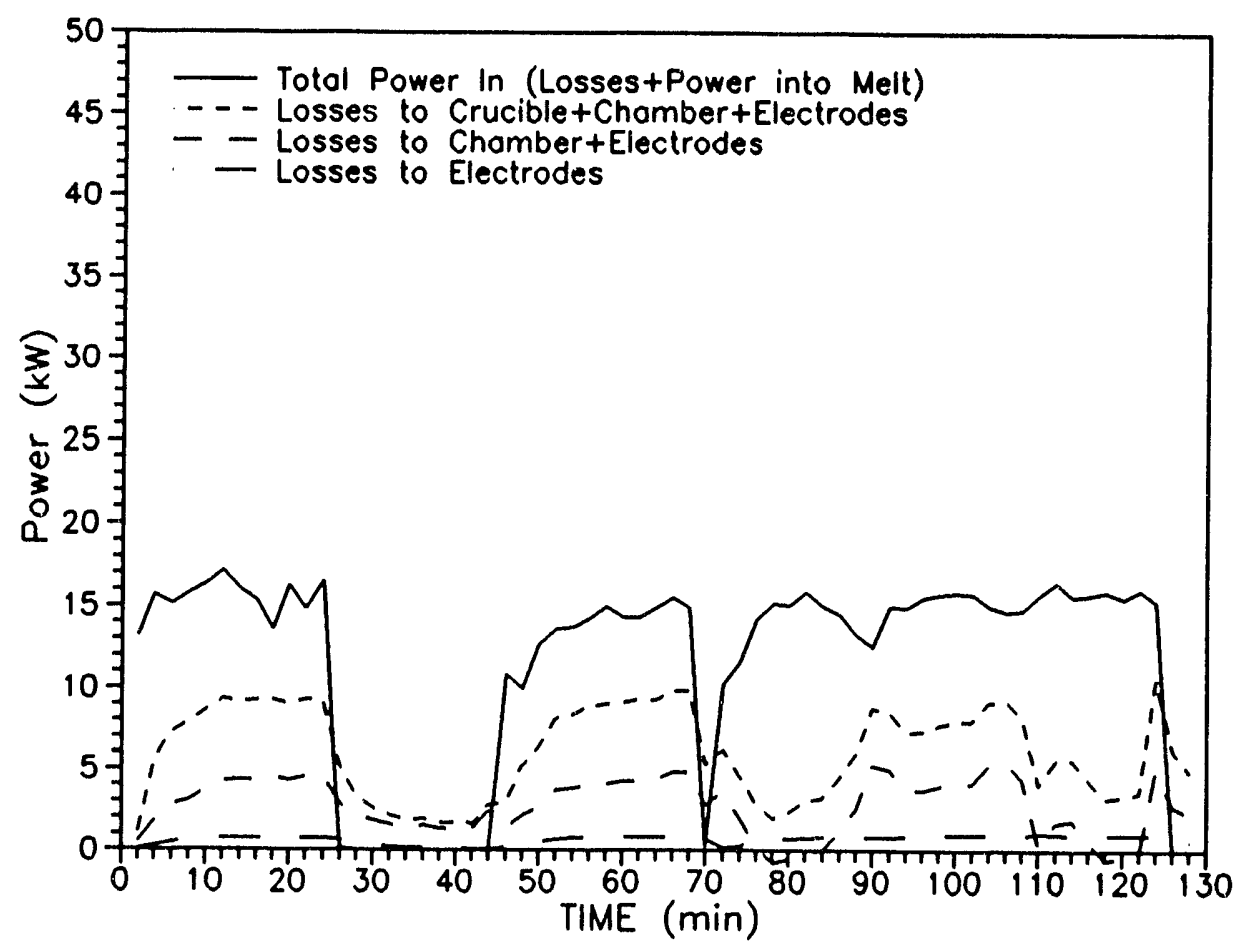

Figure 35. Power input and losses to cooling for Test $10 \mathrm{~b}$ on IEB4/H-series. 


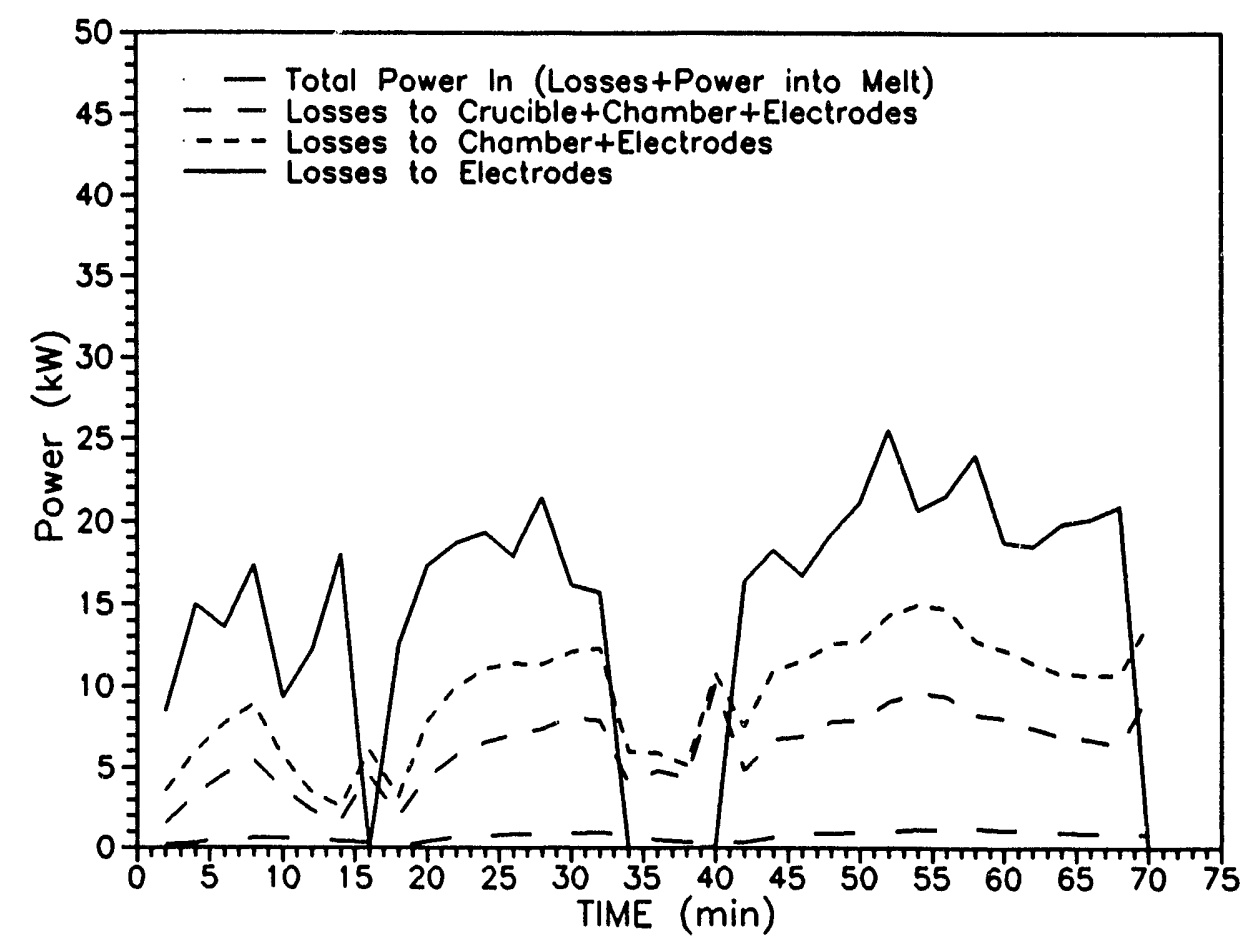

Figure 36. Power input and losses to cooling for Test 11 on metal dissolution with ambient argon.

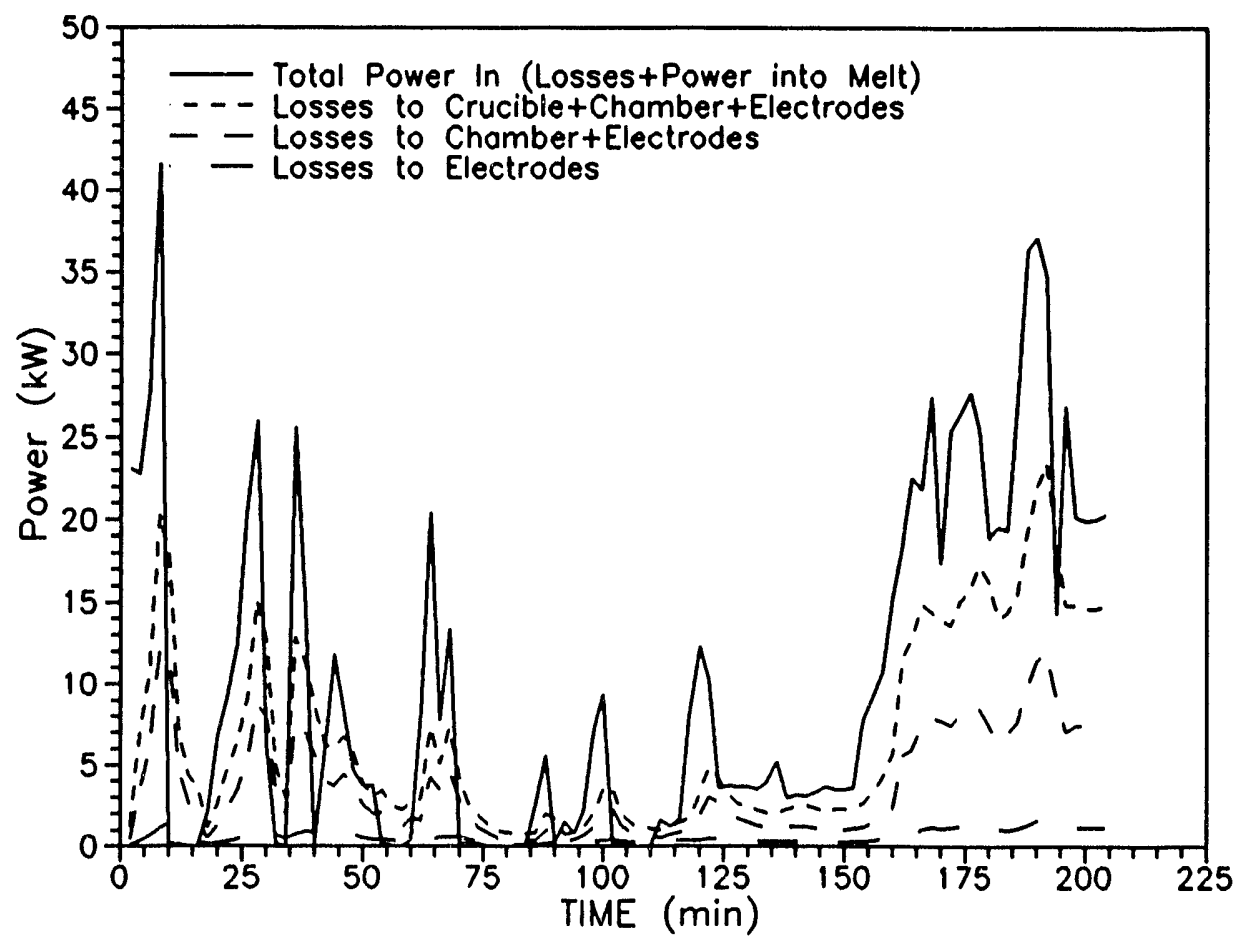

Figure 37. Power input and losses to cooling for Test 12 on metal dissolution with ambient air. 


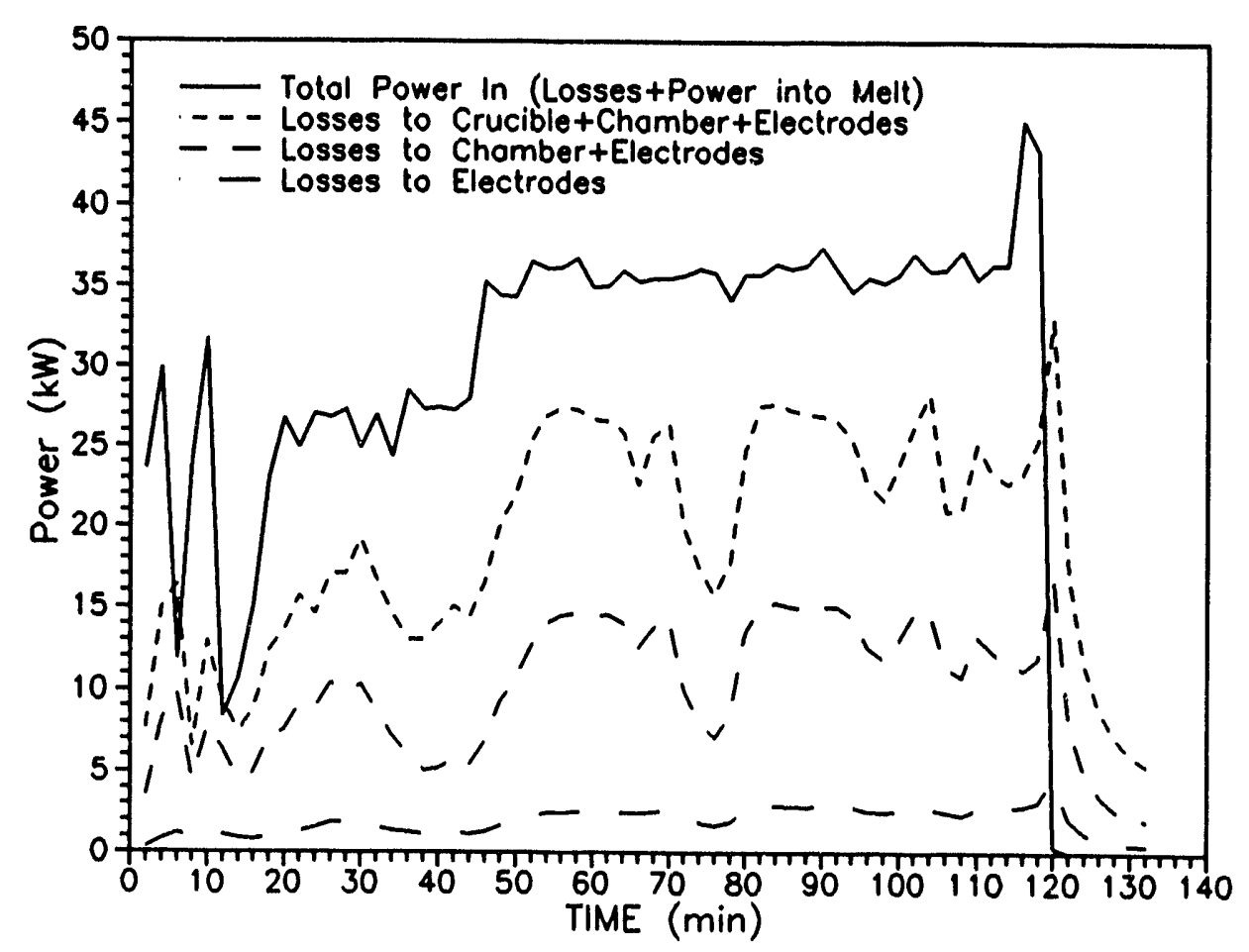

Figure 38. Power input and losses to cooling for Test 13 on metal dissolution with air lance.

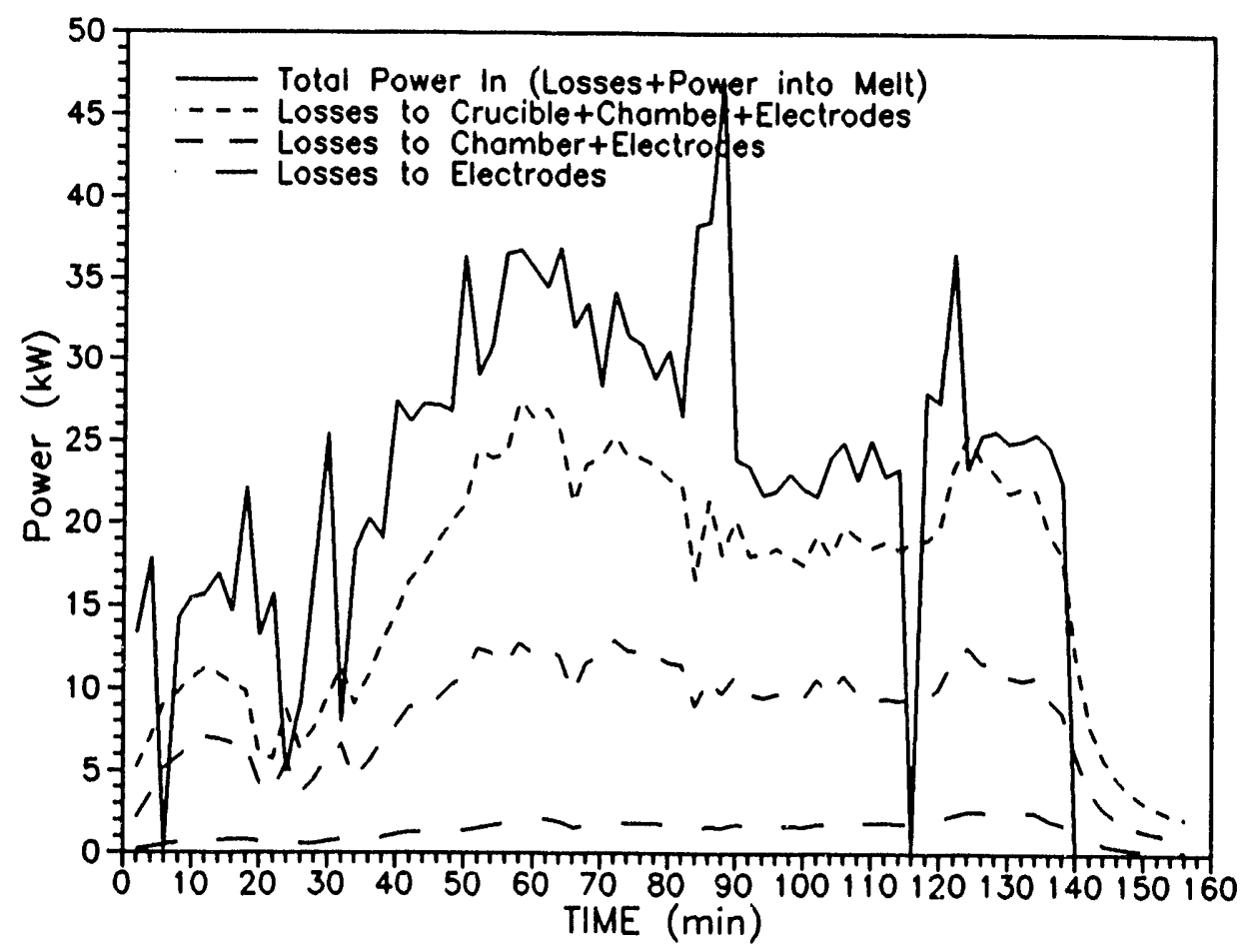

Figure 39. Power input and losses to cooling for Test 14 on silicated organics. 
significant variations. The obvious dips in the curves are the result of soil additions during the course of the experiment. When soil is added, the melt is cooled and energy is used in melting the extra soil. This has the effect of temporarily reducing cooling water losses and effectively increasing the amount of energy input into the melt.

Figures $40-43$ show soil temperature data as recorded by a thermocouple (TC) placed directly into the soil about 1 in. from the crucible wall and equidistant from the electrodes. The type $\mathrm{C}$ thermocouples are surrounded by a ceramic sheath for protection, although once the soil becomes melted around the thermocouple, eventually the ceramic will melt along with the thermocouple. As seen from the tests for which data were available, temperature remains quite low until the melt pool actually reaches the TC. The TC then records a rapid rise in temperature to about $1,500-1,600^{\circ} \mathrm{C}$, which is followed by failure. The Test 8 temperature profile is similar to Tests 6 and 7 (Figure 15 and Figure 16) where a temperature plateau occurs around $1,300^{\circ} \mathrm{C}$ before increasing to higher temperatures. The plateau may be due to a change of phase. In the case of the high power Tests 13 and 14, the TCs were completely incorporated into the melt, leaving the wire hanging above the melt. The two TC wires later became fused together, creating another TC that continued to record the temperature just above the melt.

The overall efficiency (power into soil divided by total power) of the arc melter varies considerably for the tests. The average efficiency for Test 8 is about $50 \%$ and is the best result. The efficiency of the remaining tests ranges to as little as $20 \%$ for Test 14 . In general, two parameters seem to affect the efficiency. In Test 8 , the efficiency is quite good at the heginning of the test $(\approx 70 \%)$ and decreases gradually to approximately $35 \%$ as the test progresses. This phenomenon is likely due to the insulating effects of the surrounding unmelted soil in the beginning of the test. As the melt pool comes closer to the edge of the steel crucible, more and more heat is lost to the cooling water. This same effect is seen in the other tests, but to a lesser extent. The other obvious parameter controlling arc melter efficiency is the total input power. While increasing the power seems to increase the amount of energy going into melting the soil (see Test 13 results), the overall efficiency goes down.

Recommendations for improving the arc melter efficiency would fall into two categories: physical modifications to the arc melter and arc melter operation. Physical modifications are limited, since they imply reducing cooling water losses by less effective cooling, but yet the cooling is necessary to prevent damage. Energy losses to the electrodes are relatively small but necessary to pu nt melting of the metal holders. Attempting improvements here would not be worthwhile. The energy losses to the are melter chamber are due primarily from radiant heat transfer directly from the melt to the chamber walls and the water cooled heat shield installed in the top of the chamber. Little can be done to prevent these losses. As indicated in Test 8 , the addition of refractory insulation would be a key factor in reducing losses to the crucible cooling water during advanced stages. A refractory (ceramic) insert for the SS crucible is planned for the next series of tests. As indicated by the energy balance data, operational methods of increasing efficiency are to operate at low or moderate power levels, if possible. Tests 10 and 13, in which simulated waste or soil were introduced during the test, seem to suggest a highly efficient method of operation. When the materials were dropped into the melt, cooling water losses plummeted; and most of the input power went into melting the additions. Thus, the best method of operation would be to start with a small melt, then add material continuously. Since a continuous feed 


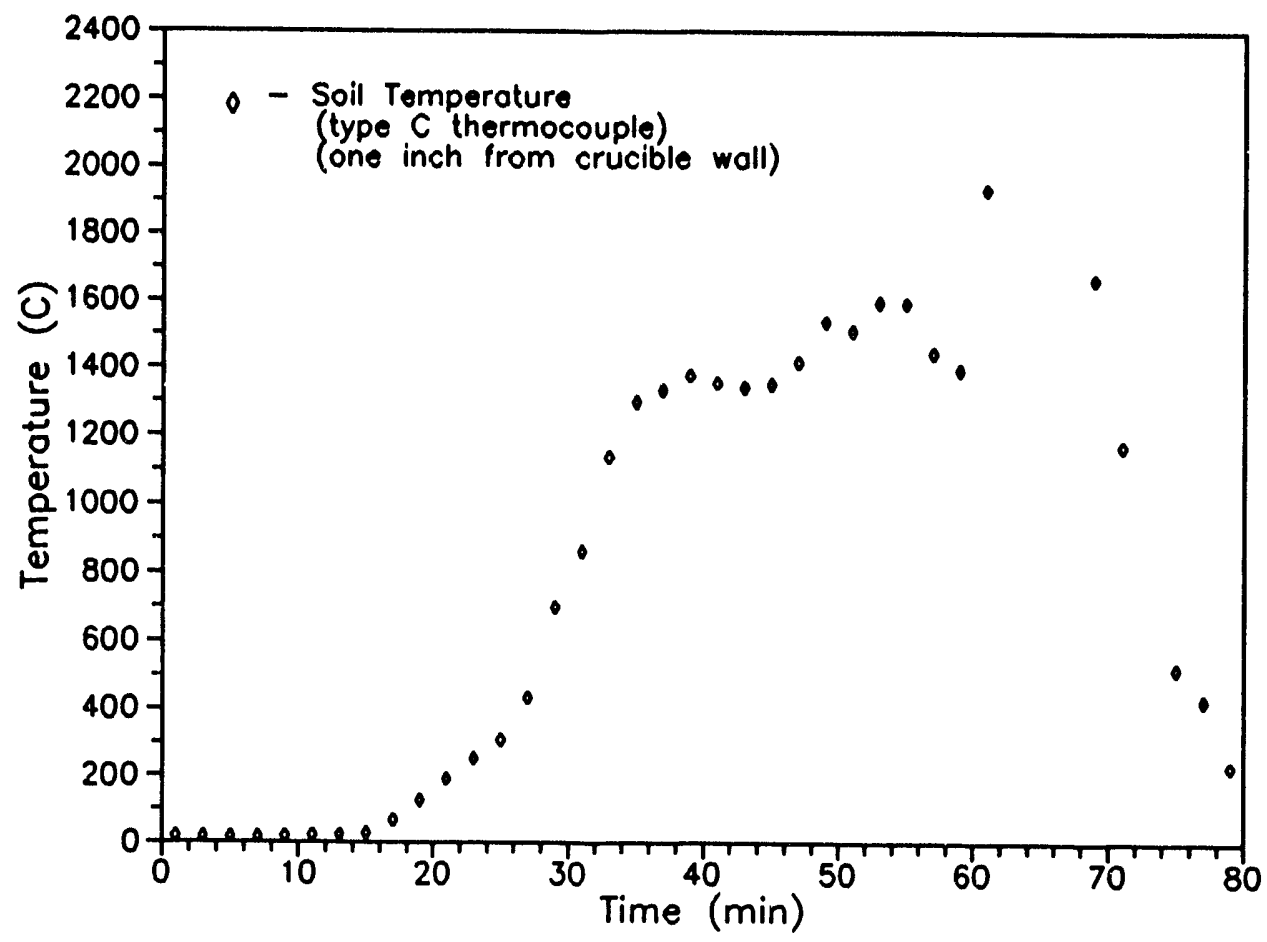

Figure 40. Soil thermocouple temperature as a function of time for Test 8 on IEB/A-100 soil.

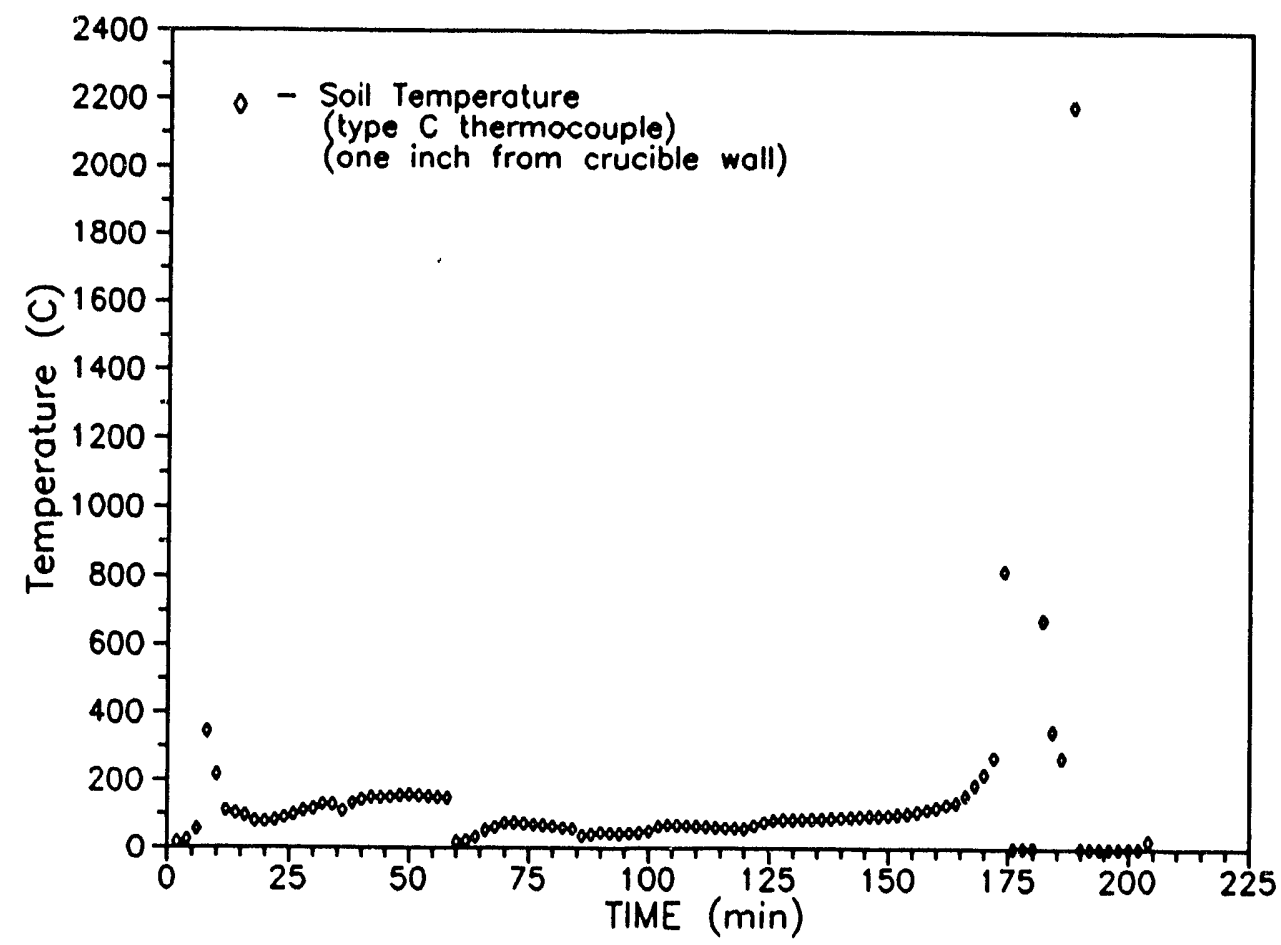

Figure 41. Soil thermocouple temperature as a function of time for Test 12 on metal dissolution with ambient air. 


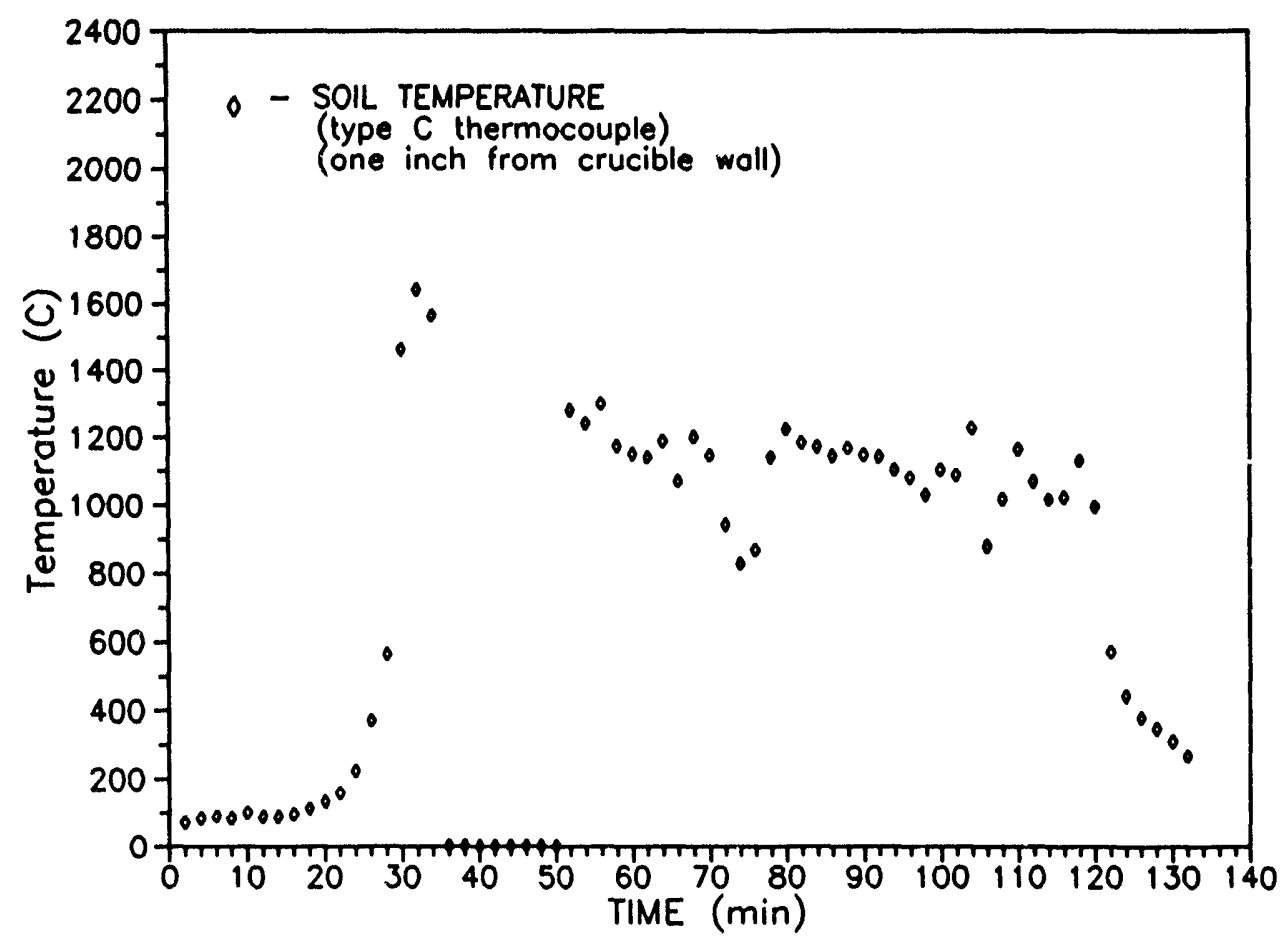

Figure 42. Soil thermocouple temperature as a function of time for Test 13 on metal dissolution with air lance.

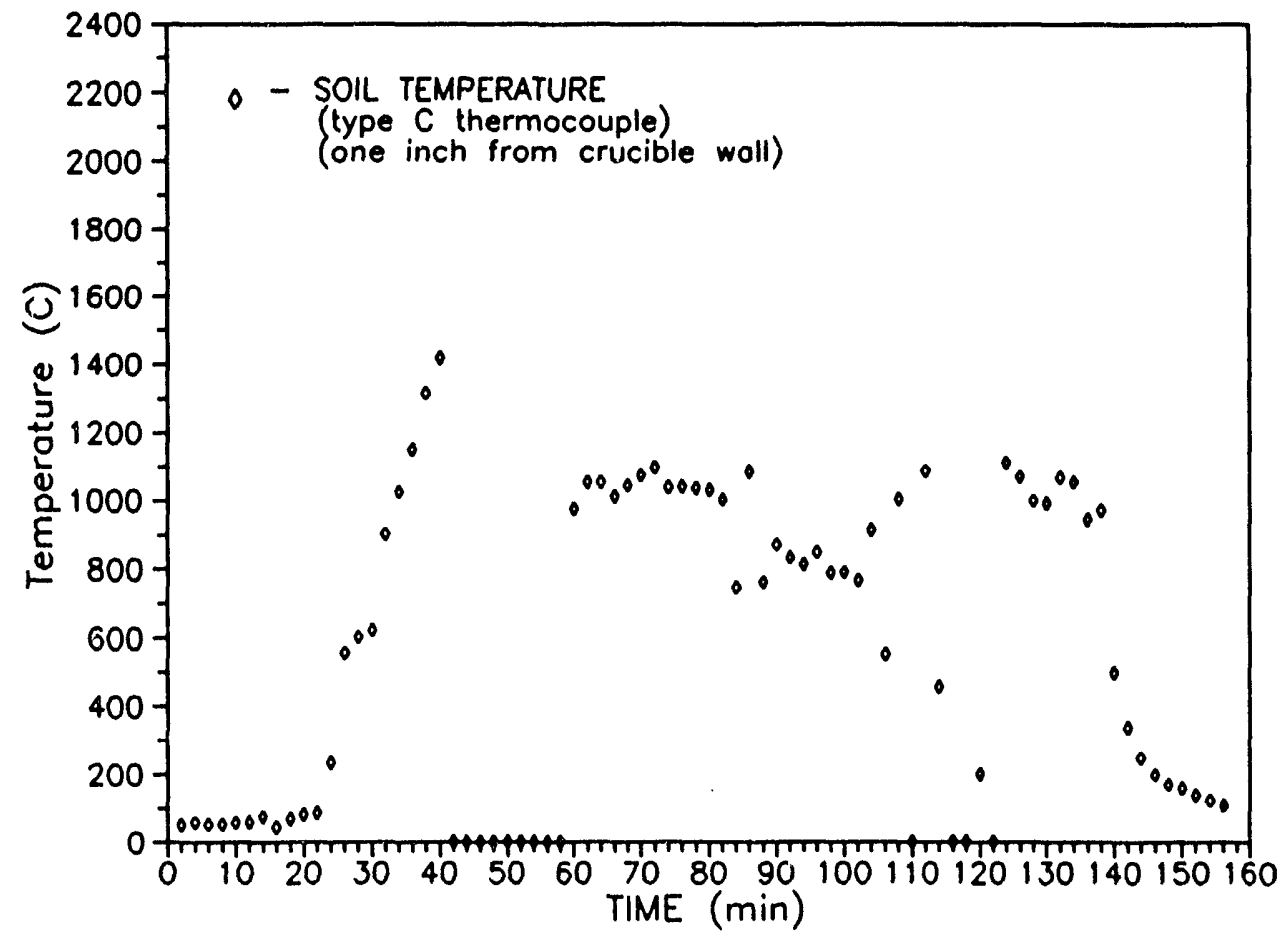

Figure 43. Soil thermocouple temperature as a function of time for Test 14 on silicated organics. 
melter system is planned for future waste reduction activities, it would only remain to do testing on the actual system to determine the optimum feed rate for highest efficiency.

\subsection{Materials Characterization}

\subsubsection{Introduction}

The aic melter vitrified waste forms were characterized with X-ray difiraction and scanning electron microscopy. The analysis was performed to determine the general composition and features of the waste forms produced from the arc melter initial shakedown and preliminary capability tests.

In Phase I, preliminary microstructure characterization had been performed on the IEB/A-40 and IEB4/A-40 glass-ceramic waste forms. In Phase II, arc melter capability tests had been carried out for processing of pure soil, IEB4/A-100 soil, simulated silicated organics, hydrated metal oxide sludges, and dissolution and oxidation of metals. These waste forms produced are glassy.

\subsubsection{Pure Soil (A-100)}

The melted slag from some of the initial tests was characterized to learn more about the waste form phase structure under these portially melted conditions. From Test 3, the pure soil (IEB/A-100) waste produced using the dumbbell graphite starter was examined io determine the effect of the graphite in direct contact with the melt. A small sample at the graphite and vitrified mass interface was analyzed by SEM (Figure 44, \#0018). Due to fast cooling rates of the melt in the water-cooled crucible, the waste form is highly glassy. A small diffusion zone with high carbon content , upper light gray region) has beer, detected next to the graphite (lower dark gray region) in the glass. Within the graphite, there is a few metal-like spheres. From EDS analysis, these spheres are found to be high in Fe (Figure 45, Spot 1, \#0034) and are formed by carbon reduction of the iron oxide in the soil. Figure 45 also shows regions (Spot 2) close to a particle exhibit higin $\mathrm{Fe}, \mathrm{Si}$, and low $\mathrm{Al}$ in the matrix. This matrix also has a very high carbon content because of the proximity of the graphite dumbell. In a small glassy region (Figure 46, \#0028), where carbon diffusion is relatively high, a relatively large number of similar metal-like spheres were also observed. EDS analysis (Figure 47, top photo, Spot 3, \#0037) shows that these spheres also contain high Fe composition and a mode : te amount of Si. These spheres are probably alloys of Fe and Si formed by carbon reduction of the melt. Spot 4 (Figure 47, bottom photo, \#0039) shows a very high silica phase, with a moderate amount of $\mathrm{Na}$ oxide (12.25\%). In this pure soil waste form, only glassy phases were observed. The buried dumbbell graphite starter in the soil affects the oxidation (redox) state of the melt and reduces the iron oxide in the soil to Fe. Under the high temperature of the melt, some $\mathrm{SiO}_{2}$ was also reduced to $\mathrm{Si}$ by the carbon. This condition is not iavorable for the waste form properties and is one of the reasons that nonimmersible electrodes were selected. When graphite is part of the input waste stream, air or oxygen will have to be added to maintain a desirable redox condition. 


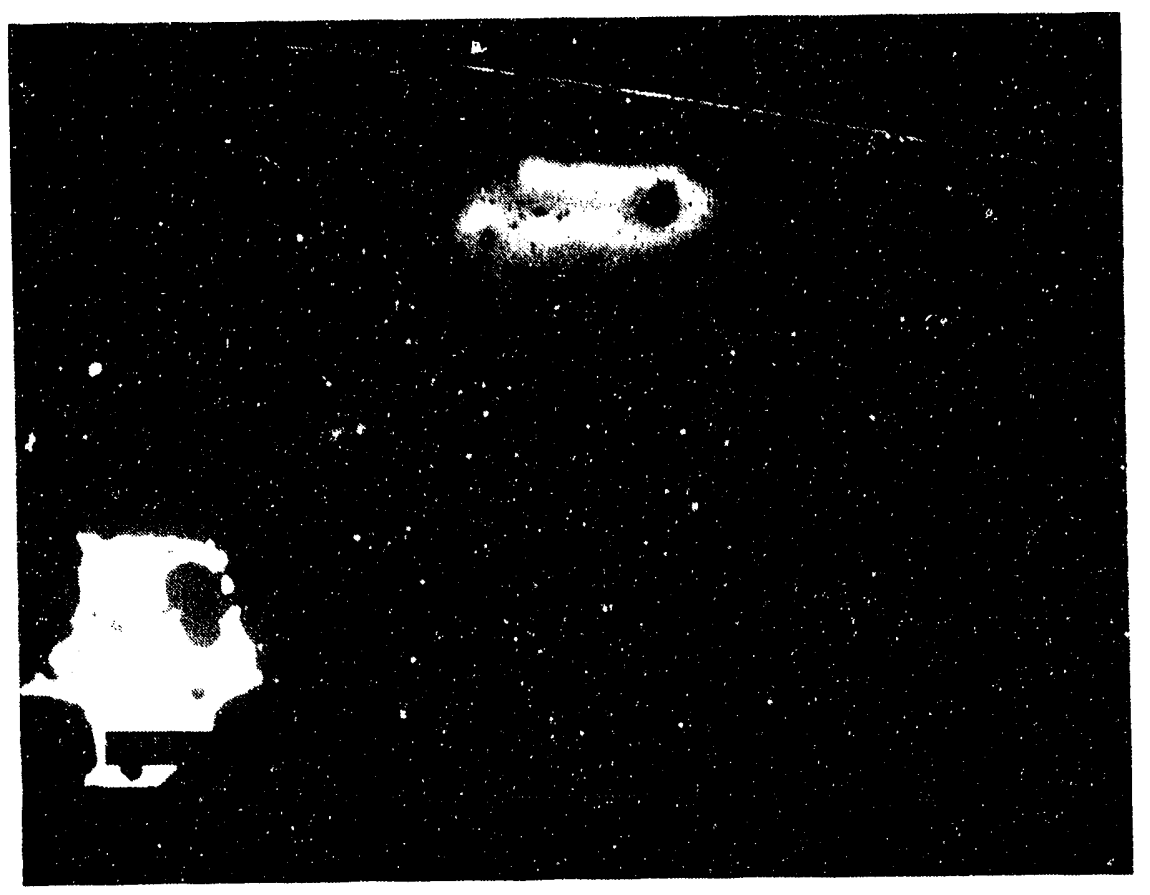

Figure 44. SEM micrograph of the pure soil IEB/A-100) waste form produced in Test 3.

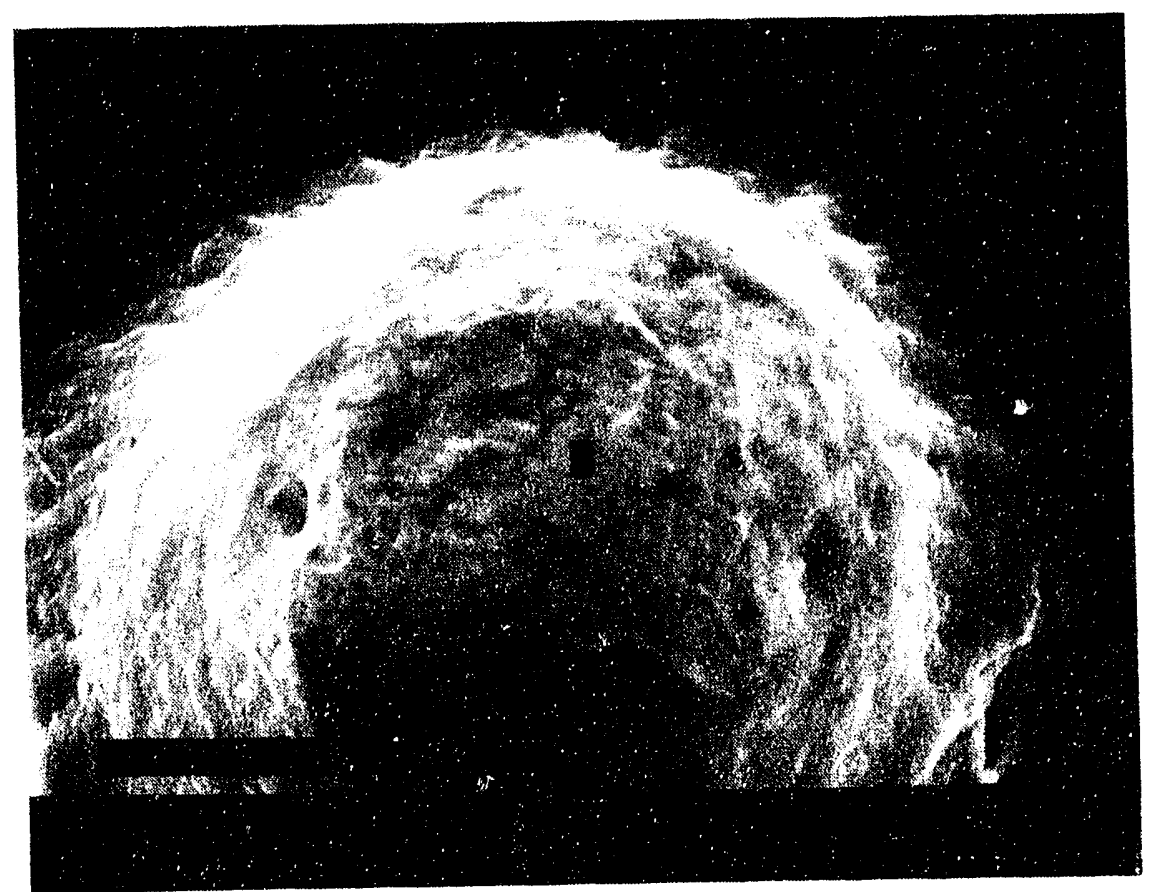

Figure 45. SEM secondary electron image of a metal-like sphere in the graphite (Test 3). 


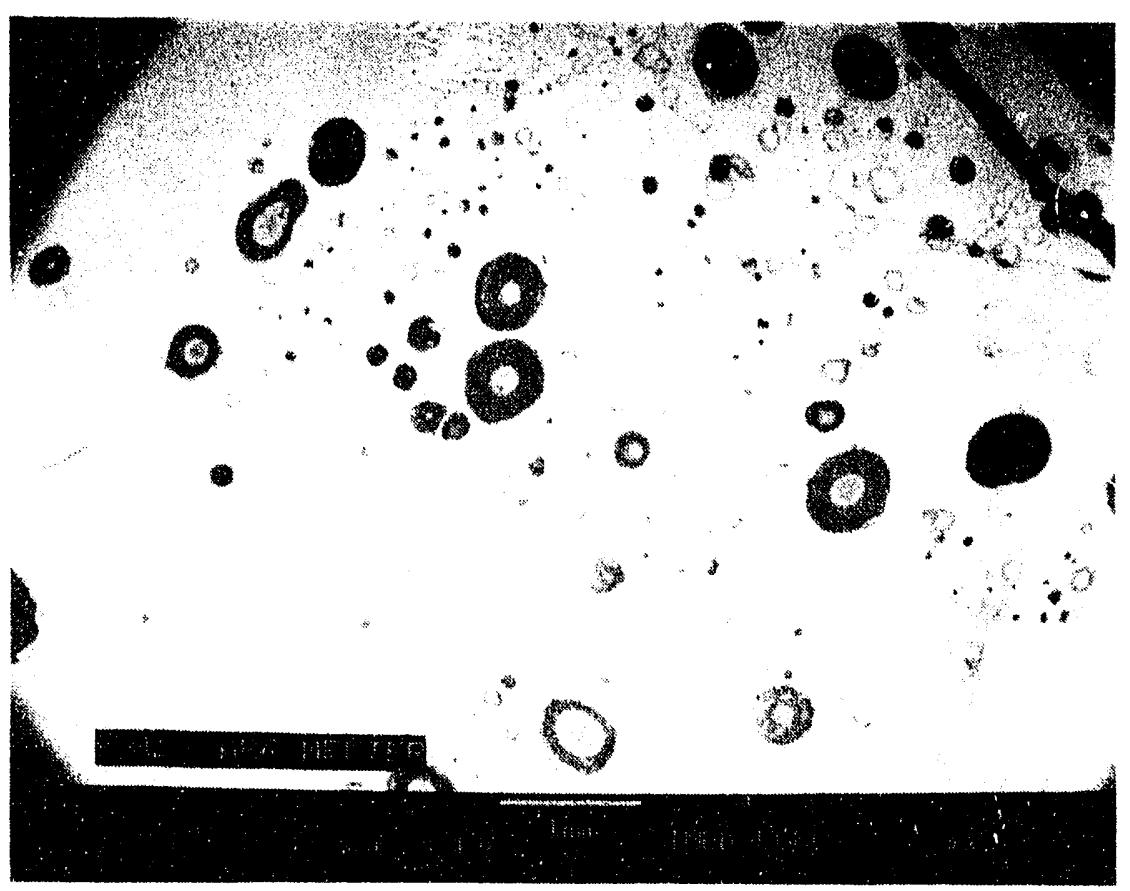

Figure 46. Metal-like spheres in the glassy region with relatively high carbon diffusion (Test 3). 

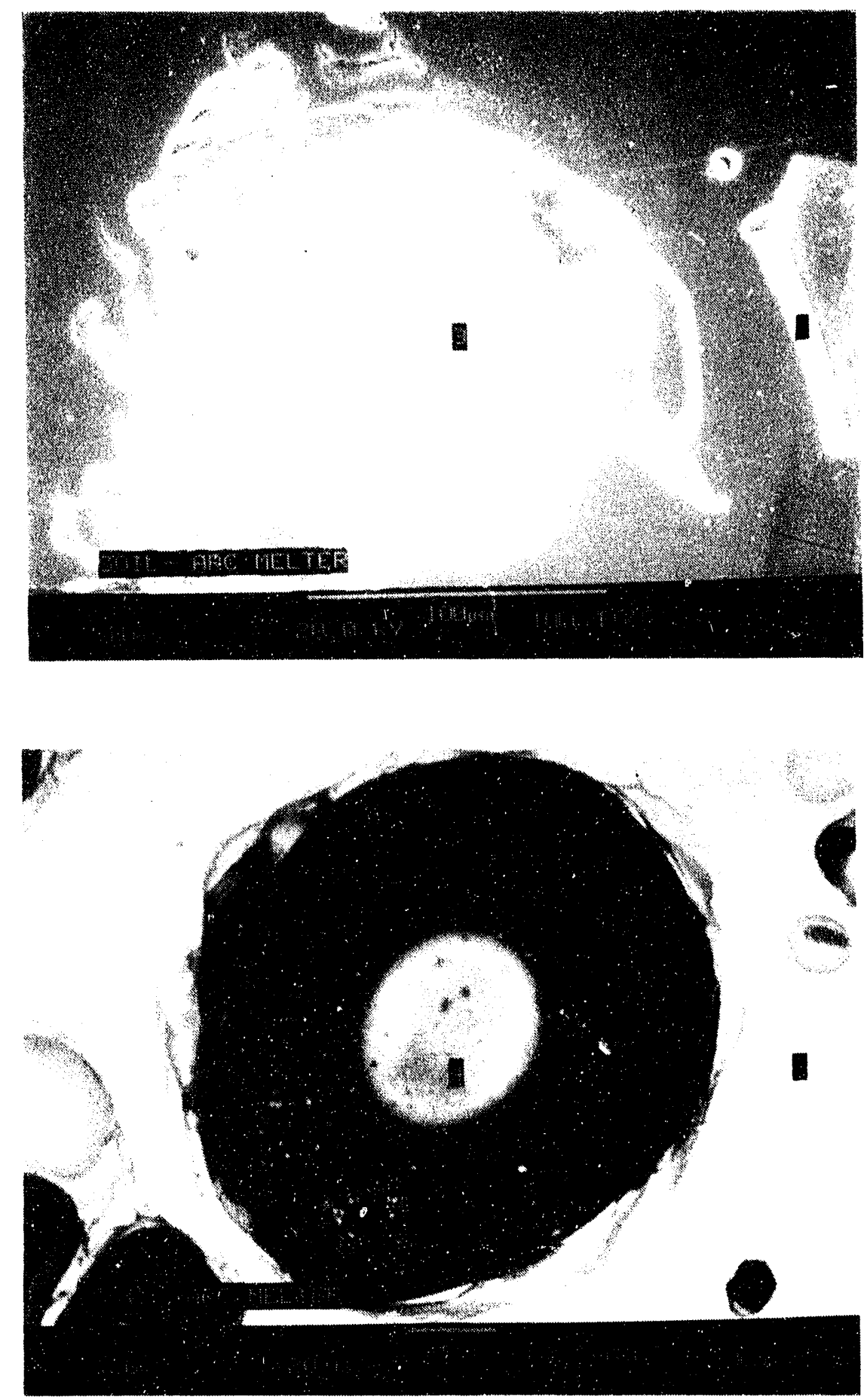

Figure 47. Composition of the metal-like spheres in the glassy region with relatively high carbon dillusion (Test 3). 


\subsubsection{IEB/A-40}

Optical microscopy, SEM, and X-ray diffraction analyses were performed on the IEB/A-40 waste form obtained from the arc melter. Figure 48 is the optical appearance of waste form chunks. The waste form consists two distinct layers, a very shiny glass phase, and a shiny rock-like (highly crystalline) phase. The glass phase forms between the thin skull $(<2 \mathrm{~mm})$ and the crystalline phase. The thickness $(<12 \mathrm{~mm})$ of the glass phase indicates a severe temperature gradient across the material. $\mathrm{X}$-ray diffraction of the more crystalline phase revealed the presence of augite $\left\{(\mathrm{CaFeMg}) \mathrm{SiO}_{3}\right\}$ and diopside $\left\{\mathrm{CaMg}\left(\mathrm{SiO}_{3}\right)_{2}\right\}$ pyroxenes, and magnetite spinel $\left(\mathrm{Fe}_{3} \mathrm{O}_{4}\right)$ as major phases. Thes major phases "are known that, from their observed durability, would appear to be either thermodynamically stable in common geochemical environments or slightly unstable but with very low rates of alteration or dissolution." ${ }^{25}$ Minor pyroxenes such as fassaite $\left\{\mathrm{Ca}(\mathrm{MgFeAl})(\mathrm{SiAl})_{2} \mathrm{O}_{6}\right\}$, aluminian diopside $\left\{\mathrm{Ca}(\mathrm{MgAl})(\mathrm{SiAl})_{2} \mathrm{O}_{6}\right\}$, and a minor residue glass are also present. The $\mathrm{X}$-ray diffraction traces for the more crystalline region is shown in Figure 49. SEM analysis of the more crystalline region is shown in Figure 50, \#0003 and 0007 . The bottom micrograph in Figure 50 shows extensive formation of dendritic pyroxene domains, with bands of magnetite spinels $\left(\mathrm{Fe}_{3} \mathrm{O}_{4}\right)$ nucleated inside the pyroxenes. The spinels are higher temperature melting phase than the pyroxenes; and when the melt cools, the spinels will form prior to the pyroxenes and act as nucleation centers for the pyroxenes. EDS analysis of the domains (Spots 1 and 4) supports the X-ray diffraction results of formation of the pyroxenes and spinels (Spots 2 and 3 ).

\subsubsection{Hydrated Metal Oxide, Metal Dissolution and Oxidation, and Cemented Organic Experiments}

SEM analysis was performed on waste forms for simulated hydrated metal oxides ( $\mathrm{H}-0)$, metallic waste (M-0) dissolution and oxidation, and simulated calcium-silicated (S-0) organics. Similar to the pure soil (A-100) melting tests, the high cooling rates resulted in waste forms that are highly glassy and have iron spheres randomly dispersed throughout the melt. As with the pure soil, carbon in the melt affected the redox state of the melt and reduces the iron oxide in the soil to iron. Figure 51 (\#0212) and Figure 52 (\#0151 and \#0058) show SEM photomicrographs of the glass for each of the waste forms tested. In Figure 51, there are two bright phases associated with the H-90 run. From EDS analysis, the round phase is an iron sphere and the bright irregular shaped particles are likely to be zirconia or zircon. Figure 52 shows the IEB4/M-90 and IEB4/S-90 SEM micrographs for metal dissolution and simulated silicated organics, respectively. The large number of Fe spheres observed in the top photo in Figure 52 is a result of steel shot addition to the melt for metal dissolution tests. The steel shot was totally molten and as a result formed round spheres upon cooling. Because of their size and the convective eddies in the melt, these spheres were trapped in the glass rather than accumulating and fusing into a slug at the bottom of the melter as was observed with larger iron nail and bolt segments. Additional detailed analysis of the waste forms was beyond the scope of this work. Only those crystalline phases observed during the general analysis of the glass were briefly investigated.

In the metal dissolution and oxidation experiment, using an argon atmosphere, small crystallites were formed in the melt. The crystallites are shown in Figure 53 (\#0141). Table 15 shows the associated EDS compositions of the specimens at Spots 2 and 3. The average chemical compositions of the specimen is designated as Ar2-1 in the table, where "1" indicates the spot. 

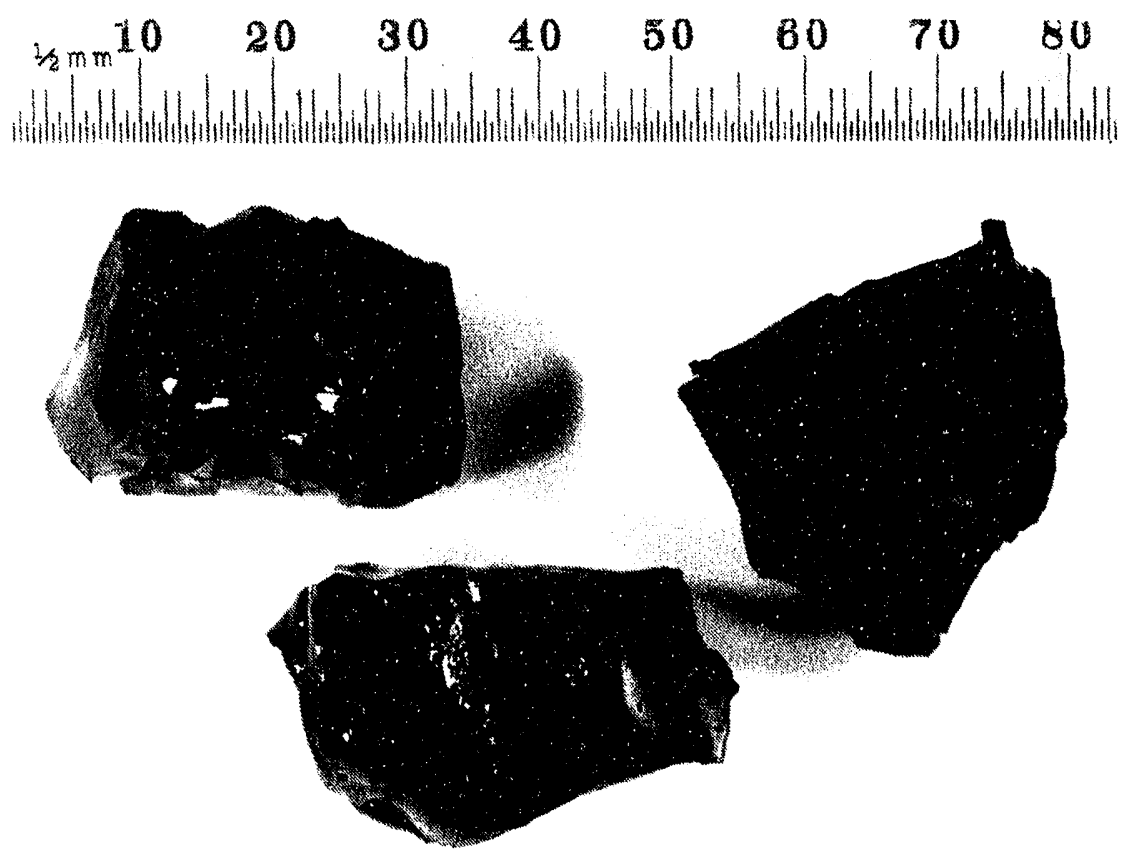

Figure 48. IEB/A-40 waste form chunks produced in the arc melter (Test 6). 


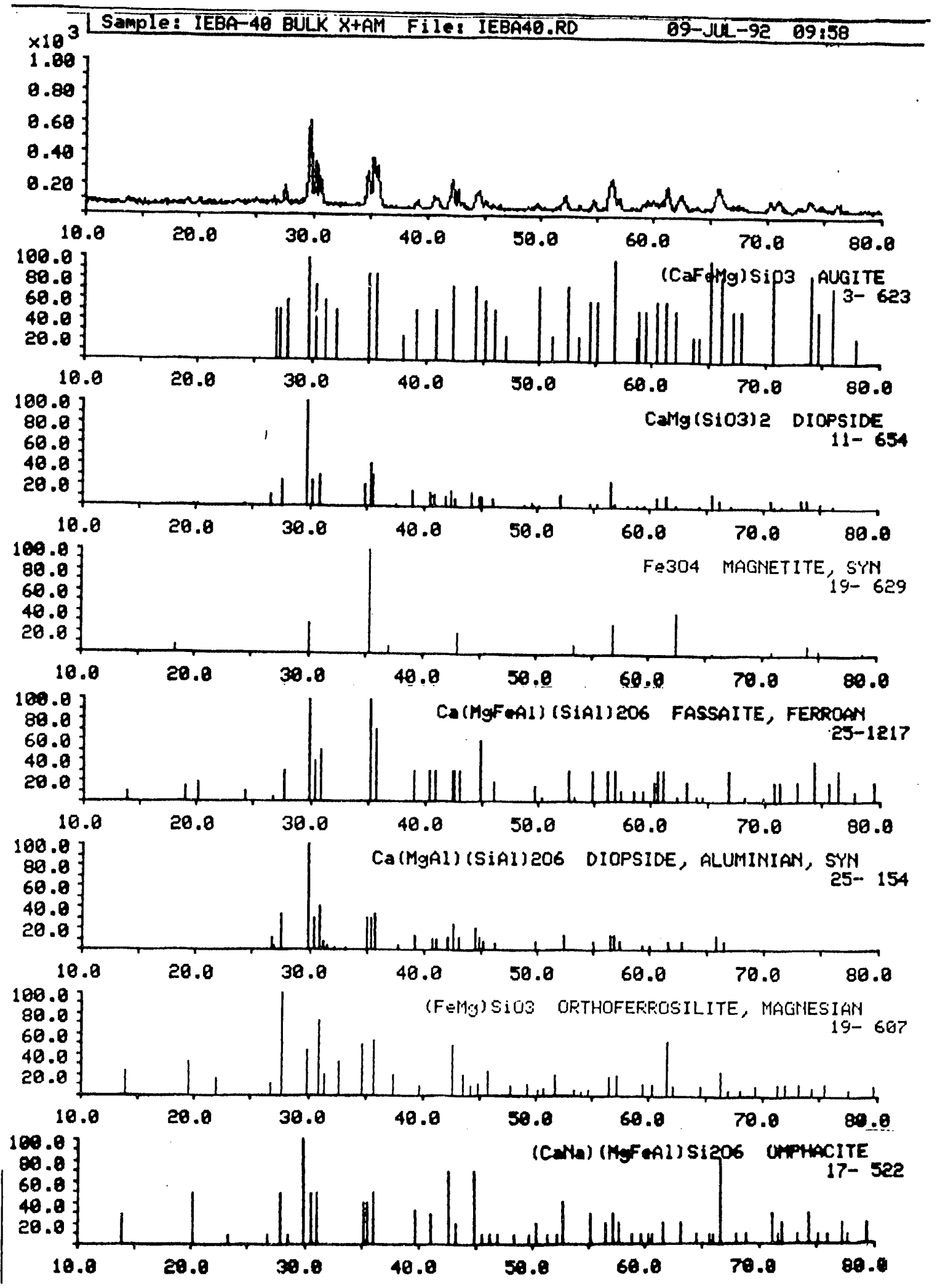

Figure 49. X-ray diffraction trace for the more crystalline region on the IEB/A-40 waste form produced in the arc melter and its possible mineral phases (Test 6). 

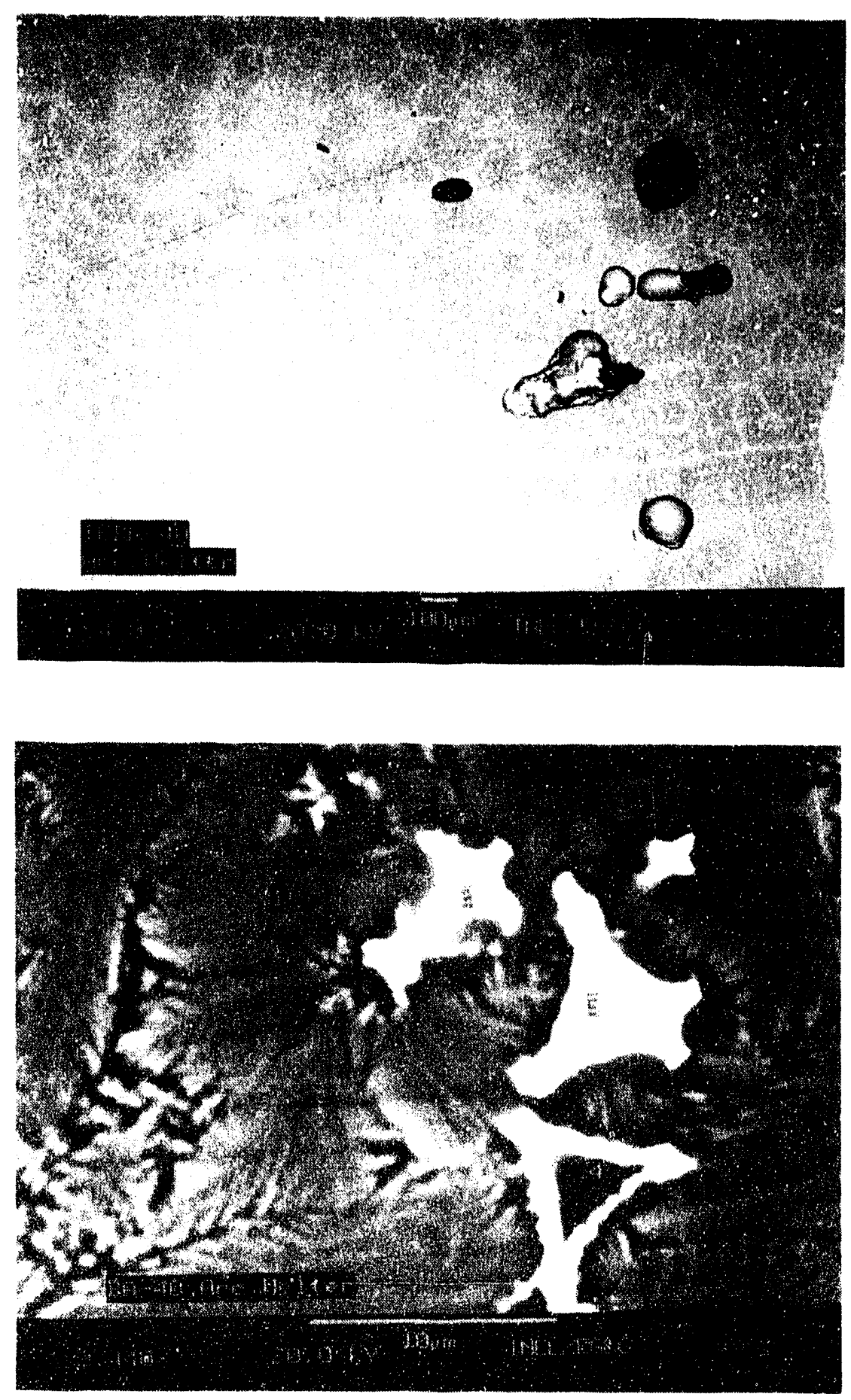

Figure 50. SEM micrographs of the crystalline region of $I E B / A-40$ produced in Test 6. 


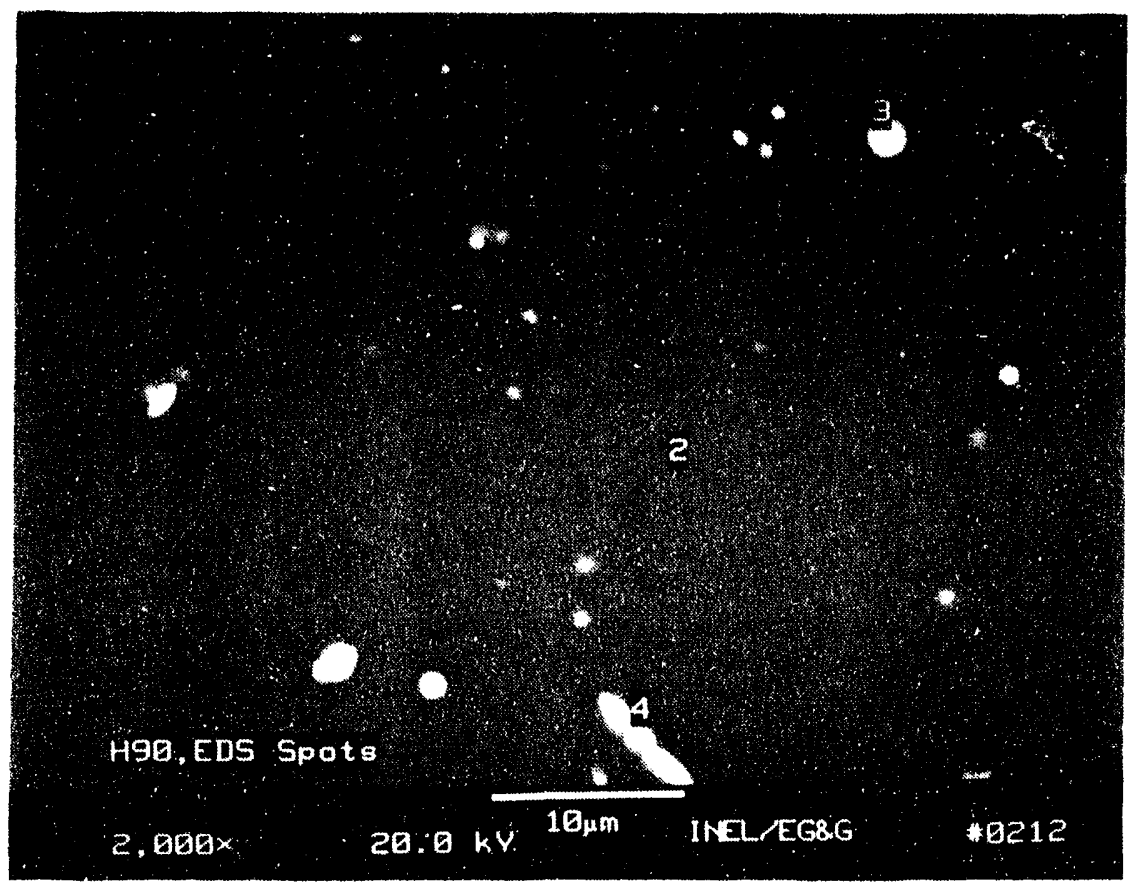

Figure 51. SEM micrograph of the IEB4/H-Y) waste form produced by the hydrated metal oxide: arc melter capability test (Test 10a). 

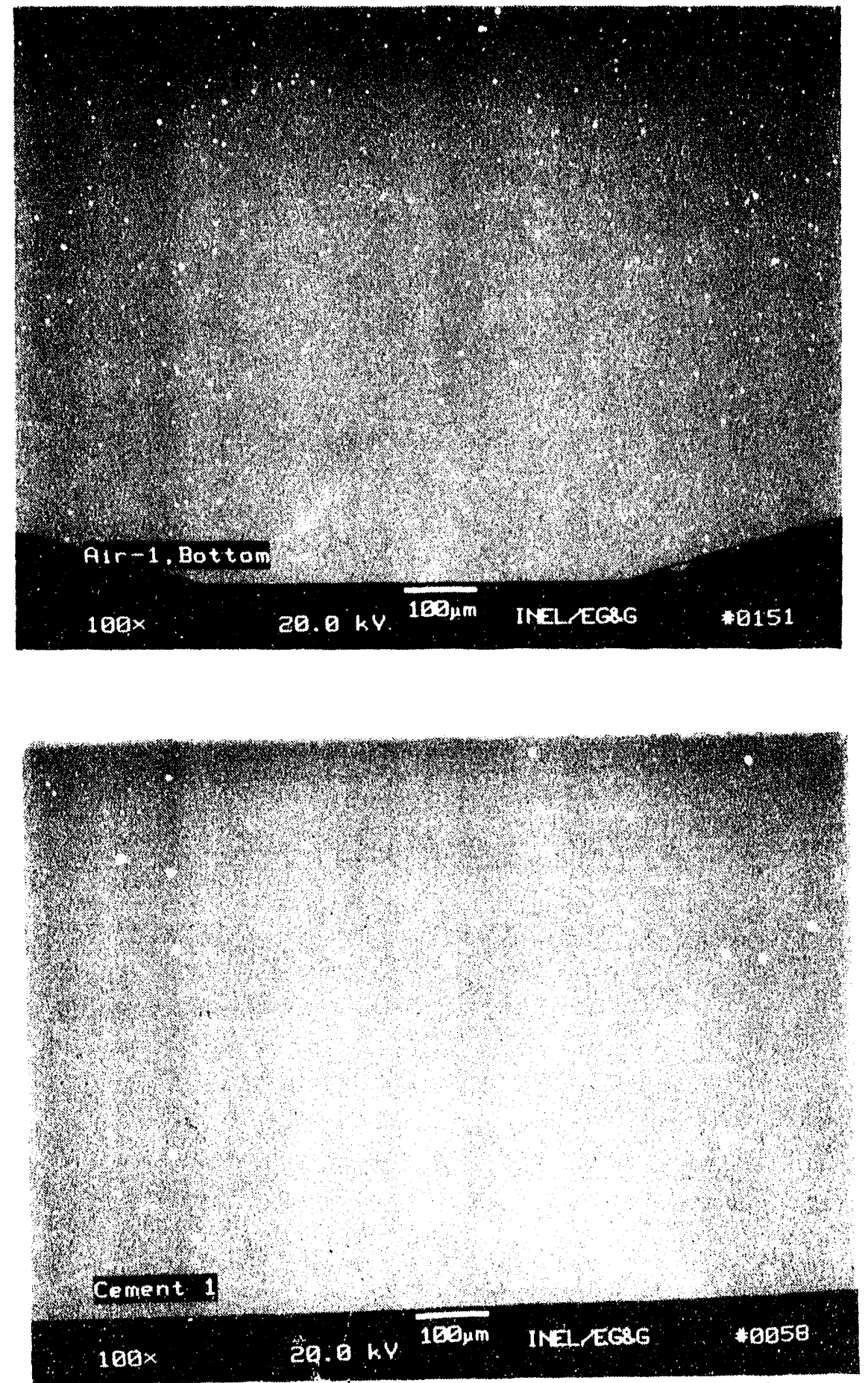

Figure 52. SEM micrographs of the IEBH/M-9) (Test 12) and IIEB4/S-90) (Test 14) wiste forms produced by the metal dissolution and oxidation and cemented organic are melter capahility lests. 


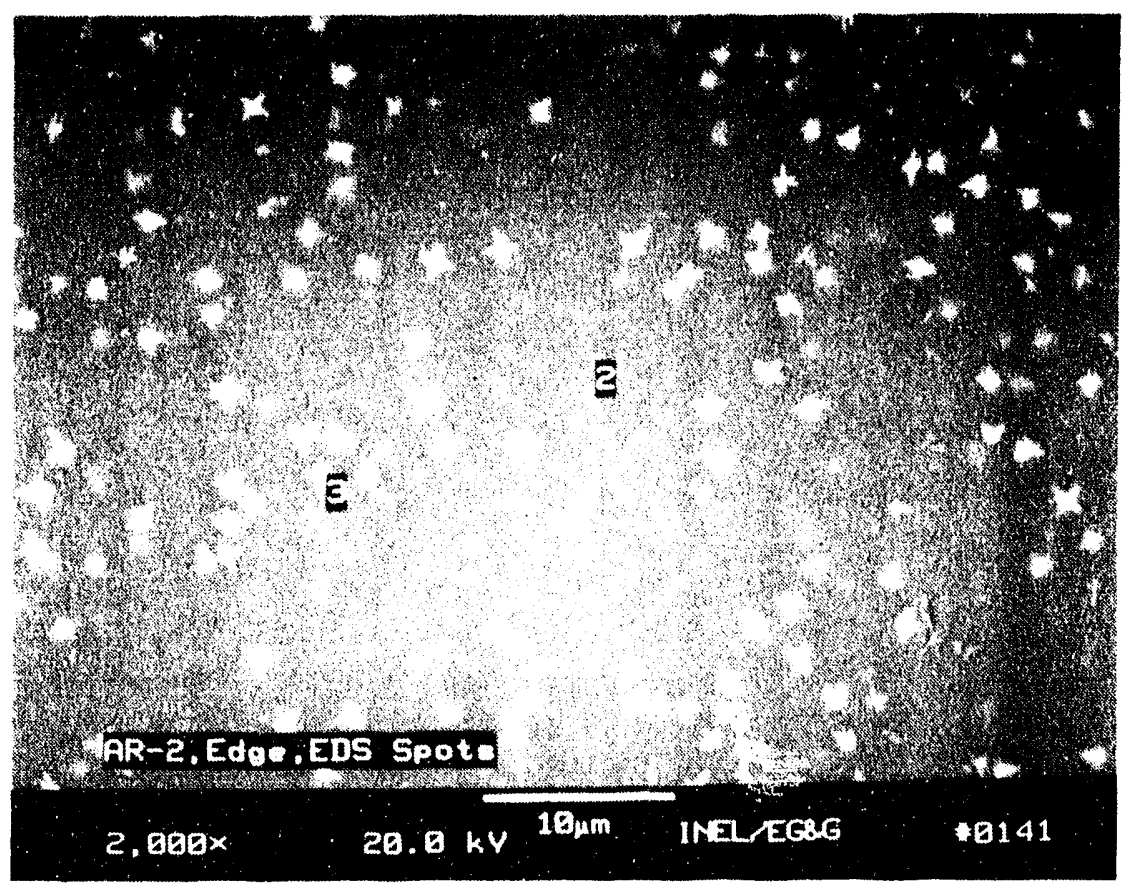

Figure 53. Speculated zirconia crystallites erystallized from the melt during the metal dissolution and oxidation (argon atmosphere) are melter capability test (Test 11). 


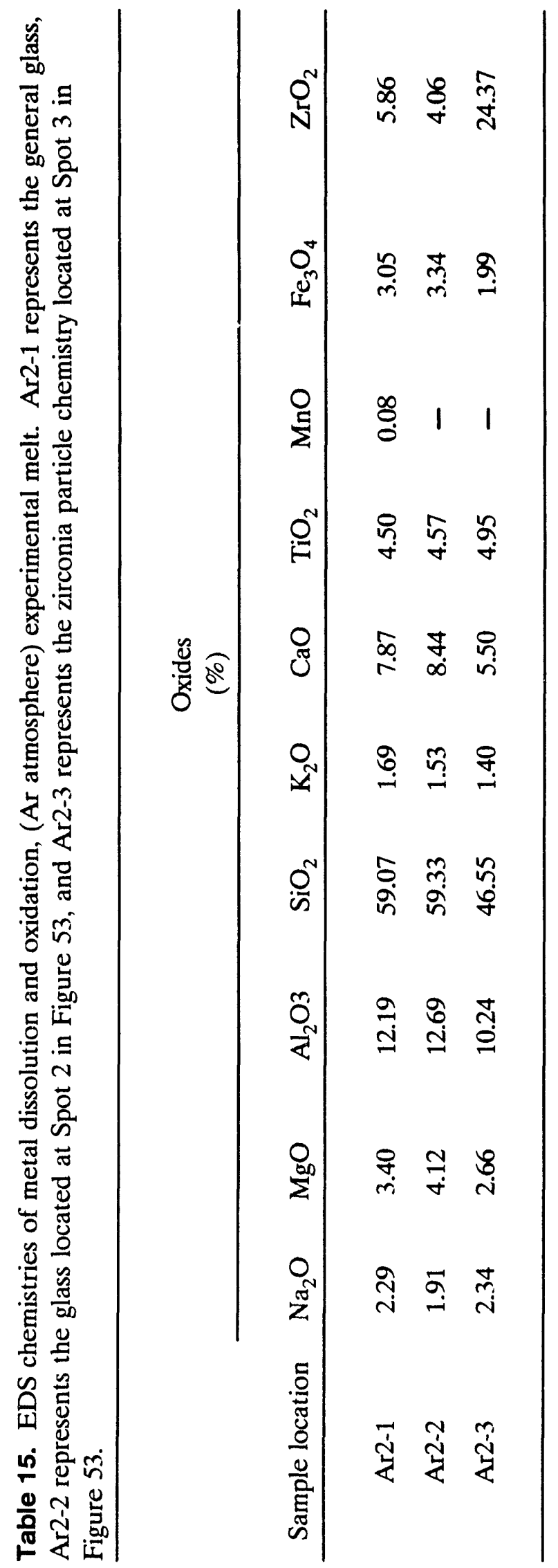


Due to the size of the particle, EDS analysis, Ar2-3, was inconclusive; however, based on all the oxides listed in Table 15 , the crystallites were speculated to be $\mathrm{Zirconia}\left(\mathrm{ZrO}_{2}\right)$ particles. If these were $\mathrm{ZrO}_{2}$ particles, the "local solubility" of $\mathrm{ZrO}_{2}$ might exceed the silicate melt capability. Upon fast cooling, an excess amount of $\mathrm{ZrO}_{2}$ could then be homogeneously precipitated as fine particles.

\subsection{Cold Trap Analysis}

\subsubsection{Introduction}

Cold trap residues collected from several arc melter runs, were identified with X-ray diffraction. The analysis was performed to identify materials that vaporized during the capability test of the arc melter for the processing of IEB4/A-100, silicated organic, hydrated metal oxide sludges, and dissolution and oxidation of metals.

\subsubsection{IEB4/A-100 Test}

Cold trap residues were collected and analyzed to determine the material that vaporizes during the melting of IEB4/A-100 soil. The composition of IEB4/A-100 was 90 wt\% soil with 5 wt\% each of zirconia $\left(\mathrm{ZrO}_{2}\right)$ and titania $\left(\mathrm{TiO}_{2}\right)$. Figure 54 shows the $\mathrm{X}$-ray diffraction traces of the cold trap residue collected. The raw profile was matched against reference standard files for component oxides and against the X-ray profile of unmelted IEB4/A-100 raw soil. The matching Table $15 . \ldots$ indicated the cold trap residue was made up of $\mathrm{TiO}_{2}, \mathrm{ZrO}_{2}$, raw soil, and $\mathrm{SiO}_{2}$. This analysis establishes a reference baseline for comparison with other runs.

\subsubsection{Hydrated Metal Oxide Test}

Metal hydroxides were added to an IEB4/A-100 melt to simulate $\mathrm{H}-90, \mathrm{H}-80, \mathrm{H}-60$ hydrated metal oxide sludge waste compositions. The chemical composition of the sludge is given in Table 16. The sludge composition represents the expected Rocky Flats waste streams, with iron oxide added to simulate the iron content of the waste container.

Cold trap residues were collected throughout the experimental run. These residues were analyzed by X-ray diffraction for escaped metal hydroxides and other metal oxides, which volatilized from the arc melter during operation. Figure 55 is the X-ray diffraction traces of the cold trap residue. When compared to the reference baseline case, it is identical to the IEB4/A-100 cold trap materials, with the exception of hematite $\left(\mathrm{Fe}_{2} \mathrm{O}_{3}\right)$ and magnetite $\left(\mathrm{Fe}_{3} \mathrm{O}_{4}\right)$. These iron oxides were added to the waste stream to simulate the iron content of the waste container. Figure 56 shows the traces of the starting hydroxides that were not detected in the cold trap residues. This suggested that the simulated hydrated metal oxide sludge wastes were totally destroyed upon entering the melt.

\subsubsection{Silicated Organic Test}

Cemented organic waste streams were simulated by adding the preblended Micro-cell $\mathrm{E}$, Floor DRI and vegetable oil to an IEB4/A-100 melt to formulate the IEB4/S-90) waste form 


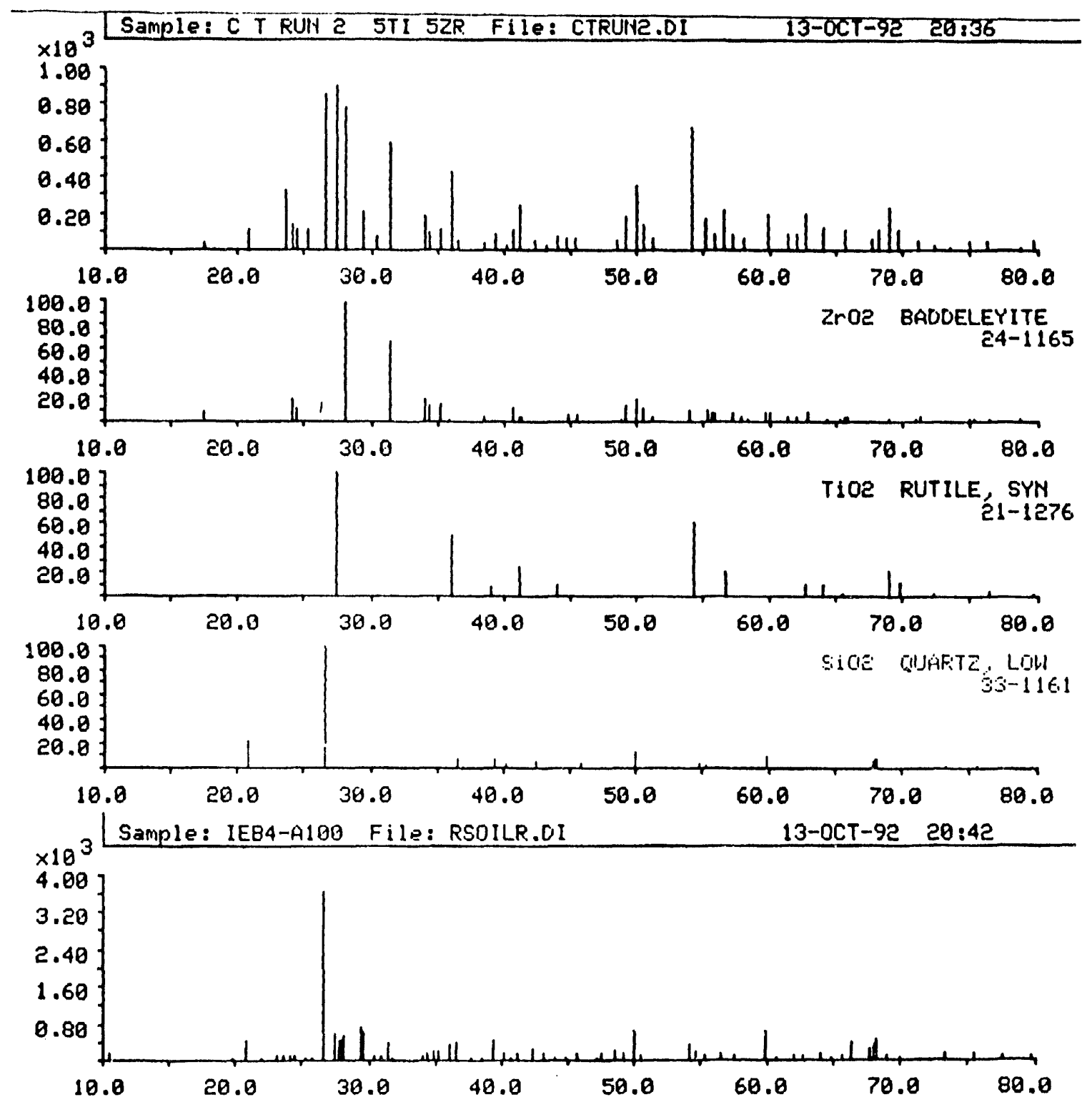

Figure 54. X-ray diffraction traces of Test 9 cold trap residue. Test 9 melted only pure IEB4/A-100 soil; there were no waste form additions.

Table 16. Hydrated metal oxide sludye chemical composition.

\section{Compound weight}

$(\mathrm{kg})$

\begin{tabular}{cccccccc}
$\begin{array}{c}\text { Soil } \\
\text { designation }\end{array}$ & $\mathrm{SiO}_{2}$ & $\mathrm{Al}(\mathrm{OH})_{3}$ & $\mathrm{Ca}(\mathrm{OH})_{2}$ & $\mathrm{Mg}(\mathrm{OH})_{2}$ & $\mathrm{NaOH}$ & $\mathrm{Fe}_{3} \mathrm{O}_{4}$ & $\mathrm{Fe}_{2} \mathrm{O}_{3}$ \\
\hline & & & & & & & \\
$\mathrm{H}-90$ & 0.090 & 0.041 & 0.015 & 0.019 & 0.106 & 0.035 & 0.063 \\
$\mathrm{H}-80$ & 0.202 & 0.092 & 0.035 & 0.043 & 0.238 & 0.080 & 0.142 \\
$\mathrm{H}-60$ & 0.538 & 0.244 & 0.092 & 0.114 & 0.634 & 0.212 & 0.378 \\
\hline
\end{tabular}




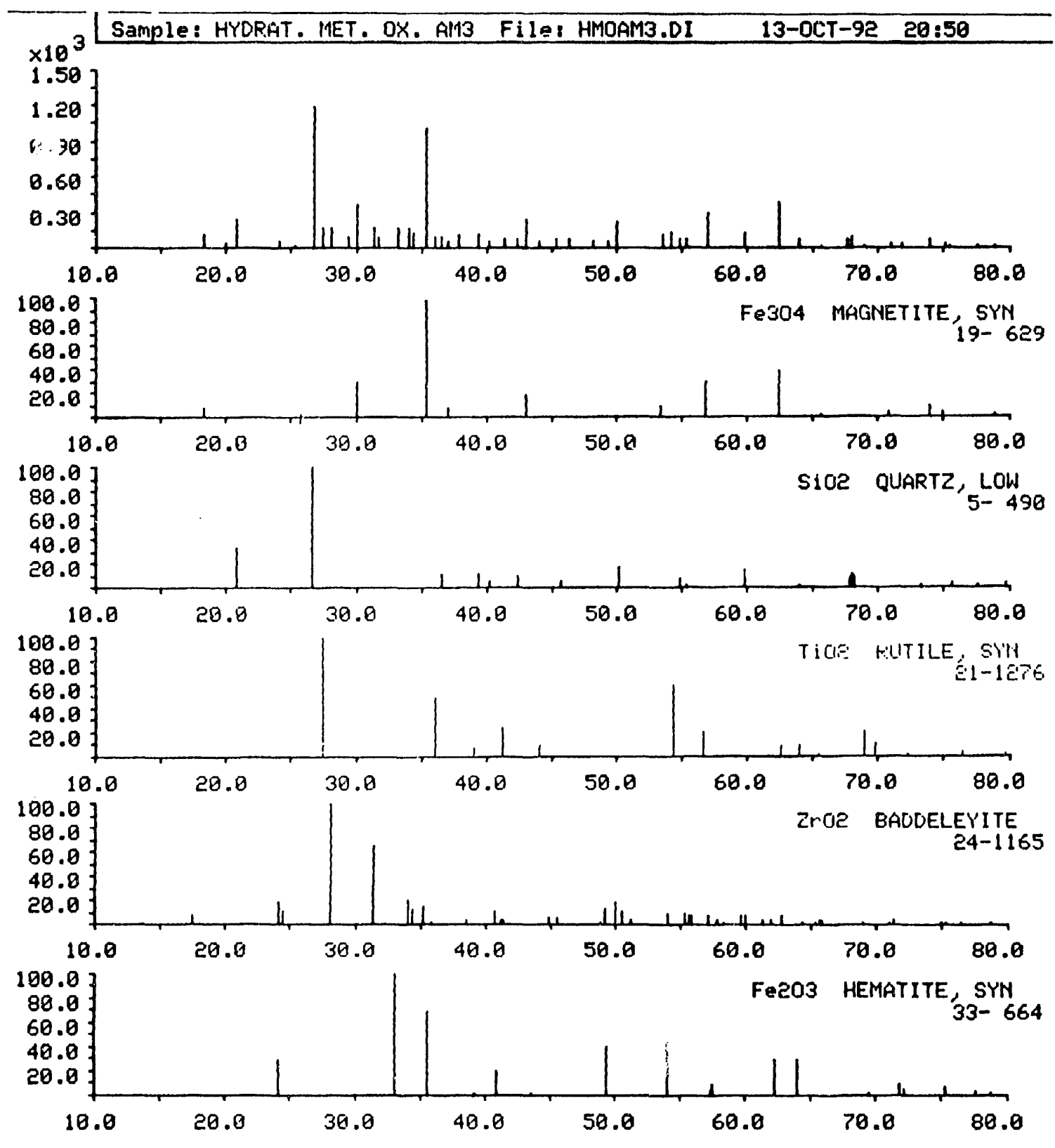

Figure 55. IEB4/A-100 plus hydrated metal oxides X-ray diffraction traces. These compounds were present in the cold trap residue. 


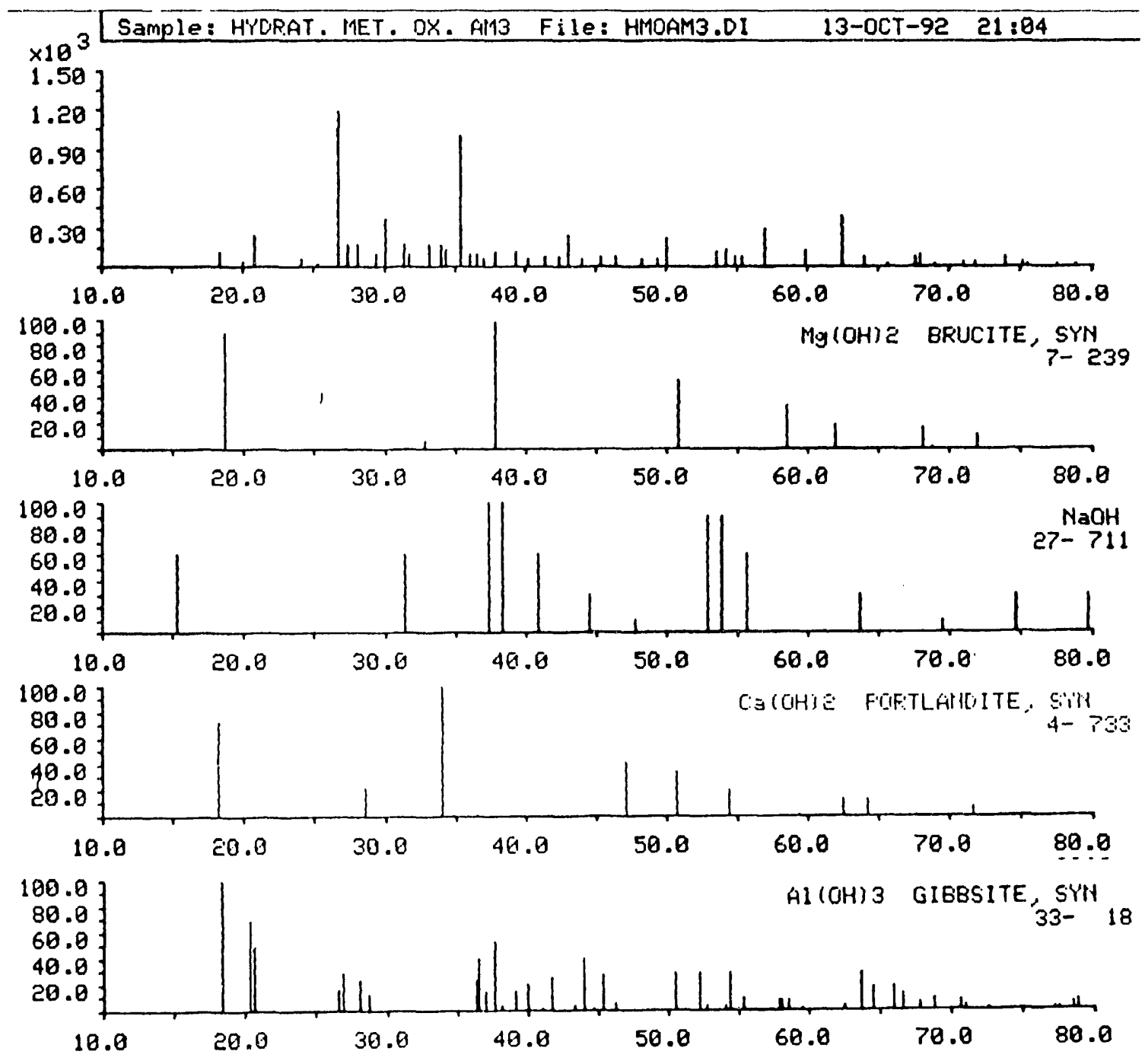

Figure 56. IEB4/A-100 plus hydrated metal oxides X-ray diffraction trace (top), plus the traces of the added metal hydroxides. The added metal hydroxides were not found in the cold trap residue. 
composition. The sludge was composed of $29.1 \%$ of Micro-cel E, $4.4 \%$ Floor DRI, and $66.5 \%$ vegetable oil. The chemical compositions of the Micro-cel $E$ and Floor DRI are given in Table 17.

The X-ray diffraction traces for the cold trap residue and monocalcium silicate are shown in Figure 57. Raw soil, quartz $\left(\mathrm{SiO}_{2}\right)$, rutile $\left(\mathrm{TiO}_{2}\right)$, baddeleyite $\left(\mathrm{ZrO}_{2}\right)$, amorphous carbon, and monocalcium silicate $\left(\mathrm{CaSiO}_{3}\right)$ were found in the cold trap residue. When the simulated cemented organic was added to the arc melter, the vegetable oil volatilized and pyrolyzed rapidly above the melt. This process caused incomplete combustion of the oil and a small but sudden increase in melter chamber gas pressure. As a consequence, some carbon residue, Micro-cel E, and Floor DRI were carried into the cold trap.

\subsubsection{Metal Dissolution and Oxidation Test}

Carbon steel was added to several IEB4/A-100 melts to simulate high metal waste streams. These runs were done to test for dissolution and oxidation of metal in argon and air environments, and air bubbling via a lance in the melt. Cold trap residues were collected and analyzed using X-ray diffraction. The rf sults were similar to those obtained in the analysis of the IEB4/A-100 soil cold trap residue.

This indicates that the elemental iron from the carbon steel did not volatilize from the melt. Experimental observation showed that the steel was partially melted and collected at the bottom of the crucible.

\subsubsection{Conclusions on Cold Trap Analysis}

Based on X-ray analysis, the cold trap materials for these tests were rather similar. The basic composition is raw soil plus $\mathrm{SiO}_{2}, \mathrm{TiO}_{2}$ and $\mathrm{ZrO}_{2}$. These materials were collected in the cold trap during initial heating, dehydration, and decomposition of the soil (e.g., carbonates) in the melter. In the dehyd, ation process, particles were entrained in the escaping water vapor and other gases or vapors and carried into the cold trap. Specific additives, such as the iron oxides of the hydrated metal oxide test or $\mathrm{CaSiO}_{3}$ of the silicated organic test, were also observed in the cold trap for specific tests. These materials could be recirculated into the melter for dissolution in the slag. Incineration prior to melting would reduce the quantity of offgas vapor and gases generated from the soil. 
Table 17. Chemical composition of Micro-cel E and Floor DRI.

\begin{tabular}{lcc} 
Element & $\begin{array}{c}\text { Micro-cel E } \\
\text { weight } \\
(\%)\end{array}$ & $\begin{array}{c}\text { Floor DRI } \\
\text { weight } \\
(\%)\end{array}$ \\
\hline $\mathrm{Si}_{2}$ & 56.0 & 89.2 \\
$\mathrm{Al}_{2} \mathrm{O}_{3}$ & 3.8 & 4.0 \\
$\mathrm{Fe}_{2} 0_{3}$ & 1.0 & 1.5 \\
$\mathrm{Ca}^{0}$ & 26.0 & 0.5 \\
$\mathrm{Mg}$ & 0.7 & 0.3 \\
$\mathrm{Na}_{2} \mathrm{O}$ & 0.6 & 0.25 \\
$\mathrm{~K}_{2} 0$ & 0.6 & 0.25 \\
$\mathrm{LOI}^{\mathrm{a}}$ & 11.3 & - \\
$\mathrm{H}_{2} \mathrm{O}$ & - & 4.0
\end{tabular}

a. LOI means material lost on ignition for analysis.

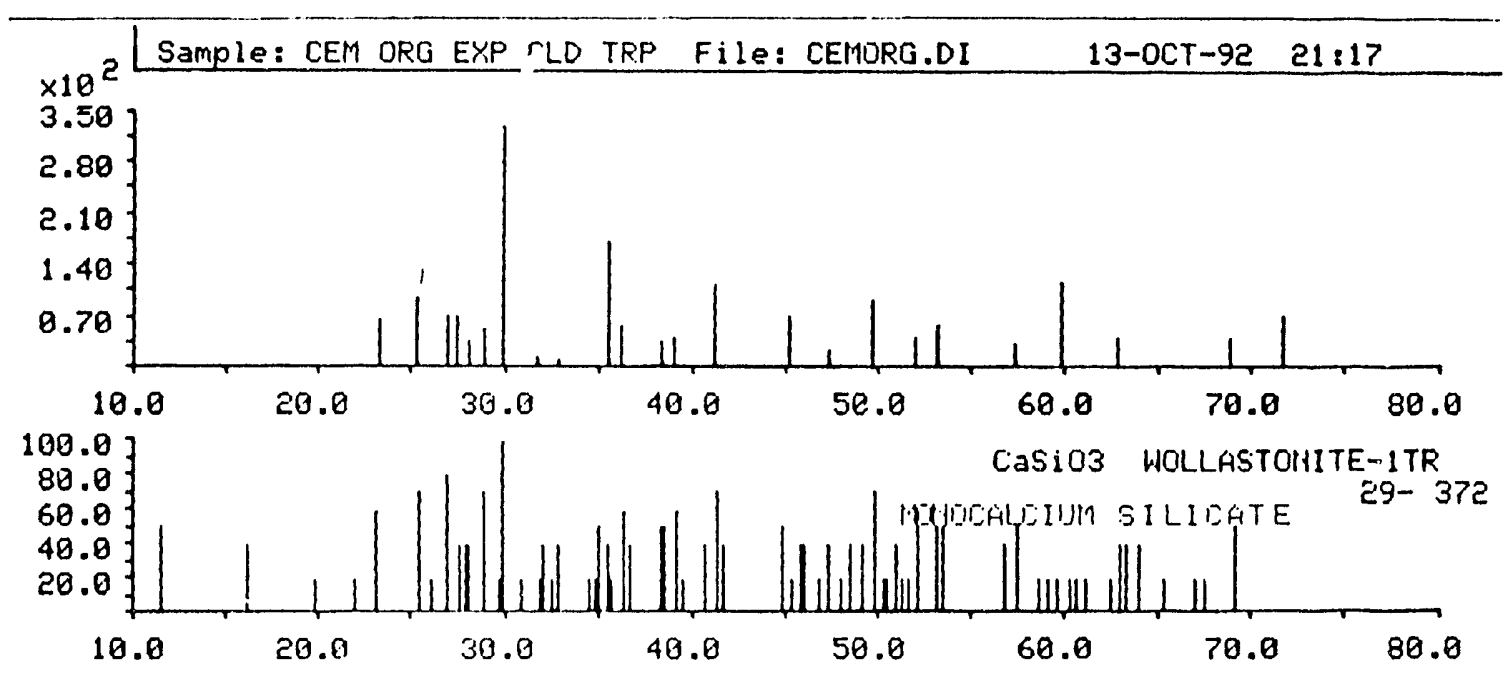

Figure 57. X-ray diffraction traces from the silicated organic experiments: cold trap and monocalcium silicate trace. 


\section{CONCLUSIONS AND RECOMMENDATIONS}

\subsection{Conclusions}

A bench-scale arc melter has been designed, constructed, modified, and operated successfully to melt essentially all of the simulated soil/waste mixtures contained therein. The only preparation required with the arc melter is some sizing of the simulated wastes. The melter is not yet equiped with an appropriate oxygen source to conveniently oxidize organics. A simple starting method using a thin graphite strip has been developed to rapidly initiate the melting of the simulated waste. A heating procedure has been devised to melt under relatively quiescent or rolling boil modes. Heating is accomplished via a combination of arc and Joule heating. The whole heating process takes about 1 hour to melt the typical mass of $7 \mathrm{~kg}$ or $15 \mathrm{lb}$. The arc melter provides an easy way to generate vitrified material for detailed cooling and crystallization studies. A data acquisition system monitors and stores process conditions for real-time control and posttest evaluation. A video camera system provides instant video feedback of the waste melting process and video tapes for later review.

\subsection{Recommendations}

A variety of prepilot plant testing could be done with this low-cost, bench-scale melter including the effects of volatilization, metal melting and oxidation, electrode erosion/corrosion, melter geometry, size effects, skull formation, the reduction/oxidation condition, and the destruction of organic and combustible materials. Specific recommendations for the next stage of work include the following.

The question of the severity of volatilization from an arc melter compared to a Joule heated melter, at lower temperature, has been raised. The quiescent or rolling boil modes of the arc melter appear to be similar to those observed in the JHM, as well as dust emission. Studies identifying the extent of volatilization of TRU surrogates and HVPMs should be made as a function of location in the arc melter and operating temperature.

Detailed studies of metal melting and oxidation are required to identify the role of the slag or melt redox state to surface oxidize or decontaminate the metal, the time and methods required for efficient metal melting and/or total oxidation. Melter operation could include separate tapping of slag and molten metal or oxidize all of the metal into the slag. The alkali nitrate sludges might be used to oxidize the metals, reducing the air or oxygen required. Simple tests to identify physical and chemical advantages and disadvantages of options are needed.

The construction of a similar arc melter for use at the INEL TRA facility with radionuclides should be initiated. The melter could include the present crucible assembly plus a special water-cooled lid for observation and electrode immersion, all designed to be located in a glove

box. Activities would repeat a limited number of cold experiments in which the disposition of the TRU is significant. Examples include TRU and LL volatilization and metal surface decontamination. 


\section{REFERENCES}

1. J. L. Mayberry, et al., Preliminary Systems Design Study Assessment Report, EGG-WTD-9594, June 1991.

2. F. Feizollahi, et al., Preliminary Stored Waste Systems Design Study for Low-Level TRU Waste Treatment Assessment Report, EGG-WTD-10254, June 1992.

3. J. E. Flinn, G. W. Gibson, M. D. McCormack, and D. E. Owen, Annual Report on the TRU Waste Form Studies with Special Reference to Iron-Enriched Basalt: 1980, EGG-FM-5366, EG\&G Idaho, Inc., June 1981.

4. J. M. Welch, C. W. Sill, and J. E. Flinn, Leach Tests of Simulated Low Level Transuranic Waste Forms Containing Transuranic Elements, EGG-FM-6153, EG\&G Idaho, Inc., January 1983.

5. G. A. Reimann, J. D. Grandy and T. L. Eddy, Survey of INEL Research on the Iron-Enriched Waste Form, EGG-WTD-10056, January 1992.

6. J. M. Welch, R. L. Miller and J. E. Flinn, Fuel and Core Storage and Disposal Development: FY-82 Immobilization of Three-Mile Island Core Debris, EGG-FM-6059, June 1983.

7. J. M. Welch, R. L. Miller and J. E. Flinn, "Immobilization of Three-Mile Island Core Debris," 2nd Int. Symp. Ceramics in Nuclear Waste Management, Chicago, IL, April 1983.

8. J. G. Conley, P. V. Kelsey, and D. V. Miley, "Investigation of the Properties of IronEnriched Basalt with $\mathrm{TiO}_{2}$ and $\mathrm{ZrO}_{2}$ Addition," American Ceramic Society 85th Annual Meeting, 1983.

9. J. M. Welch, P. V. Kelsey, S. P. Henslee and R. L. Tallman, Iron-Enriched Basalt for Containment of High Level Nuclear Wastes, EGG-M-5281, December 1981.

10. R. L. Miller, J. M. Welch and J. E. Flinn, Scoping Studies on Recovery of Uranium from Man-Made Ores, EGG-MS-6351, August 1983.

11. R. L. Miller, J. M. Welch and J. E. Flinn, Uranium Recovery from a Nuclear Fuel, EGG-MS-6522, February 1984.

12. R. L. Miller, J. M. Welch and J. E. Flinn, "Uranium Recovery from a Nuclear Fuel Waste Form," Minerals and Metallurgical Processing, pp. 51-51, February 1985.

13. W. Lutze \& R. C. Ewing (Eds.), Radioactive Waste Forms for the Future, North Holland, Amsterdam, 1988.

14. R. C. Ewing \& W. Lutze, "High-Level Nuclear Waste Immobilization with Ceramics," Ceramics International, Vol 17, pp. 287-293, 1991.

15. B. A. Staples, J. R. Berreth and D. A. Knecht, "Technology for the long-Term Management of Defense HLW at the ICPP," Adv. in Ceramics, Vol. 20, Nuclear Waste Management II, P. $45,1 \% 86$.

16. T. L. Eddy, P. C. Kong, B. D. Raivo and G. L. Anderson, Thermal Processing System Concepts and Considerations for RWMC Buried Waste. EGG-WTD-10058. INEL/EG\&G Idaho, Idaho Falls, II), February, 1992. 
17. P. C. Kong, G.A. Reimann, et al., "Recommended Final Waste Form Requirements for TRU Waste," Proc. Spectrum '92: Nuclear and Hazardous Waste Management International Topical Meeting, Boise, ID, August 23-27, 1992.

18. A. D. Donaldson, R. J. Carpenedo and G. L. Anderson, Melter Development Needs Assessment for RWMC Buried Wastes, EGG-WTD-9911, February, 1992.

19. Handbook of Chemistry and Physics, 52nd Ed., 1971-72, pp. E5

20. B. V. Karlekar and R. M. Desmond, Engineering Heat Transfer, West Publishing Co., St. Paul, MN, 1977, p. 14.

21. A. P. Colburn, "A Method of Correlating Forced Convection Heat Transfer Data and a Comparison with Fluid Friction," Trans. A.I.Ch.E., Vol. 29, p. 174, 1933.

22. H. Hausen, VDIZ. Beih. Verfahrenstech., V()l. 4, pp. 91-98, 1943.

23. E. R. G. Eckert and R. M. Drake, Analysis of Heat and Mass Transfer, McGraw Hill, New York, 1972.

24. R. A. Callow, L. E. Thompson, J. R. Weidner, C. A. Lochr, B. P. McGrail and S. O. Batcs, In Situ Vitrification Applied to Buried Waste: Final Report of Intermediate Field Tests at the Idaho National Enginecring Laboratory, EGG-WTD-9807, August 1991, p. 28.

25. P. J. Hayward, "Glass-Ceramics," Ch. 7, p. 431, in Radioactive Waste Forms for the Future, Eds. W. Lutze and R. C. Ewing, North Holland, Amsterdam, 1988. 
Appendix A Schematics 


\section{Mechanical Schematics}



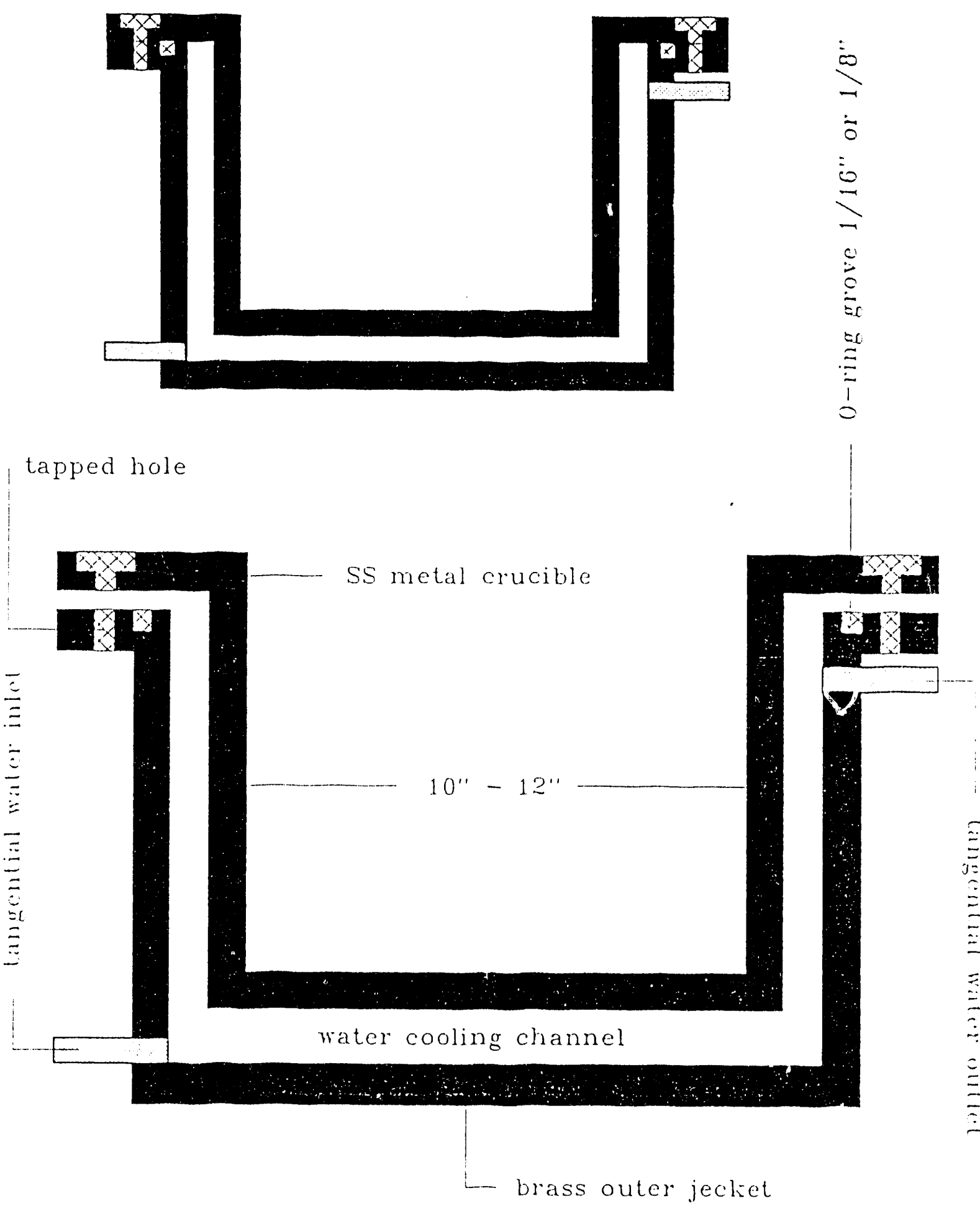

Figure A-1. Schematic of the crucible assembly showing the crucible insert, the jacket or pot, and the cooling water inlet and outlet. 


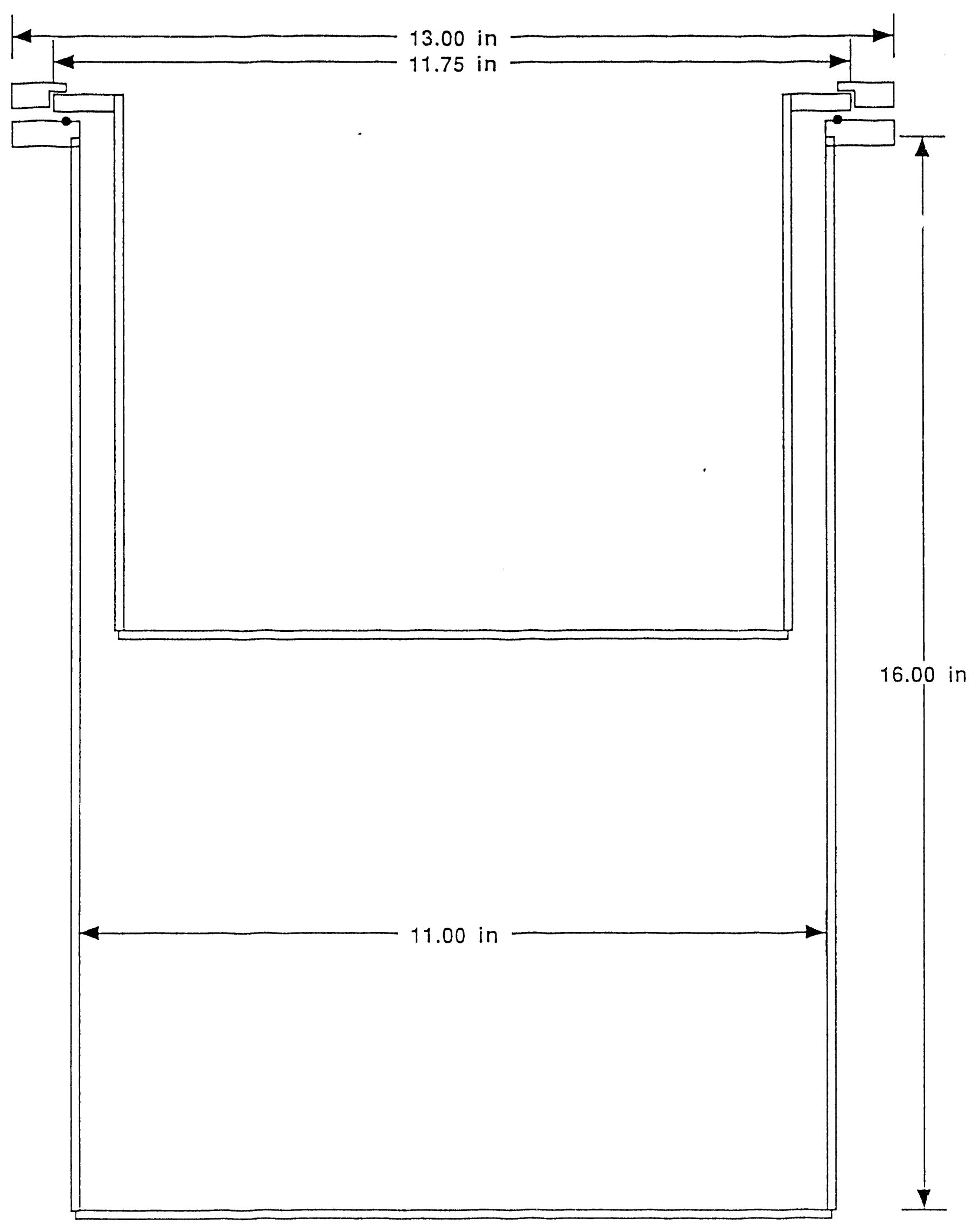

Figure A-2. Drawing of the crucible insert, jacket pot, and retaining ring with dimensions. 


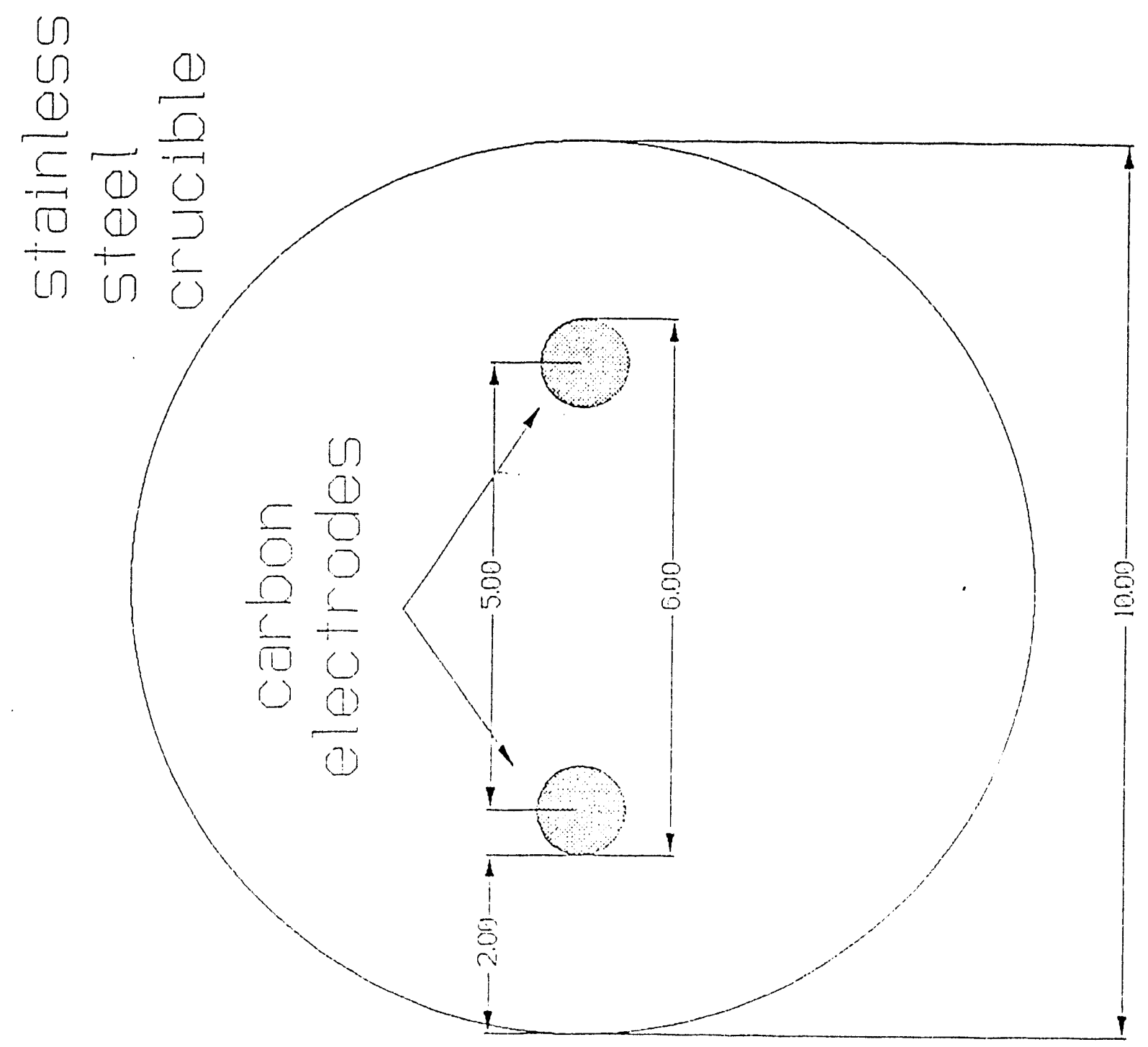

$\begin{array}{ll}0 & 0 \\ 0 & 0 \\ 0 & 0 \\ \cdots & 0\end{array}$

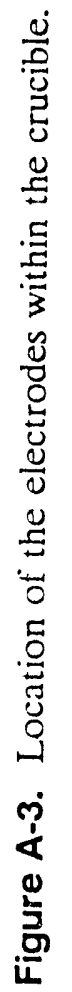




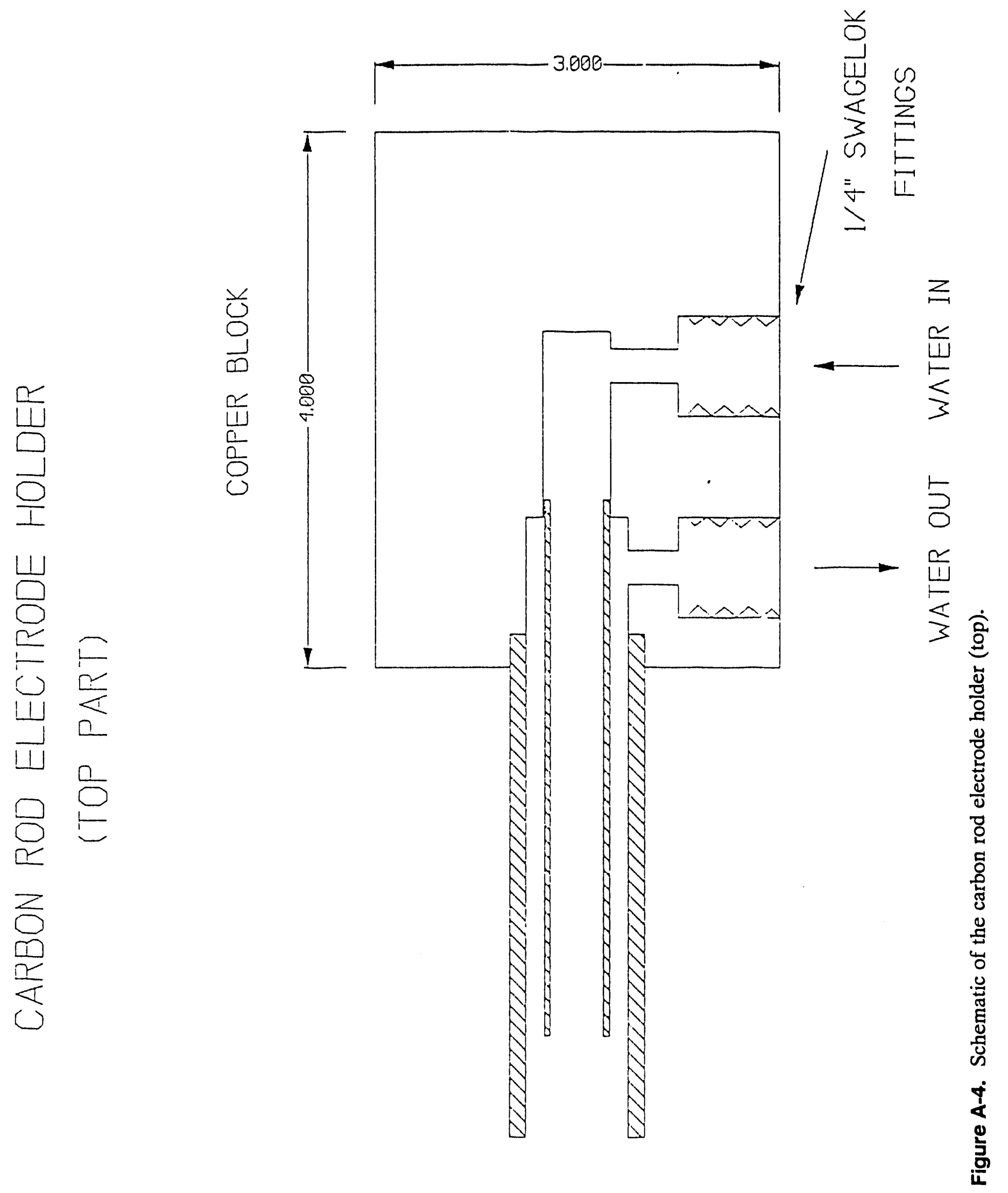



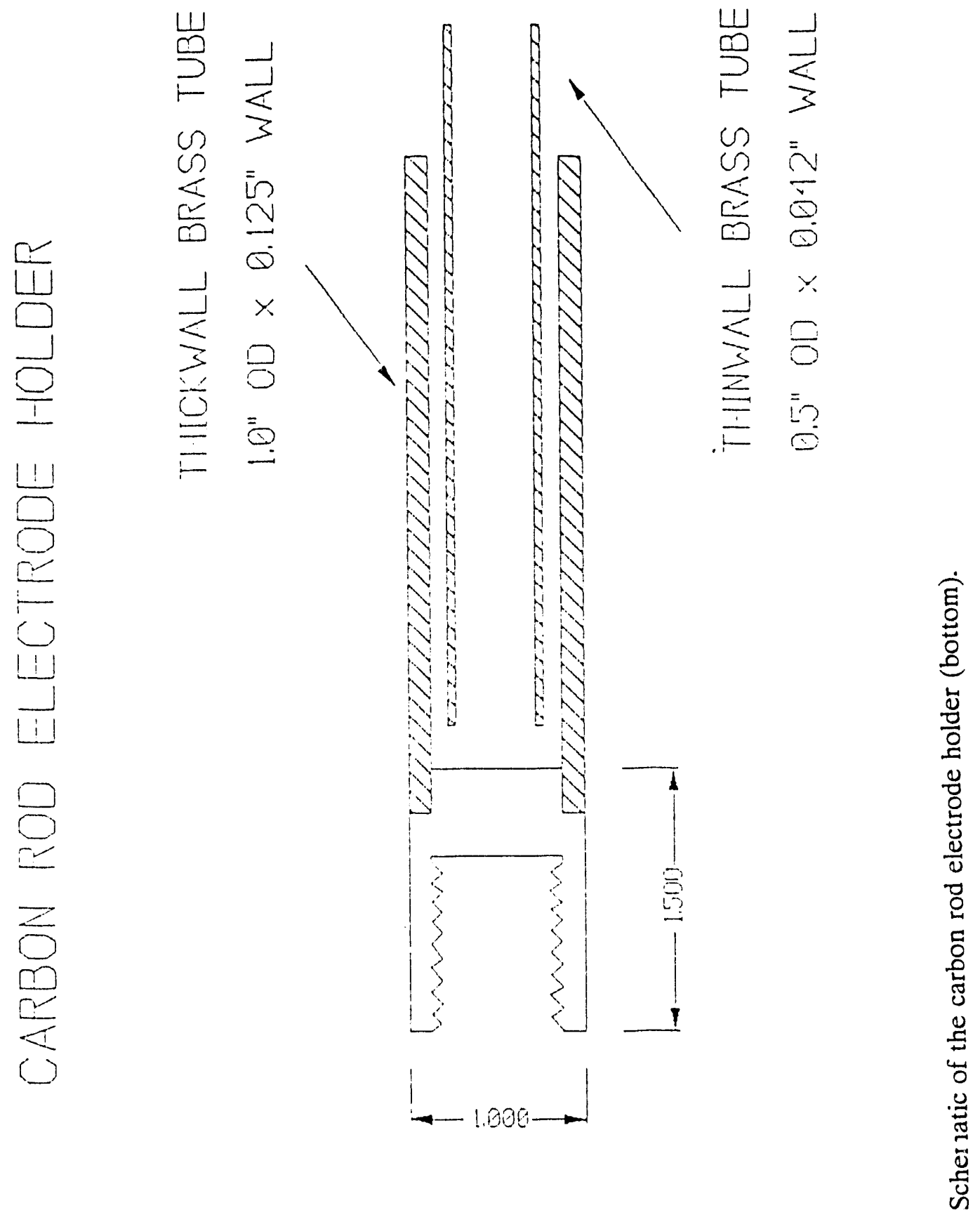

占 


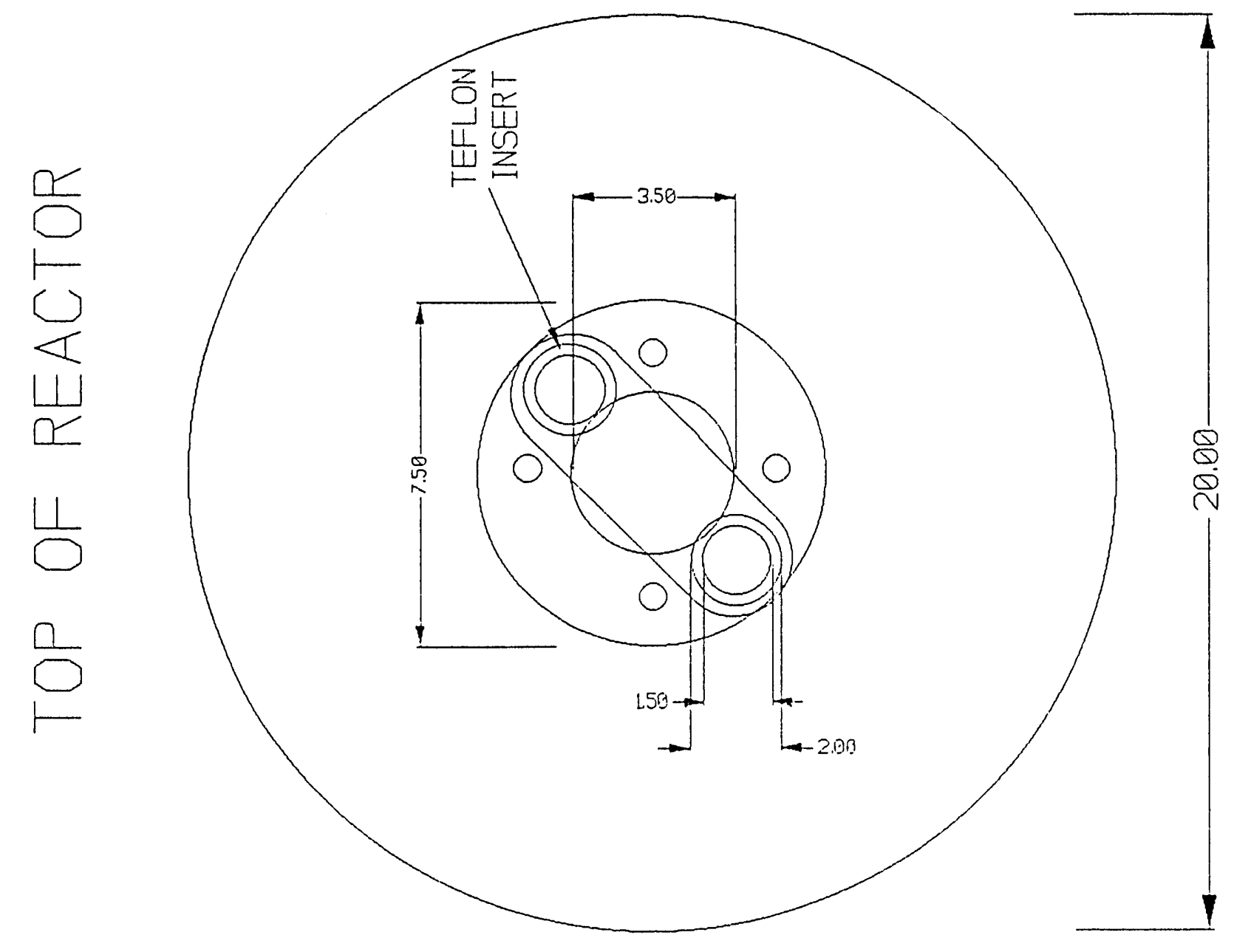

$w$
$\infty$
0
0
$m$
$m$
$m$

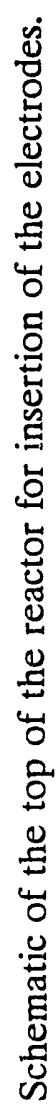

这 


\section{Electrical Schematics}




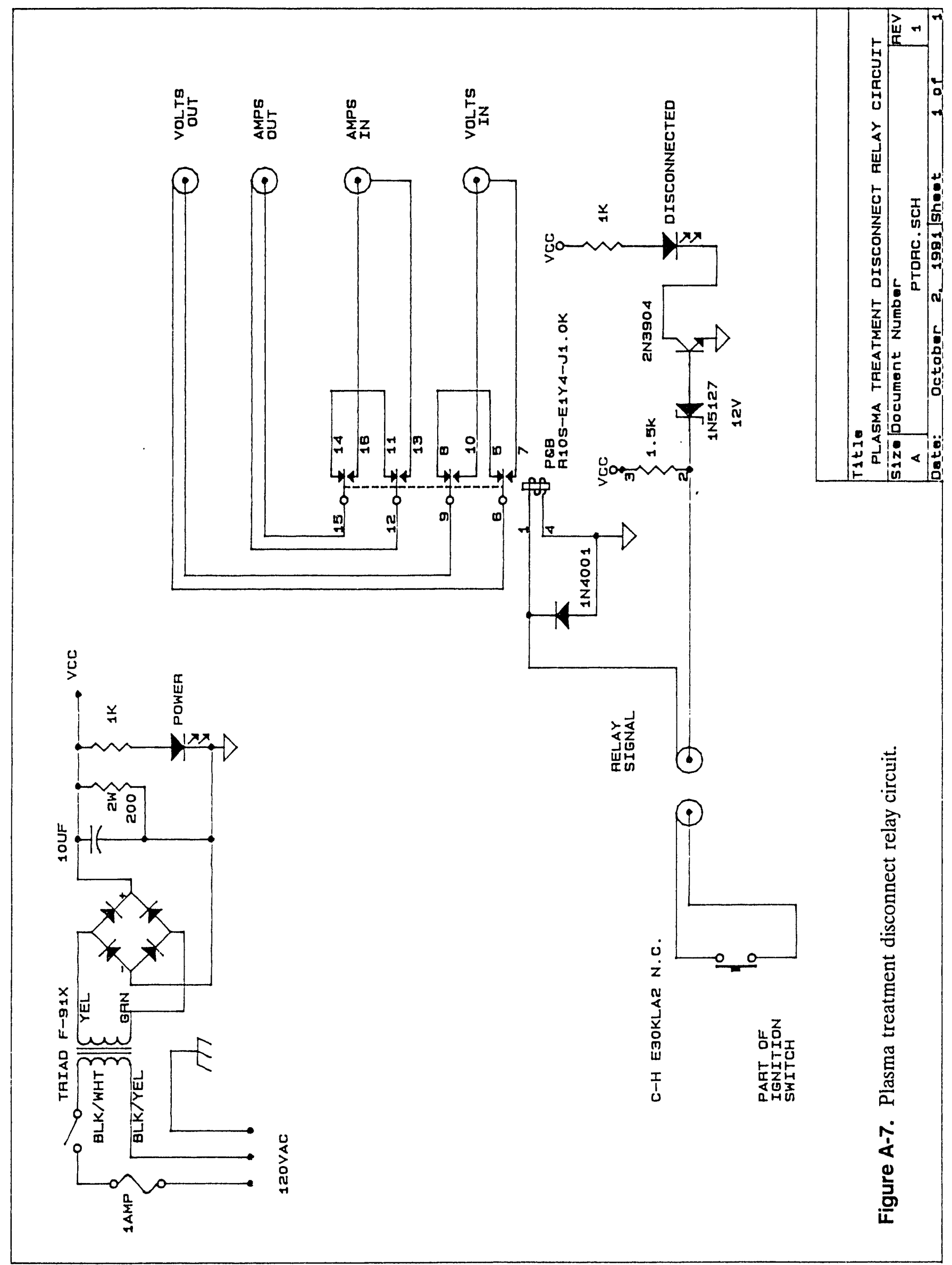




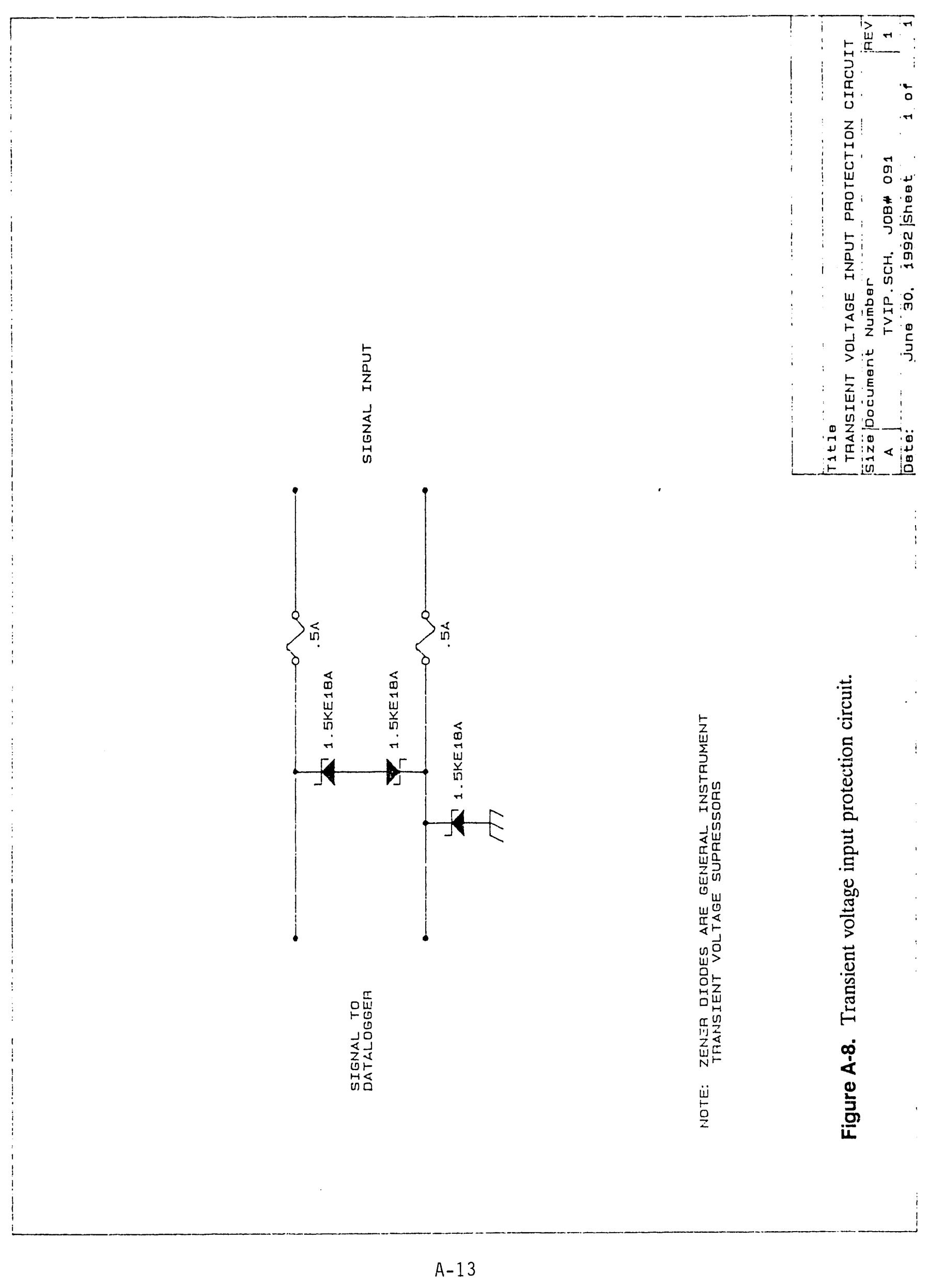



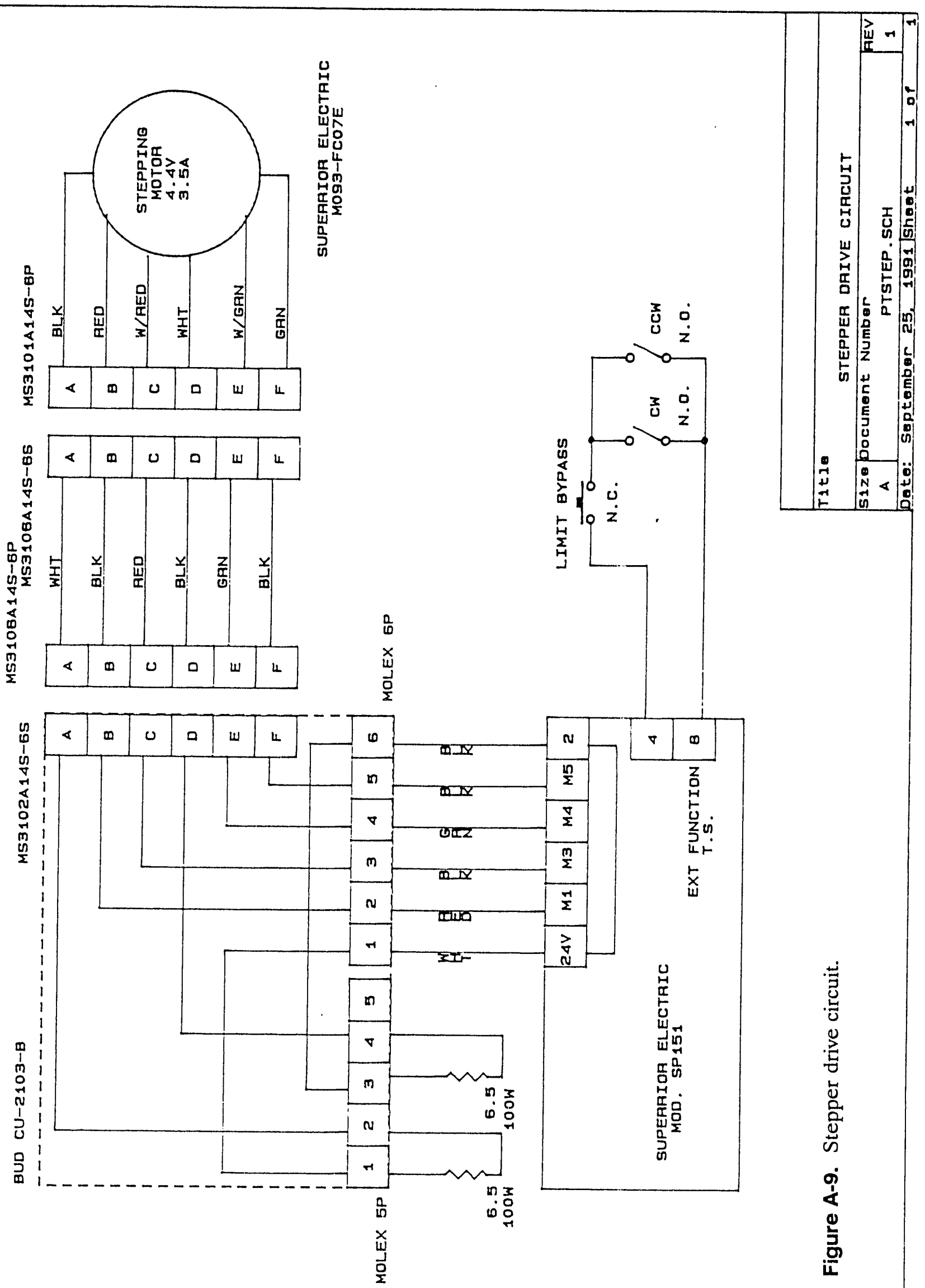

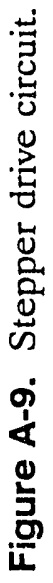




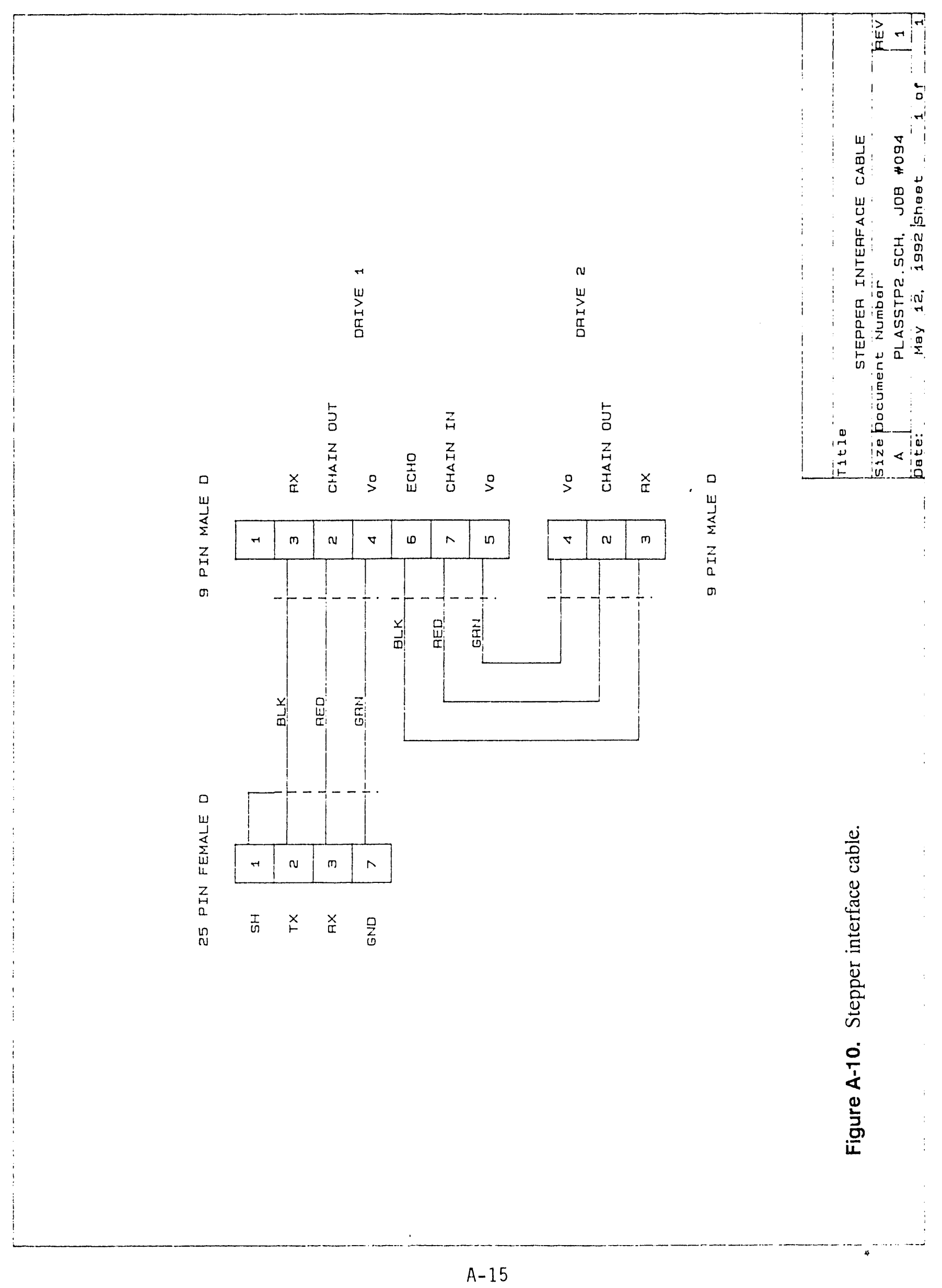



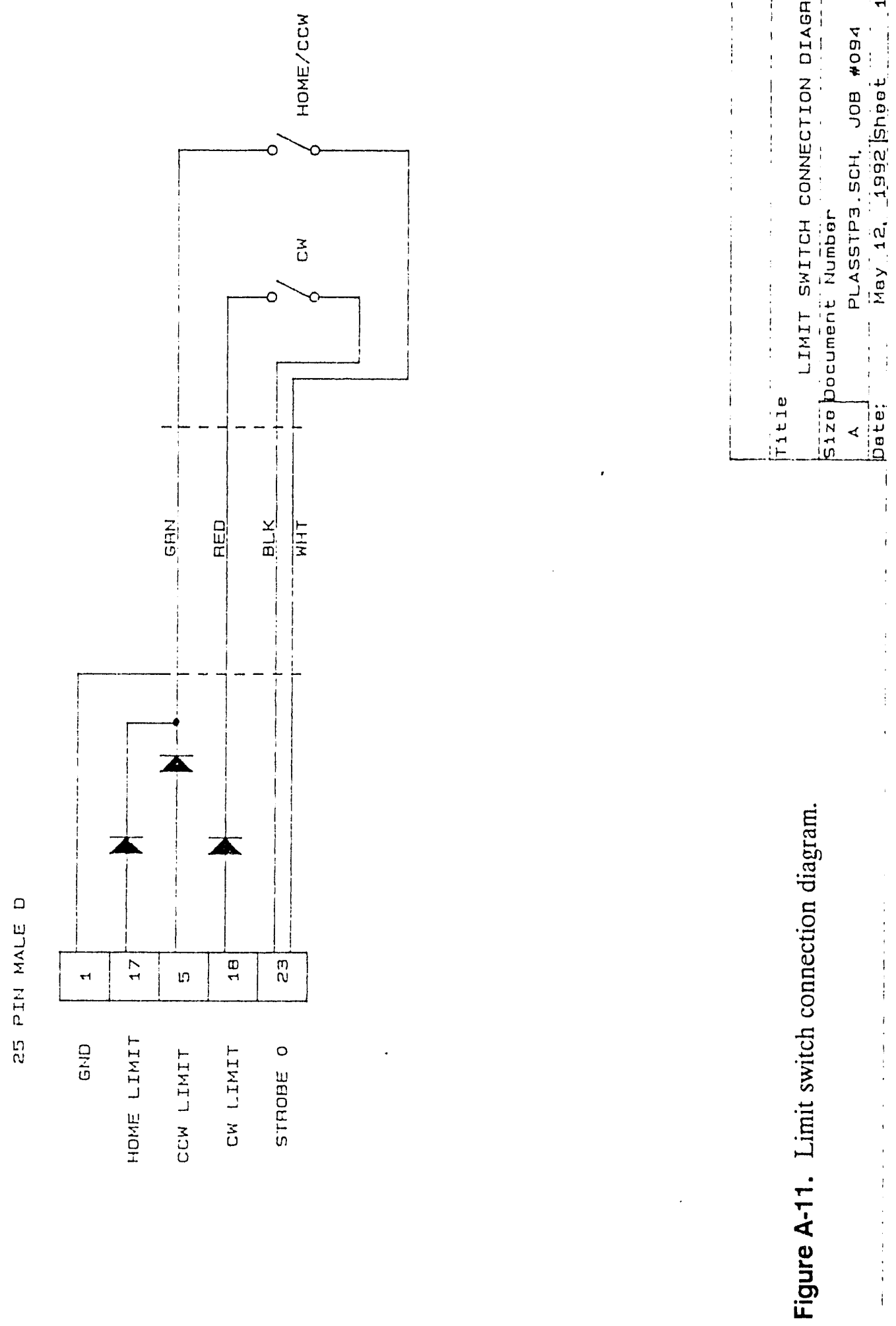

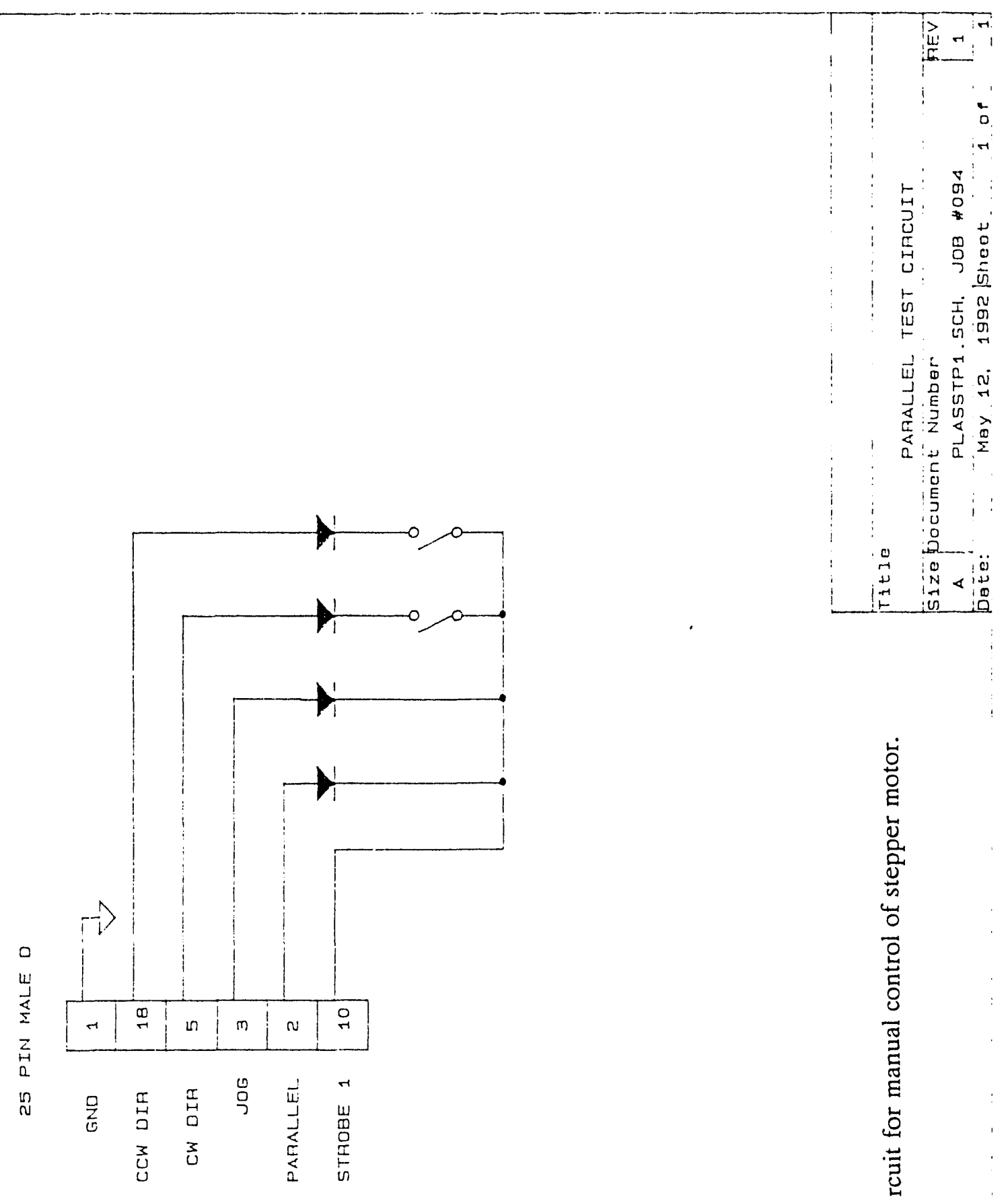

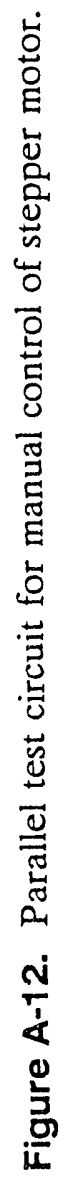




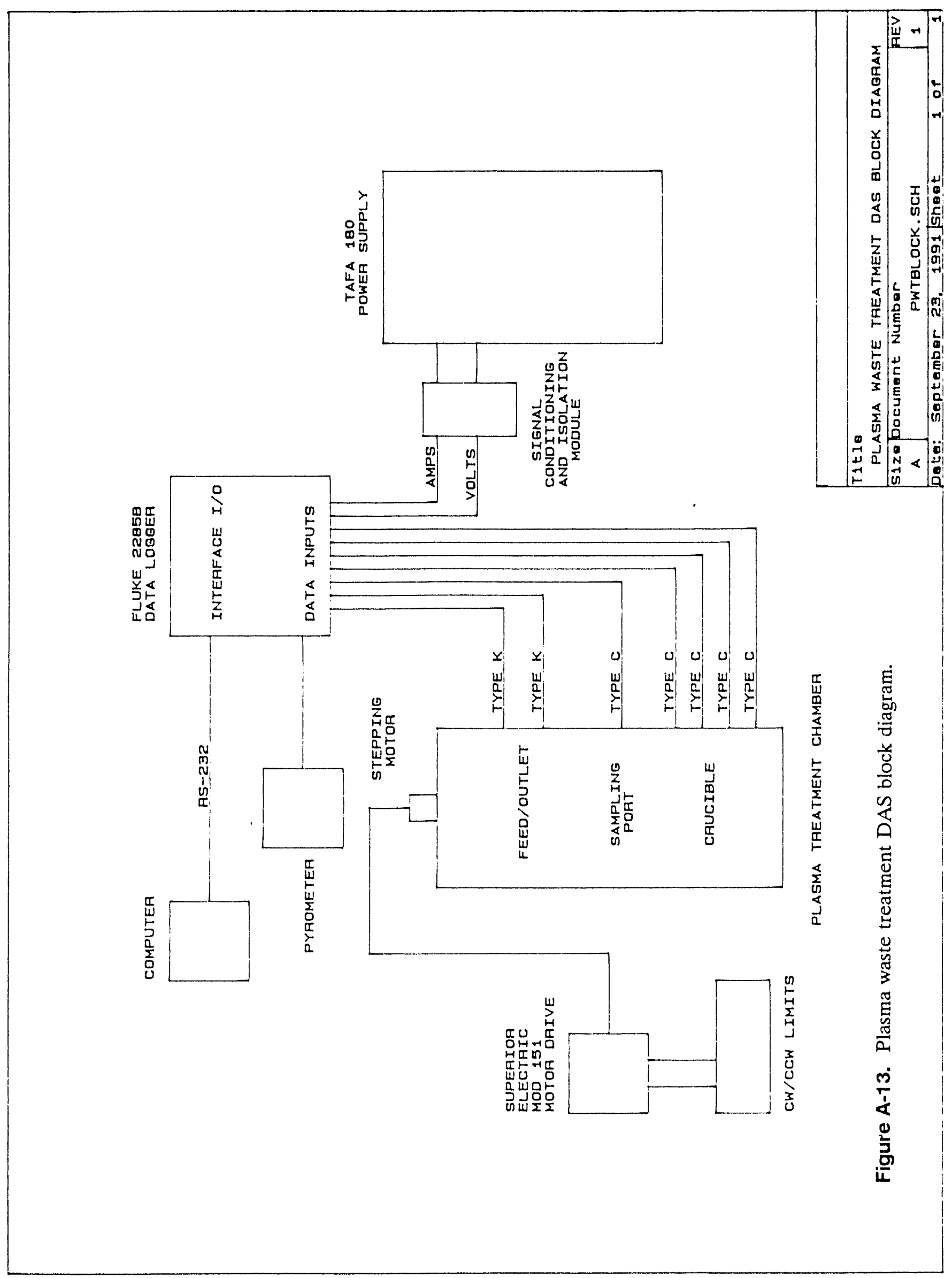




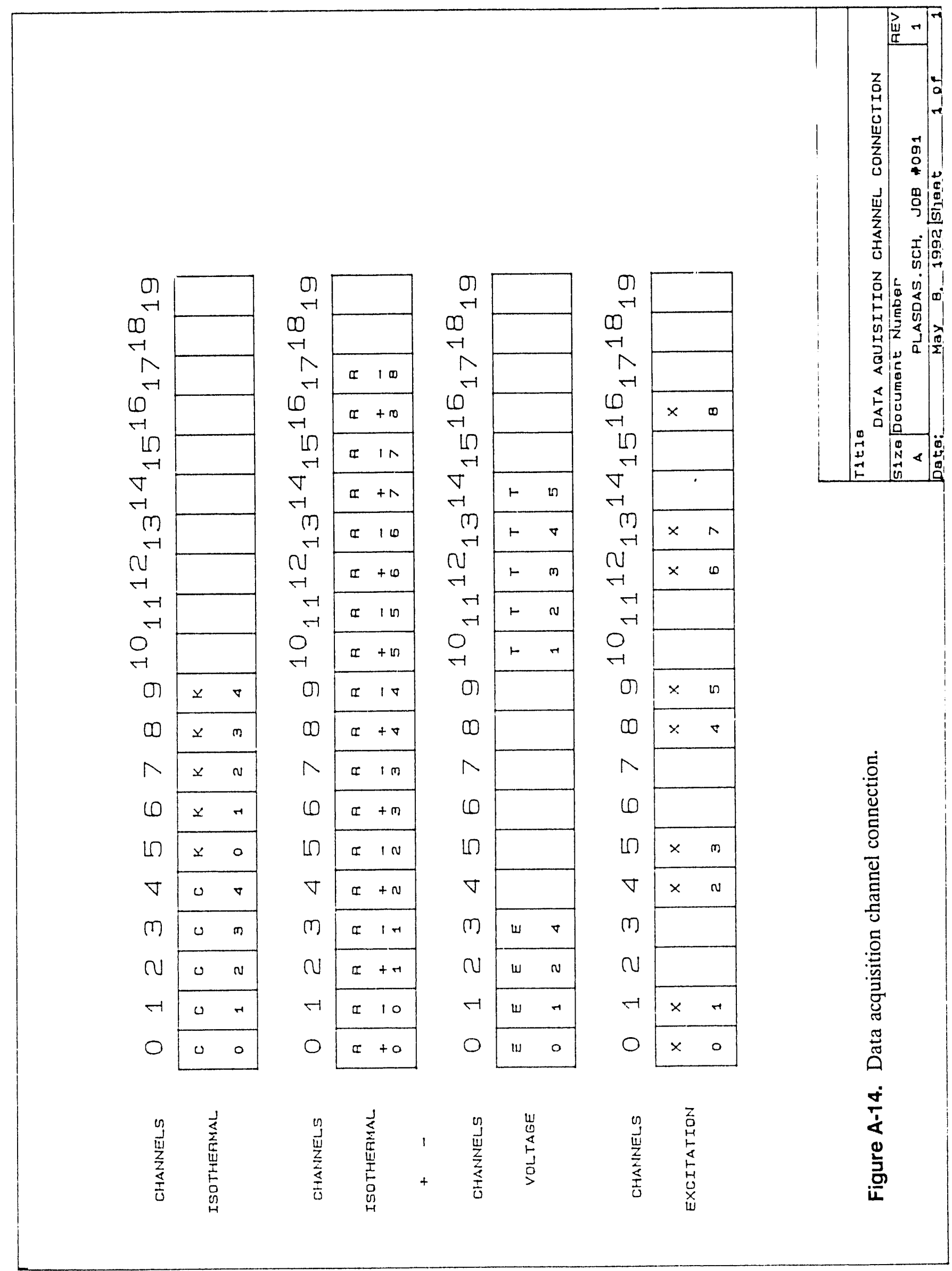




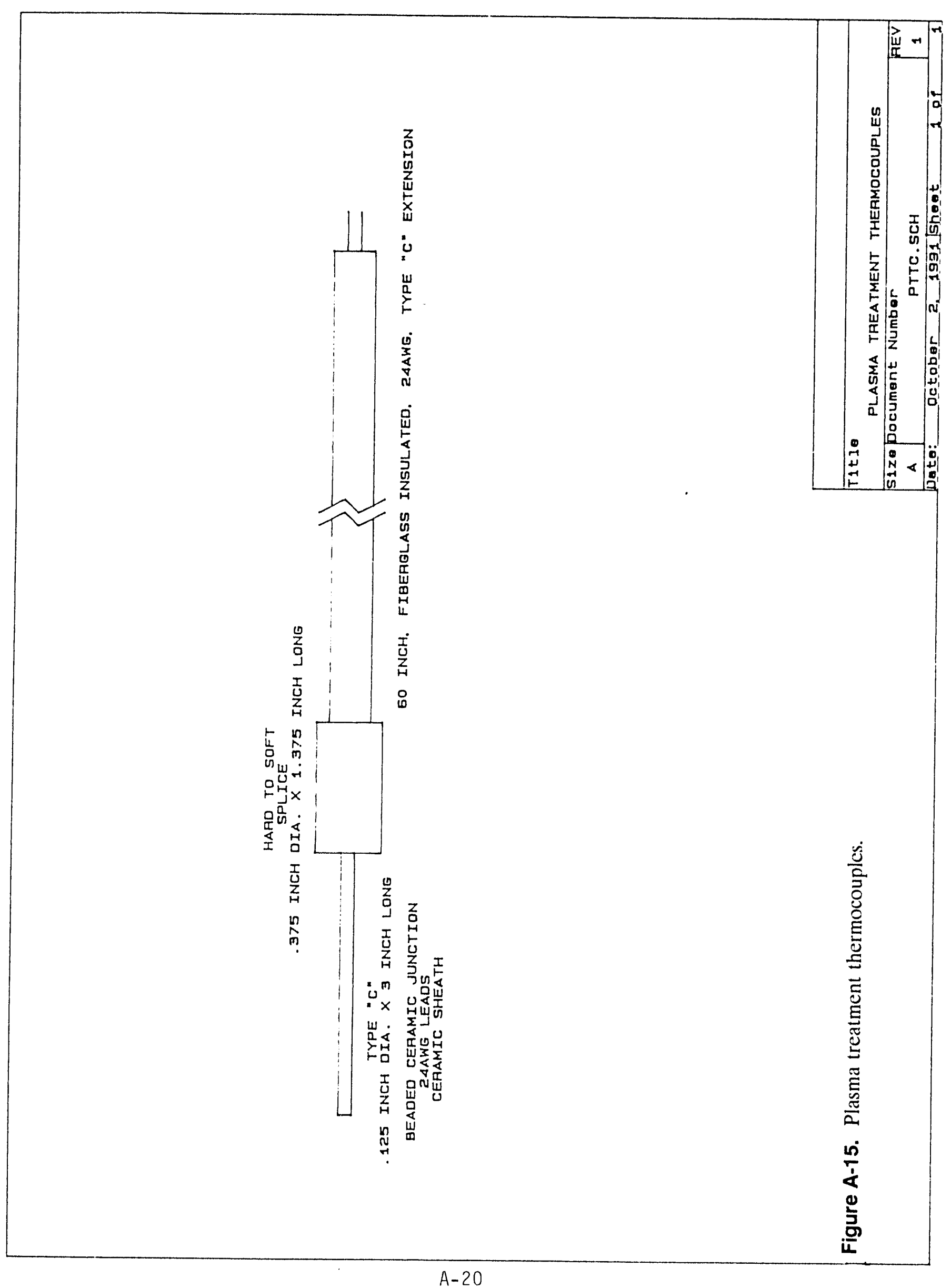


Appendix B

Test Summaries

B-1 


\section{Appendix B}

\section{Test Summaries}

The investigations into starting procedures, "soil" heating procedures, and the injection and melting of various simulated waste streams are discussed below in some detail. This is included to remind us of the envelope in which arc melting processes must occur and so that researchers can appreciate some of the nuances of arc melting, its differences from Joule heater melting, and some of the characteristics of melting different materials under different operating conditions. Additions and modifications were made to the instrumentation and equipment throughout Tests 1-7 as a part of developing the melting facility. These changes are also documented below.

\section{Test 1: Initial Starting Trials}

The first test was run on 6/5/92 to study starting methods. It used a portable Miller welding power supply having an overall capability of supplying $14 \mathrm{~kW}$ of power. The power supply has an open circuit voltage of $80 \mathrm{~V}$ and can operate at up to $300 \mathrm{~A}$ maximum depending on the operating voltage. The stainless steel (SS) crucible was filled with 3.5 in. of "clean" Radioactive Waste Management Complex (RWMC) soil (approximate A-100 composition). Large lumps in the soil were broken apart, but many small ones remained. A graphfoil strip approximately $1 \mathrm{x}$ 6 in. was placed on top of the soil to start the melting process. With the carbon electrodes lowered onto the graphfoil, the power supply was turned on and the current was increased to $50 \mathrm{~A}$ until the graphfoil started to glow red. After heating for approximately 5 minutes, the electrodes were raised, which drew an arc on one electrode. Two minutes later, the electrode broke off at the base of the threaded part, ending the test.

In the next run with a graphfoil conducting strip, the current was raised to approximately $150 \mathrm{~A}$. Argon (instead of ambient air) was put into the chamber to stabilize arcing effects. The graphfoil evaporated near the hotter electrode, but arced across the space. Then the graphfoil laminations peeled upward and the arc/current went out. Whenever the circuit was broken, it was usually not possible to restart without opening the chamber port and reforming a conducting path with graphfoil.

Instead of the graphfoil with its de-lamination problem, a new technique was tried in the form of a hand-packed cylinder of aluminum shavings. However, the overall conductive area of the shavings was apparently too small and the metal melted or areed/sparked temporarily across small gaps. The current capability was only 25-50 A and melting of the shavings soon broke the circuit. Very little joule heating was evident.

Next some graphite was ground from an old electrode and poured between and under the electrodes in a depression formed in the soil. The amount of graphite was probably half what might be needed, and the shape of the depression resulted in a flatter conducting path than desired. The current path was started at approximately $50 \mathrm{~A}$, but soon obtained an open circuit (presumably because the graphite powders were blown away by the strong are jet) and would not restart. It appeared that the graphite electrode to graphite powder was not a good conductor and/or a higher breakdown voltage $(>80 \mathrm{~V})$ was needed. 
Additional graphite was added to the conducting path, plus some cut up aluminum from the shavings, plus a square of graphfoil under each electrode, plus a $1 \times 4$ in. piece of graphfoil was laid on top of the path between the electrodes. Higher currents 100-150 A were obtained, but again the conducting path was broken and was not able to be restarted. Arcing under one electrode with conduction only under the other electrode was observed.

Steel shot in a $3 / 4$ in. semicircular stainless boat was next used for the conducting path. The current was started about $50 \mathrm{~A}$ and was raised to 150-200 A. The left electrode was the hottest in that arcing occurred between the electrode and melted shot, which melted the end of the boat; whereas, the right electrode operated in conduction mode and the soil/melt was dull red. As the iron melted and the electrodes lowered to maintain operation, the right electrode teeter-tottered the boat near the left electrode up to break the circuit. A large amount of arcing from the left electrode (anode) was observed normal to the attachment point, which often rose to the side of the electrode and circled the electrode in irregular fashion.

The circuit appeared to be broken when the arc length or circuit path was increased. The Miller P.S. appeared to be operating near or at the top of its operating voltage at the current used. Power supply characteristics decrease voltage with increase in current; whereas, arc characteristics increase voltage with current above approximately $100 \mathrm{~A}$. Attempted increases in current would increase arc voltage needed, but decrease voltage available. In addition, the open circuit voltage available was apparently insufficient to enable restarting a higher resistance path. As a result, a power supply with more favorable voltage-current characteristics was used for further tests.

Power for the arc melter was switched to a single TAFA power supply with $200 \mathrm{VOC}$ and capable of operating at $100 \mathrm{~V}$ and $400 \mathrm{~A}$. The power supply was operated manually and not through the power console. Steel shot under the electrodes with the remains of the $3 / 4$ in. semicircular boat used between electrodes was the conducting path. A piece of graphfoil was placed on top of the steel shot between the electrodes. The current was started about $50 \mathrm{~A}$ and was slowly raised to $350-400 \mathrm{~A}$ over $1 / 2 \mathrm{~h}$. At the low currents, 50-200 A, the graphfoil became red (about $800^{\circ} \mathrm{C}$ ), but the shot under it did not melt. At 250-300 A (about $30 \mathrm{VDC}$ ), the color turned yellow, and the shot near the left electrode (anode) melted and an arc appeared as the melted metal sank into the soil. The right electrode remained in the conduction mode, and the soil/melt under the graphfoil became dull red. As the current was increased to 350-400 A (at $<50$ VDC), the iron melted and sank "uniformly" into the soil (as was found after excavation). About this time, a dramatic storm occurred in the melter, with clouds of whitish-grey "smoke" swirling around making it difficult to see the melt surface. Later, the smoke subsided and the melt surface had become quiescent with a larger reddish glow near the left electrode and a smaller one near the right electrode, both under the surface of the melt. The surface of the melt had cooled and appeared dark, like the surface of a lava flow. Variations in current did not appear to have much influence on the appearance. Attempts to increase the current further resulted in spurious voltage fluctuations from the operating 50 VDC up to 150-200 VDC, during which the circuit was broken. Restarting by lowering the electrodes did not occur, even with 200 VDC open circuit. The electrodes were raised to find a significant amount of material attached to and stretching below and between the electrodes. There was also one or two layers of material attached to the bottom of this material. It was left to cool over the weekend. 
With the higher voltage capability provided by the TAFA power supply, the are melter ran for about 30 minutes, when the are suddenly extinguished. Attempts at restarting were unsuccessful. The resulting melt comprised $0.525 \mathrm{~kg}$ of slag and $0.320 \mathrm{~kg}$ of carbon steel in the form of a solid mass at the bottom of the melt. This metal came from the shot and shavings used in starting the melt.

Excavation showed that the steel shot had melted and sunken fairly evenly to a depth of about $5-8 \mathrm{~cm}(2-3 \mathrm{in}$.). The left electrode (anode) arced all the way down to the melted metal through a hole surrounded by melted soil. At the right electrode, similar arcing was not apparent, with a solid connection (electrical?) to the melted metal and also a sloping down of the melted (glassy) soil toward the metal under the left electrode. The soil surrounding the melted shot was partially vitrified. It may be that continuing stcadily at 300-350 A ( $<50$ VDC) would have resulted in additional melting of the soil; however, much of the current was being carried in the metal melt with a low Joule heating effect. (The melt thickness around the metal was only about 1-2 mm.)

\section{Test 2: Graphite Dumbbell Starter}

Voltage-current characteristics for the test run on 6/11/92 were improved by connecting two of the TAFA power supplies in parallel giving $400 \mathrm{VOC}$ and $200 \mathrm{~V}$ at $600 \mathrm{~A}$ (120 kW total). The power supplies were connected to the remote control console. This is the normal method of operation and also provides for rf starting capability, if needed. The taps on each power supply were changed to provide an VOC of $400 \mathrm{~V}$ and an operational power of $60 \mathrm{~kW}$ at $200 \mathrm{~V}$ and $300 \mathrm{~A}(120 \mathrm{~kW}$ total $)$.

A new crucible was used with 4 in. of soil (approximately $6.5 \mathrm{~kg}$ ) with the lumps crushed and screened so that the lumps are no larger than $1 \mathrm{~mm}$ in diameter. To aid in starting, two carbon cylinders 3 in. high by 1.5 in. in diameter were connected by a $1 / 2$ in. diameter rod near the cylinder bottoms. This carbon piece, similar to a dumbell in appearance, was inserted into the soil with the cylinders located just below the electrodes.

The test lasted 15 minutes and ended when the right electrode broke ofl. Most of the soil heating occurred under the right electrode after an are was initiated by raising the electrodes. The left electrode remained in contact with the carbon cylinder. Figure B-1 shows the extent of soil melting around the carbon starting block. The maximum soil temperature as measured by a ceramic coated thermocouple located about $1 \mathrm{in}$. from the outside of the crucible and eentered on the electrodes was almost $40^{\circ} \mathrm{C}$. The left electrode also broke off at a slight touch when attempting to remove it from its holder.

\section{Test 3: Electrode and Melter Modifications}

Test 3 was run on 6/15/92. The power supply configuration remained the same as for Test 2 , with two TAFA units in series giving 400) VOC with 200) V and 600 A operating conditions. To prevent the electrodes from breaking, the attachment was reworked so that the metal holder screws into the carbon rods rather than the rods screwing into the holder. The soil and crucible from Test 2 was reused. Approximately $2.3 \mathrm{~kg}$ of the soil was melted, resulting a greenish, very light slag. The density was low because of the many bubbles entrained in the slag. 


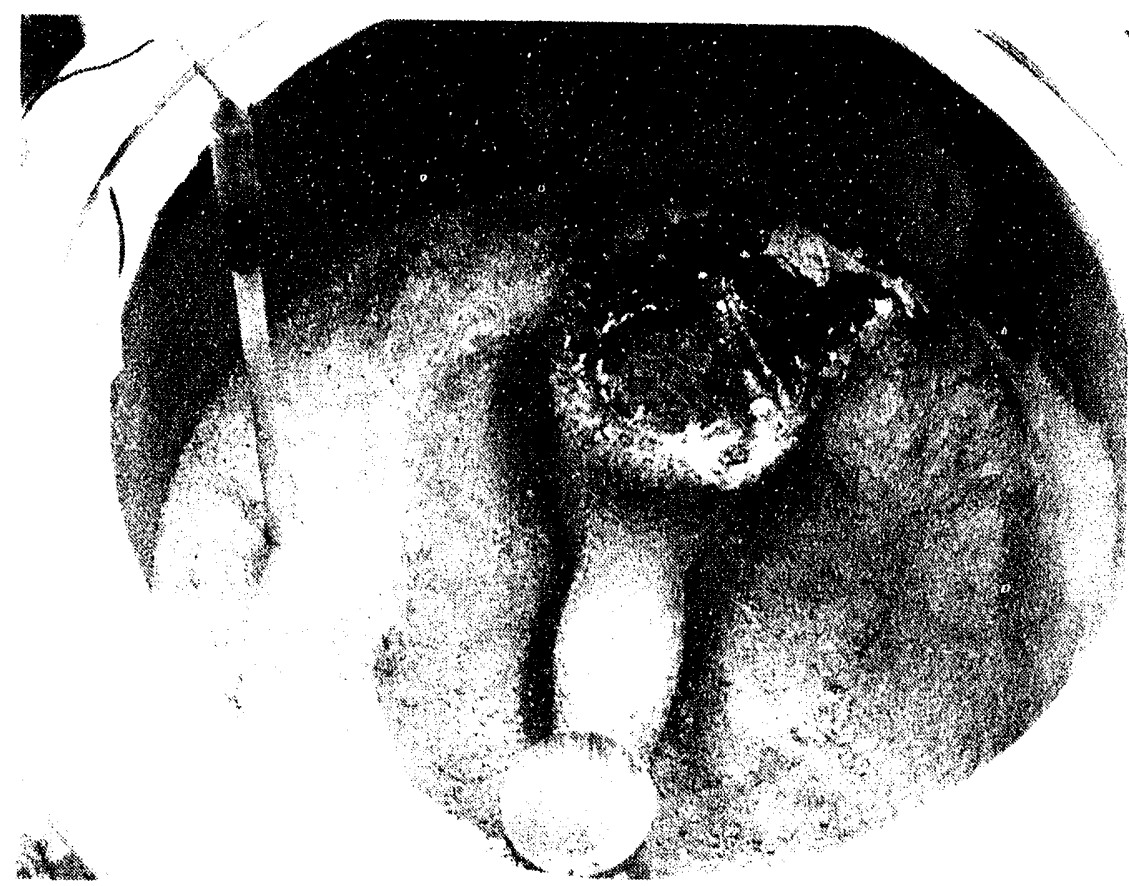

Figure B-1. Soil has been removed to reveal partial meiting around "dumbbell" carbon starter during Test 2. Note the placement of the thermocouple 1 in. from the crucible wall and the tip) about halliaty down into the soil.

The test lasted 30 minutes and was halted when the top of the are melter jacket became extremcly hot. During the melt, the carbon starting cylinders rotated sideways and floated to the top of the melt. The temperature measured by the thermocouple rose gradually during the experiment to almost $1(1) 0^{\circ} \mathrm{C}$, then rose dramatically to $913^{\circ} \mathrm{C}$ just before shutdown. Figure $\mathrm{B}-2$ shows a cutaway view of the melt with the carbon cylinders inside. Immediately after the melter was shut down, a small water leak was discovered inside the melter. After tearing the system down, a pinhole inside a crater on the side of the erucible was discovered. The crater may have been the result of an are strike.

\section{Test 4: Graphite Starting Strip}

For Test 4 on 6/19/92, the power supply setup was the same with two TAFA units in parallel and $4(x)$ VOC. A cooling plate and insulation were added on the inside top of the chamber as protection against overheating. Thermocouples were placed on all water cooling inlets and outlets. The power supply cooling water was hooked into the are melter jacket and conling plate. Water llow meters were on all inlet cooling lines. A new crucible was lilled with $6.651 \mathrm{~kg}$ of soil (about $4.5 \mathrm{in}$. deep) with a thermocouple placed as in previous experiments and approximately 2 in. deep. A small carbon starting strip) with dimensions as in Figure 9 wass used to start the melt.

This test was stopped temporarily after 10 minutes when an accidental movement of the electrodes drove them into the mell. The melt was removed from the electrodes and the test was resumed for an additional 8 minutes resulting in a total melt of $2.440 \mathrm{~kg}$. The soil cemperature 


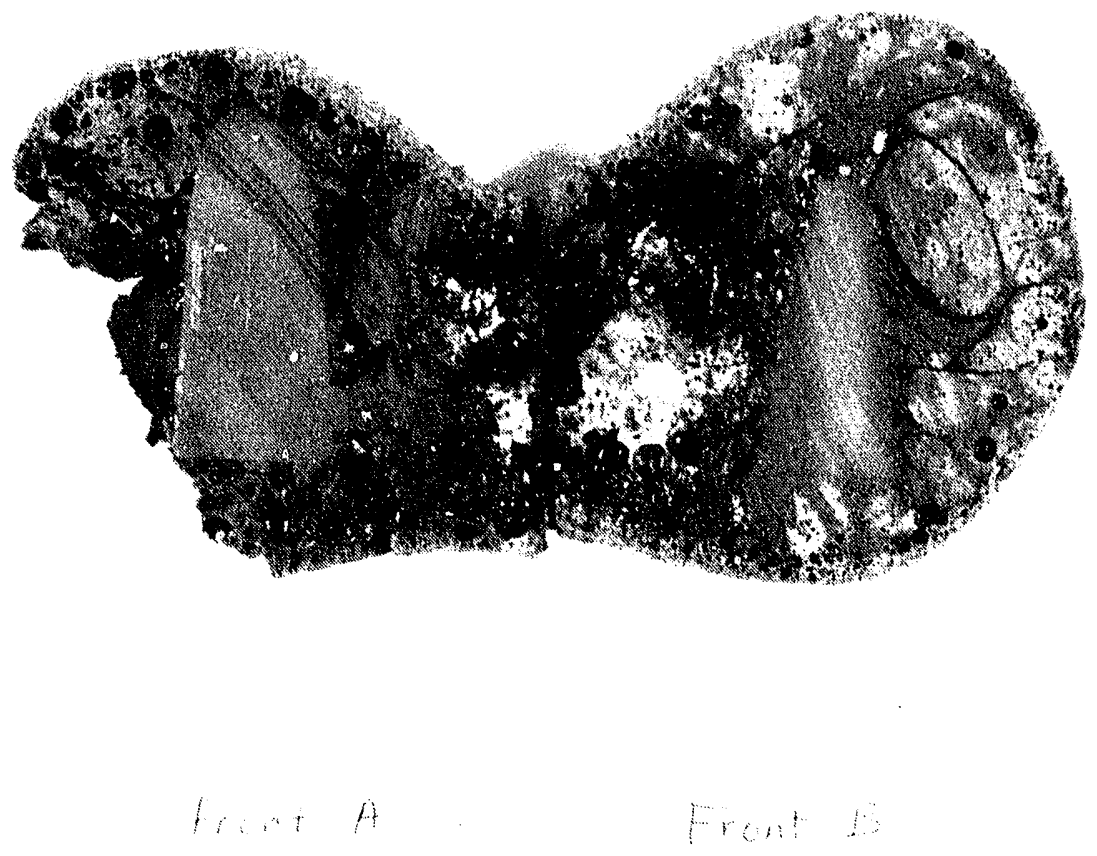

Figure B-2. Cutaway view of Melt 3 showing the numerous bubbles that formed in the melt. The carbon starter, also shown, had turned sideways and floated to the top of the melt (Test 3).

measured by the thermocouple reached a maximum of $622^{\circ} \mathrm{C}$ eight minutes after shutting down the are melter. The are melter was turned off when large pufl's of smoke and steam began to escape from holes and windows in the jacket. Examination afterward showed that dust on the walls and in the window ports was wet, but there were no pools of water. The origin of the water still remains unknown.

\section{Test 5: Heating Procedure Trial}

Test 5 , on $6 / 20 / 92$, had the purpose of (1) double checking the new starting procedure with the $1 / 4$ in. thick graphite strip, (2) checking the initial heating current-time procedure, and (3) determining if additional cooling methods were necessary when most of the soil melted to slag.

The remaining dirt from Test $4(2.5 \mathrm{in}$. deep and $4.211 \mathrm{~kg}$ ) was used. Another carbon strip as in Test 4 was used for starting. The starting procedure worked well, with the only exception that the right electrode was predominantly in the conduction mode instead of arcing.

The configuration of the are melter remained the same as in Test 4. The thermocouple was placed about $1 / 2$ in. from the crucible wall. The run lasted for 18 minutes and resulted in a melt of $0.932 \mathrm{~kg}$. The resulting slag was green in color as in Test 3, and it had less entrained bubbles with a resulting higher density. 
The heating procedure consisting of a high initial current and low voltage followed by a decreasing current as the voltage rises worked well. The melt became red over a large area of the surface. Contrary to previous runs, the dust storm did not occur and vision inside the chamber was not obscured until the arc went out.

The arc melter shut down by itself at the same time large puffs of smoke and steam blew out of the melter. The crucible and melter jacket were filled with water. Subsequent investigation showed that a 6-mm hole had been burned in the bottom of the crucible allowing cooling water to ilood the melt.

\section{Test 6: IEB/A-40 Simulated Average Waste Trial}

Test 6 , on $6 / 26 / 92$, switched from a pure soil to simulated average waste plus $40 \%$ soil, the IEB/A-40 mixture. This mixture was used to determine the effect of a mixture with a more favorable slag electrical conductivity and viscosity, as well as to test the simulated waste mixture.

The power supply configuration remained unchanged. Modifications prior to this test included the installation of a disk under the crucible. The disk has a 1.0 in. diameter hole in the center to direct water flow to the center of the bottom of the crucible to increase heat transfer limits when the slag reaches the bottom of the crucible. Copper coils placed along the side of the crucible will direct water flow with increased velocity and improve heat transfer from the sides of the crucible. The soil for this test was modified by adding iron oxides, etc., to conform to an A-40 mixture. The crucible contained $6.727 \mathrm{~kg}$ of material with a depth of $4.5 \mathrm{in}$.

The test went smoothly and lasted about one hour and resulted in a slag mass of $5.669 \mathrm{~kg}$ with a volume reduction of about $1 / 2$. The slag broke into small pieces, less than 1 in. in diameter, when it was removed from the crucible. The slag in general was dense with no bubbles. Its color was black, with a shiny glassy appearance.

The starting technique with the $1 / 8$ in. graphite strip worked perfectly. After the starting sequence and the melt were well established in Test 6 , the current was subsequently increased from about $50 \mathrm{~A}$ to as high as $175 \mathrm{~A}$ near the end of the test. The voltage also increased from a conservative $150 \mathrm{~V}$ during initial heating, to a relatively steady $250 \mathrm{~V}$ during the lasi half of the test. As the current increased later in the test, the rate of melting increased and caused some of the A-40 left on the sides of the crucible to fall into the melt. Figures 10 and 11 show the current, voltage, and resulting power input data recorded manually during the course of the test. Figure 15 shows the temperature profile recorded by the ceramic coated thermocouple embedded in the soil. The Type-C thermocouple was placed 1 in. from the crucible wall, equidistant from the electrodes.

Figures B-3 and B-4 show the vitrified waste immediately after removing the crucible from the chamber. Figure B-5 shows the crucible contents after loosening (breaking) the solidified slag into chunks to remove it. Essentially all of the A-40 mixture was melted and turned into slag.

During Test 6, heating could be operated in several modes depending on arc gap, current, and stage of melting: (1) a quiescent mode with small arc gap and modest current where most of the surface was dark and yellow circles occurred around the arc attachment immediately below 


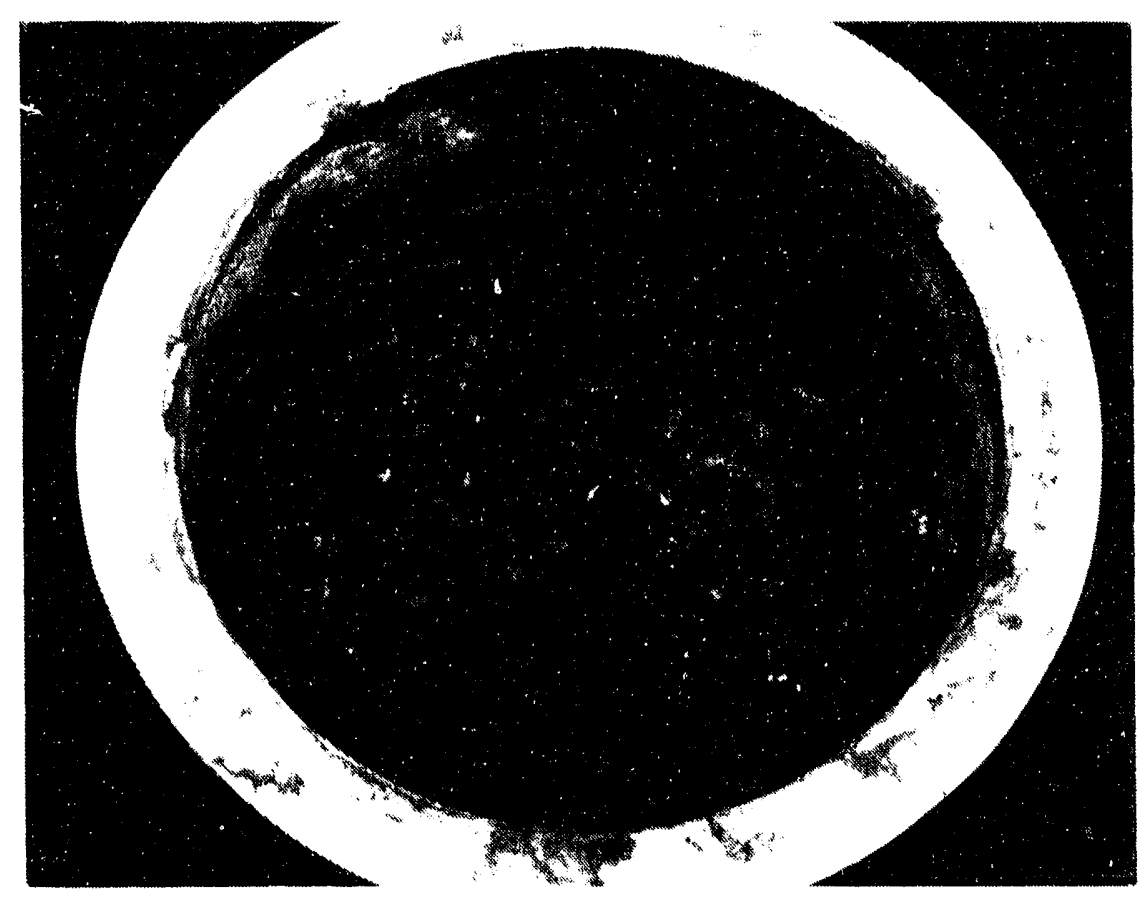

Figure B-3. Crucible with slag after Test 6. Bubbles formed on top of the slag when water from pinhole leaks on the side of the crucible sprayed onto the melt.

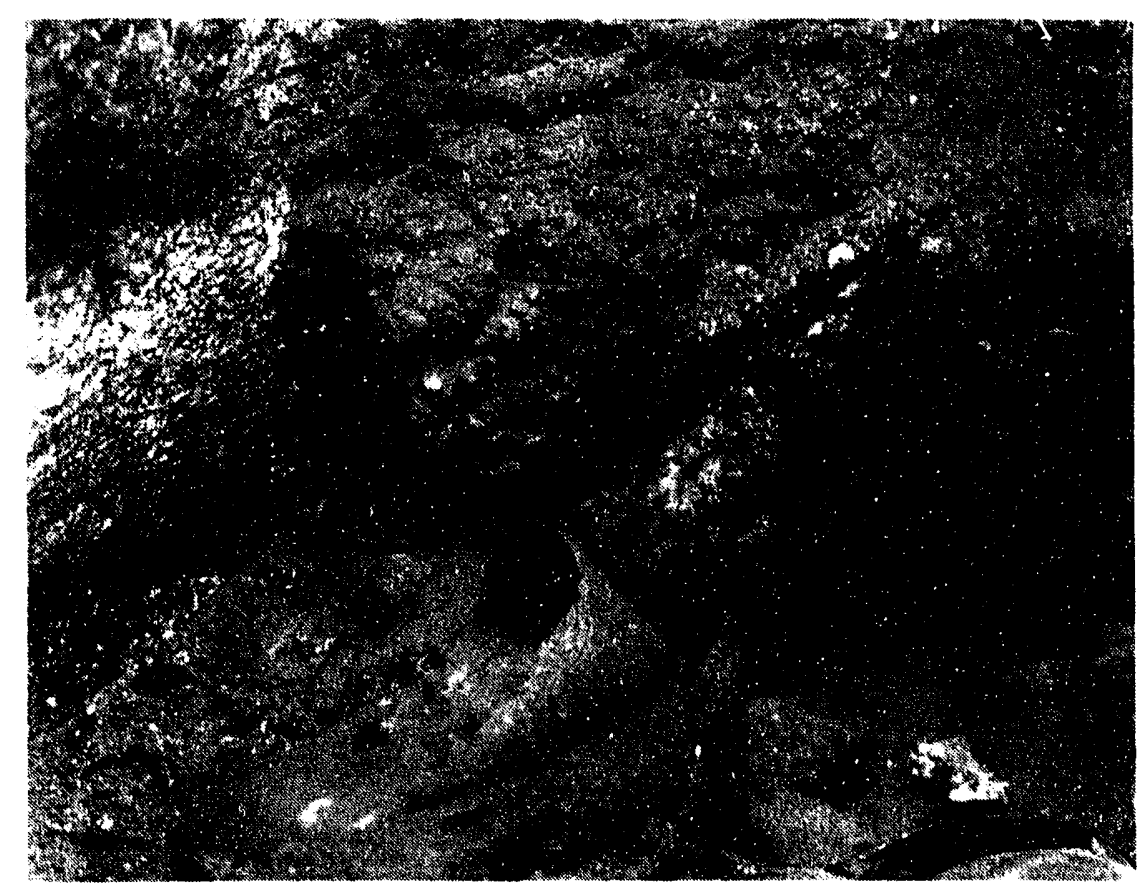

Figure B-4. Closeup view of Test 6 shows where the soil has fallen away from the side of the crucible and into the melt. This was the result of increased power input near the end of the test. 


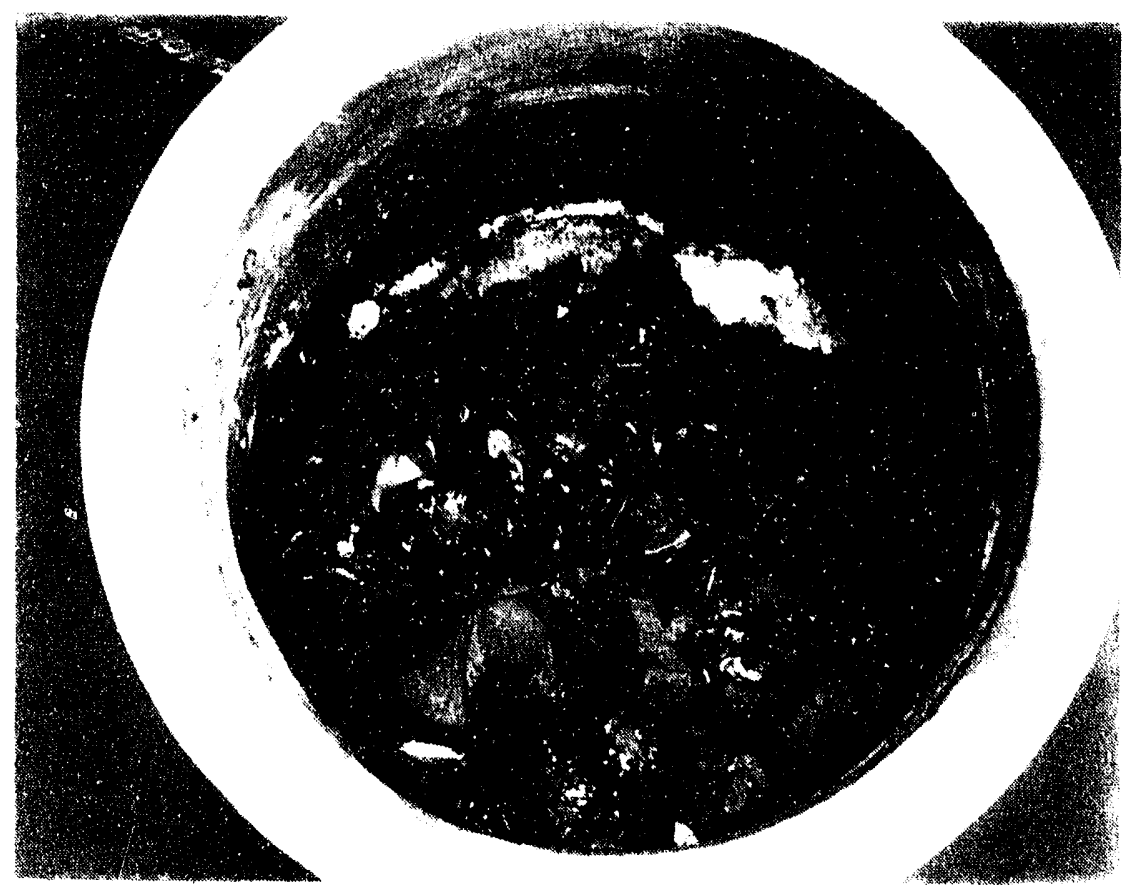

Figure B-5. Removal of the slag caused it to break into glassy shards. The melting extended to the bottom corners of the crucible.

each electrode: (2) a rolling boil mode in which either the slag under the electrodes (early on) or at a location between the electrodes (later), and/or at alternate sides of the crucible in regions where melting had not been obvious before, and finally the whole top of the melt appeared as a slowly or moderately rolling boil; (3) a firecracker mode that appeared to be when the electrodes were just in contact with the surface and at the highest currents which allowed continued operation with the V-I characleristics available here. The lirecracker mode resembled the random trajectory of bright yellow (as viewed through the protective glass) rockets emitted from the slag at the base of the electrodes and landing elsewhere in the melt or on the walls. At other times, the electrodes were immersed in the slag and operated totally in the Joule heater type of mode. There was no slag stuck to the electrodes upon emerging from the slag melt and was litte difference in operating conditions (voltage or current).

Both starting technique and heating procedure worked atmost perfectly. More than half of the time was spent in all operating mode characterized by direct short arcing to the pool surface with Joule heating via current flow through the liquid slag. During the heating procedure, when the current limits of the melter were being lested the circuit would open, but could be immediately restarted by lowering the electrodes to make contact with the melted slag. No dust storms, significant vaporization, or foaming was observed throughout the test.

The end of the kest occurred while lesting the current limits and atlempting to melt the rest of the A-40 skull. A pin hole leak developed in the side wall of the crucible, above the melt, but below the original fill line. It is unlikely that the spot is are-initiated, since it oceurred well after transition to a predominantly Joule-heater operating mode. While the cause is not definitely 
known, it may be simply due to the shift from nucleate to film boiling on water side of the crucible. This reinfores the need to implement a better design for eooling the crucible side walls. The bottom of the crucible indicated only slight discoloring, so its cooling modification may be adequate.

\section{Test 7: IEB4/A-40 Simulated Average Waste Trial}

Test 7, on 7/2/92, was performed to compare the effect of the addition of $\mathrm{ZrO}_{2}$ and $\mathrm{TiO}_{2}$ to the IEB/A-40 in Test 6 , as well as to try a conservative run without straining the system.

The most important change prior to this test was modilication to the copper coils surrounding the crucible. Spaces between the coils were filled with plumbers putty. This reduction in volume forces the water to flow faster and to increase heat transfer to the crucible walls. The data logger was set up to automatically monitor voltage and current. In addition, an optical pyrometer and a video camera system were set up to monitor the piogress of the melt.

The soil used for this test was the remaining A-40 $(6.638 \mathrm{~kg})$ plus $5 \mathrm{wt} \%$ additions each of titanium oxide $\left(\mathrm{TiO}_{2}\right)$ and zirconium oxide $\left(\mathrm{ZrO}_{2}\right)$. This created a total mass of $7.375 \mathrm{~kg}$, which filled the crucible to 4.75 in. when compacted. The test went smoothly and lasted slightly more than 1 hour resulting in $6.199 \mathrm{~kg}$ of dark glassy slag (IEB4). The material was very dense and hard, even more so than the material in Test 6 . Although the slag broke into pieces as in the previous test, the pieces were much larger, at least 2 in. in diameter for the larger pieces. The surface appearance was not quite as glassy, but slightly duller, indicating some possible crystallization during cooling.

For Test 7, the starting technique and heating procedure again worked almost perfectly, with exceptions discussed below. Figures 12 and 13 show the current, voltage, and resulting power input data during the course of the test. The data was recorded using the $\mathrm{PC}$ and data logger system. This data recorded every 30 seconds shows the operating transition that occurs early on in the melt, that is from a low voltage - high current mode to the steady state high voltage - low current operating mode.

The melt exhibited some foaming not observed in the previous IEB melt. During foaming, the are would occasionally extinguish, but could immediately be restarted by lowering the electrodes to make contact. This occurred at an early stage in the heating but after depletion of the starting stick. Even without a significant slag channel area, the 400$) \mathrm{V}$ open circuit voltage is sufficient (at low current of about $50 \mathrm{~A}$ ) to restart by contact for this geometry. The electrodes remained free and elean of solidified slag even though dipped into the slag or after foaming. The foaming was small corresponding to 1 to 2 in. in height and fairly uniform across the meit. The atmosphere within the chamber remained elear, with relatively little dust attaching to surfaces compared to initial runs.

Optical pyrometer readings indicated the slag under the electrodes was 1,600$)-1,800^{\circ} \mathrm{C}$, while the nearby "darker" matcrial, a crust on the slag, was about $1,300{ }^{\circ} \mathrm{C}$. Figure 16 shows the soil temperature profile 1 in. from the crucible wall as recorded by the thermocouple. After the temperature of the thermocouple in the slag exeecded $1,500^{\circ} \mathrm{C}$ and the time of operation reached 1 hour, the system was shut down by simply raising the electrodes. 
In this test, the system was not put under stress by raising the current near the end in order to try and melt the soil clinging to the sides of the crucible. Figure B-6 shows the crucible and slag after being removed from the melter. Note the unmelted soil around the edges. An indication of the constituency is given in Figure B-7, in which agglomerated IEB4/A-40 mixture was melted early in the process around the thermocouple insulation and ceramic shield and remained in place throughout the test. Increasing the heating period and/or power level may have melted this agglomerated slag/soil. An insertable and removable thermocouple is planned for future work. The soil contained within the slag however, melted thoroughly under these low-power conditions. After shutdown, the melt appeared a uniform red by naked eye over the whole pot surface. When removed from the crucible, the chunks were similar to those from Test 6, but appeared to be more brittle and had many sharp edges and small slivers typical of vitrification, but without crystallization. After being washed, the samples lost the reddish color and appeared dark brown. The cooling rate, measured with the optical pyrometer, was relatively rapid due to the water cooling of the crucible.

\section{Tests 8 \& 9: IEB/A-100 \& IEB4/A-100 RWMC Soil Trials}

Test 8 , on $8 / 3 / 92$, and Test 9 , on $8 / 6 / 92$, were performed for the purpose of demonstrating the arc melter capability to melt the high n elting temperature RWMC soil, and soil plus $5 \mathrm{wt} \%$ each of $\mathrm{TiO}_{2}$ and $\mathrm{ZrO}_{2}$, respectively. The soil plus additive test is to also see if the addition of $5 \mathrm{wt} \% \mathrm{TiO}_{2}$ and $\mathrm{ZrO}_{2}$ will lower or raise the melting temperature of the soil.

In Test 8 , the operation started with $10 \mathrm{~kg}$ of pure soil. The arc melter was started lollowing the standard procedure. Figures 24 and 32 show the current, voltage, and resulting power input data during the course of the test. In the early phase of melting, a localized molten pool formed beneath the electrodes. The cathode pool was larger in size than the anode pool and the anode are root motion was more intense. The consuming graphite strip provided a current path between the two pools. The end of the graphite strip close to the anode was consumed much faster than the other end. The are became unstable and required higher voltage from the power supply to sustain the current when the anode arc gap became too large. Finally, the circuit opened when the graphite strip burned too short. A second graphite strip was used to restart the are, and finally a molten conducting path between the electrodes was achieved. It is important that the molten pools of soil beneath the electrodes coalesce to establish a conducting path for a self-sustaining arc prior to consuming the graphite strip to a critical length. In the progress of soil melting, a gentle dust storm was observed before the soil was completely melted. This dust storm was caused by out gassing (dehydration and carbonate decomposition) of the soil when it reached a certain temperature. After melting for about 1 hour, the soil appeared all molten and the arc was cut off. Figure 40 shows the soil temperature profile 1 in. from the crucible wall as recorded by the thermocouple. When examining the pure soil waste form, it was found that only $2 / 3$ of the soil, about $7 \mathrm{~kg}$ had been melted. All the soil could have been melted if the process was kept longer.

In Test 9, soil plus $5 \mathrm{wt} \%$ each of $\mathrm{TiO}_{2}$ and $\mathrm{ZrO}_{2}$, the same general observations were made. Figures 25 and 33 show the current, voltage, and resulting power input data during the course of the test. With approximately the same heating time and power requirement, the soil plus additives were completely melted. It appeared that additives behaved as fluxes to lower the melting temperature of the soil. The desired explicit comparison of temperatures was not possible 


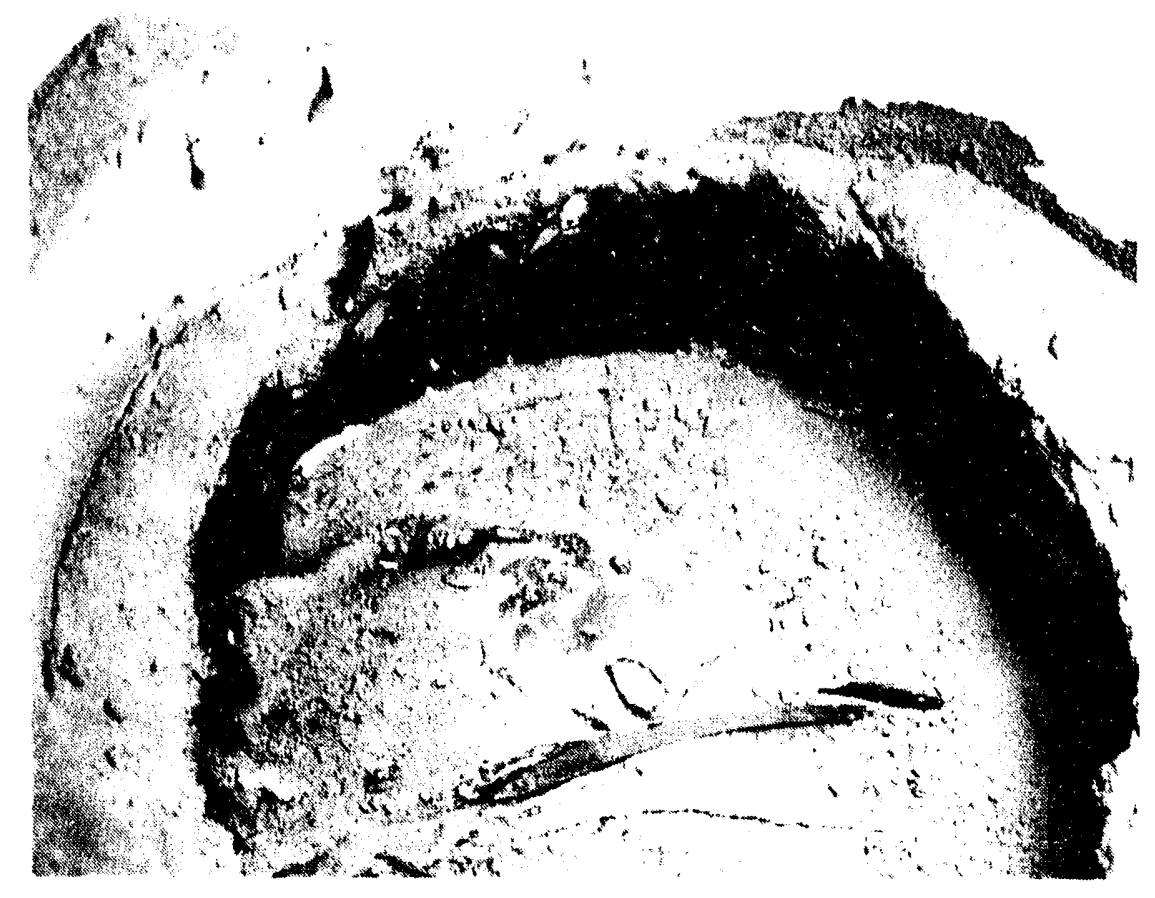

Figure B-6. Crucible with slag after Test 7. In this test, the power levels were maintained low throughout the test; and the soil around the edges did not melt away from the sides of the crucible.

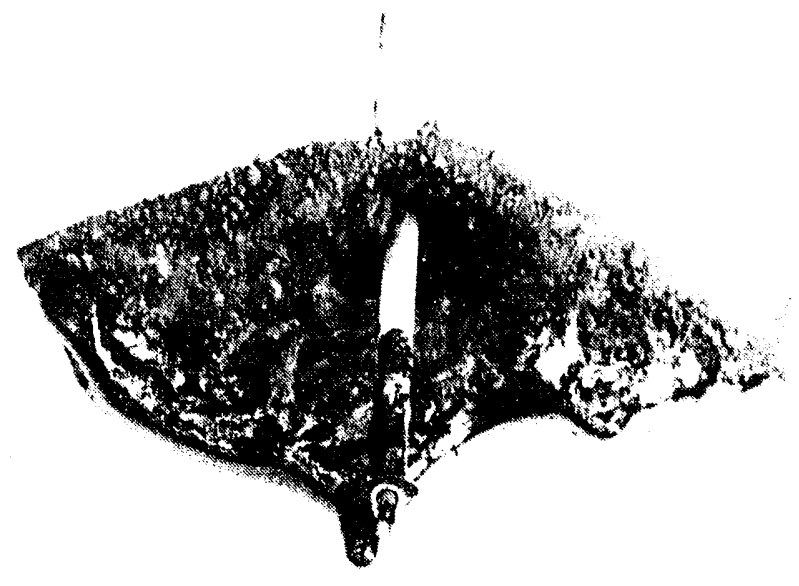

Figure B-7. A crust of agglomerated soil formed around the thermocouple carly on and remained throughout the lest. 
because valid optical measurements were not obtained for Test 8 (out of calibrated range) and valid thermocouple measurements were not obtained in Test 9 (thermocouple malfunctioned early). Comparable voltage-current characteristics were essentially identical, suggesting that the $\mathrm{ZrO}_{2} / \mathrm{TiO}_{2}$ addition had no significant effect. Comparing the two waste forms, the soil plus $\mathrm{TiO}_{2}$ and $\mathrm{ZrO}_{2}$ gave a much denser and better glass than the pure soil.

The conclusions and recommendations from this test are the following.

1. There is no particular problem melting pure soil or soil plus $\mathrm{ZrO}_{2}$ and $\mathrm{TiO}_{2}$.

2. There is no particular difference in the melting characteristics of IEB with or without $\mathrm{ZrO}_{2}$ and $\mathrm{TiO}_{2}$ (IEB/A-100 or IEB4/A-100).

3. Both Tests 8 and 9 processes completely melted the IEB/IEB4 at essentially constant voltage and current throughout the process.

\section{Test 10: IEB4/H-Series Hydrated Metal Oxide Trial}

Test 10 to melt simulated Rocky Flats 741 sludge was performed in two parts, the first on 9/8/92 (Test 10a) and the second on 9/9/92 (Test 10b). The purpose of this experiment is to demonstrate the arc melter capability for processing the hydrated metal oxides ( $\mathrm{H}$ series high $\mathrm{Na}$ waste stream) and to evaluate the effects of oxide dehydration on the melting process. The changes in the slag composition with increasing waste additions are investigated. Aluminum was also added to the melt at the end of the $\mathrm{H}$-series runs to determine the $\mathrm{Al}$ limits $\left(\mathrm{as}_{2} \mathrm{Al}_{2} \mathrm{O}_{3}\right)$ in the slag that will freeze the melt and to identify changes in the slag composition with increasing amounts of aluminum oxide.

The composition of simulated hydrated metal oxides used was that for simulated sludge compositions given by Landman ${ }^{a}$ and did not include the container or contents other than the simulated sludge. The compositions are given in the table below. The high Na sludge (analogous

Composition of simulated hydrated metal oxide sludge from Landman. ${ }^{\text {a }}$

\begin{tabular}{lccccccc}
\hline & $\mathrm{SiO}_{2}$ & $\mathrm{Al}_{2} \mathrm{O}_{3}$ & $\mathrm{Fe}_{2} \mathrm{O}_{3}$ & $\mathrm{CaO}$ & $\mathrm{MgO}$ & $\mathrm{Na}_{2} \mathrm{O}$ & $\mathrm{K}_{2} \mathrm{O}$ \\
\hline High Na & 36.3 & 14.0 & 6.6 & 4.8 & 5.3 & 28.4 & 4.6 \\
High Ca & 46.9 & 4.3 & 5.9 & 22.8 & 10.7 & 5.7 & 3.7 \\
\hline
\end{tabular}

a. W. H. Landman, Jr., "Sludge Compositions," TWTF/Reedy Creck Engineering Design File No. 19, TWTF-68, November 13, 1981. 
to H1-Series) was used in Test 10. The $\mathrm{H} 1$ series compositions include both container and other contents as obtained by Grandy ${ }^{\mathrm{b}}$

The operation started with the melting of $3 \mathrm{~kg}$ IEB4/H-100 base soil (90\% soil plus $5 \%$ each of $\mathrm{TiO}_{2}$ and $\mathrm{ZrO}_{2}$ ) in the are melter crucible under ambient air. Figures 26, 27, 34, and 35 show the current, voltage, and resulting power input data for Tests $10 \mathrm{a}$ and $10 \mathrm{~b}$ during the course of the test. Metal hydroxides (to simulate the hydrated metal oxide sludge) were later added to the melt to decrease the base soil composition by $10 \%$. The resulting slag composition is designated H-90. After the melt reestablished equilibrium, a slag sample was taken for analysis. More simulated waste was added to the melt to further decrease the IEB4/100 base soil composition. successively, by $10 \%$ to produce $\mathrm{H}-80, \mathrm{H}-70$, and $\mathrm{H}-60$ slags. Slag samples were taken, after each addition of the simulated waste, for analysis. With each addition of the high Na simulated waste the melt became more fluid. This property was expected for high alkali flux additions to a silicate melt. During the H-70 run, the are circuit opened and it could not be reestablished by touch starting. Unfortunately, the melt cooled down too fast to allow for sampling, and H-70 was declared a "no-test."

On 9/9/92, the remaining simulated hydrated oxide was added to the solidified slag to help restart the are melter, in addition to the graphite strip. After the $\mathrm{H}-60$ composition had been reached and a specimen was taken, aluminum metal was then added to the melt. The effect of $\mathrm{Al}$ (as $\mathrm{Al}_{2} \mathrm{O}_{3}$ ) on the slag chemistry should be to stiffen or freeze up the melt. During addition, the aluminum floated on top of the melt then eventually melted. Diffusion of molten $\mathrm{Al}$ into the melt and ignition of metal vapor were evident. Finally the electrode burned too short and the test had to be terminated. Only $2 \mathrm{wt} \%$ of $\mathrm{Al}(100 \mathrm{gm}, 1 / 10$ of originally planned) was able to be added. In this experiment, chemical corrosion was much more severe on the graphite electrodes than in ambient air. This was due to accelerated attack on the carbon electrodes by $\mathrm{H}_{2} \mathrm{O}(\mathrm{g}), \mathrm{OH}$, $\mathrm{H}$, and $\mathrm{O}$ from the decomposing metal hydroxides in the melt. The anode corrosion rate was noticeably much higher than the cathode. Both electrodes achieved a tapered shape.

The following general conclusions and recommendations evolved from this test.

1. The metal oxide mix provided a good starting medium (with graphite starting strip).

2. The aluminum did not melt fast enough nor oxidize fast enough to affect the melt/slag in this application.

3. The amount of water vapor or hydroxides should be minimized in a melter with graphite electrodes to minimize wear rate.

\section{Test 11: IEB4/M-Serics Soil and Metal with Argon Atmosphere Trial}

Test 11 was performed on 9/11/92. The melt was initiated on IEB4/M-100) witu an argon flow rate of 25 seth for 13 minutes; whereupon, a lot of dust was formed and the are went out.

b. J. D. Grandy, T. L. Eddy, and G. L. Anderson, TSA Waste Stream and Final Waste Form

Composition, EGG-MS-10617, January 1993. 
Figures 28 and 36 show the current, voltage, and resulting power input data during the course of the test. After restarting, melting continued for 47 minutes before adding iron nails. After five minutes, $0.805 \mathrm{~kg}$ of iron had been added and an apparent eruption, from steam or carbonate release, occurred. The experiment was terminated because it was thought that the chamber had developed a leak. See other metal test descriptions.

\section{Test 12: IEB4/M-Series Soil and Metal with Air Atmosphere Trial}

Experiment 12, to melt soil and metal in an air atmosphere, was performed on 9/18/92. Figures 29 and 37 show the current, voltage, and resulting power input data during the course of the test. The first attempt to run the experiment failed because the soil did not melt sufficiently between the two electrodes, and when the current was disrupted (after 6 minutes of operation) it could not be restarted. This apparently occurred because the $1 \times 6 \times 3 / 16$ in. graphite strip did not reach sufficient temperature (yellow-hot) to heat the soil beneath it. Even though the current was raised to $250 \mathrm{~A}$, the strip did not get red hot. It appears that the strip was too thick and did not offer enough resistance to heat up $\left(I^{2} R\right)$ sufficiently.

The slag generated was removed and the experiment was restarted with a new charge of soil. The thicker starter strips (about 3/16 in.) were cut back into a dumbbell shape to give similar cross-sectional area as successful starts. The starting procedure was reinitiated at 4:15 p.m. Initial currents were 200-250 A and reduced as the voltage rose with time. The strip still did not get yellow hot other than at each end near the are attachment. As the ends sublimed/burned away (no flame was evident) the strip decreased in length, the are length to the strip ends increased, and the voltage rose. The current was decreased to maintain the arc, but near the end the rate of decrease increased drastically with time and the current ceased even at the lowest setting. The latter change occurred over a few seconds. The are would not start, again because the soil had not sufficiently melted.

A thin graphite strip ( $1 \times 6 \times 1 / 32$ in.) was placed over the other imbedded strip. When the electrodes made contact, the strip fractured on each end. Some of the steel shot was placed on each end of the graphite strips under the electrodes, and after a false start and some more steel shot, the arc was restarted. Very erratic starting and heating ensued, characterized by voltage and current fluctuations, spurious arcing, and power supply cracking sounds. Operation was even unstable at low currents of $9 \mathrm{~A}$ and voltages of $2000-300 \mathrm{~V}$. At $6: 00 \mathrm{pm}$ we decided to check if the are V-I characteristics were now increasing by steadily increasing the current rheostat by 10 unit intervals and monitor $V$ and $I$. As the rheostat setting increased, the current increased (from a low of $9 \mathrm{~A}$ ) and the voltage also slowly increased (from a low of $300 \mathrm{~V}$ ). During this time, the additional power heated up the slag/soil sufficiently to operate in a stable mode and the test was off and running. The soil was apparently heated throughout in about 1 hour (7:15 p.m.) as indicated by a $30^{\circ} \mathrm{C}$ crucible leaving temperature and observation of the sides of the melt. Prior to that time, some of the unmelted top material had slagged and hardened. It was partially pushed into the melted material. Figure 41 shows the soil temperature as obtained from the thermocouple measurements. After reaching a peak value, the thermocouple malfunctioned.

Next (7:20 p.m.), a slag sample was dipped and the first five metal decontamination samples were taken. Starting at 7:33 p.m., metal rod pieces were dropped into the melt between the electrodes over a period of 15 minutes. The rods would plop into the melt and melt or sink, and 
subsequently fell on top of each oiher and slowly melt and/or sink. The rest of the shot enc. $\mathrm{g}$ was then added in a couple of minutes. Two $\mathrm{kg}$ of steel and iron were added to the $6 \mathrm{~kg}$ of melted soil. During this and the above soil melting, the current was often operated near $200 \mathrm{~A}$; whereas, in frevious melts the current was held below $100 \mathrm{~A}$. At one time, the partially melted slag-metal at the side was partially pushed into the melt to encourage melting. The completion of the metal melting was suggested by observations of the melt, time, and repeated high and stable crucible leav:-g water temperatures. 'The second five metal decon samples were taken (8:33 p.ril.;. The 'secon samples had considerable slag surrounding them so it was decided to use them as the slag samples also. The cathode electrode was operated slightly submerged to keep the anode arc gap smaller and to prevent arcing to the SS chamber near the anode. The current was extinguished about 8:43 p.m., because the electrodes were getting quite short; otherwise, the experiment could apparently have continued indefinitely.

Conclusions and recommendations made as a result of this test were:

1. The starting/heating procedure is inconsistent. It appears that we need to return to the previously determined starting procedures with the approx. 1/16 thick graphite rod, high $(200 \mathrm{~A})$ initial starting currents to melt the soil between the electrodes. (Suosequent tests started with a $3 / 32$ in. graphite strip and higher currents and have not had problems starting.)

2. A short starting and heating cycle is needed to be able to run the main tests for a reasonable duration without having to replace the electrodes. In the actual pilot/treatment facility, starting would probably be done with a more easily started material, e.g., an A-40 mixture. This is not advantageous when we are also making basic IEB and IEB4 for use in waste form materials characterization tests. Nevertheless, we may wish to determine and specify a different stariing series-soil $m$. $x$ if this continues to be a nuisance. (All subsequent starts were performed with soil or soil plus $\mathrm{ZrC}_{2} / \mathrm{TiO}_{2}$ mixture without significant problems.)

3. The powe- supply noise may be caused by the are motion. It was not heard or a problem when more than one power supply was connected in parallel. Even though the process operates at well below the $100 \%$ duty cycle curve, we may want to use two units in parallel to see if the noise continues. (Suosequent tests used two power supplies and did not experience the stated noise or instabilities.)

4. With streng soil concentrations and V/I fluctuations, we are riding and apparently fluctuating across the envelope on the V-I characteristics for one power supply unit. The second pewer supply may need to be hooked in series to give a steeper V-I characteristic and more stable operation. (Subsequent use of two power supplies in parallel did not indicate that additional voltage would be necessary.)

5. The melt is not melting as unilormly as it should, especially in the regions farthest from the electrodes. This appears to be caused by the lack of an optimum thickness of melt. The melt is so thin compared to its diameter or length that the convective eddics developed in the electrode region are not reaching or are out of syne with the unmelted regions. The pattern also appears to be a function of the operating current. It is recommended that different size soil melts be run successively, varying the current at each condition, to check the optimum melt thickness for improved convection in the present geometry. Recommended soil mass/slag heights to be 
examined are (1) $6 \mathrm{~kg} / 1.5 \mathrm{in.}$., (2) $8 \mathrm{~kg} / 2.0$ in., (3) $10 \mathrm{~kg} / 2.5 \mathrm{in.,}$ (4) $12 \mathrm{~kg} \cdot 3.0$ in., (5) $14 \mathrm{~kg} / 3.5 \mathrm{in}$., and (6) $16 \mathrm{~kg} / 4.0 \mathrm{in}$. (Eight $\mathrm{kg}$ gave nice horizontal streamlines following a hyperbolic streamlines. Larger mass streamlines were not as well defined, but may have had a more vertical orientation.)

6. The electrodes burned more equally (possibly because the cathode was kept under the surface near the end), were less pointed (flatter ends) with the zirconia coating, and were operated for at least twice as long as in the other experiments. The alumina coatings should also be tested and the best of the two coatings be used in future melts.

\section{Test 13: IEB4/M-Series Soil and Metal with Air Lance Trial}

Objectives. This experiment, performed on $9 / 23 / 92$, is the first attemp to melt soil and metal with an air lance in the arc melter. The topics to be investigated were •

1. Melt depth studies: Observation of the melt flow patterns after each of $2-\mathrm{kg}$ additions of soil to the initial $6 \mathrm{~kg}$.

2. Voltage drop measurements: immersing both, one and neither electrodes to estimate the effect of electrode fall (voltage drop) heating compared to Joule heating.

3. Oxidation by air lance of metal added to the slag: to compare oxidation rates and processes with similar runs with ambient air and argon.

Starting Procedurc. Recent starting procedures have not been smooth or timely. This experiment attempted to return to the standard starting strip and current-time procedure developed in Phase I of this project. The standard graphite dumbbell starting strip has been about 3/32 in. (though on the original plans 0.065 in., a little over 1/16 in., is given). The first strip used (0.059 in., a little under $1 / 16$ in.) became yellow hot at $200 \mathrm{~A} / 100 \mathrm{~V}$, but burned up rapidly. The arc became unstable, went out, and was unable to be touch started. The remainder of the strip was removed and a 0.090 in. (almost $3 / 32$ in.) strip of 1 in. width (not dumbbell shaped) was used. After starting, the strip did not glow at $200 \mathrm{~A}$, and as the arc voltage increased to over $250 \mathrm{~V}$ and the current was decreased to less than $50 \mathrm{~V}$, the arc went out, and was unable to be touch started. Some steel shot was poured around and between cach electrode contact region, the arc started, but was erratic and went out. Finally two $0.060 \mathrm{in}$. graphite dumbbell strips were placed, one on top of the other, over the other materials. After starting, both ends of the graphite strip burned away, and longer horizontal arcs occurred. The long arcs are important in radiant heating of the slag, as well as the hot graphite strip. At the same time, the soil/slag under each electrode melted with the current oscillating between melt conduction and arc to graphite. As time went on, the graphite was shifted toward and under the right electrode (anode) in a similar way to that in Phase I Experiments 6 and 7. The current is alternating between the melt and the arc-graphite mode. As the strip burned away, the slag between the electrodes became yellow and the melt was on its way.

Two TAFA power supplies were connected in parallel for $400 \mathrm{VOC}$ (open circuit), and a $200 \mathrm{~V} / 300 \mathrm{~A} 100 \%$ duty cycle. Figures 30 and 38 show the current, voltage, and resulting power input data during the course of the test. During starting, there was none of the "cracking" heard in Experiment 12 when only one unit was used. At $200 \mathrm{~V}$ and $150 \mathrm{~A}$, one would not expect to 
exced the power supply envelope, but the signals were transient and the melers did not indicate the current fluctuations observed from the multimeter connected to the current shunt. It appears that the current variation, in switching from conduction to arcing modes, varies much more than the voltage. At later, stabler periods, the voltage could extend to $350 \mathrm{~V}$ and maintain the are. Figure 42 shows the soil temperature as obtained from the thermocouple measurements. After reaching a peak value, the thermocouple malfunctioned.

In summary, it appears what is needed is to return to a dumbbell graphite strip, 0.094 in. ( $3 / 32$ in.) thick, 6 in. long, 1 in. square ends, and $1 / 2$ in. wide between the ends. The initial starting current needs to be high (about $200 \mathrm{~A}$ ) to get the electrode regions melted, but should continue to be decreased as the strip decreases in length to reduce fluctuations. Keeping the electrodes near the melt also helps because of partial current flow through the slag and arcing through any vapor. Additional hardware to reduce fluctuations would be a choke or doubling the power supply voltage. The starting phase should take 5 to 10 minutes. A small amount of more conducting soil (e.g., A-40) could be placed in a shallow region between the electrodes to improve starting (but may alter the desired composition).

Once the starting procedure takes hold, the current can be raised in the rolling boil mode (with the electrodes just touching or just above the melt surface) up to the point where the boil shifts into a more violent mode. If the are goes out, it has always been immediately restarted by touching the melt. See table of time, video index, power settings, and comments.

Heating Procedure. After the 4th restart, stable operation occurred in about 6 minutes. The following heating period was marked by a much larger current (c.g., $170 \mathrm{~A}$ versus $50 \mathrm{~A}$ ) compared to many of the previous runs. This was accompanied by a larger voltage (e.g., $180 \mathrm{~V}$ versus $100 \mathrm{~V}$ ). The $6 \mathrm{~kg}$ of soil became mostly melted after an additional 25 minutes. Two $\mathrm{kg}$ of soil were added in scoops through a $1.5^{\prime \prime}$ tube at $60^{\circ}$ to horizontal. The soil landed between and in front of the electrodes, rapidly melt into the slag, and was essentially all melted when the addition stopped after 18 minutes. The voltage and current were relatively steady, averaging about $140 \mathrm{~A}$ and $190 \mathrm{~V}$ over the period. On one occasion the soil put out the are, which was immediately restarted by touching the slag with the electrodes.

With the additional melt depth due to $8 \mathrm{~kg}$ instead of $6 \mathrm{~kg}$ of soil (estimated at $2.4 \mathrm{in}$. versus 1.8 in.), hyperbolic-like llow streamlines developed in each quadrant with the flow toward the origin and through the melt attachment under each electrode. Video frames of the flows for $8 \mathrm{~kg}$ of soil are shown in Figure 14. The llow streamlines are nonexistent for $6 \mathrm{~kg}$, strongest at $8 \mathrm{~kg}$, and weaker at $10 \mathrm{~kg}$. The second addition of $2 \mathrm{~kg}$ of soil took only 7 minutes with the soil again being melted essentially when the addition stopped. For the second addition of soil, the current was raised and remained relatively steady at approximately $170 \mathrm{~A}$ and $210 \mathrm{~V}$.

Metal Addition. After the second soil addition, $1 \mathrm{~kg}$ of iron concrete bolts cut into 2 " lengths were added over a period of 8 minutes. As in Exp. 12, they seemed to melt and/or sink immediately. Later, one bolt with a head was found unmelted and merged into the solidified iron mass at the bottom of the melter, as well as some of the large nails added later. As soon as the iron bolt rods were added, bubbles appeared in the slag between the electrodes. 
Air Lance. Approximately, 1 hour and 37 minutes after the 4 th start, the air lance was lowered into the melt. A $3 / 32^{\prime \prime}$ hole normal to the $1 / 2^{\prime \prime}$ mullite tube and $3 / 8^{\prime \prime}$ from the bottom passed $61.6 \mathrm{scfh}$. The bottom of the lance tube was filled with $1 / 4^{\prime \prime}$ of Sauerisen cement above which was a $1 / 4$ " boron nitride plug. The lance was inserted near the side wall between the electrodes. The air jet was directed back between the electrodes under the melt and stirred up a whitish frothy slag as it was immersed. The flow was reduced to $49.3 \mathrm{scfh}$ air to reduce the extent of agitation. In a short period of time (about a minute), the bottom of the lance appeared to melt or break off (evenly) from thermal stresses. Later the open ended lance was reinserted. The flow and reaction splashed whitish slag onto the melter walls, electrodes, and the lance. The bottom of the lance again was broken off or melted almost as rapidly as it was fed into the melter. After reaching the top of the SS tube to which the lance was attached, it was removed. Upon removal, a 4-5" length was observed to fall off the lance into the melt. The end of the lance as removed showed no signs of melting, but then was above the piece broken off.

A cup sample was dipped out of the slag followed by the addition of $1 \mathrm{~kg}$ of $10 \mathrm{p}$ nails. The nails are about 5 " long and often "stuck" in the melt, to slowly tip and fall into the melt, receive arcs from an electrode, or melt into the slag. The iron appeared to have been melted into the slag after about 5 minutes. Most of the nails and rods were found to have been melted, but several were sticking out of the solidified iron on the bottom of the melter.

A second alumina lance was being prepared for oxidation studies when the arc went out. The anode copper adapter and a little of bronze supporting tube had melted, dropping the remaining graphite anode and boron nitride radiation ring into the melt. The graphite anode floated to the cathode region and resembled a slowly burning cork in a red hot bath. The boron nitride ring dropped straight down, became partially covered with slag, but remained essentially intact for reuse. No evidence of the copper was to be seen. We now know that the critical length of anode to maintain the arc at $>200 \mathrm{~A}$ is approximately $2 "$. The total operating time was 2 hours.

After the cooling and breaking up of the slag, it was found that essentially all of the soil had been melted except a very thin layer next to the Sauerisen cement-lined crucible on which the Sauerisen cement was still intact. The metal was in the shape of an irregular monolith on the bottom of the melter and in an "elliptical" shape covering the areas under and between the electrodes. The solidified metal indicated that the first $210 \mathrm{~kg}$ of steel shot probably sank and solidified first. The bolt rods solidified at the bottom on top of and around the $210 \mathrm{~kg}$ mass. The melted nails merged into the top of the bolt rods in the middle, but gave a porcupine effect at the edges of the metal monolith. The copper was found sporadically resolidified around the anode end of the solidified iron at the bottom of the melter.

Voltage Drop Measurements. An experiment on the measurement of the anode and cathode fall values at the electrodes and at the arc-melt interfaces was made to quantify the heating effect of the arc-nelt interface fall regions. The fall region is a thin, high voltage drop region where free electrons are accelerated into the current path, or recombination and subsequent ionization occurs to maintain quasineutrality and the ion current. The relatively large "V $\mathrm{x} I$ " energy in the region is dissipated as heat. The information obtained can provide information on the electric energy disposition for modeling and design as well as optimization. The procedure involves alternately immersing both, one, and neither electrode in the melt to 
measure the differences in overall voltage (at constant current) and by difference the respective fall voltage drops. The heat dissipation is obtained from VxI.

Between the additions of soil, a brief study of electrode voltage fall values was made. The values read on the current and voltage multimeters oscillated several units during the measurements. The results are therefore qualitative at best. The current was approximately $140 \mathrm{~A}$. No attempt was made to do a parameter study with current because of the relatively large fluctuations. With both electrodes in the melt with negligible fall region the voltage was 195 volts. Raising the anode just out of the melt, the change in voltage was $35 \mathrm{~V}$; therefore, the estimated sum of the anode plus melt falls (double fall) is $35 \mathrm{~V}$. Raising the cathode also just out of the melt, increased the voltage an additional $10 \mathrm{~V}$. Neglecting the are length voltage drop, the average double fall is $(35+45 / 2) / 2=29 \mathrm{~V}$. If the operating mode is with both electrodes just out of the melt, and if the fall at the melt is directly heating the melt, then two of the four falls or one double fall results in heating the melt. The fall and Joule heating contributions for this condition are estimated at:

$$
\begin{aligned}
& \text { Fall heating: } \quad 29 \mathrm{~V} * 140 \mathrm{~A}=4.06 \mathrm{~kW} \\
& \text { Joule heating: }(240-29) \mathrm{V} * 140 \mathrm{~A}=29.54 \mathrm{~kW}
\end{aligned}
$$

This shows that when the electrodes are kept close to the melt, most of the heating is by the Joule heating mode. The short electrode-melt gap also provides the most quiescent operating condition (which also depends on the current level). The fraction of fall heating will vary depending on melt depth, current, and molten metal in the bottom of the melter.

Conclusions and Recommendations from Test 13 are the following.

1. The starting procedure is still unstable and needs to be relined as recommended above.

2. The heating period has been reduced by increasing the rate to $24-30 \mathrm{~kW}$.

3. The optimum melt depth for the soil in this melter appears to be that corresponding to 7 to $9 \mathrm{~kg}$ of soil load. The soil is melted essentially as soon as it is added (within several minutes). Excellent flow streamlines in the slag are shown on the video tape that could be used to check models.

4. Metal added appears to melt and then solidify on the bottom. If desired, additional thicknesses of Sauerisen cement, Ruby refractory, or equivalent should be added to the bottom and sides of the melter to reduce heat loss, to keep more of the metal molten inside the melter for tapping or reactions, and to make the melter more energy eflicient. The metal must remain molten if tapping is to be used in continuous treatment systems.

5. By the time the lance experiments were started, the electrodes were so far along in their life cycle that air lanee experimentation time was limited. Longer electrodes could be used or shorter more focussed experiments could be run. The lanee may have broken from thermal stresses or shocks. The necessity of using a lanee in licu of slag and convective oxidation requires a much more sophisticated experiment than can be done within the seope of work on this $\mathrm{p}$ et 
and would require other modifications in the melter (e.g., the additional refractory discussed above) to be successful.

6. The power supply noise experienced in Exp. 12, was not found with the two power supplies connected in parallel. The noise was probably caused by current and voltage fluctuations exceeding the operating envelope of one power supply. These fluctuations are not as obvious on the panel meters as observed on the digital meters.

7. The melter is capable of operating in the steady state with all of the soil molten. The addition of refractory will put even less strain on the cooling system. The main limitation to long runs is the electrode erosion/corrosion. In practice, consumable electrodes would be continuously fed into the melter. There are therefore no obvious maintenance problems to this type of melter. The auxiliaries will have maintenance and repair schedules identical to those practiced in similar industrial applications.

Table of Test 13 Time, Video Index, Current, Voltage and Comments.

$\underline{\text { Time Video }}$ SetPoint Amperes Volts $\underline{\text { Comments }}$

$2: 51$

$2: 53$

$3: 38$

$3: 45$

$4: 20$

$4: 27$

$4: 28$

5:09

$4: 48$

331

133

218

218

309

314

314

365

5:16

5:18

5:21

$5: 27$

5:29

\section{4}

547

547

556
20

20

30

240

240

280

310

210

100-180

40

40

50

(1)

20

20

200

170

170

200
120

180

120

150

180

250

300

arc out

4th and final start (added $210 \mathrm{~g}$ steel shot)

mass spec. \#1 taken (same as before start)

arc out, touch restart

180

160

arc out, touch restart stable operation, video tape off unique arc jet video in. 1st start (1/2 x 0.059 in.)

arc out

2nd start (1 x 0.090 in.)

arc out

3rd start (+ two $1 / 2 \times 0.059$ in.) 
start adding $2 \mathrm{~kg}$ soil (to $8 \mathrm{~kg}$ ) T-soil

video off

stopped adding soil

video on, bubbles at side and convection

video of melt streamlines

video in. for complete melt

video off

optical Pyrometric reading \#1

(anode, cathode, middle)

electrode fall measurements: both electrodes in melt

cathode in melt

both electrodes out (large

fluctuations)

started second $2-\mathrm{kg}$ addition of soil (to $10 \mathrm{~kg}$ )

stopped adding soil (almost all melted when stop)

video on (llow patterns not as good as with $8 \mathrm{~kg}$ )

optical pyrometer readings \#2 adding $2 \mathrm{~kg}$ of metal: (bolts, nails, 2.21 total kg)

adding air via lance $(61.6 \mathrm{scth})$ bottom of lance melted or broken, withdrawn lowered broken lanee into melt, splashing

arc out, touch restart

dip slag sample \#1

add $2 \mathrm{~kg}$ more metal (4.21 total $\mathrm{kg}$ ) raised current, stopped video mass spec. reading \#2 (no change) lost arc: anode copper fitting melted, rolling in slag near cathode essentially intact, boron nitride ring dropped straight down, copper/fitting not to be seen.

shut down, anode graphite floating near cathode dip slag sample \#2 
Test 14: IEB4/S-Series Calcium Silicated Organics Trial

Objective. Test 14 was performed on $9 / 29 / 92$, with the following objectives.

1. To gain experience in melting calcium silicated organics to (a) determine the response when injected into the melter, (b) determine melting rates and how melting compares to added soil, (c) determine possible sizing constraints, and (d) compare V-I characteristics and temperature-viscosity effects.

2. To generate vitrified samples of the S-series as a base for future FWF experiments.

3. To continue testing the starting procedure, soil heating procedure, and equipment operation under different melting conditions.

Starting Procedure Stage. It took four restarts (as with Experiment 12) to get through the starting bottleneck of heating the soil between the electrodes sufficiently to get melt conduction. It appears that a better conducting medium than INEL soil or the higher voltages is required to ensure starts in the shortest time in this melter. Large melt pools were formed under the electrodes very early in the starting stage. The heat is being transferred to the area between the electrodes apparently by radiation from the arc to the end of the retreating graphite strip.

Heating Procedure Stage. The heating procedure, after starting, was run at near the highest currents manageable. Figures 31 and 39 show the current, voltage, and resulting power input data during the course of the test. The arc went out on several occasions because of oscillations beyond the V-I envelope available or occasionally during injection of simulated waste when the electrodes were above the melt. In each case, the current was easily restarted by touching the melt with the electrodes.

This experiment resulted in more fumes during the soil heating (not related to the ingestion of CSO) than in other experiments, with the exception of some of the initial experiments in which the power levels were also kept high. Another source of the fumes is when the electrodes are under the melt surface at high current. It was difficult to establish that this was the cause at this writing. Detailed examination of the videotapes may shed light on the origin of the fumes. At the end of the soil heating stage, the melt was level all around and looked totally melted with the exception of small amounts of fused soil on opposite sides of the crucible walls and farthest away from the electrodes.

Calcium Silicated Organics Stage. The calcium silicated organics (CSO) were prepared in accordance with simulated waste used for testing the method of sizing by cryofracturing with liquid nitrogen. ${ }^{1}$ The CSO mixture was prepared in $1.297 \mathrm{~kg}$ batches with $0.378 \mathrm{~kg}$ of MICRO-CEL E (powdered calcium silicate), $0.057 \mathrm{~kg}$ of an oil adsorbent, and $946 \mathrm{ml}(0.862 \mathrm{~kg})$ of household vegetable oil (to simulate the organic wastes). The amount of oil was insufficient to give a solidified product. The consistency of the CSO mixture resembled an oil-agglomerated material that is no longer powdery containing lumps of oil-impregnated Oil-dry. The CSO mixture is to be combined with soil in an S-series final waste lorm, indicated by S-X, where $\mathrm{X}$ indicates the initial wt\% of soil and $1-\mathrm{X}$ the initial $w t \%$ of $\mathrm{CSO}$ in the series. Individual 
containcrs with CSO mixture weights for mixing with the melted soil to give S-100, S-90, S-80, S-70, S-60, S-50, and S-40 were prepared for the experiment.

After the soil was almost if not eompletely melted, the CSO were added to the melt by shoveling $0.667 \mathrm{~kg}$ (about $2 \mathrm{l}$ ), approximately a tablespoon at a time, down the feed funnel and tube. Air is blown through a $1 / 4$ in. tube down into the crucible melter at a rate of $61.6 \mathrm{sefh}$. The response of the system on each injection was consistent. Immediately, a burst of llame tlashes back up the tube and out the funnel. On the video, the CSO are seen to drop onto the melt, with smoke or fumes quickly released. Sometimes the smoke oceludes the whole chamber; other times there is little emission. The melt is briefly and thinly covered with a cold cap of CSO. There were also mild smells reminiscent of cooking oil in a hot pan.

The melter operation was quite steady all during the 40 minutes of feeding the CSO. Changes in current from 100 to $160 \mathrm{~A}$ as initiated by the operator were relatively stable (in both current and voltage) at each current range. The material not in the fumes or smoke melted into the slag at a slower rate than the soil added (also at a faster rate) in Experiment 13, but appeared to be almost completely melted when the run was terminated. Figure 4.3 shows the soil temperature as obtained from the thermocouple measurements. After reaching a peak value, the thermocouple malfunctioned.

An excessive amount of earbon soot was released during the CSO leeding. The melter chamber and cold trap were covered with soot. When the exhaust duct was raised from the cold trap exit, streamlines of soot could be seen flowing from one to the other. The environment in the present melter was not designed for combustion (time, temperature, and turbulence), and this test emphasized that point. The RETECH plasma centrifugal reacior (PCR) at the INEL CDIF at Butte, Montana, has demonstrated excellent combustion of wood chirs and diesel oil in that plasma reactor system. It may be prudent to examine "pot melter" combustion in the are melters at the USBM-Albany or the MIT-EPI installations, if that is one of their proposed functions. The System Design Studies ${ }^{2,3}$ and Thermal Processing Technologies study ${ }^{4}$ recommended the melter be located after an incinerator. For future input waste stream limits and waste form development, it is not necessary to include the combustibles with the noncombustibles and metals in the bench-scale are melter generation of waste form materials. This test conlirmed our suspicions.

Table of Test 14 Time, Video Index, Current, Voltage and Comments.

\begin{tabular}{|c|c|c|c|c|c|}
\hline Time & $\underline{\text { Video }}$ & Setpoint & Amperes & Volts & Comments \\
\hline \multirow[t]{2}{*}{$8: 50$} & 112 & 20 & 200 & 42 & $\begin{array}{l}\text { Start } 1: 3 / 32 \text { graphite dumbbell strip, } \\
\text { strip is bright - not original dark }\end{array}$ \\
\hline & & 10 & & & reduced current \\
\hline $8: 53$ & & 20 & 180 & 150 & $\begin{array}{l}\text { strip stuck to cathode, increased } \\
\text { current to melt off }\end{array}$ \\
\hline \multirow[t]{2}{*}{$8: 55$} & 180 & & 160 & & \\
\hline & 184 & & & & $\begin{array}{l}\text { are out, strip melted away too fast, } \\
\text { anode coating llaked ofl more than } \\
\text { cathode }\end{array}$ \\
\hline
\end{tabular}


Start 2: 3/32 in. graphite dumbbell strip

bright strip as before

9:48

arc out, could not touch restart

Start 3: 4 in. $x 1$ in. $x$ 1/8 in. graphite on top of dumbbell, granulated slag put between electrodes (much slag formed in previous runs)

$\begin{array}{ll} & 268 \\ 9: 51 & 302 \\ 9: 52 & \\ 9: 55 & \end{array}$

195

180

steady operation

video off

decreased electrode gap

arc out, no touch restart

10:11

303

115

100

10:14

$10: 15$

10:19

339

110

180

$10: 20$

$10: 22$

10:24

$10: 25$

10:25

10:26

10:27

10:27

10:28

10:29

378

340

10

121

75

250

140

$10: 39$

conduction mode, dust storm, foaming? (cathode too deep?), arc out, touch restart.

stopped video tape

arc out, touch restart

soil $\mathrm{T}=602^{\circ} \mathrm{C}$

smoke storm/dust storm 
471

10:50

10:53

$10: 58$

472

10

need to lower electrodes to keep from arcing and high voltage excursions smoking out cracks, cold trap probably plugged no llow from exhaust pipe

system cloudy

cloudy but clearing, weak light at clectrode-melt interface, is changing to more arc and bubbling at cathode clearing up, cold trap found plugged, frozen liquids in bottom soil TC over temperature, are out, smoking stopped, touch restart air in (61.6 scfh), no change in video picture air off move cathode down until hear hissing, then back off slightly videotape off looks all melted (thru glass thru window)

optical pyrometer readings (anode, cathode) cleaned out cold trap, cut 2 in. ofl end inside

start adding Ca Silicated Org. (CSO), (0.667 kg CSO for S-90), flame burst out feed tube, arc out, touch restart air on $(61.6 \mathrm{sc} / \mathrm{h})$

continue 1st addition of CSO, procedure repeats for all additions: throw tablespoon of CSO down lunnel into tube, llame llashes back up tube from funnel, smoke/tumes are seen when CSO hits melt, smoke/fumes emit from cracks and feed lube, video view is occluded by smoke fumes, and/or melt is brictly and thinly cold capped, mild smells of hot vegetable oil in pan. tried air off to minimize blow out, but no change, are out, touch restart 


\begin{tabular}{|c|c|c|c|c|c|}
\hline $11: 50$ & $7(0)$ & 15 & 105 & 220 & air on $(24.6 \mathrm{scth})$ \\
\hline 11:54 & 731 & & & & $\begin{array}{l}\text { many little boiling bubbles(?), under } \\
\text { dark top, dropped electrodes to melt }\end{array}$ \\
\hline $11: 57$ & & 15 & 125 & 185 & trying to put CSO in faster. \\
\hline $11: 59$ & & & & & $\begin{array}{l}\text { Mass Spec } 2 \text { (first was before start } \\
\text { and before fecding CSO) }\end{array}$ \\
\hline & & & & & $\begin{array}{l}\text { Note: Dark videos are smoke/fume } \\
\text { conditions }\end{array}$ \\
\hline 12:02 & & 15 & 118 & 220 & $\begin{array}{l}\text { air increased to } 61.6 \mathrm{sch} \text {, much } \\
\text { carbon soot on cold trap outlet }\end{array}$ \\
\hline 12:05 & 842 & & & & $\begin{array}{l}\text { more liquid nitrogen added to cool } \\
\text { trap exhaust }\end{array}$ \\
\hline 12:07 & & 20 & 110 & 220 & raise power - not melting on side \\
\hline $12: 10$ & & & & & $\begin{array}{l}\text { Mass Spec } 3 \text { sounds/smells like frying } \\
\text { something (quictly) }\end{array}$ \\
\hline 12:11 & & 30 & 160 & 215 & raise power \\
\hline $12: 18$ & & 20 & 105 & 225 & $\begin{array}{l}\text { reduce power to save anode, cannot } \\
\text { see it under the boron nitride ring } \\
\text { anymore }\end{array}$ \\
\hline $12: 23$ & & 20 & 150 & 2.30 & $\begin{array}{l}\text { Mass Spec 4, cup slag samples ( } 3 \\
\text { taken) }\end{array}$ \\
\hline & 878 & 20 & 90 & 260 & $\begin{array}{l}\text { last video after slag samples, almost } \\
\text { all melted, except top front away } \\
\text { from electrodes } \\
\text { terminated test. }\end{array}$ \\
\hline
\end{tabular}




\section{REFERENCES}

1. R. A. Callow, L. E. Thompson, J. R. Weidner, C. A. Lochr, B. P. McGrail and S. O. Bates, In Situ Vitrification Applied to Buried Waste: Final Report of Intermediate Field Tests at the Idaho National Engineering Laboratory, EGG-WTD-9807, August 1991, p. 28.

2. J. L. Mayberry, et al., Preliminary Systems Design Study Assessment Report, EGG-WTD-9594, June 1991.

3. F. Feizollahi, ct al., Preliminary Stored Waste Systems Design Study for Low-Level TRU Waste Treatment Assessment Report, EGG-WTD-10254, Junc 1992.

4. T. L. Eddy, P. C. Kong, B. D. Raivo, and G. L. Anderson, Thermal Processing System Concepts and Considerations for RWMC Buried Waste, EGG-WTD-10058, INEL/EG\&G Idaho, Idaho Falls, ID, February, 1992. 


\section{Appendix C Computer Code Listings}




\section{Data Logger Formating Code}




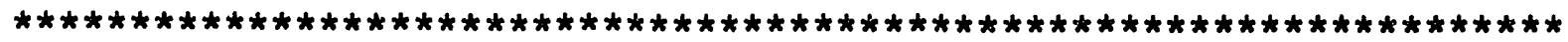
Convert Data-Logger files to regular data by Jon Grandy

$9 / 14 / 92$

To be used with AMRUN01X. DAT

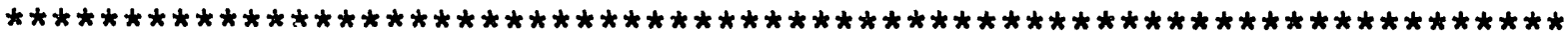
PROGRAM LOGTODAT

C

C

C

C

COMMON/DATAO/ NODP

COMMON/DATAI/ VOLTS (90), AMPS (90), TCI (90), TCO (90), HZC(90)

COMMON/DATAI/ TJI (90), TJO (90), HZJ (90),TEO (90), TEI (90), HZE (90)

COMMON/PERRI/ PEA(90), PEV (90), PETIC(90), PET2C (90), PEHZC (90)

COMMON/PERR1/ PETIJ (90), PET2J (90), PEHZJ (90)

COMMON/PERR1/ PETIE(90), PET2E(90), PEHZE(90)

DIMENSION TEX $(90), T S L(90)$

CHARACTER *21 D, DT

CHARACTER *24 INFILE, OUTFILE, EINFILE, VIFILE

$\mathrm{C}$

$I=1$

NODP $=1$

$\mathrm{MAX}=90$

MTIME $=0$

clear screen and get input/output data file information from operator

CALL SYSTEM ("CLS")

WRITE $(*, *)$ '

WRITE $(*, *) \quad$

PROGRAM: ITD01.FOR

WRITE $(*, *)$ '

THIS PROGRAM READS A DATALOGGER FII

WRITE $(*, *)$ 'PLUS AN TNPUT AND CREATES A NEW "DATA ONLY" FITE

WRITE $(*, *)$

WRITE $(*, *)$

WRITE $(*, *)$

READ $(*, *)$ INFIIE

WRITE $(*, *)$

WRITE $(*, *)$,

READ $(*, *)$ OUTFILE

WRITE $(*, *)$

WRITE $(*, *)$ '

READ $(*, *)$ EINFILE

WRITE $(*, *)$

WRITE $(*, *) \quad 1$

READ $(*, *)$ VIFILE

WRITE $(*, *)$

WRITF $(*, *)$,

REAL $(*, *) \quad M T$

ENTER NUMBER OF MINUTES BETWEEN DATA ENTRIES - 1

WRITE $(*, *)$

NAME OF ENERGY BALANCE INPUT FILE - '

NAME OF VOLTAGE/CURRENT PLOT FILE - '

NAME OF INPUT FIIE - '

NAME OF OUTPUT FIIE - 1 


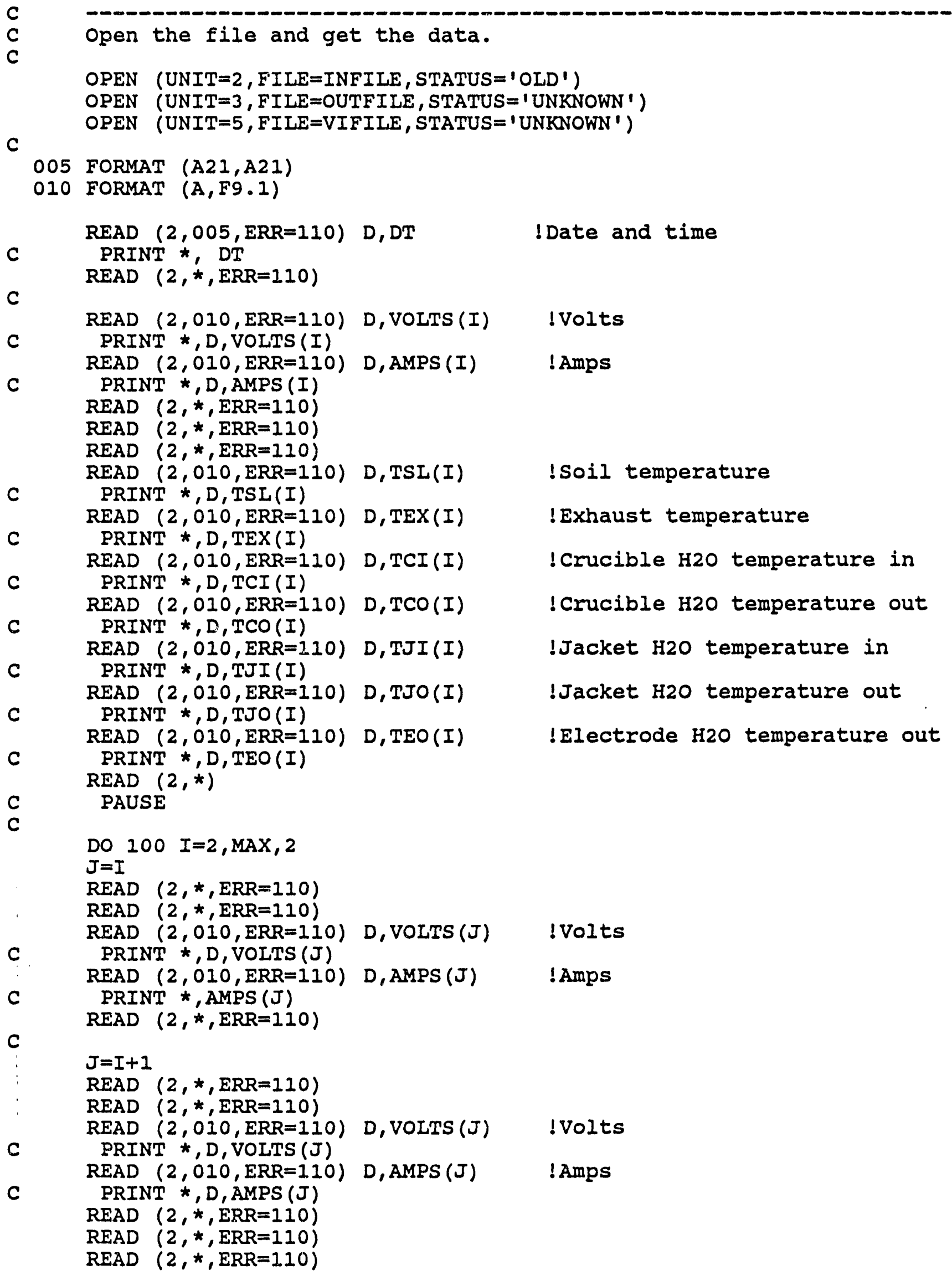




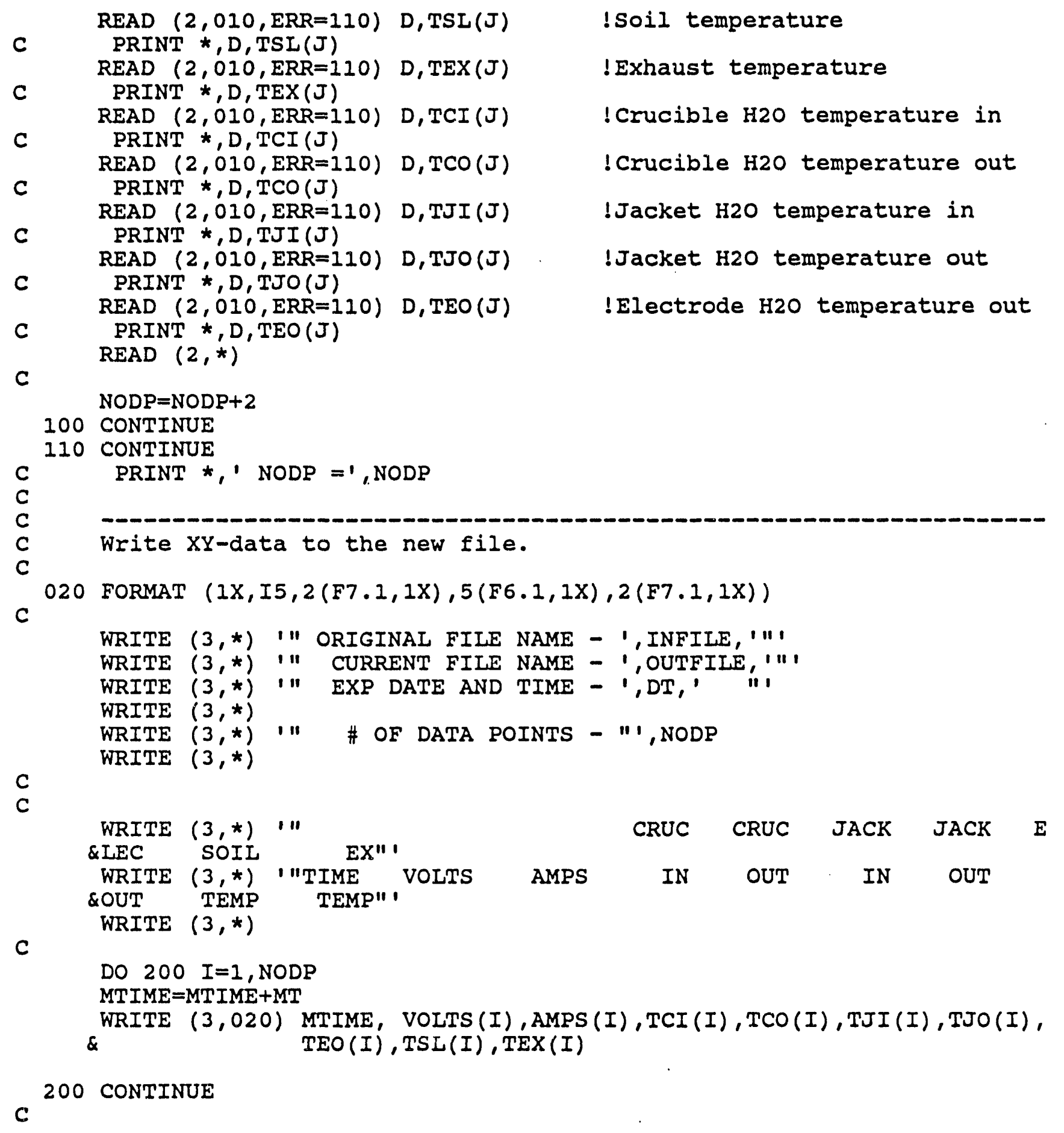




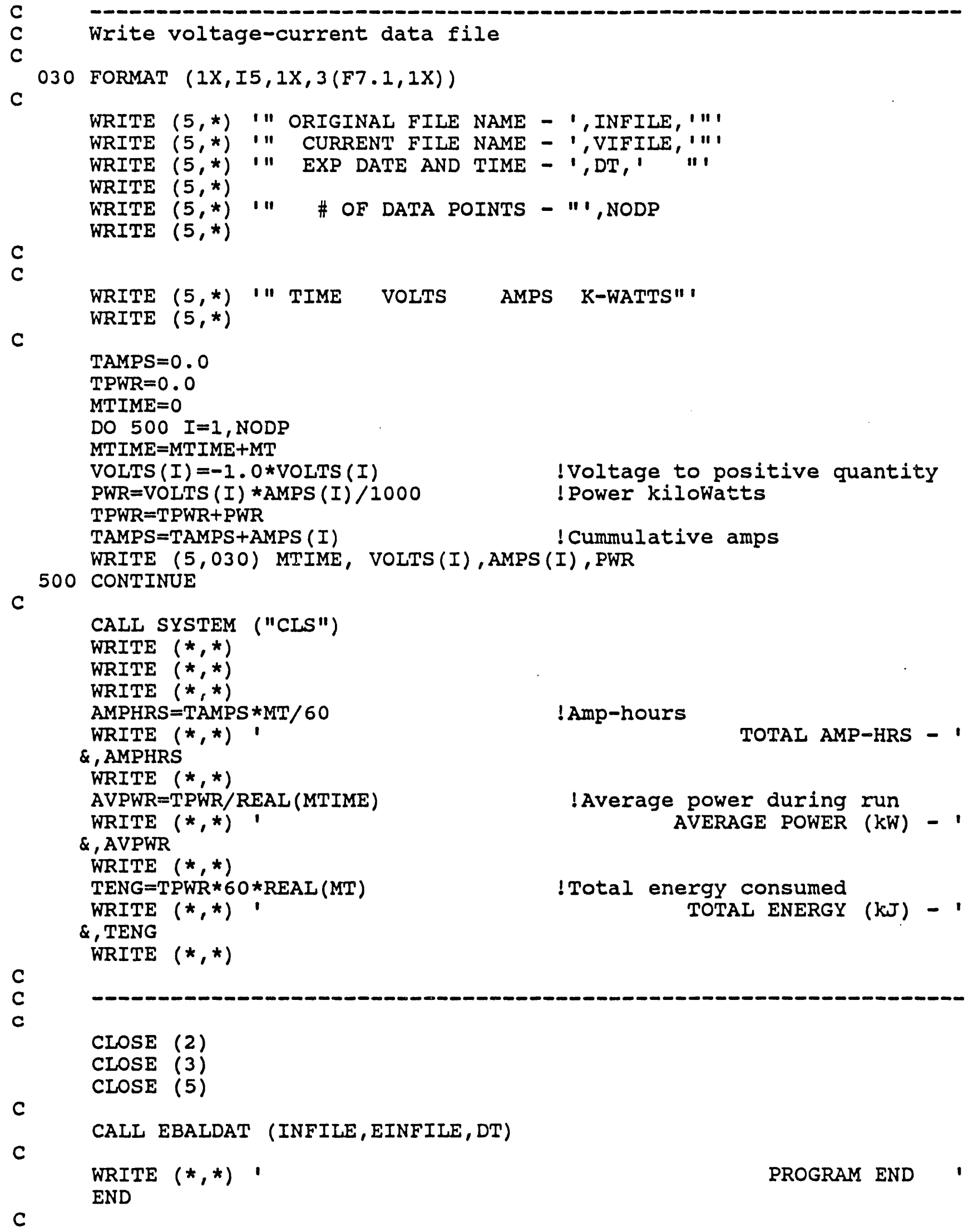




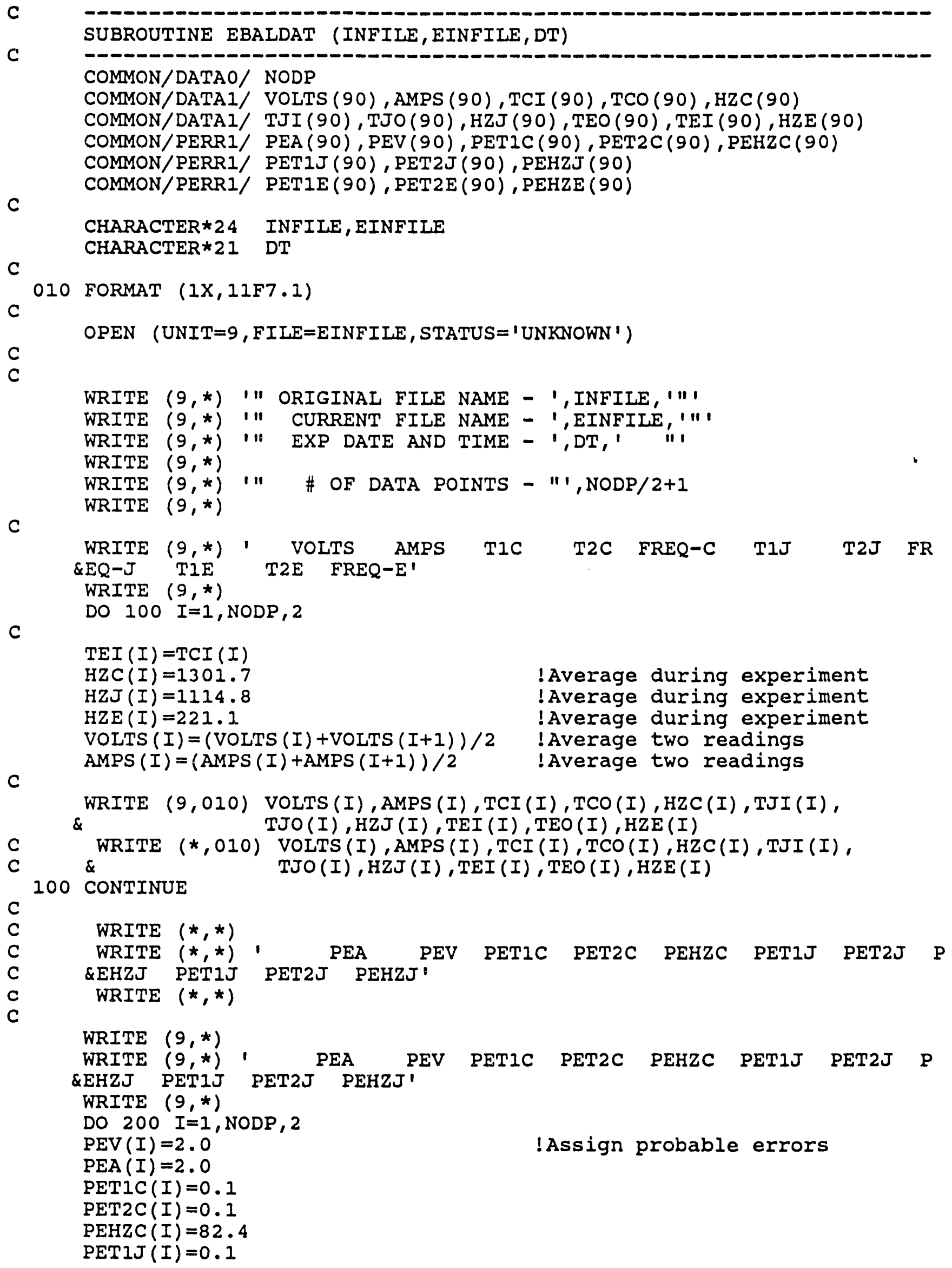




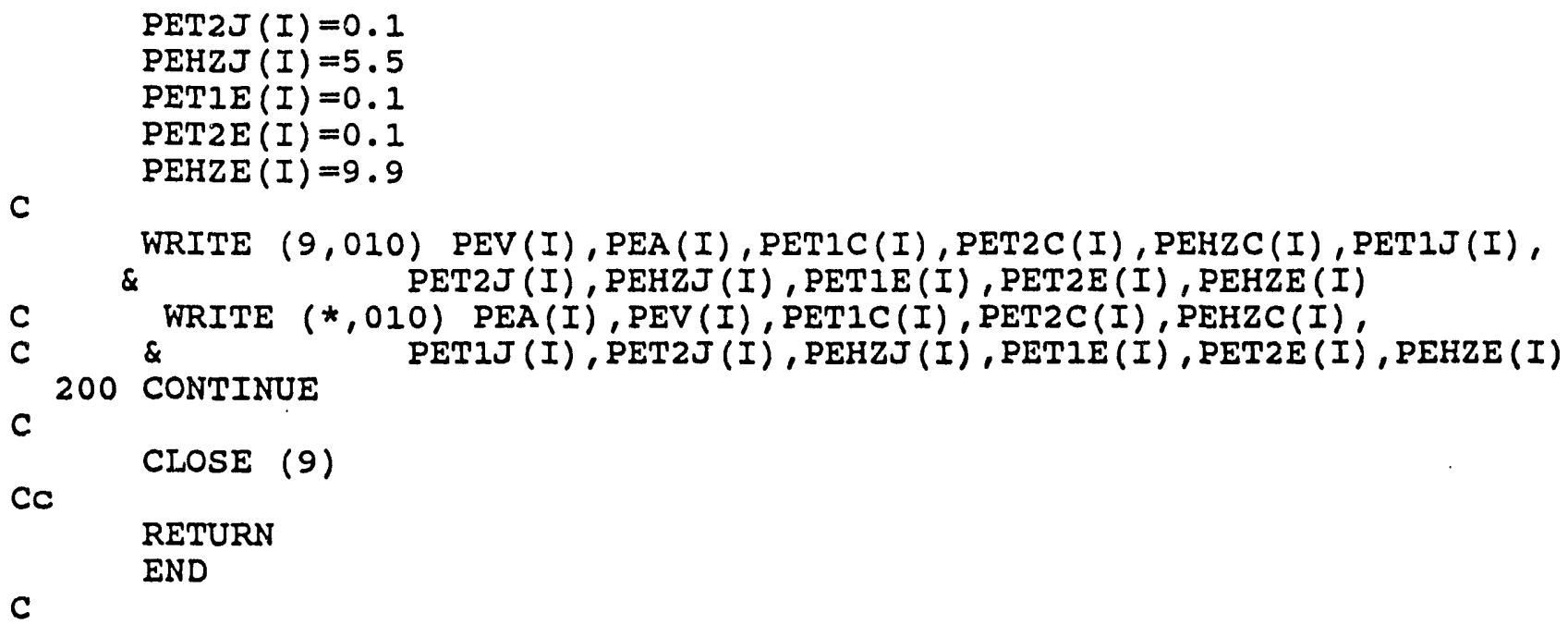




\section{Energy Balance Code}


J. D. Grandy 10/23/91 INEL/EG\&G Idaho, Inc. - IRC, M.S. -2210

EHBAL: JDG 10/23/91 Complete Modification of EBALx programs EBAL_AM: JDG 6/29/91 Do calculations for Arc Melter. EBALAM7: JDG 9/25/92 Do calculations for AMRUN07 data. EBAL_AM1: JDG 9/30/92 Do calculations for AMRUNO1 data.

This program calculates net power and power losses to the arc melter and its cooling systems.

COMMON/DATAO/ NODP

COMMON/DATAI/ VOLT $(90), \operatorname{AMP}(90), \mathrm{T} 1 \mathrm{C}(90), \mathrm{T} 2 \mathrm{C}(90), \mathrm{HZC}(90)$

COMMON/DATAI/ TIJ $(90), \mathrm{T} 2 J(90), \mathrm{HZJ}(90), \operatorname{TIE}(90), \mathrm{T} 2 E(90), \mathrm{HZE}(90)$

COMMON/PERRI/ PEA(90), PEV(90), PETIC(90), PET2C(90), PEHZC(90)

COMMON/PERRI/ PETIJ (90), PET2J (90), PEHZJ (90)

C

COMMON/PERRI/ PETIE(90), PET2E(90), PEHZE(90)

COMMON/DATA2/ PWRIN(90), PWRNT (90), EFFIC (90)

COMMON/DATA2/ PWRWC(90), PWRWJ (90), PWRWE (90)

COMMON/DATA2/ FLOWC(90), FLOWJ (90), FLOWE(90)

COMMON/PERR2/ PEPIN(90), PEPNT (90), PEEFF(90)

COMMON/PERR2/ PEPWC (90), PEPWJ (90), PEPWE (90)

C

COMMON/PERR2/ PEFC(90), PEFJ(90), PEFE(90)

CHARACTER *25 INFILE, OUTFILE, GRAFILE

CHARACTER $* 42$ EXPR $(3)$

$C$
$C$
$C$
$C$
$C$
$C$
$C$
$C$
$C$
$C$
$C$
$C$
$C$
$C$
$C$
$C$
$C$
$C$
$C$
$C$
$C$

-

NODP - Number of data points (up to 10)

AMPS - Torch operating amperage (V)

VOLTS - Torch operating voltage (A)

TIC - Temperature (C) of input cooling water to crucible

T2C - Temperature (C) of output cooling water to crucible

HZC - Frequency (Hz) of crucible water flowmeter

TIJ - Temp. (C) of input cooling water to arcmelter jacket

T2J - Temp. (C) of output cooling water to arcmelter jacket

HZJ - Frequency ( $\mathrm{Hz})$ of arcmelter jacket water flowmeter

TIE - Temp. (C) of input cooling water to electrodes

$\mathrm{T} 2 \mathrm{E}$ - Temp. (C) of output cooling water to electrodes

HZE - Frequency (Hz) of electrode water flowmeter

PEx - Probable error of " $x$ " 


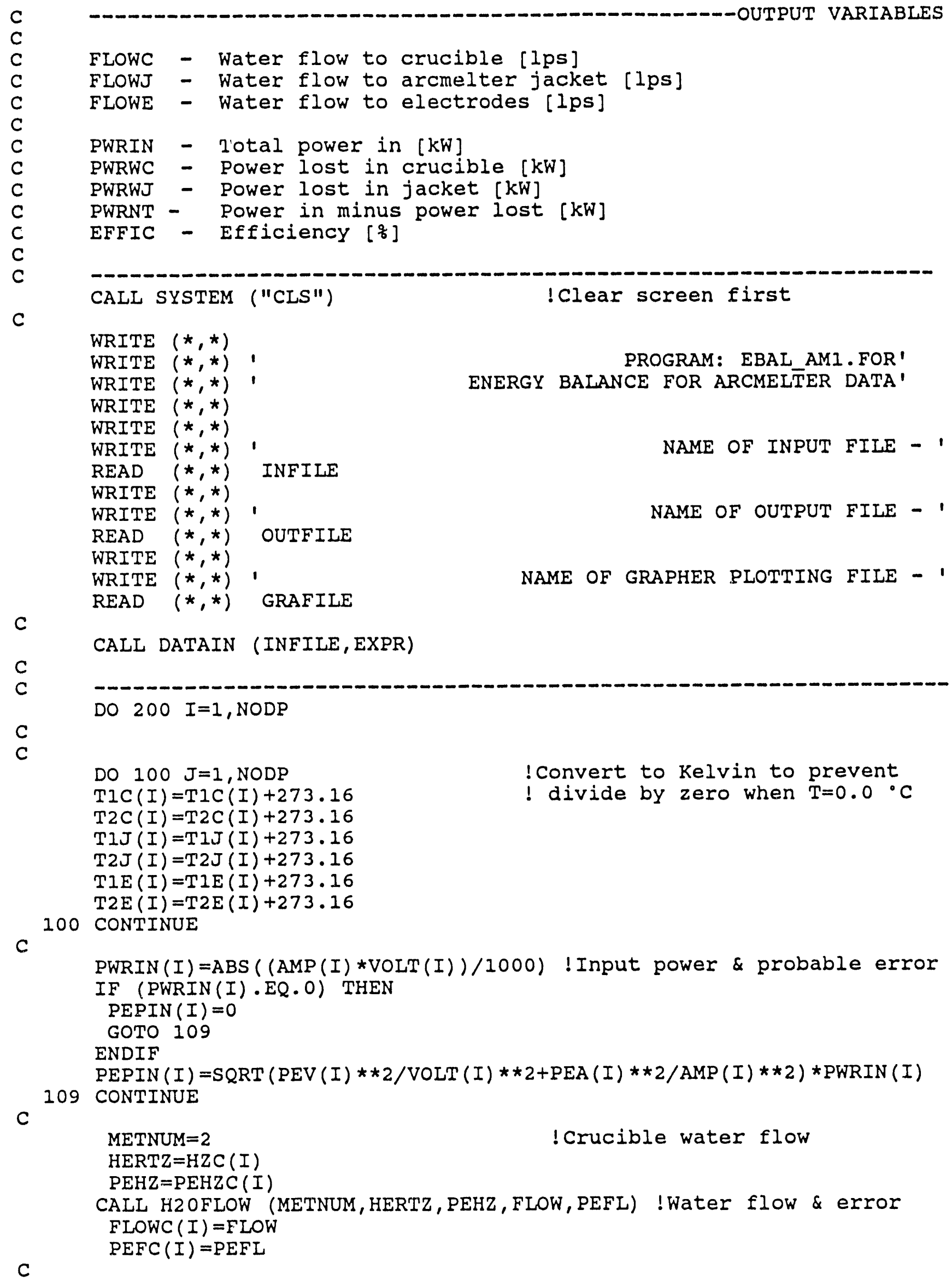




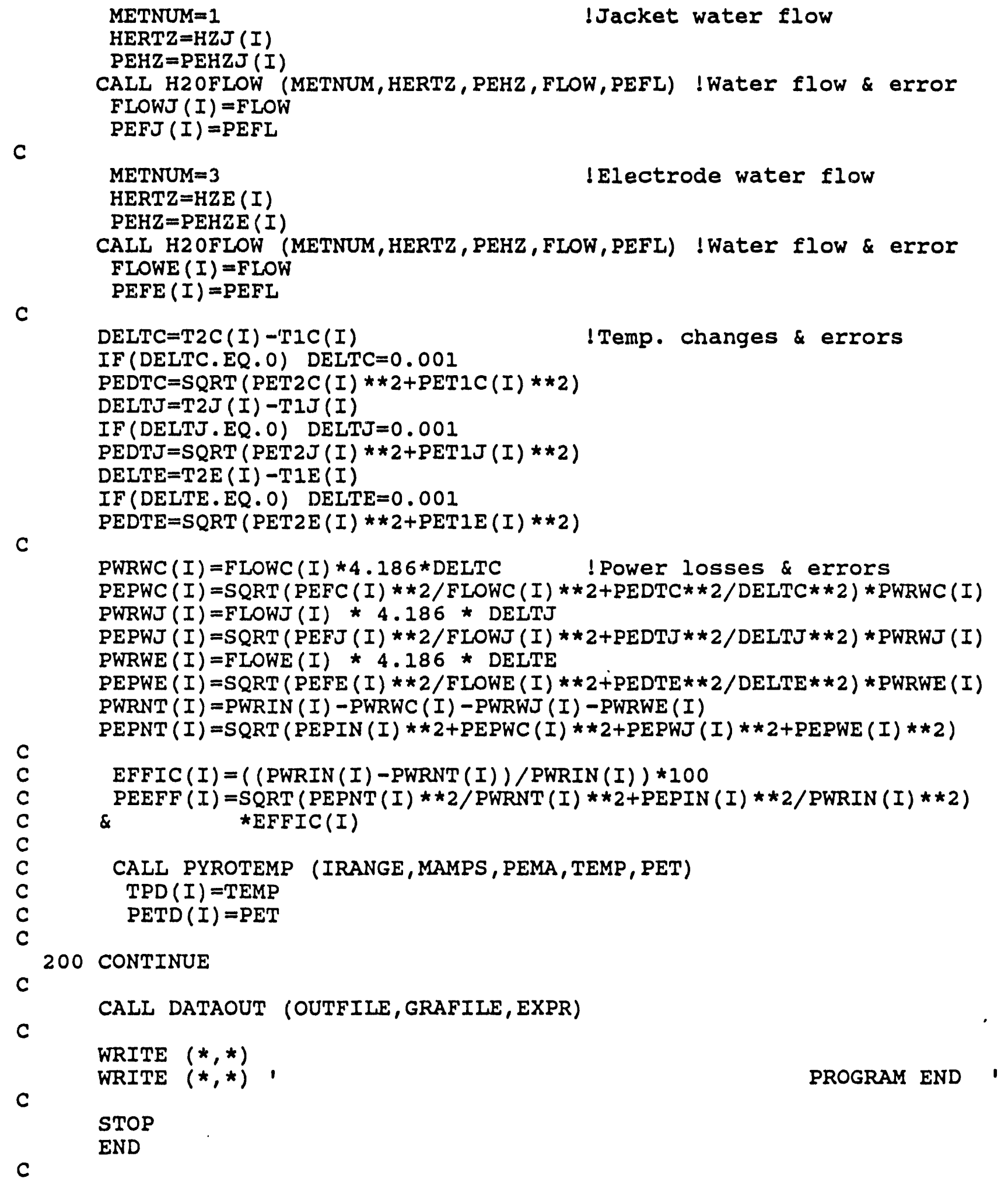

c

C

C

C

C

C

C

C

C

C

200 CONTINUE

C 


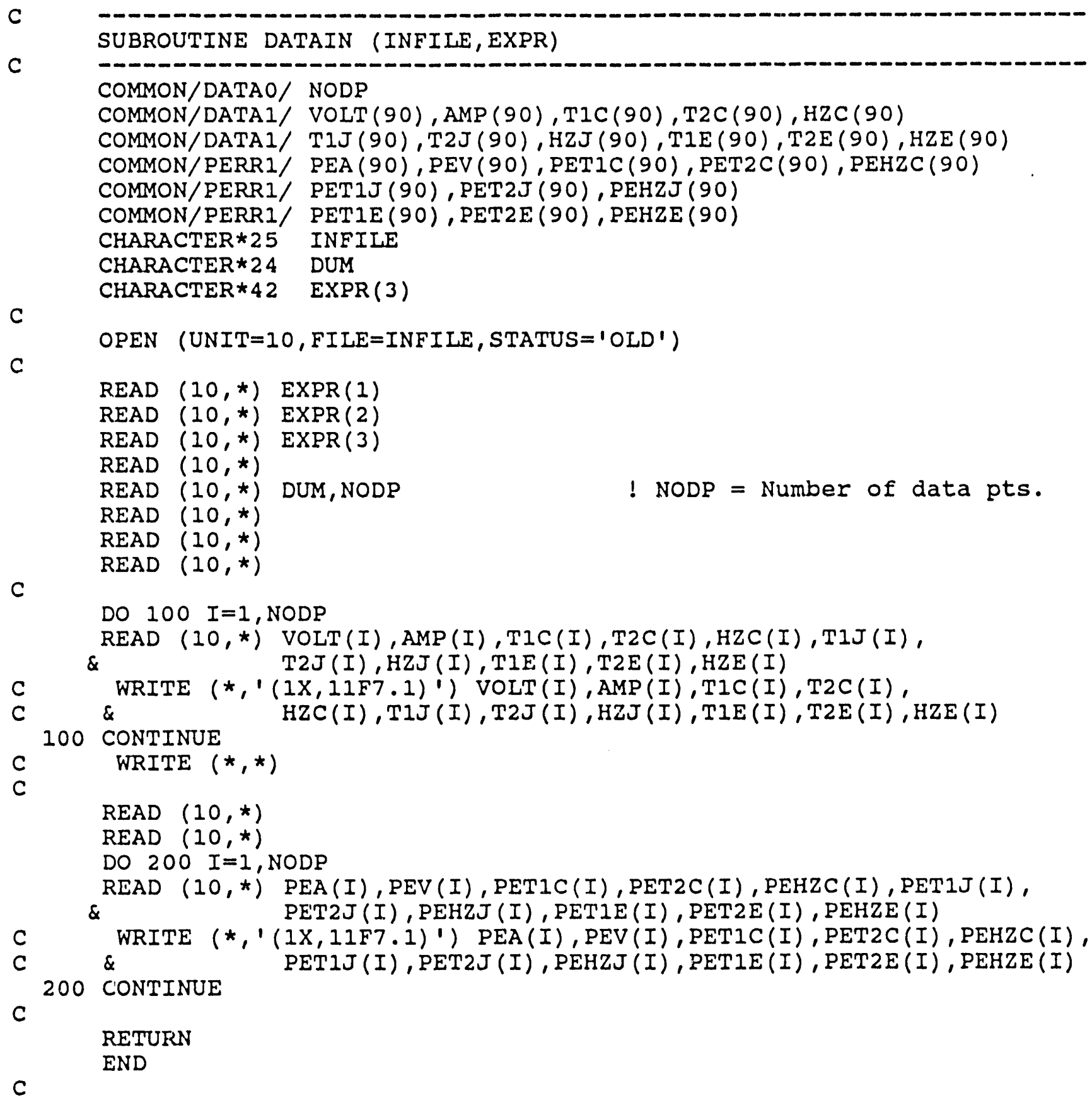

C

DO $100 \quad I=1$, NODP

$\operatorname{READ}(10, *) \operatorname{VOLT}(I), \operatorname{AMP}(I), \operatorname{TIC}(I), \operatorname{T2C}(I), \operatorname{HZC}(I), \operatorname{TIJ}(I)$,

$\&$ $\operatorname{T2J}(I), \operatorname{HZJ}(I), T 1 E(I), T 2 E(I), H Z E(I)$

C WRITE (*,'(IX,IIF7.1)') VOLT(I), AMP(I),TIC(I),T2C(I),

$C \& \operatorname{HZC}(I), T 1 J(I), T 2 J(I), \operatorname{HZJ}(I), T 1 E(I), T 2 E(I), H Z E(I)$

100 CONTINUE

C WRITE $(*, *)$

$\operatorname{READ}(10, *)$

$\operatorname{READ}(10, *)$

DO $200 \quad I=1$, NODP

$\operatorname{READ}(10, *) \operatorname{PEA}(I), \operatorname{PEV}(I), \operatorname{PET} 1 \mathrm{C}(I), \operatorname{PET} 2 \mathrm{C}(I), \operatorname{PEHZC}(I), \operatorname{PET} 1 J(I)$,

$\&$ $\operatorname{PET} 2 J$ (I) , PEHZJ (I) , PET1E (I) , PET2E (I) , PEHZE (I)

C WRITE (*,'(1X,11F7.1)') PEA(I), PEV(I), PETIC(I),PET2C(I), PEHZC(I),

C $\& \quad \operatorname{PETIJ}(I), \operatorname{PET} 2 J(I), \operatorname{PEHZJ}(I), \operatorname{PET} 1 E(I), \operatorname{PET} 2 E(I), \operatorname{PEHZE}(I)$

C

RETURN

END

C 


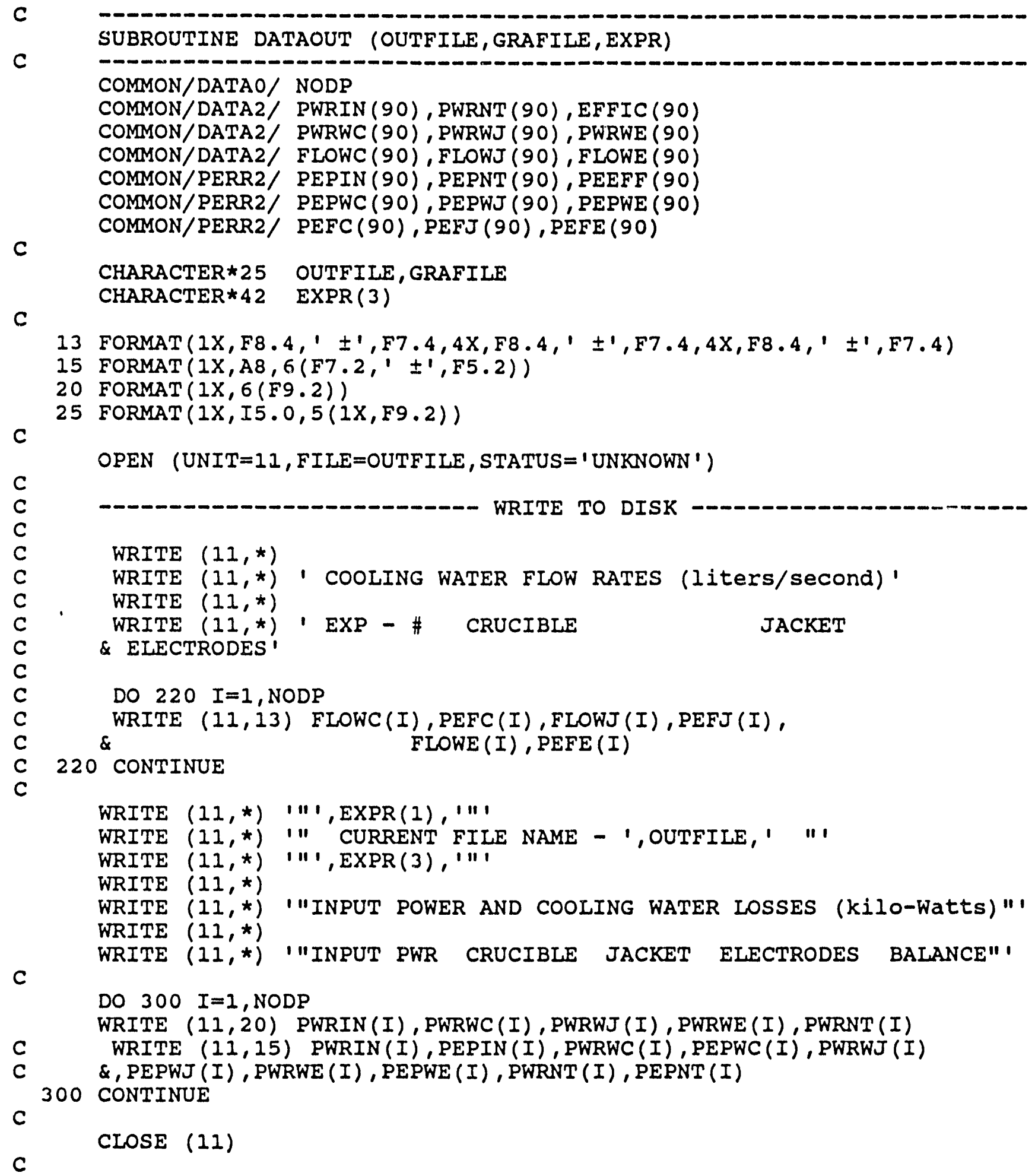


C

WRITE TO GRAPHER FILE

C

C

OPEN (UNIT $=12$, FILE=GRAFILE, STATUS = ' UNKNOWN' )

$\checkmark$

WRITE $(12, *) \quad 1 " 1, \operatorname{EXPR}(1), 1 " 1$

WRITE $(12, *)$ '" CURRENT FILE NAME - ',GRAFILE,' "' WRITE $(12, *) 1 ' 1, \operatorname{EXPR}(3), 1 " 1$

WRITE $(12, \star)$

$\mathrm{MT}=0$

DO $400 \quad I=1$, NODP

$\mathrm{MT}=\mathrm{MT}+2$

$E 1=$ PWRWE $(I)$

!Two minute intervals

$E 2=$ PWRWE $(I)+$ PWRWJ $(I)$

E3 $=$ PWRWE $(I)+\operatorname{PWRWJ}(I)+\operatorname{PWRWC}(I)$

$E 4=$ PWRIN (I)

$E 5=P W R N T(I)$

WRITE $(12,25) \quad M T, E 1, E 2, E 3, E 4, E 5$

C

400 CONTINUE

c

CLOSE (12)

RETURN

END

C 
SUBROUTINE H2OFLOW (METNUM, HERTZ, PEHZ, FLOW, PEFL)

This subroutine calculates the water flow and probable errors

from frequency readings taken with one of a number of flowmeters.

METiUM - An integer identifying a particular meter.

HERTZ - Frecuency reading ( $\mathrm{Hz}$ )

PEHz - Probable error in measurement (Hz)

FLOW - Calculated flow (lps)

PEFL - Probable error in flow (lps)

E0,E1 - Coefficients of curvefit to calibration data

PECE - Probable error (lps) due to linefit

FOI WFI data:

Flow Technology S/N 120287 Prop. ID No. L-11228

Calibration $6 / 3 / 88 \quad(\mathrm{E} 0=-0.18405 \mathrm{E}-02, \quad \mathrm{E} 1=0.64396 \mathrm{E}-03)$

Calibration ?/?/91 (EO $=-1.18559 \mathrm{E}-02, \quad \mathrm{E} 1=1.00739 \mathrm{E}-02) \mathrm{gpm}$

IF (METNUM.EQ.1) THEN

$P E C E=0.0005031$

$\mathrm{EO}=-0.18405 \mathrm{E}-02 \quad !$ in $1 \mathrm{ps}$

$\mathrm{EI}=0.64396 \mathrm{E}-03 \quad !$ in $\mathrm{Ips} / \mathrm{Hz}$

GOTO 109

$1 \ldots+2$

For WF2 data:

Flow Technology S/N 8605584 EG\&G S/N 701084

Cilibration $6 / 7 / 88$

IF (METNUM.EQ.2) THEN

PECE $=0.0003491$

$\mathrm{EO}=-.76973486 \mathrm{D}-03 \quad$ ! in Ips

$\mathrm{E} 2=.16123227 \mathrm{D}-03 \quad$ ! in $1 \mathrm{ps} / \mathrm{Hz}$

GOTO 109

ENDIF

C

For WF3 data:

Flow Technology S/N 806067 EG\&G $S / N$ ?

Calibration $8 / 11 / 92$

(GRI.PHER $\ldots$ EO $=-5.931 \mathrm{E}-04 \mathrm{lps}, \mathrm{EI}=2.92598 \mathrm{E}-04 \mathrm{lps} / \mathrm{hz}$ )

IF (METNUM.EQ.3) THEN

$P E C E=0.0003491$

$E 0=-.5931 D-03$

$\mathrm{E} 1=.292598 \mathrm{D}-03$

GOTO 109

ENDIF

C

WRITE $(*, *)$ ' ERROR: FLOWMETER NUMBER NOT SPECIFIED CORRECTLY'

C STOP

109 FLOW $=$ EO + EI*HERTZ

FLOWE $=E O+E I *($ HERTZ + PEHZ $)$

C

PEFL $=(F L O W E-F L O W)+$ PECE 


$$
\begin{aligned}
& \text { RETURN } \\
& \text { ENT } \\
& \text { C }
\end{aligned}
$$

C -19 
